\title{
Electrochemical Modulation of Sickle Cell Haemoglobin Polymerisation
}

\author{
Zeshan Iqbal
}

\author{
A thesis submitted in \\ partial fulfilment for \\ the degree of \\ Doctor of Philosophy
}

University College London

University of London

January 2008 
UMI Number: U591581

All rights reserved

\section{INFORMATION TO ALL USERS}

The quality of this reproduction is dependent upon the quality of the copy submitted.

In the unlikely event that the author did not send a complete manuscript and there are missing pages, these will be noted. Also, if material had to be removed, a note will indicate the deletion.

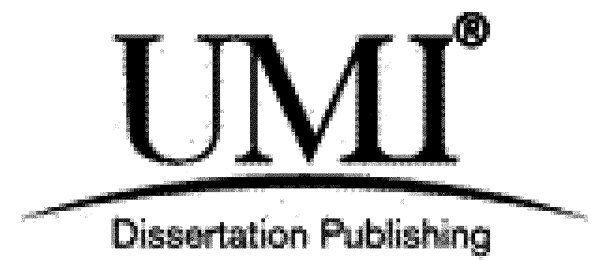

UMI U591581

Published by ProQuest LLC 2013. Copyright in the Dissertation held by the Author.

Microform Edition (c) ProQuest LLC.

All rights reserved. This work is protected against unauthorized copying under Title 17, United States Code.

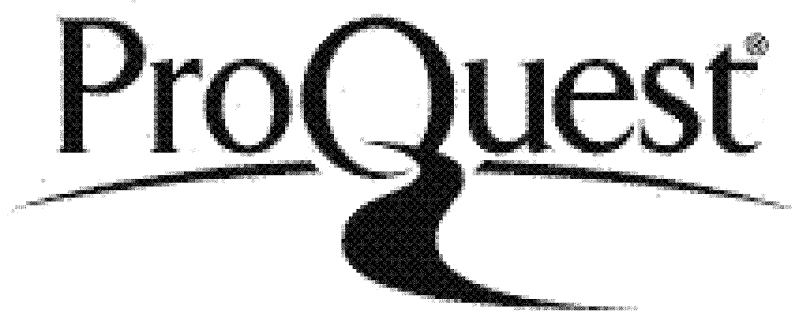

ProQuest LLC

789 East Eisenhower Parkway

P.O. Box 1346

Ann Arbor, MI 48106-1346 
بم الشاركن.إحيم 
Dedicated to my Parents 


\section{Acknowledgements}

I'd like to thank Dr. Daren Caruana for all his support, encouragement and brainstorming discussions in his office over the last 4 years. It has been a pleasure to have worked with him as a colleague and known him as a friend over the last five vears and his help in writing up this thesis has been immense. His enthusiasm and determination for all his work is an infectious and admirable quality.

I would also like to thank Profesor Mike Horton and Dr Rachel McKendry for their help and discussions regarding my work and for choosing me to participate in the National Institute of Material Science Conference in Tsukuba in Japan. Looking at the facilities in Japan and the work being done in the ficld of nanotechnology was an incredible experience, and climbing Mount Tsukuba in torrential rain whilst being "chased" by. giant hornets is something I will always remember. Thanks also go to Dr Laurent Bozec for his discussions and analysis regarding the AFM experiments as well as training me on the Dimension AFM. A special thank you goes to Matthew Li who performed the mathematical modeling of oxigen depletion at the electrochemical cell and Dr. Enrique Millan for his help with the direct electrochemistry experiments; his stories about lenezuela ensured the lab was never quiet over the summer months.

Special compliments are also due to Jim Stevenson in the technical workshop for his amazing manufacturing stills; the look on his face when I asked him to help manufacture the matrix electrode still brings a smile to my face, whilst thanks must also go to Dick Walmark for his incredible electronic skills, John Hughes for the consistently perfect glassware he made, and to the rest of UCL Chemistry Department technical support team.

A big thank you is also reserved for the wonderful people that I have worked with in Glo over the past 4 lears: Bushra Chaudry, who I have known since the beginning of my undergraduate degree, for her help in study related and general matters over the last seren vears, Emina Hadzifejzovic for her motherly nature in taking care of crervone in the lab and for the supplying me with fiuits and daily encouragement. Jorge Sanchez for our daily discussions on the state of Spanish football as well as Katherine Knight, Katherine Holt and Estelle Bernard. I would also like to thank Moyu Watari, Dr. Patrick Mesquida, Jaco Groot and Macarena Blanco all of whom I've had the pleasure 
of working with at some point during my time at UCL and for funding I would like to thank the IRC and UCL Chemistry Department.

An immense thank you also goes to my friends and colleagues at Merck Sharpe and Dohme, Hoddesdon: to my manager Mukesh Solanki for letting me write up my thesis after hours at work; to Murtaza Kaderbhai and Ish Matharu for the laughs, jokes and tips and most importantly for keeping me sane during my time at MSD; to Neeta Camadoo who was my writing colleague in the office eren if she was more interested in talking than studving; and to the rest of the guys there.

Finally, a special thank you and deep gratitude is reserved for my family; in particular to my wonderful parents for all their unconditional love, support, encouragement and prayers. I can never thank you enough or ever repay you for all you have done for me in my life and so it goes without saving that this thesis is dedicated to you both. I would also like to thank my brothers Osman and Ali for taking my mind off the long hours of uriting by playing ProEvo Soccer and rightfully earning the title of "Champ of the House", and to my mother-in-law and brothers-in-law Haris and Hamza for their kind words and support. I would also like to thank Shiraz Malik. Zahoor Yousaf and the rest of the "ikhwa" for their encouragement and dua's and to Adil Hussain for covering my. voluntary duties when I was writing up.

Lastly, an enormous thank you is reserved for my wonderful wife Sarah for all her love and endless patience in putting up with me during the writing period. Her kindness, generosity and regimental efforts in ensuring that I completed this thesis have been a sight to behold and I thank her from the bottom of my heart for bearing with me during the difficult periods.

And finally all Praise and Hamd is for Allaah Azzawajal (subhanahu wa'ta Allaah) without whom notihing is possible. I thank Him for giving me the strength and desire to complete my thesis and for the numerous blessing He's bestowed upon me and my family:. "wa akhirana dawana Alhamdolillahi Rabbil Alameen". 


\title{
Electrochemical Modulation of Sickle Cell Haemoglobin Polymerisation
}

\author{
Zeshan Iqbal \\ University College London. 2008
}

\begin{abstract}
Sickle cell haemoglobin differs from normal haemoglobin by a single amino acid in its $\beta$ chain. This amino acid replacement. from glutamic acid to valine. causes polymerisation of proteins into defined long insoluble fibres with a typical diameter of $21.5 \mathrm{~nm}$. The polymerisation is triggered by the formation of deoxyhaemoglobin from oxyhaemoglobin in low oxygen partial pressures. which results in a conformational change in the secondary structure of the protein. Pathogenesis in sickle cell disease depends on the polymerisation and gelation of deoxygenated HbS molecules.

In this work. an electrochemical method has been described to modulate the oxygen concentration in an optically transparent thin layer cell to produce deoxyhaemoglobin whilst monitoring the extent of polymerisation using turbidit! measurements. The oxygen was depleted in the vicinity of the electrode and triggered the polymerisation. The dependence of protein concentration. temperature. $\mathrm{pH}$ and ionic strength on the nucleation and elongation of $1 \mathrm{hbS}$ polymerisation was characterised at the electrode surface and the kinetics of polymerisation was investigated using a model for fibrillogenesis describing a twostep process of nucleation followed by elongation. The rate constants. determined for a number of conditions. showed that nucleation is far slower than the growth whilst polymerisation at the surface was demonstrated to occur in three stages. with an initial time delay when no structures were observed followed hy growth of fibrous hair-like strands and finally gel-like aggregation. An understanding of the factors which affect polymerisation at a surface and an insight into the dynamics and mechanism of polymer aggregation and the pathophysiology of sickle cell disease has been provided. A screening method for substances that effect the fibre nucleation and/or growth that could be valuable to the pharmaceutical industry for treating sickle cell disease is also presented.
\end{abstract}




\section{Table of Contents}

\section{Introduction}

1.1 Sickle Cell Anaemia 2

1.1.1 Structure of Hacmoglobin 3

I.I.2 Polymerisation of HbS 5

1.I.3 Structure of HbS Molecule 7

1.1.4 Structure of HbS Polymers 8

1.1.5 Aggregated Forms of HbS 9

1.2 Critical Conditions for Polymer Formation 10

1.2.1 $\mathrm{O}_{2}$ Saturation $\quad 10$

1.2.2 Effectors of $\mathrm{O}_{2}$ Saturation 11

$\begin{array}{ll}\text { 1.2.3 HbS Concentration } & 12\end{array}$

$\begin{array}{ll}\text { 1.2.4 Temperature } & 14\end{array}$

1.2.5 Experimental Conditions for Polymerisation $\quad 15$

of $\mathrm{HbS}$

$\begin{array}{ll}1.3 \text { Thermodynamics and Kinetics of HbS Polymerisation } & 17\end{array}$

$\begin{array}{ll}\text { 1.3.1 Thermodynamics of HbS Polymerisation } & 17\end{array}$

$\begin{array}{ll}\text { 1.3.2 Kinetics of HbS Polymerisation } & 19\end{array}$

$\begin{array}{ll}\text { 1.3.3 Double Nucleation Mechanism } & 21\end{array}$

$\begin{array}{ll}\text { l.3.4 Polymer Melting } & 24\end{array}$

1.3.5 Nucleation and Growth of Fibres in Literature 25

$\begin{array}{ll}1.4 \text { Electrochemistry } & 29\end{array}$

1.4.1 Electrochemical Reduction $\mathrm{O}_{2} \quad 29$

1.4.2 Chronoamperometry 32

l.4.3 Cyclic Voltammetry (CI) 33

1.5 Summary 34 


\section{Experimental Materials, Methods and Equipment}

2.1 General Experimental 36

2.2 Materials $\quad 37$

2.3 Instrumentation 38

2.4 Construction of Thin Layer Electrochemical Cells 40

2.5 HbS Polymerisation 41

2.6 Electrochemistry 43

2.7 Optical Microscope Experiments 45

2.8 Spectroelectrochemistry Experiments 46

2.8.1 R to T State Conversion of $\mathrm{Hb} \quad 47$

2.8.2 Spectrophotometric Assay, 48

\section{HbS Aggregation in Pt Coil Cell}

3.1 Introduction $\quad 50$

3.2 Experimental 51

3.2.I Materials, Instrumentation and Procedures 51

3.2.2 Construction of Pt Coil Thin Layer Electrochemical Cell

3.3 Electrochemical Cell Design 53

3.4 Optimisation of the Pt Coil Cell 54

3.5 Growth of HbS Fibrous Structures at Pt Coil Cell 55

3.6 Control Experiments $\quad 58$

3.7 Stages of Growth 60

3.8 Growth Rate 63

3.9 AFM 66

$\begin{array}{ll}3.10 \text { Conclusions } & 70\end{array}$ 


\section{HbS Aggregation in Au Micromesh Cell}

4.1 Introduction 72

$\begin{array}{ll}4.2 \text { Experimental } & 73\end{array}$

4.2.1 Materials, Instrumentation and Procedures 73

4.2.2 Construction of Au Micromesh Thin Layer $\quad 74$

Electrochemical Cell

4.3 Growth of HbS Aggregated Structures $\quad 75$

4.4 Turbidity Measurements of HbS Aggregated Structures $\quad 77$

4.5 Control Experiments 80

4.6 Kinetics of Protein Aggregating Systems 82

4.6.I Kinctics of HbS Polymerisation 83

4.7 DPG 86

4.8 Conclusions 88

\section{HbS Aggregation in Pt Matrix Cell}

5.1 Introduction 90

5.2 Experimental 91

5.2.1 Materials, Instrumentation and Procedures 91

5.2.2 Construction of the Pt Matrix Thin Layer 92

Electrochemical Cell

5.3 Optimisation of Pt Matrix Electrochemical Cell 93

5.4 Modeling of $\mathrm{O}_{2}$ Depletion in Pt Matrix Thin Layer Cell 94

5.5 Growth of Fibrous Structures at Pt Matrix Cell 98

5.5.1 Analysis of Growth Rates 99

$\begin{array}{ll}\text { 5.5.2 Effect of Changing HhS Concentration } & 101\end{array}$

$\begin{array}{ll}5.5 .3 \mathrm{HbS} \text { Concentration Analysis } & 103\end{array}$

$\begin{array}{ll}5.5 .4 \text { Effect of Changing Temperature } & 106\end{array}$

$\begin{array}{ll}5.5 .5 \text { Temperature Analysis } & 108\end{array}$ 
$\begin{array}{ll}\text { 5.5.7 Effect of Changing pH } & 118\end{array}$

5.5.8 pH Analysis $\quad 120$

5.5.9 Effect of Changing Salt Concentration 123

5.5.10 Salt Concentration Analysis $\quad 125$

$\begin{array}{ll}\text { 5.6 Double Nucleation Mechanism at Surfaces } & 129\end{array}$

5.7 Conclusions 132

\section{Anti-Sickling Strategies}

6.1 Introduction 135

$\begin{array}{ll}6.2 \text { Experimental } & 136\end{array}$

6.2.1 Materials and Procedures 136

6.2.2 Forming a Thiol Monolaver on Au 137

$\begin{array}{ll}6.3 \text { Pathophysiology of SCD } & 139\end{array}$

6.4 Current Therapies for SCA 142

6.5 Use of Compounds which Modify HbS Protein Structure or 146

Composition

6.5.1 I'anillin 147

$6.5 .2 .5 H M F$

6.5.3 Different Proportions of $\mathrm{HbS} \quad 153$

6.6 Use of Compounds which Modify Surface Properties 155

6.6.1 Effect of changing surface properties on the Growth 156

of HbS Aggregates in Au matrix cell

6.6.2 Effect of changing surface properties on the (irowth

of IhbS Aggregates in Au micromesh cell

6.7 Conclusion 160 


\section{Direct Electrochemistry of HbS Polymers}

$\begin{array}{ll}7.1 \text { Introduction } & 162\end{array}$

$\begin{array}{ll}7.2 \text { Experimental } & 164\end{array}$

7.2.1 Materials, Instrumentation and Procedures 164

7.2.2 HbS Fibre Formation and Experimental Preparation 165

7.3 Direct Electrochemistry of HbS Polymers 166

$\begin{array}{ll}7.4 \text { Conclusions } & 173\end{array}$

\section{Concluding Remarks}

$\begin{array}{ll}8.1 \text { Conclusions } & 175\end{array}$

$\begin{array}{ll}8.2 \text { Future Work } & 179\end{array}$

8.2.1 Characterisation using AFM 179

8.2.2 Screening for SCA and Anti-sickling Agents 181

8.2.3 Direct electrochemistry $\quad 183$

$\begin{array}{ll}8.3 \text { Summary } & 184\end{array}$

9 References $\quad 185$

\section{Appendices}

Appendix A: Publication

Appendix B: HbS Polymers Published on the Front Cover of The Analyst

Appendix C: Sickle cell Microcell 


\section{Table of Figures}

Figure 1.1: A schematic diagram of the $T$ and $R$ conformational 3 states of $\mathrm{Hb}$

Figure 1.2: The mechanism for the $T$ to $R$ state switch upon oxygenation

Figure 1.3: Schematic depiction of the "Wishner-Love" double strands of dexoyHbS

Figure 1.4: Cross section of the seven double-strand fibre model 8

Figure 1.5: The curve for polymer formation as a function of $\mathrm{O}_{2} \quad 10$ saturation of unfractionated sickle cell RBCs

Figure 1.6: Effect of $\mathrm{pH}$ on solubility of $\mathrm{HbS} \quad 11$

Figure 1.7: Temperature dependence of deoxy-HbS solubility 14

$\begin{array}{ll}\text { Figure 1.8: } & \text { Time course of } \mathrm{HbS} \text { polymerisation }\end{array}$

Figure 1.9: The double nucleation mechanism of $\mathrm{HbS}$ polymerization 21

Figure 1.10: Fracture of a single HbS fibre and rapid filling of 27 the field after fracture

Figure 1.11: The $\mathrm{O}_{2}$ reduction reaction scheme 29

Figure 1.22: The excitation waveform for a single potential step 32 experiment

Figure 1.13: Triangular potential ramp is applied in CV. 33

Figure 2.1: A typical current density evolution response seen 43 in our experiments

Figure 2.2: Cyclic voltammogram of $\mathrm{HbS}$ solution before and after reduction of oxygen.

Figure 2.3: Spectroelectrochemistry experiment showing the conversion of oxygenated $\mathrm{HbS}$ to deoxygenated $\mathrm{HbS}$ at Au micromesh electrode. 
Figure 3.1: Plan view of Pt coil thin layer electrochemical cell incorporating a three electrode system

Figure 3.2: Optical images of the Pt working electrode showing the initial stages of $\mathrm{HbS}$ aggregate formation at the electrode surface

Figure 3.3: Optical images of the Pt working electrode showing the nucleation and growth of HbS aggregates

Figure 3.4: Optical images of the Pt working electrode when $\mathrm{HbA}$ was electrochemically deoxygenated

Figure 3.5: Optical images of the $\mathrm{Pt}$ working electrode in the early 6() stage growth and the late stage growth.

Figure 3.6: Optical images of the Pt working electrode

Figure 3.7: Optical images of the Pt working electrode showing the differences in growth when different additives were used

Figure 3.8: A single optical image of the Pt working electrode taken 63 as part of a video clip showing growth of $\mathrm{HbS}$ aggregates at the surface

Figure 3.9: Graph of $\mathrm{HbS}$ growth $(\mu \mathrm{m})$ is. time (s) depicting the 64 growth of fibrous structures

Figure 3.10: Dimension AFM imaging of $\mathrm{HbS}$ protein aggregates 67 on freshly cleaved mica

Figure 3.11: Figures showing the dimensions of the two fibre like 68 Structures imaged with AFM

Figure 3.12: AFM images of deoxyHbS polymers showing a variety of polymeric structures

Figure 4.1: Plan view of Pt micromesh thin layer electrochemical cell and actual image of the Pt micromesh cell

Figure 4.2: Optical microscopy images showing HbS aggregate growth 76 and the control $\mathrm{HbA}$ on $\mathrm{Au}$ micromesh working electrode 
Figure 4.3: Wavelength independent light scattering due to formation

of $\mathrm{HbS}$ fibres by electrochemical reduction of $\mathrm{O}_{2}$ at a $\mathrm{Au}$ micromesh electrode

Figure 4.4: UV-visible spectroelectrochemistry time traces for $\mathrm{HbS}$ showing changes in turbidity at Au micromesh electrode

Figure 4.5: Wavelength independent light scattering due to HbA by electrochemical reduction of $\mathrm{O}_{2}$ at a Au micro-mesh electrode

Figure 4.6: UV-visible spectroelectrochemistry time traces for $\mathrm{HbA}$ showing changes in turbidity at a bare Au electrode

Figure 4.7: Solid lines showing the experimental values of normalized turbidity using a max turbidity of 75 corresponding to maximum absorbance due to fibres at $800 \mathrm{~nm}$, versus time for (A) $50 \mathrm{mg} \mathrm{cm}^{-3}$, and (B) $300 \mathrm{mg} \mathrm{cm}^{-3}$

Figure 4.8: UV-visible spectroelectrochemistry time traces for HbS with 86 addition of different concentrations of 2.3-DPG showing changes in turbidity at a bare Au micromesh electrode

Figure 5.1: Plan view of the Pt matrix thin layer electrochemical cell and actual image of Pt matrix cell

Figure 5.2: Simulations of the Pt matrix electrochemical cell using 96 Comsol $R$ showing the concentration of $\mathrm{O}_{2}$ in and around the Pt matrix electrode at (a) $0 \mathrm{~s}$ with a specific hole highlighted in red and (b) at $1000 \mathrm{~s}$ with sectioned area highlighted

Figure 5.3: Plots showing (a) the change in $\mathrm{O}_{2}$ concentration horizontally across the hole highlighted in figure $\mathbf{5 . 2}$ for various times: (b) the change in $\mathrm{O}_{2}$ concentration vertically $5 \mu \mathrm{m}$ away from the electrode and $5 \mu \mathrm{m}$ into the bulk at either end of the hole highlighted in figure $\mathbf{5 . 2}$ at various times

Figure 5.4: Solid lines showing the experimental values of normalized turbidity versus time for (A) $40 \mathrm{mg} \mathrm{cm}^{-3}$. and (B) $100 \mathrm{mg} \mathrm{cm}^{-3}$

Figure 5.5: Turbidity profile exhibiting the three phases seen 100 experimentally: Phase I is the nucleation phase; Phase 11 is the intermediary phase and Phase III is the growth phase. 
Figure 5.6: UV-visible spectroelectrochemistry time traces showing

the changes seen in turbidity levels at $700 \mathrm{~nm}$ at a Pt matrix electrode with increasing $\mathrm{HbS}$ concentrations.

Figure 5.7: UV-visible spectroelectrochemistry time traces showing changes in turbidity seen at the Pt matrix cell with increasing solution temperature at two $\mathrm{HbS}$ concentrations.

Figure 5.8: A plot of the log of nucleation rate as a function of reciprocal temperature in kelvin.

Figure 5.9: A plot of the nucleation rate constant over temperature as a function of reciprocal temperature.

Figure 5.10: UV-visible spectroelectrochemistry time traces showing changes in turbidity at a Pt matrix cell with increasing buffer $\mathrm{pH}$ at two $\mathrm{HbS}$ concentrations.

Figure 5.11: UV-visible spectroelectrochemistry time traces showing changes in turbidity at a Pt matrix cell with increasing $\mathrm{NaCl}$ concentration at two $\mathrm{HbS}$ concentrations.

Figure 5.12: A schematic representation of the shift in turbidity profiles from low to high protein concentrations.

Figure 6.1: CV of 3-mercapto-1-propenesulfonic acid thiolated Au surface performed at a scan rate of $100 \mathrm{mV} \mathrm{s}^{-1}$ to ascertain the potential window for the reduction of the thiol.

Figure 6.2: Structures of the thiol compounds used in the experiments:

(a) 2-mercaptoethanol; (b) 3-mercapto-1-propenesulfonic acid: (c) 1-butanethiol; (d) cystamine dihydrochloride

Figure 6.3: Sickle cell vasoocclusion.

Figure 6.4: Membrane cytoskeleton and plasma membrane damage due to HbS polymerisation.

Figure 6.5: The structures of (a) vanillin and (b) 5HMF.

Figure 6.6: UV-visible spectroelectrochemistry time traces showing changes in turbidity at Pt matrix electrode for different concentrations of vanillin. 
Figure 6.7: UV-visible spectroelectrochemistry time traces showing changes in turbidity at Pt matrix electrode when vanillin was added at different points in the aggregating system.

Figure 6.8: UV-visible spectroelectrochemistry time traces showing changes in turbidity at Pt matrix electrode for different concentrations of 5HMF.

Figure 6.9: UV-visible spectroelectrochemistry time traces showing changes in turbidity at Pt matrix electrode for different proportions of $\mathrm{HbS}$.

Figure 6.10: UV-visible spectroelectrochemistry time traces showing 158 the effect of different surface properties on changes in turbidity at thiolated Au matrix electrode.

Figure 6.11: UV-visible spectroelectrochemistry time traces showing 160 the effect of different surface properties on changes in turbidity at thiolated Au micromesh electrode.

Figure 7.1: $\mathrm{CV}$ (scan rate $200 \mathrm{mV} \mathrm{s}^{-1}$ ) detailing the response of a bare $\mathrm{Au}$ microelectrode (a) in the presence of $\mathrm{HbS}$ fibres formed using the ex-situ isothermal method and $\mathrm{HbS}$ monomers and (b) in the presence of $\mathrm{HbS}$ fibres at the beginning of the experiment (HbS fibres 1) and $\mathrm{HbS}$ fibres after 20 minutes (HbS fibres 2) in blank pH 7, 1.5 M phosphate buffer.

Figure 7.2: $\quad \mathrm{CV}$ (scan rate $200 \mathrm{mV} \mathrm{s}^{-1}$ ) detailing the response 168 of a bare Au microelectrode in (a) the presence of HbS fibres formed using the ex-situ isothermal method in blank pH 6.1, 1.5 $\mathrm{M}$ phosphate buffer: and (b) in the presence of HbS fibres formed using the ex-situ isothermal method and HbS monomers in blank pH 8.49, 1.5 $\mathrm{M}$ phosphate buffer.

Figure 7.3: $\mathrm{CV}$ (scan rate $200 \mathrm{mV} \mathrm{s}^{-1}$ ) detailing the $\mathrm{pH}$ dependence 169 of a response of a bare $\mathrm{Au}$ microelectrode in the presence of $\mathrm{HbS}$ fibres formed using the ex-situ isothermal method in blank pH 6.1, pH 7.0 and pH 8.49 $(1.5 \mathrm{M})$ phosphate buffer. 
Figure 7.4: $\quad \mathrm{CV}$ (scan rate $200 \mathrm{mV} \mathrm{s}^{-1}$ ) detailing the response

of a bare Au microelectrode in the presence of

HbS fibres at the beginning of the experiment (HbS fibres 1 ).

after 5 minutes (HbS fibres 2 ) and after 10 minutes

(HbS fibres 3 ) in blank pH 8.49.1.5 M phosphate buffer.

Appendix B: Front cover of January 2007 (volume 132) edition of The

Analyst showing colour enhanced optical images of HbS

polymers electrochemically grown at a Pt surface 


\section{Table of Tables}

Table 1.1: Conditions for $\mathrm{HbS}$ polymerisation and methods of

nucleation used in literature.

Table 1.2: Description of the techniques used in literature for the

visualisation and monitoring of nucleation and growth

of HbS polymers.

Table 3.1: Average growth rates of HbS fibres at a Pt coil electrode.

Table 4.1: $\quad$ Nucleation rate constants $k_{1}$ and growth rate constants $k_{2}$

describing the $\mathrm{HbS}$ aggregation formation for $50 \mathrm{mg} \mathrm{cm}^{-3}$

and $300 \mathrm{mg} \mathrm{cm}^{-3}$ at a Au micro-mesh electrode surface.

Table 5.1: The bulk and boundary equations used in the $\mathrm{O}_{2}$ depletion model.

Table 5.2: Values used to approximate experimental conditions that were applied to the bulk liquid in the model

Table 5.3: Nucleation rate constants $k_{1}$ and elongation rate constants $k_{2}$ to describe the aggregation formation for $\mathrm{HbS}$ concentration in the range $30 \mathrm{mg} \mathrm{cm}^{-3}$ to $100 \mathrm{mg} \mathrm{cm}^{-3}$ at a Pt matrix electrode

Table 5.4: Linear regression analysis for protein concentration in the range $30 \mathrm{mg} \mathrm{cm}^{-3}$ to $100 \mathrm{mg} \mathrm{cm}^{-3}$ at a Pt matrix electrode.

Table 5.5: Nucleation rate constants $k_{1}$ and growth rate constants $k_{2}$ 108 describing the $\mathrm{HbS}$ aggregation formation for temperature in the range $25{ }^{\circ} \mathrm{C}$ to $42{ }^{\circ} \mathrm{C}$ for $\mathrm{HbS}$ concentration of $30 \mathrm{mg} \mathrm{cm}^{-3}$ at a Pt matrix electrode.

Table 5.6: Linear regression analysis, for temperature in the range 109 $30 \mathrm{C}$ to $42 \mathrm{C}$ for $30 \mathrm{mg} \mathrm{cm}^{-3} \mathrm{HbS}$ concentration at a $\mathrm{Pt}$ matrix electrode.

Table 5.7: Linear regression analysis for temperature in the range 110 $30 \mathrm{C}$ to $42 \mathrm{C}$ for $75 \mathrm{mg} \mathrm{cm}^{-3} \mathrm{HbS}$ concentration at a $\mathrm{Pt}$ matrix electrode. 
Table 5.8: A comparison of the activation energies calculated for $\mathrm{HbS}$.

Table 5.9: A comparison of certain thermodynamic parameters for $\mathrm{HbS} \quad 116$ polymerisation and $\beta$-amyloid fibrillation.

Table 5.10: Thermodynamic parameters for deoxy-HbS polymerisation obtained from scanning calorimetric measurements.

Table 5.11: Nucleation rate constants $k_{1}$ and growth rate constants $k_{2}$ describing the $\mathrm{HbS}$ aggregation formation for $\mathrm{pH}$ in the range 6.80 to 7.62 at a $\mathrm{HbS}$ concentration of $30 \mathrm{mg} \mathrm{cm}^{-3}$ at Pt matrix electrode.

Table 5.12: Linear regression analysis for $\mathrm{pH}$ in the range 6.8 to 7.62 for $30 \mathrm{mg} \mathrm{cm}^{-3} \mathrm{HbS}$ concentration at a Pt matrix electrode

Table 5.13: Linear regression analysis, for $\mathrm{pH}$ in the range 6.8 to 7.62 for $75 \mathrm{mg} \mathrm{cm}^{-3} \mathrm{HbS}$ concentration at a Pt matrix electrode.

Table 5.14: Nucleation rate constants $k_{1}$ and growth rate constants $k_{2}$ describing the $\mathrm{HbS}$ aggregation formation for $\mathrm{NaCl}$ salt concentration in the range $0.25 \mathrm{M}$ to $1.00 \mathrm{M}$ at $\mathrm{HbS}$ concentration of $30 \mathrm{mg} \mathrm{cm}^{-3}$ at a Pt matrix electrode.

Table 5.15: Nucleation rate constants $k_{1}$ and growth rate constants $k_{2}$ describing the $\mathrm{HbS}$ aggregation formation for $\mathrm{NaCl}$ salt concentration in the range $0.25 \mathrm{M}$ to $1.00 \mathrm{M}$ at $\mathrm{HbS}$ concentration of $75 \mathrm{mg} \mathrm{cm}^{-3}$ at a Pt matrix electrode.

Table 5.16: Linear regression analysis, for $\mathrm{NaCl}$ salt in the range $0.1 \mathrm{M}$ to $1.0 \mathrm{M}$ for $30 \mathrm{mg} \mathrm{cm}^{-3} \mathrm{HbS}$ concentration at a Pt matrix electrode surface.

Table 5.17: Linear regression analysis, for $\mathrm{NaCl}$ salt in the range $0.1 \mathrm{M}$ to $1.0 \mathrm{M}$ for $75 \mathrm{mg} \mathrm{cm}^{-3} \mathrm{HbS}$ concentration at a Pt matrix electrode surface.

Table 6.1: $\quad$ Linear regression gradient calculations of Phase I, Phase II 150 and Phase III for turbidity profile curves of varying vanillin concentrations.

Table 6.2: Linear regression gradient calculations of Phase I, Phase II and Phase III for turbidity profile curves of varying $5 \mathrm{HMF}$ concentrations.

Table 6.3: Structure and functionality of the thiol-based compounds. 


\section{Index of Abbreviations}

\begin{tabular}{|c|c|}
\hline AFM & $=$ Atomic force microscopy \\
\hline $\mathrm{Au}$ & $=$ Gold \\
\hline $\mathrm{Ag}$ & $=$ Silver \\
\hline $\mathrm{CO}$ & $=$ Carbon monoxide \\
\hline $\mathrm{CO}-\mathrm{HbS}$ & $=$ Carbon monoxide sickle cell haemoglobin \\
\hline $\mathrm{c}_{0}$ & $=$ Initial concentration \\
\hline$c_{p}$ & $=$ Concentration of haemoglobin in the polymer phase \\
\hline $\mathrm{CE}$ & $=$ counter electrode \\
\hline$\Delta C_{P}$ & $=$ Polymerisation heat capacity change \\
\hline$c_{\text {sat }}$ & $=$ Solubility \\
\hline $\mathrm{CV}$ & $=$ Cyclic voltammetry \\
\hline$D$ & $=$ Diffusion coefficient \\
\hline DeoxyHb & $=$ Deoxygenated haemoglobin \\
\hline DeoxyHbS & $=$ Dexoygenated sickle cell haemoglobin \\
\hline DIC & $=$ Differential interference contrast \\
\hline$\Delta$ & $=$ Diffusion layer thickness \\
\hline 2,3-DPG & $=2,3$-diphosphoglycerate \\
\hline E & $=$ Potential \\
\hline$E_{\text {initial }}$ & $=$ Initial potential \\
\hline$E_{\text {final }}$ & $=$ Final potential \\
\hline $\mathrm{Fe}$ & $=$ Iron \\
\hline $\mathrm{Fe}(\mathrm{III}) / \mathrm{Fe}(\mathrm{II})$ & $=$ Iron $(I I I / I I)$ redox couple \\
\hline$\Delta G$ & $=$ Polymerisation Gibbs free energy change \\
\hline
\end{tabular}




\begin{tabular}{|c|c|}
\hline Glu & $=$ Glutamic acid \\
\hline$\gamma$ & $=$ Activity coefficient \\
\hline $\mathrm{H}_{2}$ & $=$ Hydrogen \\
\hline$\Delta H$ & $=$ Polymerisation enthalpy change \\
\hline $\mathrm{Hb}$ & $=$ Haemoglobin \\
\hline $\mathrm{HbA}$ & $=$ Adult haemoglobin \\
\hline $\mathrm{HbA}_{2}$ & $=$ Haemoglobin $\mathrm{A}_{2}$ \\
\hline $\mathrm{HbC}$ & $=$ Haemoglobin $\mathrm{C}$ \\
\hline $\mathrm{HbF}$ & $=$ Fetal haemoglobin \\
\hline $\mathrm{HbS}$ & $=$ Sickle cell haemoglobin \\
\hline $\mathrm{HCl}$ & $=$ Hydrochloric acid \\
\hline $\mathrm{He}$ & $=$ Helium \\
\hline $\mathrm{H}_{2} \mathrm{O}_{2}$ & $=$ Hydrogen peroxide \\
\hline HOPG & $=$ Highly oriented pyrolytic graphite \\
\hline $\mathrm{H}_{2} \mathrm{SO}_{4}$ & $=$ Sulphuric acid \\
\hline IHP & $=$ Inositol hexaphosphate \\
\hline K & $=$ Equilibrium constant \\
\hline$k_{1}$ & $=$ Nucleation rate constant \\
\hline$k_{1}$ & $=$ Elongation rate constant \\
\hline $\mathrm{KCl}$ & $=$ Potassium chloride \\
\hline Leu & $=$ Leucine \\
\hline $\mathrm{N}_{2}$ & $=$ Nitrogen \\
\hline $\mathrm{NaCl}$ & $=$ Sodium chloride \\
\hline $\mathrm{NaOH}$ & $=$ Sodium hydroxide \\
\hline $\mathrm{O}_{2}$ & $=$ Oxygen \\
\hline
\end{tabular}




\begin{tabular}{|c|c|}
\hline $\mathrm{O}^{2-}$ & $=$ Superoxide \\
\hline $\mathrm{OH}^{-}$ & $=$Hydroxyl ions \\
\hline OTE & $=$ optically transparent electrode \\
\hline $\mathrm{OxyHb}$ & $=$ Oxygenated haemoglobin \\
\hline OxyHbS & $=$ Oxygenated sickle cell haemoglobin \\
\hline PG & $=$ Pyrolytic graphite \\
\hline Phe & $=$ Phenylamine \\
\hline PLL & $=$ Poly-L-lysine \\
\hline $\mathrm{Pt}$ & $=$ Platinum \\
\hline $\mathrm{R}$ & $=$ Rest state of heamoglobin \\
\hline $\mathrm{RBC}$ & $=$ Red blood cell \\
\hline RE & $=$ Reference electrode \\
\hline s & $=$ Seconds \\
\hline $\mathrm{SCA}$ & $=$ Sickle cell anaemia \\
\hline SCD & $=$ Sickle cell disease \\
\hline $\mathrm{T}$ & $=$ Tense state of haemoglobin \\
\hline$T \Delta S$ & $=$ Polymerisation entropy change \\
\hline Val & $=$ Valine \\
\hline WE & $=$ Working electrode \\
\hline
\end{tabular}


Chapter 1: Introduction 


\subsection{Sickle Cell Anaemia}

Sickle cell anaemia (SCA) is the most common type of a group of autosomal recessive disorders termed as sickle cell disease (SCD). It is a genetic disorder of the blood in which the red blood cells (RBC) curve into a sickle shape due to the production and, most importantly, polymerisation of mutant sickle haemoglobin $(\mathrm{HbS})$. It is a disease which afflicts millions of people throughout the world, in particular those whose ancestors come from equatorial regions such as sub-Saharan Africa, Saudi Arabia, South America and India, and clinical manifestations include amongst others severe haemolytic anaemia, pain crises, stroke, and chronic damage to vital organs such as lungs, kidneys and liver.

The fundamental process of $\mathrm{HbS}$ polymerisation inside sickle erythrocytes has been studied by almost every physical technique of protein chemistry, including electron microscopy, single-crystal X-ray diffraction, nuclear magnetic resonance, circular dichroism spectroscopy, laser photolysis and temperature jump kinetics. A large part of the success in understanding this process can be attributed to the application of these many different techniques. However, even though the polymerisation of $\mathrm{HbS}$ has probably become the best understood of all protein selfassembly systems, SCA is still a major global health problem, with an estimated 120,000 to 250,000 affected infants born annually [1], and at present most clinical interventions can be classified as tertiary prevention, such as therapies to ameliorate anaemia, reduction of the frequency of pain crises, or prevention of stroke recurrences. As of yet, there are no preventative treatments.

In this chapter, recent advances into the study of $\mathrm{HbS}$ polymerisation, it's structural and physical properties as well as the critical conditions required for polymer formation, are described. Electrochemistry is also introduced and a summary of relevant visualisation techniques is reported. 


\subsubsection{Structure of Haemoglobin}

Haemoglobin $(\mathrm{Hb})$ is the iron-containing metalloprotein in the RBCs of mammals responsible for binding oxygen $\left(\mathrm{O}_{2}\right)$ in the lung and transporting the bound $\mathrm{O}_{2}$ throughout the body where it is used in aerobic metabolic pathways. Vertebrate $\mathrm{Hb}$ consists of four polypeptide chains: two alpha $(\alpha)$ and two beta $(\beta)$, with each subunit consisting of one haem group and one $\mathrm{O}_{2}$ binding site per subunit. The maximum capacity of a single $\mathrm{Hb}$ molecule is four $\mathrm{O}_{2}$ molecules.

An important aspect of the structure of $\mathrm{Hb}$ is the major conformational change it undergoes upon binding an $\mathrm{O}_{2}$ molecule. In 1938, Felix Haurowitz found that crystals of deoxygenated $\mathrm{Hb}\left(\right.$ deoxyHb) shattered when they were exposed to $\mathrm{O}_{2}$ [2]. It was shown many years later through x-ray crystallographic studies that the deoxygenated and oxygenated forms of $\mathrm{Hb}$ differ drastically in quaternary structure. The quaternary structure of deoxyHb is termed the tense (T) state whilst that of oxygenated $\mathrm{Hb}(\mathrm{oxyHb})$ is termed the relaxed $(\mathrm{R})$ state (figure 1.1).

Figure 1.1: A schematic diagram of the $T$ and $\mathrm{R}$ conformational states of $\mathrm{Hb}$, showing that the $T$ state has a larger cavity than the $\mathrm{R}$ state [3].

The $\mathrm{R}$ state or oxygenated molecule is more compact as the iron $(\mathrm{Fe})$ atomic distance of the $\beta$ chains decreases from 40 to $33 \AA$ on oxygenation. However, the $\mathrm{T}$ form has a lower affinity for $\mathrm{O}_{2}$ and is a more constrained molecule than its counterpart because of the presence of eight additional salt-links [4].

The mechanism for this $T$ to $R$ state switch is illustrated in figure 1.2. In the $T$ state, the $\mathrm{Fe}$ atom does not lie in the plane of the porphyrin ring but is about $0.4 \AA$ out of the plane towards the proximal histidine. This causes the haem group to be domed in the same direction. On oxygenation, an $\mathrm{O}_{2}$ molecule binds to the sixth 
coordination site of $\mathrm{Fe}$, displacing water $\left(\mathrm{H}_{2} \mathrm{O}\right)$, which causes the $\mathrm{Fe}$ atom to move into the plane of the porphyrin and the haem group to become more planar.

Figure 1.2: The mechanism for $T$ to $R$ state switch upon oxygenation. In the deoxygenated state the $\mathrm{Fe}$ atom is not in the plane of the porphyrin rings causing the haem group to be domed. When an $\mathrm{O}_{2}$ molecule attaches to the 6th coordination site the haem group becomes planar causing conformational changes through the whole molecule [3]

The movement of the $\mathrm{Fe}$ atom into the plane of the haem produces a level effect which causes a conformational change that is transmitted through the whole molecule. This allows the switch in quaternary structure from $\mathrm{T}$ to $\mathrm{R}$ state to occur. Thus, a structural change within a subunit is translated into structural changes at the interfaces between subunits. The binding of $\mathrm{O}_{2}$ at one haem site is thereby communicated to parts of the molecule which are far away. The $T$ to $R$ state conformational change is an important aspect of the polymerisation of $\mathrm{HbS}$, and therefore needs to be understood at the onset. 


\subsubsection{Polymerisation of $\mathrm{HbS}$}

$\mathrm{HbS}$ is a single point genetic mutation of normal adult haemoglobin $(\mathrm{HbA})$ that results in a hydrophobic valine residue replacing hydrophilic glutamic acid in the sixth codon of each of the two $\beta$ chains $[5,6]$. X-ray diffraction studies have shown that the $\beta 6$ glutamate residue is situated on the surface of the protein. Consequently, the substitution of a valine residue does not have a significant effect on the protein conformation, whilst the $\mathrm{O}_{2}$ affinity and allosteric properties are also virtually unaffected by this change. However, this alteration markedly reduces the solubility of the deoxygenated but not the oxygenated form of $\mathrm{HbS}$.

The key to $\mathrm{HbS}$ polymerisation is the interaction of a $\beta 6$ valine residue with a sticky hydrophobic pocket formed by the $\beta 85$ phenylamine and $\beta 88$ leucine residues on a different tetramer. This donor-acceptor interaction, in which $\beta 6$ valine is donated to the EF acceptor pocket, requires the $\mathrm{T}$ or deoxygenated state, as exposure of the pocket only occurs in this state [7]. Subsequently, this causes the association of $\mathrm{HbS}$ monomers to form a "Wishner-Love" double strand of deoxyHbS [8], as depicted in figure 1.3. This is the first stage of polymer formation. See section 1.1.3 for further details on the structure of the deoxyHbS double strands.

Figure 1.3: (a) schematic depiction of the phenylamine and leucine hydrophobic pocket formed for $6 \beta$ valine (b) crystal structure of the "Wishner-Love" double strands of dexoy-HbS, showing the lateral contacts and the axial contacts which occur during coupling [8]. 
It is important to note that the exposure of the hydrophobic pocket also occurs in $\mathrm{HbA}$ when in the $\mathrm{T}$-allosteric state but charge and size effect prevent $6 \beta$ glutamic acid from binding.

The second stage is the growth and polymerisation of the deoxyHbS double strands. At high concentrations (close to those found in RBCs), single double strands of deoxyHbS polymerise into long stiff insoluble rod-like fibres of $21.5 \mathrm{~nm}$ diameter and variable length. A fibre consists of six Wishner-Love double strands wrapped around a central strand in the form of a twisted rope with a pitch of 270 $\mathrm{nm}$ (see section 1.1.4). These fibres form non-covalent cross-links with each other to create a gel, causing the RBC to become rigid, and as a result block blood flow in the capillaries. The polymerisation process therefore triggers a sequence of pathogenic consequences by altering the shape and rigidity of the RBC. On reoxygenation, the polymers disassemble and the cells usually resume their normal biconcave disk shape. Thus, the consequence of the mutation is a catastrophic change in the intermolecular interaction of $\mathrm{HbS}$ molecules, more so than in its structural or functional properties. 


\subsubsection{Structure of $\mathrm{HbS}$ Molecule}

The major advance in the structural analysis of the $\mathrm{HbS}$ molecule came from single crystal X-ray diffraction studies, first at 5.0 A [8] and then at 3.0 A resolution [9]. Recently, the crystal structure of deoxyHbS has also been refined at $2.05 \mathrm{~A}$ resolution [10]. These studies have shown that the Wishner-Love double strand of $\mathrm{Hb}$ tetramers is the basic building block of the intracellular sickle cell fibre (figure 1.3). The HbS molecules pack within the crystal as parallel strands which are stabilised by axial contacts within each strand and lateral contacts between strands that involve the mutated valine residue. In the crystal structure there are two crystallographically distinct axial contacts and two distinct sets of lateral contacts. The axial contacts involve the $\alpha_{1}$ and $\beta_{1}$ subunits of one tetramer and the $\alpha_{2}$ and $\beta_{2}$ subunits of a different tetramer directly above it in the same strand, whilst the lateral contacts involve the valine residue of one $\beta$-chain and the hydrophobic valine-binding site, made up of phenylamine, leucine and several haem atoms, of a $\beta$-chain in an adjacent molecule [11]. In all instances, the molecular interactions are predominantly of the Van der Waals type and there are only a small number of potential hydrogen bonds and specific ion pair interactions present. 


\subsubsection{Structure of HbS Polymers}

The predominant polymeric structure formed from the addition of $\mathrm{HbS}$ double strands is a solid fibre having a diameter of $21.5 \mathrm{~nm}$ and a variable length [12, 13]. Electron microscopy studies have further established that the HbS fibre consists of seven double-strands twisting about a common helical axis. Figure $\mathbf{1 . 4}$ shows a cross-section of a single HbS fibre, showing the fourteen strands [14-16].

Figure 1.4: Cross section of the seven double-strand fibre model. There are fourteen strands in the fibre with a central double strand surrounded by six other double strands [14].

The molecular contacts which stabilise the $\mathrm{HbS}$ fibre are intra-strand contacts (axial and lateral) and intermolecular contacts. Intra-strand lateral and axial contacts are similar in each molecule of the fibre. However, unlike the lateral contact regions, the number of axial contact residues decreases as a function of the radial position of the strand. Twenty two residues are involved in the axial contacts at the fibre centre (strand 12), whereas only six are involved at the fibre periphery (strand 1) [17].

Intermolecular double strand contacts on the other hand involve largely different residues for each strand of the fibre. The number of residues per strand is small, ranging from five residues on strand 2 to thirteen on strand 10 and therefore the fibre is a relatively loose-packed and plastic structure [17, 18]. These can be distinguished as either contacts between parallel double strands or contacts between anti-parallel double strands. 


\subsubsection{Aggregated Forms of $\mathrm{HbS}$}

$\mathrm{HbS}$ can aggregate into a number of macroscopic forms. The physiologically relevant structure is believed to be a gel, formed through cross-linking and branching of $\mathrm{HbS}$ fibres, because it has the structural characteristics which form inside deoxygenated sickle cells. Some insight into the gel structure has come from observations with a polarising microscope in the course of kinetic studies [19]. These studies have shown that the organisation of $\mathrm{HbS}$ polymers in gelled solutions is generally found to be in the form of domains with the polymer long axes pointing in a radial direction. The largest domains are formed on a timescale of hours and these can be millimetres in diameter, whilst the smallest domains are typically microns or less in diameter and these are formed relatively rapidly. The size and number of these domains are therefore determined by the timescale over which polymerisation occurs. The detailed arrangement of these domains and the polymers within the domains are not yet known. However, it is known that it is the domains of single fibres and fibre bundles that cause deformation of the RBC into the characteristic sickle shape, which if not limited by the $\mathrm{Hb}$ in a single cell, would be much larger than the cell itself.

A closely related but physically distinct form of polymeric $\mathrm{HbS}$ structure is obtained by stirring deoxyHbS solutions while they are being heated to produce aggregation [20,21]. A free flowing suspension of elongated fascicles, found by electron microscopy to be bundles of parallel fibres packed in square or hexagonal arrays, are obtained instead of a gel $[16,22]$. If the stirring is continued for a long time, for example in $50 \mathrm{mM}$ Tris buffer at $\mathrm{pH} \mathrm{6.7,} \mathrm{macrofibres} \mathrm{are} \mathrm{formed} \mathrm{by} \mathrm{the}$ association of small, organised bundles of partially fused fibres. Whereas in a fibre, four of the seven double strands are antiparallel to the remaining three, macrofibres are composed such that adjacent rows are antiparallel. Microscopic crystals have also been observed to grow from gels formed in the absence of stirring or any other shear forces after periods of months [23-25]. 


\subsection{Critical Conditions for Polymer Formation}

\subsection{1 $\mathrm{O}_{2}$ Saturation}

The physiological variable to which $\mathrm{HbS}$ polymerisation is most sensitive to is $\mathrm{O}_{2}$, with polymer formation being inhibited by $\mathrm{O}_{2}$ saturation. Conceptually, the simplest model for the effect of $\mathrm{O}_{2}$ on polymerisation is a straightforward two-state allosteric model [26]. DeoxyHb packs in a $\mathrm{T}$ conformation whereas oxyHb packs in an $\mathrm{R}$ conformation. However, for HbS polymer formation the registry between polymer-stabilizing molecular contacts present in the $\mathrm{T}$ structure is absent when $\mathrm{HbS}$ assumes the $\mathrm{R}$ structure. Therefore, it is the structural changes accompanying oxygenation which prevent polymer formation.

Experimentally, ${ }^{13} \mathrm{C} /{ }^{1} \mathrm{H}$ magnetic double-resonance spectroscopy has been used to measure the amount of $\mathrm{HbS}$ polymer within sickle erythrocytes as a function of $\mathrm{O}_{2}$ saturation. Measurements show that the amount of intracellular deoxyHbS polymer increases monotonically with decreasing $\mathrm{O}_{2}$ saturation, whilst the polymer can be detected even at $\mathrm{O}_{2}$ saturation values above $90 \%$ (figure 1.5 ) [27].

Figure 1.5: The curve for polymer formation as a function $\mathrm{O}_{2}$ saturation of unfractionated sickle cell RBCs at pH 7.65. and - is data obtained from samples of different individuals. $\mathrm{O}_{2}$ saturation was varied by using equilibration in a tonometer with gas mixtures containing varying amounts of $\mathrm{O}_{2}$ and was measured directly for each sample. Each data point represents 1024 spectral accumulations, $X, \square, \circ$ and $\Delta$. The solid line represents the theoretical calculation for polymer fraction as a function of oxygen saturation with an allosteric model [27]. 


\subsubsection{Effectors of $\mathrm{O}_{2}$ Saturation}

pH Level:

Studies have shown that the aggregation of $\mathrm{HbS}$ is markedly dependent on $\mathrm{pH}[28$, 29]. One such study involved the measurement of the solubility $\left(\mathrm{C}_{\mathrm{sat}}\right)$ of $\mathrm{HbS}$ solutions, dialysed exhaustively against $0.06 \mathrm{M}$ phosphate buffers of $\mathrm{pH} 5.5$ to 8.1 , by ultracentrifugation and sedimentation methods. As shown in figure 1.6, the solubility changes very little between pH 6 and 7, and then sharply increases at more acidic and basic values, whilst the minimum in the solubility-pH profile is seen at $\mathrm{pH}$ 6.5. This suggests that a significant effect of an increase or decrease in $\mathrm{pH}$ is destabilisation of the polymer through an increase in the net electrostatic repulsion between molecules. The $\mathrm{pH}$ dependence may also be due to the titration of histidines that form hydrogen bonds or ion-pair in intermolecular contacts [28].

Figure 1.6: effect of $\mathrm{pH}$ on solubility of $\mathrm{HbS}$ in $0.06 \mathrm{M}$ sodium phosphate buffer at $25^{\circ} \mathrm{C}$. $\mathrm{Hb}$ solutions were dialysed extensively against phosphate buffers of pH 5.5 to 8.1 [28].

\section{Other effectors of $\mathrm{O}_{2}$ Saturation:}

2,3-diphosphoglycerate (2,3-DPG), inositol hexaphosphate and ATP all act in a similar manner. All of these molecules have a strong negative charge and bind in the central cleft of deoxyHb, and thus act by biasing the conformational equilibrium in $\mathrm{Hb}$ toward the deoxygented form, and favouring $\mathrm{O}_{2}$ release. However, they interact at distinctly different sites, and therefore their effects can be additive. The effect of 2,3-DPG on $\mathrm{HbS}$ polymerisation is investigated in more detail in Chapter 4.7. 


\subsubsection{HbS Concentration}

The concentration of fully deoxyHbS is another factor that determines in vivo polymer formation. When deoxyHbS concentration exceeds the solubility, polymer formation begins. Therefore, increasing $\mathrm{HbS}$ concentration increases the extent of polymerisation. In understanding this concept it is important to appreciate the molecular crowding in a solution of $\mathrm{Hb}$ at concentrations typically found in a RBC. At $340 \mathrm{mg} \mathrm{cm}^{-3}$, Hb molecules are 1.6 molecular diameters apart centre to centre, but only 1.1 molecular diameters apart edge to edge and their natural motion ensures that they will encounter each other every few nanoseconds. In concentrated solutions, $\mathrm{HbS}$ particles are greater in number and much closer and thus there is an increase in molecular collisions and more chance of a hydrophobic interaction occurring between the mutated valine residue of one $\mathrm{HbS}$ and the $\beta$-subunit of another [30]. High $\mathrm{HbS}$ concentrations normally required experimentally for the assembly of $\mathrm{HbS}$ fibres [30] poses a problem as an experiment can require more than $200 \mathrm{mg} \mathrm{cm}^{-3}$ of $\mathrm{HbS}$ protein per single experiment. However, numerous studies $[31,32]$ of the polymerisation of $\mathrm{HbS}$ in $1.5 \mathrm{M}$ phosphate buffer have found that in high molarity buffer solutions polymerisation occurs at much lower concentrations (ca. $50 \mathrm{mg} \mathrm{cm}^{-3}$ ).

Wang et al. [14] compared the structures of $\mathrm{HbS}$ fibres formed in high molar phosphate buffer $(1.5 \mathrm{M})$ with low molar buffer $(0.05 \mathrm{M})$ to determine whether the high buffer concentration affected the structure of the polymers being formed and found that in all cases the polymers formed in $1.5 \mathrm{M}$ had the same structures as those formed in $0.05 \mathrm{M}$ phosphate buffer. The general appearance, spacings and intermediates of the polymers from negative staining, imaged with cryo-electron microscopy and Fourier transforms, were used for the comparison.

The influence of non-HbS on the polymerization process needs to be discussed briefly aswell as $\mathrm{HbS}$ frequently occurs in red cells in combination with a large fraction of other $\mathrm{Hb}$, such as $\mathrm{HbA}$, fetal haemoglobin $(\mathrm{HbF})$ and haemoglobin $\mathrm{C}$ (HbC) [33]. The fraction of $\mathrm{HbS}$ in red cells differs considerably among the various types of sickle cell disease. $\mathrm{HbA}$ and $\mathrm{HbC}$ have been shown to increase the solubility of deoxy-HbS in mixtures with $\mathrm{HbS}$, whilst $\mathrm{HbA}_{2}$ and $\mathrm{HbF}$ have an even greater sparing effect; a sparing effect is where normal or abnormal $\mathrm{Hb}$ that may be present along with $\mathrm{HbS}$ in human erythrocytes act to elevate its solubility under 
conditions of partial or total desaturation [34]. The HbS molecular crowding is diminished with a variable intracellular $\mathrm{Hb}$ composition, and thus the molecular collisions between $\mathrm{HbS}$ particles are fewer [33]. Increased proportions of $\mathrm{HbA}$, $\mathrm{HbF}$ or $\mathrm{HbC}$ therefore results in decreased clinical severity. 


\subsubsection{Temperature}

Studies performed to see the effect of temperature on the solubility of deoxy-HbS have shown that polymer formation is favoured by elevated temperature. In a 0.15 $\mathrm{M}, \mathrm{pH} 7.15$ potassium phosphate solution, solubility of $\mathrm{HbS}$ decreases from about $320 \mathrm{mg} \mathrm{cm}^{-3}$ at $0{ }^{\circ} \mathrm{C}$ to a minimum of $160 \mathrm{mg} \mathrm{cm}^{-3}$ at about $35{ }^{\circ} \mathrm{C}$, and then increases again (figure 1.7) $[35,36]$.

Figure 1.7: Temperature dependence of deoxy- $\mathrm{HbS}$ solubility in a solution of $0.15 \mathrm{M}$ phosphate buffer and $0.05 \mathrm{M}$ sodium dithionite as an additional reducing agent [36].

Therefore, at total concentrations below $160 \mathrm{mg} \mathrm{cm}^{-3}$. deoxyHbS solutions remain liquid between $0{ }^{\circ} \mathrm{C}$ to $45^{\circ} \mathrm{C}$ : at concentrations above $320 \mathrm{mg} \mathrm{cm}^{-3}$, the solution contains polymers at all temperatures; and between $160 \mathrm{mg} \mathrm{cm}^{-3}$ and $320 \mathrm{mg} \mathrm{cm}^{-3}$. the solution undergoes reversible polymerisation and depolymerisation on heating and cooling $[30,36]$. 


\subsubsection{Experimental Conditions for Polymerisation of $\mathrm{HbS}$}

There is a wealth of literature concerning the formation of $\mathrm{HbS}$ aggregates in vitro, and a summary of the conditions used for $\mathrm{HbS}$ polymerisation in these studies is presented in table 1.1. It is noticeable that a wide range of $\mathrm{HbS}$ protein concentrations have been used from low values of only $6 \mathrm{mg} \mathrm{cm}^{-3}$ to extremely highly concentrated ones of $940 \mathrm{mg} \mathrm{cm}^{-3}$ whilst the molarity of phosphate buffer used was dependent on the $\mathrm{HbS}$ concentration; high concentrations of $\mathrm{HbS}$ were associated with low buffer concentrations. Furthermore, solution $\mathrm{pH}$ was limited to the physiological $\mathrm{pH}$ range.

The method by which HbS polymerisation was initiated in each study is also summarised in table 1.1. Heating of the protein solution, commonly referred to as the temperature jump method, has been favoured by many investigators to induce polymerisation because of its simplicity and compatibility with all the monitoring techniques. However, although the temperature jump method has many advantages, another being disassembly of the polymers by cooling, a major limitation is its non-applicability to high $\mathrm{HbS}$ concentrations. The shortest delay times which can be accurately measured are the thermal equilibration times of the order of $10 \mathrm{~s}$ which at $37{ }^{\circ} \mathrm{C}$ corresponds to a concentration of $230 \mathrm{mg} \mathrm{cm}^{-3}$, slightly lower than those found in sickle RBCs [37].

Therefore many recent studies, especially those investigating kinetics of polymerisation, have employed a laser photolysis technique developed by Ferrone et al. in which the polymerisation reaction is initiated by rapid removal of carbon monoxide ( $\mathrm{CO}$ ) from a $\mathrm{CO}$ saturated $\mathrm{HbS}$ solution [30,37]. The advantages of this technique are that polymerisation can be achieved extremely quickly and the experiment can be repeated many times as recombination of $\mathrm{CO}$ results in depolymerisation.

Electrochemistry has been used as the method of initiation in this present investigation. Electrochemical reduction of $\mathrm{O}_{2}$ at an electrode surface in contact with $\mathrm{HbS}$ solution causes local deoxygenation, and thus induction of fibre formation. This removes the need to deoxygenate the whole solution as only deoxygenation at the surface is required. 


\begin{tabular}{|c|c|c|c|c|c|}
\hline Reference & $\begin{array}{l}\text { HbS conc. } \\
\left(\mathrm{mg} \mathrm{cm}^{-3}\right)\end{array}$ & $\begin{array}{l}\text { Phosphate } \\
\text { buffer (M) }\end{array}$ & $\mathrm{pH}$ & Other conditions & Method of nucleation \\
\hline 10 & 120 & 0.03 & 7.0 & $\begin{array}{c}\text { HbS in buffer } \\
\text { conc. to } 120 \mathrm{mg} \mathrm{cm}^{-3}\end{array}$ & $\begin{array}{l}\text { polymerisation } \\
\text { occurred in } 2 \text { days }\end{array}$ \\
\hline 14 & 25 & 1.5 & 6.7 & $-25^{\circ} \mathrm{C}$ & temp jump to $25^{\circ} \mathrm{C}$ \\
\hline 20 & 20 & 0.1 & 7.0 & IHP and EDTA; $25^{\circ} \mathrm{C}$ & gentle stirring \\
\hline 37 & 440 & 0.15 & 7.35 & Sodium dithionite & photolyse $\mathrm{CO}-\mathrm{HbS}$ \\
\hline 38 & 55 & 1.8 & 7.3 & Sodium dithionite & photolyse $\mathrm{CO}-\mathrm{HbS}$ \\
\hline 39 & 240 & 0.1 & 7.2 & $25^{\circ} \mathrm{C}$ & photolyse $\mathrm{CO}-\mathrm{HbS}$ \\
\hline 40 & 240 & 0.1 & 7.2 & $25^{\circ} \mathrm{C}$ & photolyse $\mathrm{CO}-\mathrm{HbS}$ \\
\hline 41 & $9-35$ & 0.15 & 7.35 & humidified $\mathrm{He}$ & temp. jump to $37^{\circ} \mathrm{C}$ \\
\hline 42 & 830 & 0.1 & 7.0 & $\begin{array}{l}\text { deoxygenated with } \\
\text { sodium dithionite }\end{array}$ & temp. jump to $28^{\circ} \mathrm{C}$ \\
\hline 43 & $6-12$ & 0.05 & 7.5 & Dextran added & $\begin{array}{l}\text { incubation for } 30 \mathrm{~min} \\
\text { at room temp. }\end{array}$ \\
\hline 44 & 68 & 1.8 & 7.4 & $2{ }^{\circ} \mathrm{C}$ & temp. jump to $30^{\circ} \mathrm{C}$ \\
\hline 45 & 270 & 0.15 & 7.35 & Sodium dithionite & photolyse $\mathrm{CO}-\mathrm{HbS}$ \\
\hline 46 & $>100$ & 0.05 & 7.4 & $37^{\circ} \mathrm{C}$; glutaraldehyde & stirring under $\mathrm{N}_{2}$ \\
\hline 47 & 1350 & 0.1 & 7.2 & $25^{\circ} \mathrm{C}$ & photolyse $\mathrm{CO}-\mathrm{HbS}$ \\
\hline 48 & 240 & 0.05 & 6.7 & $\begin{array}{c}\text { stained with } \\
\text { phosphotungstic acid }\end{array}$ & $\begin{array}{c}\text { photolyse CO-HbS } \\
\text { and temp.jump }\end{array}$ \\
\hline
\end{tabular}

Table 1.1: Conditions for HbS polymerisation and methods of nucleation initiation used in selected studies found in literature. 


\subsection{Thermodynamics and Kinetics of $\mathrm{HbS}$ Polymerisation}

\subsubsection{Thermodynamics of HbS Polymerisation}

Thermodynamically, the simplest description of $\mathrm{HbS}$ polymerisation consists of the aggregation of $\mathrm{HbS}$ into helical polymers or three-dimensional crystals. A two component system consisting of a solution plus polymer phase is commonly referred to as a gel, and the overall process of forming a collection of domains of aligned polymers as gelation or polymerisation. Each of the two phases of the polymerisation model are distinct entities, in which the solution phase of the gel contains only $\mathrm{HbS}$ molecules of $64.5 \mathrm{kDa}$ as the monomers, with no clear evidence for aggregation in this phase, whilst the polymer phase behaves like an ordered crystal in equilibrium with a solution of $\mathrm{HbS}$ monomers. Although, the crystal is the thermodynamically more stable structure, polymers always form first.

The separation of a gel into solution and polymer phases can be achieved by centrifugation $[49,50]$ and the concentration of $\mathrm{HbS}$ in each phase measured by sedimentation into a compact pellet. The concentration of $\mathrm{HbS}$ in the solution phase can be measured using an analytical sedimentation technique, and the results confirm the presence of singular $\mathrm{HbS}$ molecules as the sedimentation velocity profile only contains a single peak whose coefficient is very similar to that of $\mathrm{Hb}$ tetramers [29].

The concentration of $\mathrm{HbS}$ in the polymer phase is taken as a measure of the solubility of deoxygenated $\mathrm{HbS}$, or in other words a measure of the intracellular $\mathrm{HbS}$ concentration in equilibrium with the polymer in solution. It can be approximately measured in solubility experiments in near-infrared spectrophotometry on the turbid pellets, from which the concentration of $\mathrm{Hb}$ in the pellet is calculated using mass conservation [51]. From these experiments the volume fraction of the solution phase is calculated to be $350 \mathrm{mg} \mathrm{cm}^{3}$ and the concentration of deoxyHbS in the pure polymer phase is $690 \mathrm{mg} \mathrm{cm}^{-3}$ [51]. The solubility data can then be used to calculate the fraction of polymerised $\mathrm{Hb}, \chi_{\mathrm{p}}$, at any temperature and the total concentration, $c_{0}$, using the mass conservation relationship [51]:

$$
\chi_{\mathrm{p}}=\left(1-c_{\mathrm{sat}} / \mathrm{c}_{\mathrm{o}}\right) /\left(1-c_{\mathrm{sat}} / c_{\mathrm{p}}\right)
$$


where $c_{s a t}$ is the solubility and $c_{p}$ is the concentration of $\mathrm{Hb}$ in the polymer phase $\left(690 \mathrm{mg} \mathrm{cm}^{-3}\right)$. The equilibrium constant, $K$, for the polymer phase in the reaction $\mathrm{Hb}$ (solution) $+n \mathrm{H}_{2} \mathrm{O}=\mathrm{Hb}\left(\mathrm{H}_{2} \mathrm{O}\right)_{\mathrm{n}}$ (polymer) is given by [51]:

$$
K=1 / a_{\mathrm{Hb}}\left(a_{\text {water }}\right)^{\mathrm{n}}
$$

where $a_{\mathrm{Hb}}$ is the activity of the $\mathrm{Hb}$ monomer and $a_{\mathrm{water}}$ is the activity of water in the solution phase. The activity of $\mathrm{Hb}$ is simply the product of the solubility and the activity coefficient $\left(a=c_{\text {sat }} \gamma\right)$.

The polymerisation enthalpy change, $\Delta H$, or the apparent molar heat of gelation is given as the heat absorbed per mole of $\mathrm{Hb}$ entering the polymer phase and can be obtained from the temperature dependence of the equilibrium constant using the van $t$ Hoff equation:

$$
d \ln K / d(1 / T)=-\Delta H / \mathrm{R}
$$

A large decrease in the apparent $\Delta H$ with temperature is seen from the van ${ }^{\circ}$ Hoff analysis of the solubility data and this is confirmed by direct calorimetric measurements [36, 52]. However, data obtained from scanning calorimetric measurements [36], the more sensitive of the two methods, gives values for $\Delta H$ which are in fair agreement with those obtained from the solubility data. but are lower by 0 to $12.6 \mathrm{~kJ} \mathrm{~mol}^{-1}$. This difference may be due to some proton or ionbinding process which has not been included in the thermodynamic analysis. 


\subsubsection{Kinetics of HbS Polymerisation}

The kinetics of fibre formation and polymerisation are extremely important and have played a central role in understanding the physical chemistry of $\mathrm{HbS}$ polymerisation as well as the pathophysiology of the SCA to subsequently improve therapeutic strategies

A large variety of techniques have been used to monitor the process of polymer formation. including nuclear magnetic resonance [53, 54], viscosity [55-57], turbidity $[21,51,58]$, linear birefringence $[25,59,60]$, light scattering $[20,60,61]$ and transverse relaxation times [62], and the results from all of these techniques show the same basic kinetic features of polymerisation. A typical progress curve for polymerisation of an initially polymer-free solution is shown in figure $\mathbf{1 . 8}$ [35].

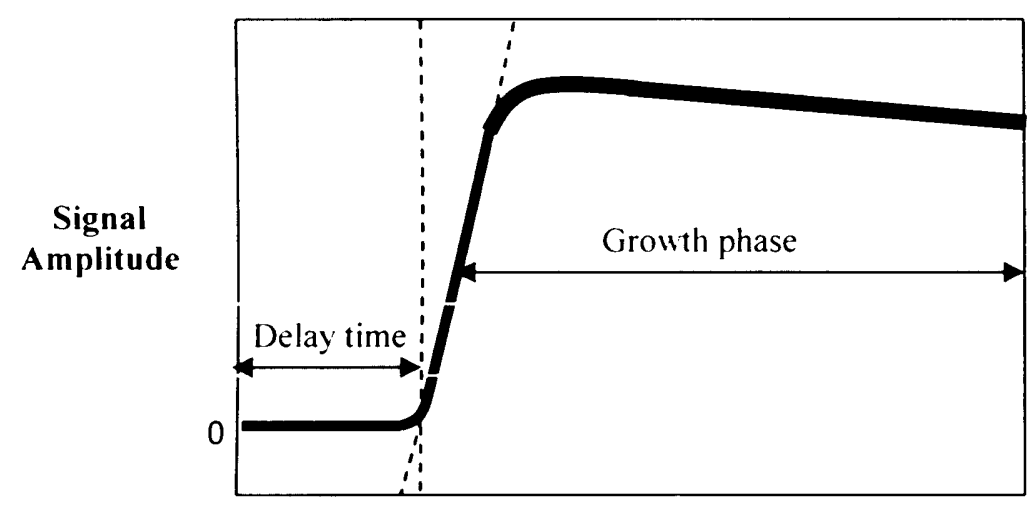

Time

Figure 1.8: Time course of HbS polymerisation. This is a typical progress curve showing a two step mechanism for polymerisation in which there is a delay period initially. during which time no change in the signal is observed. This period corresponds to the time taken for nucleation to occur and so is also referred to as the nucleation time. This is followed by the appearance of the polymer and subsequently growth proceeds exponentially.

There is a marked delay in the initial part of the progress curve during which time no change in the signal is observed, and this corresponds to a period called the delay or nucleation time during which no polymer formation. The delay is followed by an explosive and highly autocatalytic formation of polymer $[63,64]$. The length of this delay time is found to be strongly dependent on the inverse initial concentration of $\mathrm{HbS}$ to a very high power. This power is not constant but varies with the $\mathrm{HbS}$ concentration from 15 at $350 \mathrm{mg} \mathrm{cm}^{-3}$ [37] to as high as 35 to 50 at $250 \mathrm{mg} \mathrm{cm}^{-3}[63,64]$. Furthermore, the delay time is also found to be related 
to the solubility of $\mathrm{HbS}$, and thus dependent on the variables which alter the solubility of $\mathrm{HbS}$ such as extent of deoxygenation, temperature and $\mathrm{pH}$. A simple empirical formula, called the supersaturation equation [65], relates the delay time, $t_{\mathrm{d}}$, to the solubility:

$$
1 / t_{\mathrm{d}}=\lambda\left(\mathrm{c}_{\mathrm{o}} / \mathrm{c}_{\mathrm{sat}}\right)^{\mathrm{n}}
$$

where $t_{\mathrm{d}}$ is the delay time, $\lambda$ is the proportionality factor, $\mathrm{n}$ is found to be approximately 30-40 under physiological conditions and the supersaturation, $\left(\mathrm{c}_{\mathrm{o}} /\right.$ $\left.\mathrm{c}_{\mathrm{sat}}\right)$, is defined as the ratio of the initial $\mathrm{HbS}$ concentration to the equilibrium solubility. 


\subsubsection{Double Nucleation Mechanism}

Originally it was thought that the dependence of the delay time on solution conditions could be explained by a simple one-step nucleation mechanism based on equilibrium nucleation and growth of individual polymers. However, this mechanism could not explain the existence of a delay period prior to polymer formation. Consequently, a double nucleation mechanism, in which all the experimental observations involving the kinetics of $\mathrm{HbS}$ polymerisation could be explained, was postulated by Ferrone et al. (figure 1.9) [66].

Figure 1.9: The double nucleation mechanism of $\mathrm{HbS}$ polymerisation consisting of an initial nucleation phase known as homogeneous nucleation followed by growth of the polymer known as heterogeneous nucleation. The homogeneous nucleation consists of the sequential addition of thermodynamically unfavourable monomers until the aggregate reaches a certain size called the critical nucleus (depicted as nucleus in this diagram). The formation of the critical nucleus is the first signal seen in a progress curve after the delay time. Once the critical nucleus is reached further addition of monomers becomes thermodynamically favourable and so growth of polymers is fast and explosive. This autocatalytic growth is termed the heterogeneous nucleation [67].

This mechanism postulates that polymer formation is the result of two types of nucleation. In the first type, aggregation of $\mathrm{HbS}$ molecules occurs in the bulk solution to form the first polymer and this is termed as homogenous nucleation. This polymer grows by the addition of monomers to the ends. In homogenous nucleation, the sequential addition of monomers is a thermodynamically unfavourable random process initially as there is significant entropic loss for the monomer associated with aggregation. The substantial loss of translational and rotational freedom of the monomer is only partially compensated for by the 
entropy gain from the centre of mass and torsional vibrations of the molecules in a polymer lattice. However, the reaction becomes increasingly favourable as the number of monomers increases due to an increase in stability associated with an increase in the number of bonds per molecule from 0.5 bonds in a dimer to 4.1 bonds in the infinite polymer. Monomer addition occurs till the aggregate reaches a certain size, termed as the critical nucleus, which in this context is the aggregate at which size the forward reaction becomes thermodynamically favourable. Consequently, the formation of the critical nucleus is the rate-determining step. Experimentally, the existence of the delay time is accounted for by the time taken to form the critical nucleus as there is no polymer formation till this stage, whilst. the energetic gain needed to form the critical nuclei is dependent on the initial concentration. The rate of growth of polymer in this stage is governed by the relationship [68,69]:

$$
\alpha=k_{+}\left(\gamma c_{0} / \gamma_{1} c_{i}\right)
$$

where $\alpha$ is the homogenous growth rate of polymer, $k_{+}$is the monomer addition rate constant and $\gamma$ is the activity coefficient of the monomer.

The second type of nucleation is termed heterogeneous nucleation and this step involves nucleation (i.e. homogeneous nucleation) on the surface of pre-existing polymers as well as growth of polymers. As more polymers form. the available surface area and thus the number of sites available for heterogeneous nucleation increases with time. As a result, there is a continuous increase in the rate of heterogeneous nucleation providing an explanation for the highly explosive and exponential growth observed in the progress curves. The contacts which create heterogeneous nucleation are a subset of the fundamental contacts within the double strand [66]. Another intriguing aspect of heterogeneous nucleation is the ability of the polymers to display considerable flexibility with intersection sites of newly generated polymers able to display maximum angular separation of $21^{\circ}$ to $26^{\circ}$ as well as polymer alignment [67].

The heterogeneous nucleation rate is proportional to the concentration of monomers already present in polymers, $g_{0} \Delta$, and thus rate is described as [70]:

$$
g_{\mathrm{o}} \Delta=\left(k_{+} \gamma\right) c c_{\mathrm{j}}
$$


where $\Delta$ is the concentration of monomers incorporated into polymers and $c_{\mathrm{j}}$ is the concentration of heterogeneous nuclei of size $\mathrm{j}$.

Consequently, the rate of polymer formation for the complete reaction is given as [66]:

$$
\omega=\alpha(c)+\left(c_{0}-c\right) g_{0} \Delta(c)
$$

where $\alpha(c)$ is the rate of homogeneous nucleation and $g_{0} \Delta(c)$ is the rate of heterogeneous nucleation per concentration of the polymerised monomer. 


\subsubsection{Polymer Melting}

Melting is the term used to describe the depolymerisation of $\mathrm{HbS}$ molecules upon oxygenation. If a cell containing polymers reaches the lungs, then oxygenation will lead to melting. However, if polymer melting is not complete by the time the cell enters the tissues where $\mathrm{O}_{2}$ pressure is low then the remaining polymers promote rapid growth through heterogeneous nucleation, and if this time for melting is longer than the 1 second required to transit deoxygenated portions of the RBCs then obstruction of the microvasculature occurs $[38,70]$. Consequently, the rates of depolymerisation could play a crucial role in the resolution of pathophysiological processes.

Unfortunately, the kinetics and mechanism of polymer melting have not been as widely studied as those of polymerisation and many early reports have provided conflicting data. Initially, the absence of a delay time observed during melting led to the prediction that melting upon reoxygenation at the lungs is fast [71]. However, other studies have indicated that this process is slow enough, on the order of tens of seconds that polymers persist during circulation, and thus contribute to occlusion [72]. In addition, it is also known that the process of depolymerisation occurs by shortening of individual fibres at their ends in the presence of $\mathrm{CO}$, whilst the affinity of polymerised $\mathrm{HbS}$ for the ligands $\mathrm{CO}$ and $\mathrm{O}_{2}$ is three to ten times lower than the affinity of solution $\mathrm{T}$ state $\mathrm{HbS}$. 


\subsubsection{Nucleation and Growth of Fibres in Literature}

Much of the literature on the nucleation and growth of $\mathrm{HbS}$ has focussed on the polymerisation of $\mathrm{HbS}$ in solution, and therefore been largely concerning homogeneous rather than heterogeneous nucleation. Homogeneous nucleation is the initiation of polymerisation through thermodynamically unfavourable random aggregation of $\mathrm{HbS}$ monomers, whilst heterogeneous nucleation consists of homogeneous nucleation and growth of polymers on the surface of existing polymers and other surfaces. Recent literature detailing the mechanistic steps of fibre formation and the techniques with which they have been visualised are summarised in table 1.2.

Homogeneous and heterogeneous nucleation was originally postulated on the basis of macroscopic data from kinetic measurements. However, a short paper by Samuel et al. [42] described the observation of the nucleation, growth and interaction of $\mathrm{HbS}$ fibres in real time using non-invasive video-enhanced differential interference contrast (DIC) and dark-field microscopy. This provided, for the first time, the direct visualisation of the polymerisation process in detail. The reported images supported most aspects of the double nucleation mechanism. The first fibres were seen 12 minutes after the temperature jump and thus a delay was apparent before polymers were seen. The polymers then grew rapidly producing a resulting network which was highly branched and cross-linked to give a gel. Branching, arising from the thick regions of the fibre, was thinner than the parent fibre, whilst, the images of the gel showed that it was a dynamic and flexible entity [42]. 


\begin{tabular}{|c|c|c|c|}
\hline Reference & Description of Study & Method of Nucleation & Visualisation Techniques \\
\hline 41 & $\begin{array}{l}\text { Liquid-liquid separation demonstrated in solutions of } \mathrm{HbS} \text { and dense } \\
\text { liquid droplets seen to act as nucleation centres for } \mathrm{HbS} \text { spherulites }\end{array}$ & temp. jump $\left(24-37^{\circ} \mathrm{C}\right)$ & DIC microscopy and AFM \\
\hline 42 & $\begin{array}{l}\text { Observation of nucleation, growth and interaction of fibres in real-time } \\
\text { demonstrated }\end{array}$ & temp. jump $\left(2-28^{\circ} \mathrm{C}\right)$ & $\begin{array}{l}\text { DIC microscopy and } \\
\text { dark-field microscopy }\end{array}$ \\
\hline 43 & $\begin{array}{l}\text { Investigation of the structure, solubility behaviour and phase distributions } \\
\text { with dextran upon } \mathrm{HbS} \text { polymerisation }\end{array}$ & $\begin{array}{l}\text { incubation for } 30 \mathrm{~min} \text { at room } \\
\text { temp }\end{array}$ & electron microscopy \\
\hline 45 & $\begin{array}{l}\text { Determination of rates of induction times of homogenous nucleation of } \\
\mathrm{HbS} \text { fibres }\end{array}$ & photolyse CO-HbS & DIC microscopy \\
\hline 46 & Determination of the content and orientation of aligned $\mathrm{HbS}$ polymer & humidified nitrogen & $\begin{array}{l}\text { differential polarisation } \\
\text { imaging microscopy }\end{array}$ \\
\hline 47 & $\begin{array}{l}\text { Observed individual events and structures in the development of gel } \\
\text { domains }\end{array}$ & photolyse $\mathrm{CO}-\mathrm{HbS}$ & DIC microscopy \\
\hline 48 & Mechanisms of depolymerisation of $\mathrm{HbS}$ fibres & $\begin{array}{l}\text { photolyse CO-HbS and temp. } \\
\text { Jump }\end{array}$ & $\begin{array}{l}\text { DIC and electron } \\
\text { Microscopy }\end{array}$ \\
\hline
\end{tabular}

Table 1.2: A description of the techniques used for the visualisation and monitoring of nucleation and growth of HbS polymers from studies found in literature. 
Another study by Briehl and co-workers [73] enhanced the use of DIC microscopy to observe individual HbS fibres in gels, and showed not only that gels and fibres were fragile and easily broken by mechanical perturbation, but breakage resulted in vast acceleration of gelation kinetics due to the creation of new, growing fibre ends (figure 1.10). Since gelation kinetics is critical in inducing microvascular obstruction, the acceleration of gelation upon breakage may have important implications in vivo to the pathogenesis of sickle cell crises.

Figure 1.10: DIC microscopy images showing fracture of a single HbS fibre and rapid filling of the field with numerous new fibres after fracture (fracture induced as a result of mechanical perturbation due to a tap on the slide): (a) before fracture only single fibre visible; (b) after fracture fibre fragments visible (arrow indicates point of fracture); (c, d) fragments grow and cross-link till field is densely filled with fibres. Hb concentration was $12.4 \mathrm{mmol} \mathrm{L}^{-1}$ (heme) at $25^{\prime} \mathrm{C}$ and fibre formed 56 minutes after the temperature increase. The width of the field is $24 \mathrm{pm}$. DIC microscopy produces images many times larger than small objects; hence, fibers are much thinner than the DIC images shown [73].

Figure 1.10 shows the time-course of a polymer initiated by a temperature increase. It can be seen that after the resulting fibre was fractured to create new growing ends polymerisation was rapid and the field filled in quickly with fibres to produce a large mass of polymers. The first fibre appeared 56 minutes after the temperature jump, but after the fracture the growth of newer fibres was far quicker. In other words, the overall rate of polymer formation in the gel was increased due to the creation of new fibre ends.

DIC microscopy coupled with ligation control, through the use of photolytic epiillumination, has also been used to define the structure and development of gel domains and to demonstrate the mechanism of fibre melting. Changes in photolytic intensity were seen to alter domain growth rates and domain structure with fibres growing slowly and radially without branching at low laser intensity, and growing faster and forming highly cross-linked, dense domains at high intensity [47]. Depolymerisation, on the other hand, occurred at two sites on the fibres. At low 
CO partial pressures the dominant mechanism of dissolution was depolymerisation at fibre ends at rates of approximately $1 \mu \mathrm{m} \mathrm{s} \mathrm{s}^{-1}$, whereas at high $\mathrm{CO}$ partial pressures the dominant mechanism was rapid dissolution, complete in one second or less, along fibre sides. A model has been postulated to describe the mechanisms of end and side-depolymerisation [48]. 


\subsection{Electrochemistry}

\subsubsection{Electrochemical Reduction of $\mathrm{O}_{2}$}

The $\mathrm{O}_{2}$ reduction reaction is a complex multi-electron process that may include a number of elementary steps involving different reaction intermediates. In general, however, the mechanisms are of two types, with a modified Wroblowa et al. [74] scheme the most effective in describing the complicated reaction pathway by which $\mathrm{O}_{2}$ is reduced at metal surfaces, see figure 1.11:

Figure 1.11: The $\mathrm{O}_{2}$ reduction reaction scheme. $\mathrm{O}_{2}$ can be electrochemically reduced either directly to $\mathrm{H}_{2} \mathrm{O}$ in a 4 electron reduction reaction governed by the rate constant $k_{1}$ or via the intermediate $\mathrm{H}_{2} \mathrm{O}_{2}$. In this case, $\mathrm{O}_{2}$ is initially adsorbed on the electrode surface and is converted to $\mathrm{H}_{2} \mathrm{O}_{2}$ through a series 2 electron reaction from which it is reduced to $\mathrm{H}_{2} \mathrm{O}$. It is important that $\mathrm{O}_{2}$ is reduced directly to $\mathrm{H}_{2} \mathrm{O}$ as the peroxide has a detrimental effect on $\mathrm{Hb}$ [74].

Based on this reaction scheme, $\mathrm{O}_{2}$ can be electrochemically reduced either directly to water $\left(\mathrm{H}_{2} \mathrm{O}\right)$ in a "direct" 4 electron reduction $\left(\mathrm{k}_{1}\right)$ or to intermediate hydrogen peroxide $\left(\mathrm{H}_{2} \mathrm{O}_{2}\right)$, termed as a "series" $2 \mathrm{e}^{-}$reduction. Subsequently, the adsorbed $\mathrm{H}_{2} \mathrm{O}_{2}$ can be electrochemically reduced to water with the rate constant $\mathrm{k}_{3}$ ("series" $4 \mathrm{e}^{-}$pathway), chemically decomposed on the electrode surface $\left(\mathrm{k}_{4}\right)$ or desorbed into the bulk solution $\left(\mathrm{k}_{\mathrm{s}}\right)$. Indeed, in some conditions the reaction only proceeds to the intermediate $\mathrm{H}_{2} \mathrm{O}_{2}$ stage, for example at mercury, $\mathrm{O}_{2}$ is reduced in two well defined steps separated by up to $1 \mathrm{~V}$ [75]. The "direct" $4 \mathrm{e}^{-}$reduction of $\mathrm{O}_{2}$ implies that cleavage of the $\mathrm{O}-\mathrm{O}$ bond by dissociative adsorption occurs at an early stage in the reduction, whilst in the "series" $4 \mathrm{e}$ " pathway the first step is the reduction of $\mathrm{O}_{2}$ to superoxide, $\mathrm{O}^{2-}$ (or $\mathrm{HO}^{2+}$ to $\mathrm{HO}_{2}$ ) [76].

Rotating ring-disc electrode experiments may be used to distinguish the two pathways and to provide an estimate of the relative importance of the pathways 
under conditions where they co-exist. $\mathrm{O}_{2}$ is reduced at a rotating disc of the active material, and the formation of $\mathrm{H}_{2} \mathrm{O}_{2}$ is monitored on a ring electrode surrounding the disc. Studies have provided at least fourteen different reaction pathways [77] for $\mathrm{O}_{2}$ reduction and thus reliable kinetic parameters cannot be obtained nor can comparisons between electrode materials be made, especially where products and mechanisms may be different. Even so, the reduction of $\mathrm{O}_{2}$ is always a slow reaction [78].

A qualitative example of the rotating disc electrode can be seen with the Pt disc electrode. Current - voltage curves at the Pt disc show only a single reduction wave, implying a complete $4 \mathrm{e}^{-}$reduction. On the other hand, the response on the ring, whose potential is held at a value where the $\mathrm{H}_{2} \mathrm{O}_{2}$ oxidises, proves that some $\mathrm{H}_{2} \mathrm{O}_{2}$ is formed during the rising region of the curve, and that at $\mathrm{Pt}$ the $\mathrm{O}_{2} / \mathrm{H}_{2} \mathrm{O}_{2}$ and $\mathrm{H}_{2} \mathrm{O}_{2} / \mathrm{H}_{2} \mathrm{O}$ processes must occur at very similar potentials [77]. This is confirmed by recent studies which have suggested that a series pathway via an $\mathrm{H}_{2} \mathrm{O}_{2}$,ad intermediate may be operative on Pt and Pt bimetallic compounds [76]. In either case, however, the rate-determining step appears to be the addition of the first electron to $\mathrm{O}_{2, \text { ad }}$.

As with $\mathrm{HbS}$ polymerisation there is a pronounced effect on $\mathrm{O}_{2}$ reduction with $\mathrm{pH}$; a gradient of $\mathrm{pH}$ with distance from the electrode surface is present with a higher $\mathrm{pH}$ at the electrode than in the bulk solution. This effect is apparent in phosphate buffer of $\mathrm{pH} 7.0$ where the wave for $\mathrm{O}_{2}$ reduction is steep and the half-wave potential is $300 \mathrm{mV}$ positive to that for $\mathrm{O}_{2}$ reduction for $0.1 \mathrm{M} \mathrm{NaOH}$. In contrast, the wave is drawn out and the half-wave potential is approximately $150 \mathrm{mV}$ in unbuffered systems. This can be readily understood in terms of the $\mathrm{pH}$ change as a result of $\mathrm{O}_{2}$ reduction itself. In the very foot of the wave, the $\mathrm{pH}$ close to the surface of $\mathrm{Pt}$ is identical to that in the bulk, whilst in the limiting current regions, the four electron protonation reactions of reduced $\mathrm{O}_{2}$ species will cause the hydroxyl $\left(\mathrm{OH}^{-}\right)$ion concentration and thus the $\mathrm{pH}$ at the surface to increase to $c a$. 11. Therefore, both the thermodynamics and kinetics of $\mathrm{O}_{2}$ reduction will change as the $\mathrm{pH}$ increases [77].

Furthermore, it is also now well established that the reaction rates of the $\mathrm{O}_{2}$ reduction reaction on $\mathrm{Pt}$ surfaces are structure sensitive. These arise due to structure sensitive adsorption of spectator species such as $\mathrm{OH}^{-}$and $\mathrm{HSO}_{4}{ }^{-}$, both of which inhibit the reduction of molecular $\mathrm{O}_{2}$ by blocking the initial adsorption. In 
addition, $\mathrm{O}_{2}$ reduction in $\mathrm{Cl}^{-}$containing solutions is accompanied with peroxide formation implying that within the same potential limits $\mathrm{H}_{2} \mathrm{O}_{2}$ is formed as an intermediate. This effect seems to manifest itself in the $\operatorname{Pt}(110)$ and $\operatorname{Pt}(100)$ structures but not in $\mathrm{Pt}(111)$ [76].

In contrast with $\mathrm{Pt}, \mathrm{Au}$ supports mainly the $2 \times 2 \mathrm{e}^{-}$step reduction of $\mathrm{O}_{2}$ ("series" $\left.4 e^{-}\right)$in acid media, a feature that can be used for the electrochemical synthesis of hydrogen peroxide. The trends in half-wave potential and shape of the first $2 \mathrm{e}^{-}$ reduction of a Au microdisc electrode are similar to that of Pt but the shape of the second wave is different because $\mathrm{OH}^{-}$ions are generated during the first stage of reduction. The subsequent reduction of $\mathrm{H}_{2} \mathrm{O}_{2}$ on these electrodes is very slow and the mechanism of $\mathrm{H}_{2} \mathrm{O}_{2}$ reduction is strongly dependent on surface orientation. In alkaline solution, reduction proceeds only by the series mechanism with $\mathrm{HO}^{2-}$ ad as an intermediate in the reduction process. The formation of $\mathrm{HO}^{2-}$ does not involve the cleavage of the $\mathrm{O}-\mathrm{O}$ bond as isotopic experiments on various surfaces provide strong evidence that all the peroxide oxygen originates from the $\mathrm{O}_{2}$ [78]. Furthermore, as at $\mathrm{Pt}$ the $\mathrm{pH}$ dependence is noticeable whilst current-potential curves show that hydrogen evolution commences at a potential expected for an alkaline environment [76].

The reduction of $\mathrm{O}_{2}$ at $\mathrm{Pt}$ and $\mathrm{Au}$ was of particular interest in our system because these were the electrodes employed in the investigations. The importance of the reaction proceeding to completion is paramount so that firstly no $\mathrm{H}_{2} \mathrm{O}_{2}$ is formed as peroxide has a detrimental effect on $\mathrm{Hb}$, whilst secondly a relatively fast reduction of $\mathrm{O}_{2}$ is achieved. 


\subsubsection{Chronoamperometry}

The study of the variation of the current response after a single potential step under potentiostatic control is called potential step chronoamperometry. In a potential step experiment the potential is stepped at a time $t_{0}$ from an initial potential $E_{\text {initial }}$ to final potential $E_{\text {final }}$ corresponding, respectively, to no electrolysis and to complete conversion of reactants to products at the electrode surface (figure 1.22).

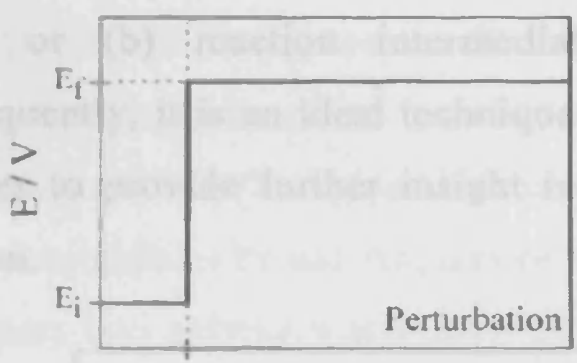

a

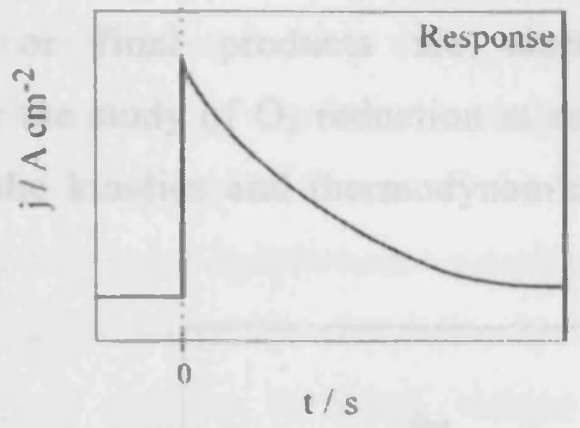

b

Figure 1.22: Figures showing (a) the excitation waveform for a single potential step experiment (b) the current density evolution response over time for the same electrochemical technique [79].

Immediately after the potential step, a large current is detected which decays steadily with time. This arises since the magnitude of the current is controlled by the rate of diffusion of the reactant to the electrode. As the reactant is converted to the product due to the heterogeneous electron transfer reaction, the reactant is depleted close to the surface, and a depletion zone is formed. Consequently, the concentration gradients shortly after the step are extremely large, since there has been little time for any depletion of electro-active species, and the currents are also very large. Gradually, as depletion occurs, the diffusion layer thickness increases and the current decreases. The thickness of this depletion zone or diffusion layer, $\Delta$, is governed by the equation:

$$
\Delta=\sqrt{ } 2 D t
$$

where $D$ is the diffusion coefficient and $t$ is the time taken for the reaction. In some experiments it is advantageous to monitor charge, instead of the current, as a function of time and this technique is referred to as chronocoulometry. 


\subsubsection{Chronoamperometry}

The study of the variation of the current response after a single potential step under potentiostatic control is called potential step chronoamperometry. In a potential step experiment the potential is stepped at a time $t_{0}$ from an initial potential $E_{\text {initial }}$ to final potential $E_{\text {final }}$ corresponding, respectively, to no electrolysis and to complete conversion of reactants to products at the electrode surface (figure 1.22).

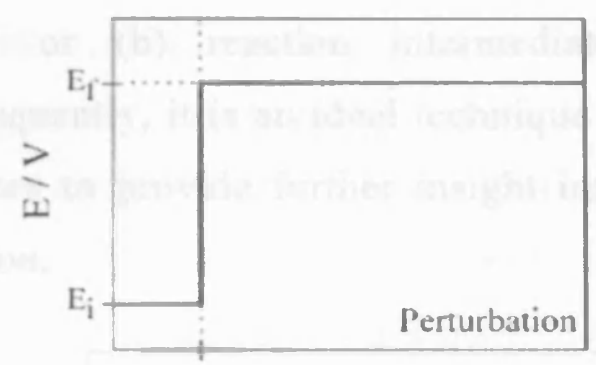

$\mathbf{a}$

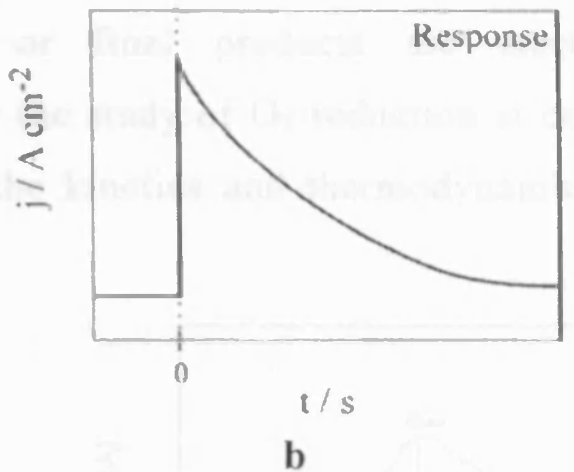

b

Figure 1.22: Figures showing (a) the excitation waveform for a single potential step experiment (b) the current density evolution response over time for the same electrochemical technique [79].

Immediately after the potential step, a large current is detected which decays steadily with time. This arises since the magnitude of the current is controlled by the rate of diffusion of the reactant to the electrode. As the reactant is converted to the product due to the heterogeneous electron transfer reaction, the reactant is depleted close to the surface, and a depletion zone is formed. Consequently, the concentration gradients shortly after the step are extremely large, since there has been little time for any depletion of electro-active species, and the currents are also very large. Gradually, as depletion occurs, the diffusion layer thickness increases and the current decreases. The thickness of this depletion zone or diffusion layer, $\Delta$, is governed by the equation:

$$
\Delta=\sqrt{ } 2 D t
$$

where $D$ is the diffusion coefficient and $t$ is the time taken for the reaction. In some experiments it is advantageous to monitor charge, instead of the current, as a function of time and this technique is referred to as chronocoulometry. 


\subsubsection{Cyclic Voltammetry (CV)}

The most common technique to study electrode reactions, and perhaps the most versatile electroanalytical technique for the study of electroactive species, is CV. It involves applying a triangular potential ramp (figure 1.13 (a)), where the potential of the working electrode (WE) is swept forward oxidising the sample in question, and subsequently the electrode potential is scanned back to its original value. The potential scan can be used to define whether (a) the product of electron transfer is stable or (b) reaction intermediates or final products are electroactive. Consequently, it is an ideal technique for the study of $\mathrm{O}_{2}$ reduction at conducting surfaces to provide further insight into the kinetics and thermodynamics of this reaction.

Figure 1.13: Figures showing (a) a triangular potential ramp is applied in $C V$ : (b) $C V$ of a reversible redox couple with the parameters of the voltammogram depicted: $\mathrm{E}_{p}$ cathodic peak potential: $i_{p c}$ cathodic peak current: $E_{p u}$ anodic peak potential: $i_{p a}$ anodic peak current [80].

A CV is obtained by measuring the current at the WE during the potential scan and the shape of the voltammogram depends on the reversibility of the redox couple. The important parameters of a voltammogram are shown in figure 1.13 (b). Small peak to peak separation and a well-defined peak are characteristic features of a reversible electron transfer reaction, i.e. a redox couple in which both species rapidly exchange electrons with the WE This is because in a reversible electron transfer reaction current flows as soon as the reduction becomes thermodynamically viable because of the rapid electrode kinetics associated with the reaction. However, slow electron transfer at the electrode causes the peak to peak separation to increase. In these reactions, no current flows until an overpotential has been applied to drive the reduction or oxidation of the sample. 


\subsection{Summary}

As the introduction has shown, much of the pioneering work in this field has established the basic structural, biochemical and biophysical properties of $\mathrm{HbS}$ polymerisation, and in this regard this process is extremely well understood. However, only recently have investigations been performed on manipulating the nucleation and growth of fibres and gel formation in order to open new avenues for the inhibition of $\mathrm{HbS}$ polymerisation or any associated pathogenic events.

Presented in this thesis are results concerning the nucleation and growth of $\mathrm{HbS}$ aggregates formed at a number of conducting surfaces using a novel electrochemical method. Local deoxygenation of $\mathrm{HbS}$ solution at the surface of electrodes, such as $\mathrm{Pt}$ and $\mathrm{Au}$, can be used to trigger hydrophobic coupling of $\mathrm{HbS}$ monomers into polymers and gels. These structures can be subsequently visualised in-situ using various imaging techniques to gain an in depth insight into the kinetics and thermodynamics of nucleation and growth of $\mathrm{HbS}$ aggregates. Consequently, the visualisation and monitoring of the protein growth using optical, UV-visible spectroscopy and scanning probe microscopic techniques are also described. Furthermore, the utilisation of this method to provide an assessment of the effectiveness of current therapies that exist for SCD is presented. In this thesis, the basis for a methodology is presented that may be used as a screening method for substances that effect the fibre nucleation and or growth, one which could be valuable to the pharmaceutical industry for treating SCD. 
Chapter 2: Experimental Materials, Methods and Equipment 


\subsection{General Experimental}

In this chapter, the experimental details and methodologies common to all experiments will be discussed and a general outline of the materials and instrumentation utilised will be provided. Furthermore, the preparation procedure and electrochemical techniques used to probe the protein solutions will be described.

However, it is important to note that this chapter only serves to outline a general experimental. Data analysis methodologies and the construction of thin layer electrochemical cells specific to each chapter will be detailed in the relevant chapters. 


\subsection{Materials}

$\mathrm{HbS}$ and $\mathrm{HbA}$ were purchased from Sigma chemical company (Poole, UK) and used as supplied. The supporting electrolyte was $1.5 \mathrm{M}$ ( $\mathrm{pH} 7.0$ ) potassium phosphate buffer solution which was prepared by mixing stock solutions of dihydrogen potassium phosphate and dipotassium hydrogen phosphate (Avocado, UK) to achieve a solution with $\mathrm{pH}$ 7.0. Changes to the stock solutions ensured correct buffer concentrations and $\mathrm{pHs}$ were obtained for experiments where the $\mathrm{pH}$ and molarity of the phosphate buffer solution varied. $\mathrm{H}_{2} \mathrm{O}$ used in experiments and for cleaning purposes was de-ionised $\mathrm{H}_{2} \mathrm{O}$ from a Millipore Milli-Q gradient ${ }^{k}$ $\left(18.2 \mathrm{M} \Omega \mathrm{cm},<0.05 \mathrm{~S} \mathrm{~cm}^{-2}\right.$ at $\left.25^{\circ} \mathrm{C}\right)$ water system. Sodium chloride $(\mathrm{NaCl})$ was obtained from BDH AnalaR whilst other chemicals were of analytical reagent grade. Sodium dithionite was obtained from Sigma chemical company (Poole, UK).

Ethylenediaminetetraacetic acid (EDTA), 3,5-dichloro-2-hydroxybenzenesulfonic acid (DHSA), horseradish peroxidise and 4-aminoantipyrene, used for the spectrophotometric assay of $\mathrm{H}_{2} \mathrm{O}_{2}$, as well as vanillin, 5-hydroxy-2-furfural (5HMF) and 2,3-DPG for the anti-sickling experiments were obtained from Sigma chemical company (Poole, UK). 3-mercapto-1-propenesulfonic acid, 2mercaptoethanol, 1-butanethiol and cystamine dihydrochloride (Aldrich, UK) were used as the thiol compounds. Free haemin, poly-L-lysine and iota carrageenan were used for modifying electrodes for direct electrochemistry experiments.

Electrodes were all obtained from Advent Research Materials Ltd, Oxford or Johnson Matthey, Cambridge. The electrodes used for each specific cell are described in the relevant experimental section of each chapter. Quartz cuvette (1 $\mathrm{mm}$ pathlength) and glass microscope slides were obtained from Hellma, UK. For the AFM experiments, 3\% glutaraldehyde was obtained from Sigma chemical company (Poole,UK) and mica and silicon nitride contact and tapping mode were obtained from Veeco (Santa Barbara, Ca). Other materials such as silver conductive paint, epoxy resin, parafilm and epphindorfs were obtained from RS (UK), pipettes were obtained from Fluka whilst argon (Ar) and nitrogen $\left(\mathrm{N}_{2}\right)$ gas cylinders were received from BOC gases (UK). 


\subsection{Instrumentation}

Electrochemistry techniques, specifically chronoamperometry and CV, were carried out in a conventional three electrode system comprising a working (WE), reference (RE) and counter electrode (CE) connected to a PC operated potentiostat ( $\mu$ Autolab Type II. Eco Chemie B.V. supplied by Windsor Scientific Ltd, UK), controlled by GPES software (version 4.7, Eco Chemie B. V. Utrecht, Netherlands). The WE is the electrode at which the electrochemical process of interest takes place, whilst the role of the RE is to provide a fixed potential to which the potential of the WE is referred. The RE is also sometimes called the ideal nonpolarisable electrode. The purpose of the CE is to supply the current required by the WE, without limiting the measured response of the cell. In this sense, it should not impose any characteristics on the measured data, and as consequence it should have a large area compared to the working electrode. In our three-electrode system an optically transparent electrode (OTE) was used as the WE, a Pt coil served as the CE whilst all potentials were given versus the quasireference electrode $(\mathrm{Ag} / \mathrm{AgCl})$.

An optical microscope (Jenalab; Carl Zeiss, Germany) connected to a video camera (TK-1085E; JVC, Japan) with PC data collection (Presto Video Works Ver 4.1 Rev 6; Newsoft Technology Corp, Taiwan) was used for image collection and processing and images were analysed using Presto Video Works PC data collection software and CorelDraw (version 8.232). Absorption spectra were recorded with an Agilent 8453 UV-visible spectrophotometer (Agilent technologies) on plain glass microscope slides $(0.80 \mathrm{~mm} \times 1.00 \mathrm{~mm}$ thick) or quartz cuvettes (pathlength $1.0 \mathrm{~mm}$ ) using UV-visible ChemStation software (Rev. A. 09. 01, Agilent technologies) in kinetic mode (i.e. spectra acquired at regular or increasing time intervals over a period of time). The spectrophotometer experiments run time ranged from $1000 \mathrm{~s}$ to $4500 \mathrm{~s}$ with spectra being recorded at intervals of $2 \mathrm{~s}$ or 10 $\mathrm{s}$. The wavelength acquisition range was from $200-1100 \mathrm{~nm}$ and time traces at $600,650,700$ and $800 \mathrm{~nm}$ were monitored.

The temperature was controlled with the use of a small peltier device (Thermo Electric Cooler Type DT1069; Marlow Industries Inc., USA) and measured with a home-made thermocouple. The copper plate above the peltier device allowed for efficient heat transfer between the peltier device and the microscope slide or quartz 
cuvette. Temperature manipulations were carried out using programmable water bath (Grant LTD6 waterbath, Grant Instruments Ltd, Cambridge) with a temperature range of $-20^{\circ} \mathrm{C}$ to $100{ }^{\circ} \mathrm{C}$. A digital $\mathrm{pH}$ meter $(\mathrm{PH} 215$, Denver Instruments, Germany) was used to produce solutions of different $\mathrm{pH}$. 


\subsection{Construction of Thin Layer Electrochemical Cells}

A series of robust and easily constructed thin-layer cells were designed specifically for optical and spectroelectrochemical measurements. The Pt coil electrochemical cell (chapter 3) was used exclusively for imaging with the optical microscope whilst the $\mathrm{Au}$ micro-mesh electrochemical cell (chapter 4) and Pt matrix electrochemical cell (chapter 5) were used to monitor protein growth with the UVvisible spectrophotometer. The fabrication of each cell is detailed in the relevant chapters.

Cleaning of the electrochemical cell followed a general procedure, termed as experimental procedure 1 . The cell was soaked in pure water and medical wipes (Kimberley-Clarke, UK) were used to draw the solution out. This was performed as many times as was necessary until the red colouration of the protein disappeared. The electrodes were electrochemically cleaned by cycling in $0.1 \mathrm{M}$ sulphuric acid until there was no further change in the voltammetric response. Two sets of thirty CV cycles were generally performed, with new acid solution being used after the first thirty cycles and the electrochemical cell was finally rinsed with copious amounts of $\mathrm{H}_{2} \mathrm{O}$. 


\subsection{HbS Polymerisation}

Three main techniques were used to achieve polymerisation of $\mathrm{HbS}$ : in-situ electrochemical deoxygenation, ex-situ temperature jump method and ex-situ salting out method. The ex-situ techniques were generally used for those experiments where imaging could not be performed immediately due to further preparation, such as in AFM experiments (chapter 3) or for the direct electrochemistry experiments (chapter 7).

\section{In situ Electrochemical Deoxygenation: Polymerisation using Electrochemistry:}

$\mathrm{HbS}$ polymerisation was primarily achieved using electrochemical means by electrochemical $\mathrm{O}_{2}$ reduction of a small volume of $\mathrm{HbS}$ solution within a purpose built electrochemical cell using step potential chronoamperometry. This is termed experimental procedure 2 and is described in more detail in section 2.6.

\section{Polymerisation using temperature jump method:}

This method (experimental procedure 3 ) is a slight modification of the procedure described by Adachi et al. [81]. A solution of $\mathrm{HbS}$ protein dissolved in $0.1 \mathrm{ml}$ phosphate buffer (1.5 M, pH 7.0) was degassed thoroughly by passing a stream of Ar gas over the top of the solution for 1 hour and was subsequently placed into a cuvette of pathlength $1 \mathrm{~cm}$ under an inert atmosphere. A further $1.0 \mathrm{ml}$ degassed $\mathrm{H}_{2} \mathrm{O}$ was added to the $\mathrm{HbS}$ solution and the cuvette was placed in a waterbath set at $2{ }^{\circ} \mathrm{C}$ for 30 minutes. The temperature jump was obtained by quickly transferring the cuvette to a water jacketed cuvette holder at a temperature of $38{ }^{\circ} \mathrm{C}$ positioned in front of the spectrophotometer light beam. The jacketed cuvette holder was also at a temperature of $38^{\circ} \mathrm{C}$. All spectra's were examined to ensure a significant increase in the absorbance was seen to indicate formation of $\mathrm{HbS}$ aggregates. If no such increase was seen then the solution was not used for any further experiments. All solutions were stored under Ar in the fridge until use and used within one day of initial preparation. 


\section{Polymerisation using Isothermal salting out method:}

This procedure [82] (experimental procedure 4) involved degassing a solution containing $2.4 \mathrm{ml}$ phosphate buffer $(2.52 \mathrm{M}, \mathrm{pH} 7)$ in a cuvette ( $1 \mathrm{~cm}$ pathlength) for 1 hour. Sodium dithionite $\left(10 \mathrm{mg} \mathrm{ml}^{-1}\right)$ was added in some cases to ensure buffer solution remained $\mathrm{O}_{2}$ free. Sodium dithionite would have been all used up scavenging buffer $\mathrm{O}_{2}$ before coming into contact with any protein. The cuvette was sealed with parafilm and placed into a waterbath set at $38{ }^{\circ} \mathrm{C}$. At the same time, a solution of $\mathrm{HbS}$ dissolved in low molarity $0.025 \mathrm{M}$ phosphate buffer solution was placed in an epphindorf vial, deoxygenated thoroughly by passing a stream of $\mathrm{Ar}$ over the top of the solution, and placed into the waterbath at $38{ }^{\circ} \mathrm{C}$. Once both solutions had equilibrated to the waterbath temperature, the cuvette was placed in a water jacketed holder positioned in the spectrophotometer and HbS solution was quickly added causing $\mathrm{HbS}$ protein aggregates to be formed. The HbS polymer formation, as a result of salting out at isothermal conditions, was followed spectrophotometrically. Spectra which did not show an increase in the absorbance were not used any further. All solutions were stored under Ar gas in the fridge until use and used within one day of its initial preparation. 


\subsection{Electrochemistry}

The two electrochemical methods mainly used were step potential chronoamperometry and CV. Deoxygenation of the HbS solution was performed by electrochemical reduction at the electrode surface using step potential chronoamperometry. The $\mathrm{HbS}$ solution was held at a potential $E=0 \mathrm{~V}$ for $3 \mathrm{~s}$ initially and then stepped to $E=-0.55 \mathrm{~V}$ versus the quasi-reference electrode. The time of the step potential experiment varied from $1000 \mathrm{~s}$ to $6000 \mathrm{~s}$. A typical chronoamperometric scan observed in our experiments is shown in figure 2.1. These were similar to the characteristic current density evolution response seen in figure 1.22; initially a large current was detected which steadily decayed with time.

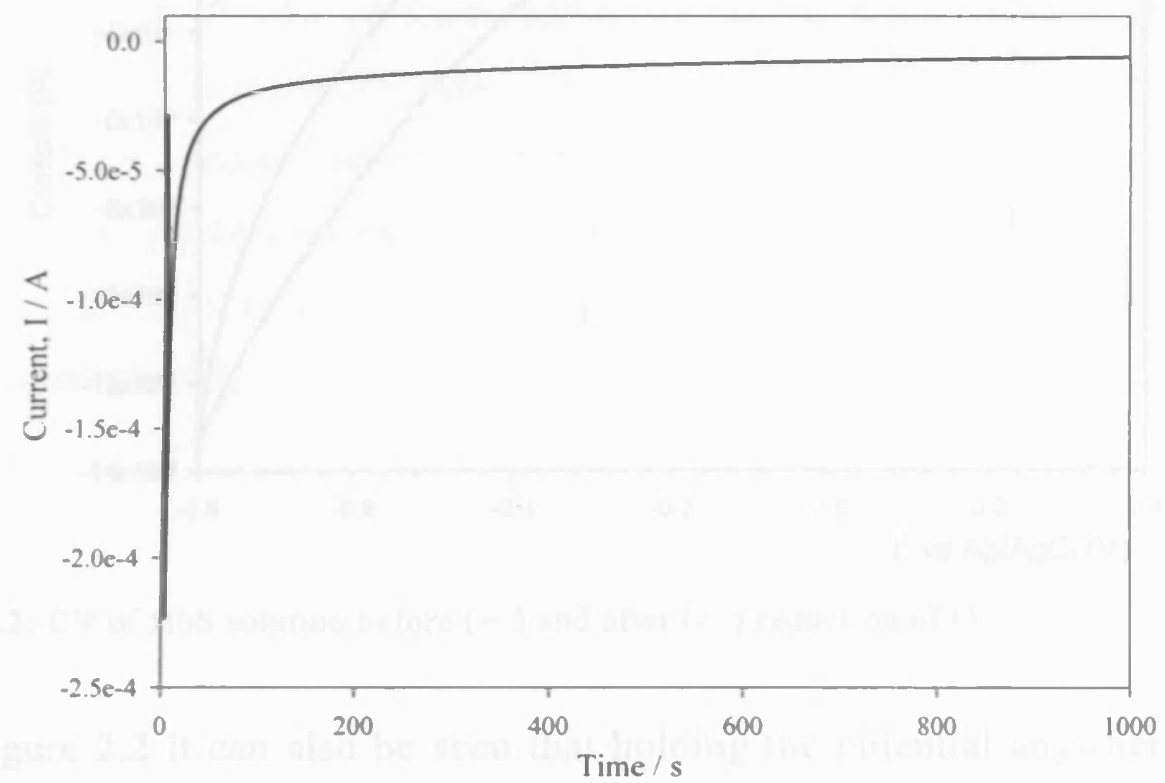

Figure 2.1: A typical current density evolution response seen in our HbS polymerisation potential step experiments.

A thorough $\mathrm{CV}$ study was performed on the $\mathrm{HbS}$ protein solution consisting of 1.5 $\mathrm{M}(\mathrm{pH} 7.0)$ phosphate buffer and $0.5 \mathrm{M} \mathrm{NaCl}$, before every experiment to ascertain the electrochemical potential window of $\mathrm{O}_{2}$ in solution at the particular electrode being used (this varied when using different electrode materials). CV potentials ranged from $+0.5 \mathrm{~V}$ to $-0.8 \mathrm{~V}$ for the forward and reverse cycle and were scanned at a rate of $25 \mathrm{mV} \mathrm{s}^{-1}$ versus the quasi-reference electrode.

CVs were also performed before and after the chronoamperometry experiments to monitor the extent of $\mathrm{O}_{2}$ reduction and to confirm electrochemically that complete 
reduction of $\mathrm{O}_{2}$ had been achieved. This was an important step to ensure that the electrode surface environment was conducive to maximal $\mathrm{HbS}$ polymerisation and growth. Figure 2.2 demonstrates a pair of $\mathrm{CV}$ plots performed on $\mathrm{HbS}$ solution before and after the potential step experiment and it can be seen that the CV performed prior to $\mathrm{O}_{2}$ reduction (solid line) has a large shoulder, attributable to $\mathrm{O}_{2}$ presence, in the potential range $-0.25 \mathrm{~V}$ to $-0.8 \mathrm{~V}$. This shoulder is not present in the $\mathrm{CV}$ (dotted line) after the reduction process meaning that $\mathrm{O}_{2}$ had been largely removed giving an anaerobic environment.

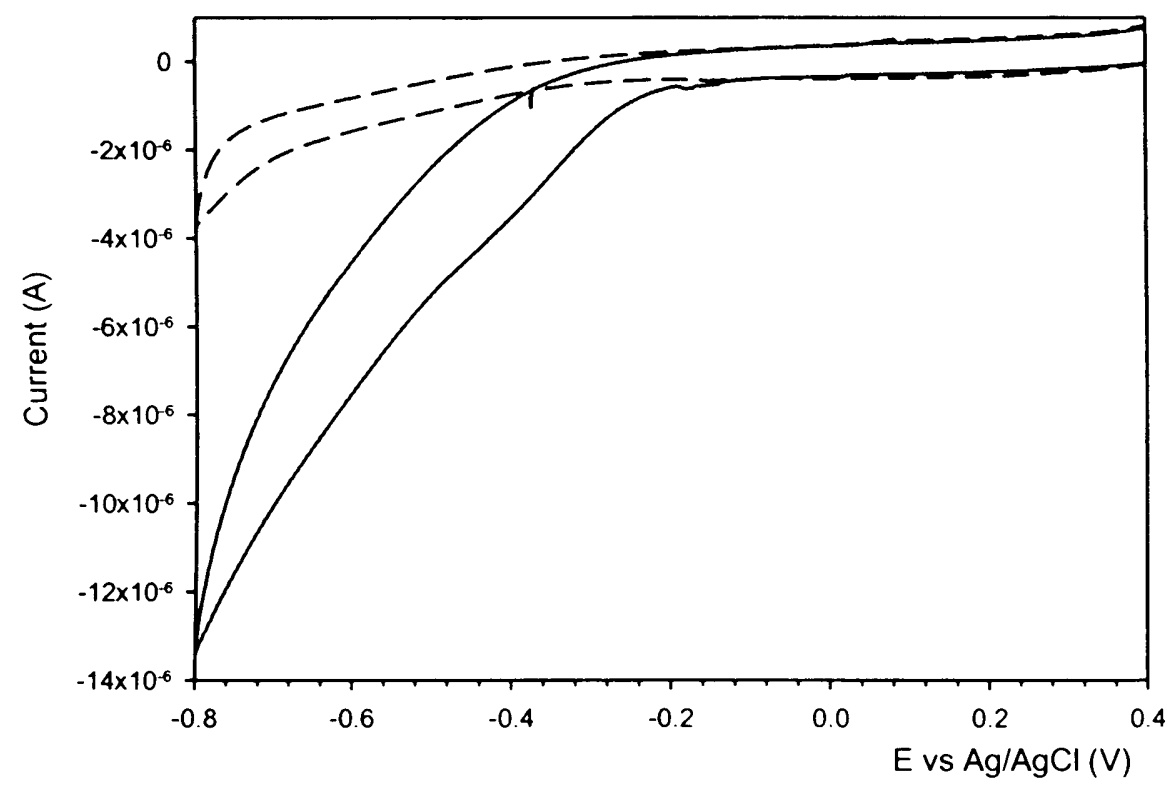

Figure 2.2: $\mathrm{CV}$ of $\mathrm{HbS}$ solution before $(-)$ and after (---) reduction of $\mathrm{O}_{2}$.

From figure 2.2 it can also be seen that holding the potential anywhere in the $\mathrm{O}_{2}$ shoulder range of -0.3 to $-0.8 \mathrm{~V}$ would cause $\mathrm{O}_{2}$ reduction and therefore a potential of $-0.55 \mathrm{~V}$ versus the quasi-reference electrode was chosen. Furthermore, complete deoxygenation was confirmed electrochemically by comparing the minimum charge needed to remove all $\mathrm{O}_{2}$ from a cell with the actual experimentally obtained value. This electrochemical method of polymerisation induction by $\mathrm{O}_{2}$ depletion is referenced as experimental procedure 2. 


\subsection{Optical Microscope Experiments}

The potentiostat was coupled with the optical microscope to allow the ensuing HbS polymerisation process to be followed in situ. A solution of $\mathrm{HbS}$ and $0.5 \mathrm{M} \mathrm{NaCl}$, added as supporting electrolyte to increase the ionic strength, was dissolved in airsaturated 1.5 M phosphate buffer ( $\mathrm{pH} 7)$ and pipetted under the coverslip. The cell was placed on the optical microscope stage and the electrodes were connected to the potentiostat and a $\mathrm{CV}$ was performed on the background solution of $1.5 \mathrm{M}, \mathrm{pH}$ 7 phosphate buffer and $0.5 \mathrm{M} \mathrm{NaCl}$ before every experiment. A Jenalab optical microscope connected to a JVC video camera was used to focus upon either a section of the electrode or the whole electrode before the start of the experiment and deoxygenation was performed by electrochemical reduction at the electrode (E $=-0.55 \mathrm{~V}$ ) using chronoamperometry methods (see experimental procedure 2 ). Changes at the electrode were monitored and images were collected and analysed using Presto Video Works PC data collection software. CV was performed straight after the chronoamperometric experiment to confirm disappearance of the $\mathrm{O}_{2}$ shoulder. The electrochemical cell was cleaned as described in experimental procedure 1. The optical microscope experimental will be referred to as experimental procedure 5 in discussions further in this thesis. 


\subsection{Spectroelectrochemistry Experiments}

A potentiostat was coupled with the UV-visible spectrophotometer so that changes in turbidity as a result of formation of protein aggregates could be monitored in situ. $\mathrm{Hb}$ protein was dissolved in a solution containing both $1.5 \mathrm{M}$ phosphate buffer ( $\mathrm{pH} \mathrm{7)}$ and $0.5 \mathrm{M} \mathrm{NaCl}$ and $50 \mu \mathrm{l} \pm 10 \mu \mathrm{l}$ of the $\mathrm{Hb}$ solution was introduced into the cell. High molarity phosphate buffer and $\mathrm{NaCl}$ were used to increase the ionic strength and thus increase conductivity of the solution. The electrochemical cell was fixed vertically on to the back of the thermostat stage which was clamped in position in front of the spectrophotometer light beam. Fixing the cell onto the thermostat allowed relatively easy control and access of the $\mathrm{HbS}$ solution temperature within the cell.

Both the potentiostat and the UV-visible spectrophotometer were started simultaneously. Absorption spectra were recorded in kinetic mode with spectra being taken every second or every $2 \mathrm{~s}$ whilst deoxygenation of $\mathrm{Hb}$ solution was performed electrochemically $(E=-0.55 \mathrm{~V}$ versus the quasi-reference electrode). In experiments where electrochemistry was not performed, solutions of phosphate buffer were thoroughly degassed with a continuous supply of Ar prior to the experiment. CVs of the initial solution were recorded before and after every experiment $(+0.5$ to $-0.8 \mathrm{~V}$ versus quasi-reference electrode at a rate of $25 \mathrm{mV} \mathrm{s}$. ') and the time of the experiments varied from $1000 \mathrm{~s}$ to $6000 \mathrm{~s}$. All solutions were used within a day of their preparation. The cell was cleaned as described in experimental procedure 1 . The spectroclectrochemistry procedure will be referred to as experimental procedure $\mathbf{6}$ in future discussions. 


\subsubsection{R to $\mathrm{T}$ State Conversion of $\mathrm{Hb}$}

Absorption spectroscopy was used to ascertain whether conversion of oxyHbS to deoxyHbS had occurred. It was important to spectroscopically demonstrate the mechanistic $\mathrm{R}$ to $\mathrm{T}$ state flip as exposure of the hydrophobic pocket by which $\mathrm{HbS}$ molecules aggregate only occurs in the T state. The spectroscopic set-up could also be utilised to check the efficiency of deoxygenation at specific points during the experiment. Figure 2.3 shows the conversion of oxyHbS to deoxyHbS at the WE. $\mathrm{HbS}$ concentration of $10 \mathrm{mg} \mathrm{cm}^{-3}$, dissolved in a salt solution comprising $1.5 \mathrm{M}$ potassium phosphate buffer and $0.5 \mathrm{M} \mathrm{NaCl}$, was used and the electrode was held at $-0.55 \mathrm{~V}$ for $1000 \mathrm{~s}$. Characteristic peaks at wavelengths $540 \mathrm{~nm}$ and $580 \mathrm{~nm}$ seen at $0 \mathrm{~s}$ indicated the presence of $\mathrm{oxyHb}$ [83], whilst the reduction of $\mathrm{O}_{2}$ through potential-step chronoamperometry allowed the $\mathrm{T}$ state of $\mathrm{Hb}$, characterised by the replacement of the two peaks by a single peak at $560 \mathrm{~nm}$, to be formed within 200 s. Consequently, all spectra were checked after each experiment to ensure complete conversion had taken place.

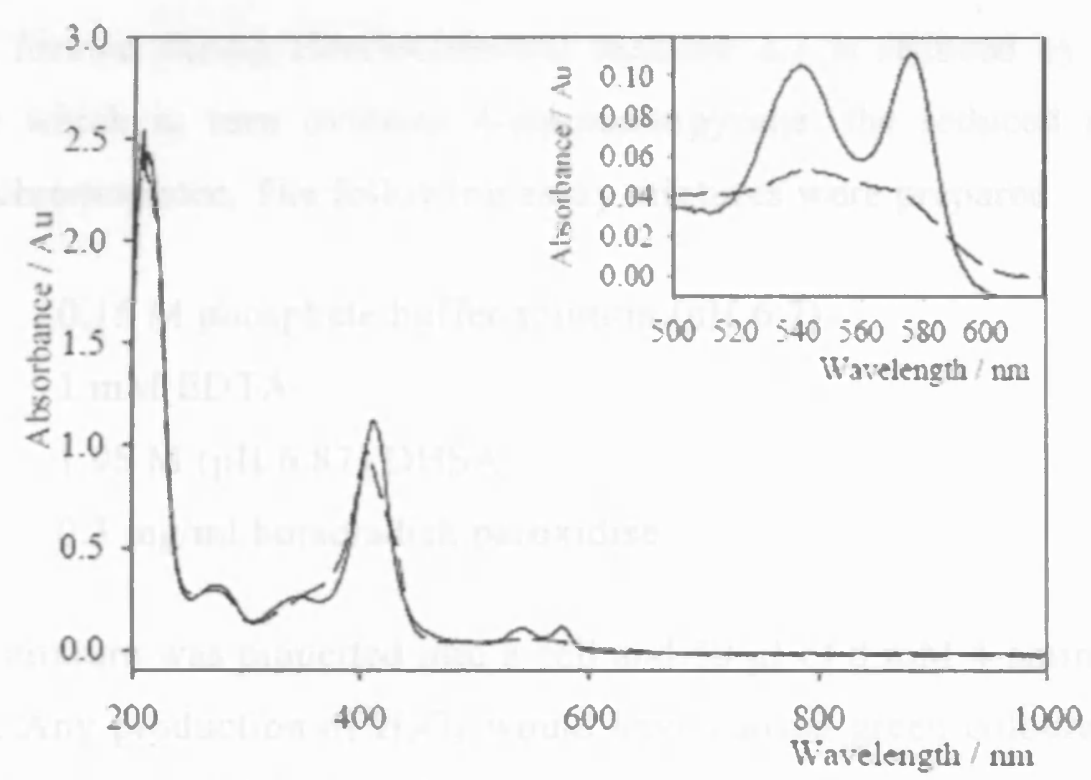

Fig. 2.3: In situ spectroelectrochemistry experiment showing the conversion of oxyHbS to deoxyHbS, before electrochemical depletion of oxygen (-) and after $1000 \mathrm{~s}(---)$. The insert shows the absorbance between 500 to $620 \mathrm{~nm}$ for the same spectra; a conversion of two peaks at $540 \mathrm{~nm}$ and $580 \mathrm{~nm}$ to a single peak at $560 \mathrm{~nm}$ is observed. Experiment conditions: HbS concentration $10 \mathrm{mg} \mathrm{cm}^{-3} ; 1.5 \mathrm{M} \mathrm{pH} 7.0$ phosphate buffer; $0.5 \mathrm{M} \mathrm{NaCl} ; \mathrm{E}=-0.55 \mathrm{~V}$ vs $\mathrm{Ag} / \mathrm{AgCl}$ for $1000 \mathrm{~s}$. 


\subsubsection{Spectrophotometric Assay for $\mathrm{H}_{2} \mathrm{O}_{2}$}

A spectrophotometric assay method was also employed to ensure that changes in absorbance were directly attributed to the formation of $\mathrm{HbS}$ aggregates. It was paramount that the $\mathrm{O}_{2}$ reduction reaction proceeded to completion to avoid any production of $\mathrm{H}_{2} \mathrm{O}_{2}$, which can cause $\mathrm{Hb}$ cell degradation and heme loss. As described earlier, the $\mathrm{O}_{2}$ reduction reaction at a metal surface is a complex multielectron process involving different reaction intermediates, with $\mathrm{O}_{2}$ either being electrochemically reduced directly to $\mathrm{H}_{2} \mathrm{O}$ or to intermediate $\mathrm{H}_{2} \mathrm{O}_{2}$. Consequently, the production of $\mathrm{H}_{2} \mathrm{O}_{2}$ in the $\mathrm{HbS}$ solution during the course of the reduction experiment was assayed by a spectrophotometric technique based on an enzyme linked detection system first described by Barham and Trinder in 1972 [84]. Essentially the reactions that take place in this system are as follows:

$$
\begin{aligned}
& \mathrm{O}_{2}+\mathrm{HbS}_{\text {(oxidised) }} \rightarrow \mathrm{H}_{2} \mathrm{O}_{2}+\mathrm{HbS}_{\text {(reduced) }} \\
& \mathrm{H}_{2} \mathrm{O}_{2}+4 \text {-aminoantipyrene } \text { (reduced) }_{\text {- Peroxidase } \rightarrow \text { 4-aminoantipyrene (oxidised) }}
\end{aligned}
$$

Any $\mathrm{H}_{2} \mathrm{O}_{2}$ formed during electrochemical reaction 2.1 is reduced by horseradish peroxidase which in turn oxidises 4 -aminoantipyrene, the reduced acceptor, to produce a chromophore. The following assay mixtures were prepared:
$1.55 \mathrm{ml}$
$0.15 \mathrm{M}$ phosphate buffer solution ( $\mathrm{pH} 6.7$ )
$1.55 \mathrm{ml}$ $1 \mathrm{mM}$ EDTA
$0.20 \mathrm{ml}$
$1.95 \mathrm{M}(\mathrm{pH} 6.87)$ DHSA
$0.20 \mathrm{ml}$
$0.3 \mathrm{mg} / \mathrm{ml}$ horseradish peroxidise

The above mixture was pippetted into a cell and $50 \mu \mathrm{l}$ of $8 \mathrm{mM} 4$-aminoantipyrene was added. Any production of $\mathrm{H}_{2} \mathrm{O}_{2}$ would have caused green colouration around the WE. The rate at which this chromophore appeared was monitored at $520 \mathrm{~nm}$ and assays were carried out in all thin-layer electrochemical cells, both in the background salt solution and in the $\mathrm{HbS}$ solution. Run time of this experiment varied from $60 \mathrm{~s}$ to $1000 \mathrm{~s}$. The detection limit of this assay was estimated, in a homogeneous cell, to be $1 \times 10^{-7} \mathrm{M}$. All assays confirmed that there was no $\mathrm{H}_{2} \mathrm{O}_{2}$ formation. 
Chapter 3: HbS Aggregation in Pt Coil Cell 


\subsection{Introduction}

In this chapter, the fabrication of the first in a series of three robust electrochemical cells used to house the previously explained $\mathrm{HbS}$ coupling reaction is described. The modulation of $\mathrm{HbS}$ fibrous growth at the electrode surface and the conditions for reproducible growth of $\mathrm{HbS}$ aggregates in the $\mathrm{Pt}$ coil electrochemical cell are presented whilst the visualisation of aggregates using optical microscopy is described. The fabrication of an electrochemical cell was required to perform electrochemical deoxygenation on small volumes of $\mathrm{Hb}$ and monitor the ensuing effects on protein aggregation, and therefore the methods by which optimisation of $\mathrm{O}_{2}$ depletion was achieved in the $\mathrm{Pt}$ coil electrochemical cell are also explained. Furthermore, experiments depicting the imaging of $\mathrm{HbS}$ aggregates with atomic force microscopy (AFM), using a number of imaging surfaces and ex-situ procedures are described. 


\subsection{Experimental}

\subsubsection{Materials, Instrumentation and Procedures}

The optical microscope experiments were performed according to experimental procedure 5. HbS protein was dissolved in air-saturated $1.5 \mathrm{M}(\mathrm{pH} 7.0)$ phosphate buffer and $0.5 \mathrm{M} \mathrm{NaCl}$ was added as supporting electrolyte to make the polymerising solution. All experiments were performed at room temperature unless otherwise stated. HbA was used for the control experiments and the mixtures were prepared in the same way as $\mathrm{HbS}$ solutions. $\mathrm{HbS}$ concentrations of $50 \mathrm{mg} \mathrm{cm}^{-3}$ and $300 \mathrm{mg} \mathrm{cm}^{-3}$ were primarily used as protein concentration needed to be high enough for aggregation to occur but also low enough so that protein use was minimised. Pt wire (diameter $0.1 \mathrm{~mm}$, hard temper, $99.99 \%$ purity) and silver (Ag) wire (grade 1, diameter $0.05 \mathrm{~mm}$ ) were employed as the electrodes (chapter 3.2.2). The general experimental and all apparatus for the above techniques are described in chapter 2.

Ex-situ AFM experiments were performed using the Dimension 3100 AFM (Veeco Instruments, Santa Barbara, Ca.) controlled by Nanoscope version 6.12 software for image collection. Silicon nitride cantilevers were used for both contact mode imaging (DNP-S, Veeco, Santa Barbara, Ca.) and tapping mode imaging (OMCTL, 280kHZ, Veeco, Santa Barbara, Ca) whilst images were analysed using offline Nanoscope version $6.13 \mathrm{r} 1$ software and WXSM software.

$\mathrm{HbS}$ aggregates for AFM imaging were produced using the ex-situ isothermal salting out method (experimental procedure 4). A solution of $10 \mathrm{mg} \mathrm{cm}^{-3} \mathrm{HbS}$ protein was added to $\mathrm{pH} 7.58,2.52 \mathrm{M}$ phosphate buffer for the stock and dilutions of 1:50, 1:500 and 1:5000 were made. No sodium dithionite was added. Freshly cleaved mica stuck on a small piece of glass was dipped into the HbS fibre solution stored under an inert atmosphere. The solution was left to incubate on the mica for $10 \mathrm{~s}$ and then fixed using $3 \%$ glutaraldehyde solution by slowly adding and removing the solution from the surface of the mica. The fixative was left to set for 15 minutes and the mica was washed by slowly immersing into pure water $(3 \times 200$ $\mu l)$ and nitrogen dried. 


\subsubsection{Construction of Pt Coil Thin Layer Electrochemical Cell}

A glass microscope slide $(25 \mathrm{~mm} \times 50 \mathrm{~mm})$ was used as the base of the electrochemical cell. Three electrodes $(100 \mu \mathrm{m}$ diameter coiled Pt wire WE, 100 $\mu \mathrm{m}$ coiled $\mathrm{Pt}$ wire $\mathrm{CE}$ and $50 \mu \mathrm{m} \mathrm{Ag}$ wire $\mathrm{RE}$ ) were fixed onto the slide and connected to copper electrical wires using silver conductive paint. Epoxy sealant was applied for electrical insulation and stability and a coverslip was fixed on top of the electrodes by carefully seeping epoxy resin. Only one edge of the coverslip was fixed to allow diffusion of atmospheric $\mathrm{O}_{2}$ into the cell and pressure was applied when fixing the coverslip to ensure a thin layer was obtained. A schematic representation of this cell is shown in figure 3.1 .

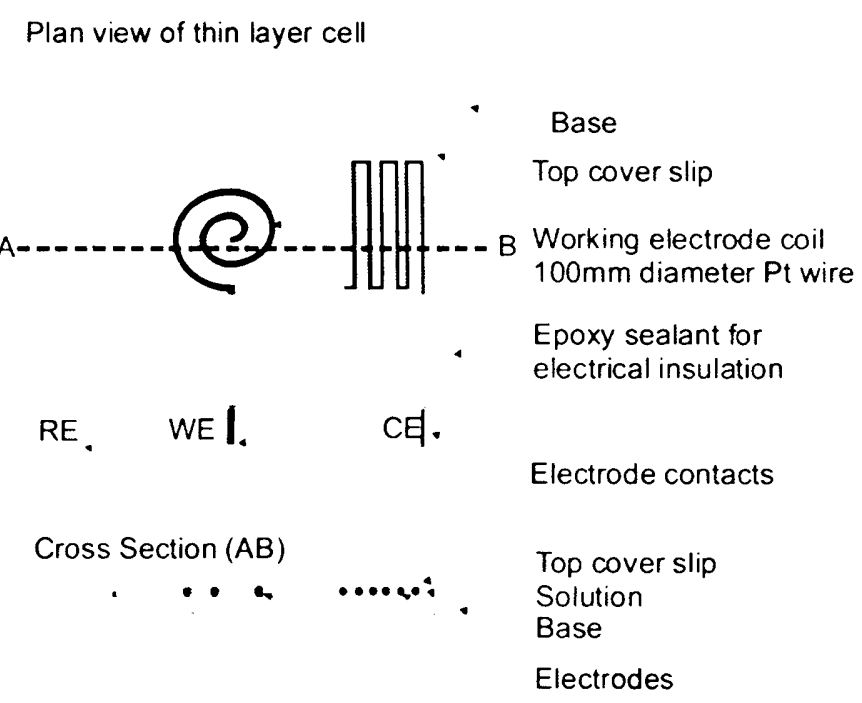

Figure 3.1: Plan view of Pt coil thin layer electrochemical cell incorporating a three electrode system with a $100 \mu \mathrm{m}$ diameter coil shaped Pt wire as the WE, a $100 \mu \mathrm{m}$ coil shaped Pt wire as the $\mathrm{CE}$ and a $50 \mu \mathrm{m} \mathrm{Ag}$ wire as the RE. The WE coil was composed of five turns, whilst the CE coil was composed of ten turns. The $\mathrm{Ag}$ wire was anodised with $\mathrm{AgCl}$ prior to use. A microscope slide was used as the base of the cell and a glass coverslip was placed on top to obtain a thin layer. Epoxy sealant was applied for electrical insulation. Not to scale.

To obtain good electrochemical measurements the RE was positioned close to the WE whilst the area of the CE was twice that of the WE. This was achieved by doubling the number of coils in the counter electrode. All materials used in the fabrication of the cell were thoroughly cleaned prior to its construction using acetone. 


\subsection{Electrochemical Cell Design}

Two essential features of the electrochemical cell, necessary for monitoring the growth of $\mathrm{HbS}$ aggregation at an electrode, were optical transparency and the capacity to perform electrochemistry on small volumes of oxygenated $\mathrm{HbS}$ solutions (i.e. a thin-layer). Optical transparency was essential so that any physical or structural changes occurring at the electrode or in the bulk solution surrounding the electrode could be easily identified and followed through optical or spectroscopic means. This was primarily achieved by incorporating an OTE as the WE. Even though the Pt coil electrode was not an OTE by definition, it could essentially be classed as one due to the compact coil geometry of the electrode allowing changes to be followed at different points along the surface. Transparency was also achieved by using a non-conductive glass microscope slide as the base of the cell and a plastic transparent coverslip.

Use of the coverslip also ensured small solution volumes. A thin layer of solution was necessary as it enabled minimal use of protein material in the solution reaction as well as caused the diffusion rate of electro-generated species moving into the bulk solution to be increased. In some electrochemical cells, small solution volumes were achieved by housing the electrodes in $1 \mathrm{~mm}$ pathlength cuvettes.

Another essential attribute was the geometry of the WE. The incorporation of a WE whose geometry allowed a more efficient electrochemical reduction of $\mathrm{O}_{2}$ ensured faster $\mathrm{HbS}$ polymerisation kinetics. Originally, a single $\mathrm{Pt}$ wire was used as the WE but by changing the geometry to a coil, an improved arrangement for $\mathrm{O}_{2}$ depletion within the thin layer electrochemical cell was achieved, see chapter $\mathbf{3 . 4}$. The fabrication of all electrochemical cells in this thesis followed similar design specifications. 


\subsection{Optimisation of the Pt Coil Cell}

The original design of the electrochemical cell incorporated a single Pt wire (25 $\mu \mathrm{m}$ diameter and $10 \mathrm{~mm}$ length) as the WE and not a coil. After unsuccessful attempts with this cell, it was thought that the electrical conductivity of the WE was not high enough to remove all of the $\mathrm{O}_{2}$ in the cell combined with the $\mathrm{O}_{2}$ diffusing into the system $\left(D=1.97 \times 10^{-5} \mathrm{~cm}^{2} \mathrm{~s}^{-1}\right)$. Therefore, the diameter of the Pt wire WE was changed from $25 \mu \mathrm{m}$ to $100 \mu \mathrm{m}$. An increase in the diameter of the electrode not only increases the current passing through it thereby increasing the conductivity but it also increases the surface area exposed to the solution and with it the volume of $\mathrm{HbS}$ solution being reduced (conductivity, $\varepsilon=1 /(R S / l)$, where $R$ is the resistance, $l$ is the length and $S$ is the cross-sectional area of a uniform specimen of the material). However, although the conductivity and exposed surface area increases, the thickness of the $\mathrm{O}_{2}$ reduction diffusion layers from the material remains uniform, as thickness is given by $\Delta=\sqrt{ } 2 D \mathrm{t}$, and therefore does not depend on the dimensions or properties of the material.

Results were finally obtained when the geometry of the WE was changed from a single Pt wire to a compact Pt coil structure of $100 \mu \mathrm{m}$ diameter with a set number of turns (figure 3.1). This was performed to increase the $\mathrm{O}_{2}$ reducing ability and achieve more efficient electrochemical $\mathrm{O}_{2}$ depletion of the solution present within the coil, not distinguishing between solution directly in contact with the electrode or that present in the bulk within the coil. The main advantage of this WE, compared to the $\mathrm{Pt}$ wire, was that instead of having a uniform $\mathrm{O}_{2}$ reduction diffusion thickness, this geometry ensured that $\mathrm{O}_{2}$ reduction efficiency increased as you moved into the middle of the coil. However, as the electrode was coiled manually, a major drawback of this geometry was the inability to control the exact dimensions of the coil such as the number of turns and the size and the compactness of the coil. This meant that reproducibility of results was difficult to achieve. In chapter 4 , the fabrication of a $\mathrm{Au}$ micromesh cell, built to overcome this problem, and its use in obtaining kinetic rate constants for the nucleation and elongation of $\mathrm{HbS}$ aggregates is described. 


\subsection{Growth of HbS Fibrous Structures at Pt Coil Cell}

Electrochemical techniques were used to investigate the growth of $\mathrm{HbS}$ aggregates in a thin layer optical cell to establish the conditions which would allow reproducibly fast $\mathrm{HbS}$ nucleation and polymerisation to occur. The geometry of the electrodes was found to be essential for the growth of $\mathrm{HbS}$ fibrous structures as the first structures were only seen when the WE was of a coiled geometry. The many experiments performed prior to using a coil did not give any results.

Figure 3.2 shows the changes in structure morphology on the surface of the Pt coil working electrode when a solution of $33 \mathrm{mg} \mathrm{cm}^{-3} \mathrm{HbS}$ dissolved in $1.5 \mathrm{M}$, pH 7.0 potassium phosphate buffer was reduced $(\mathrm{E}=-0.70 \mathrm{~V}) .5 \mathrm{mM}$ sodium dithionite was also added and the solution was degassed for an hour and then stirred for a further four hours before any electrochemistry was performed on the solution.
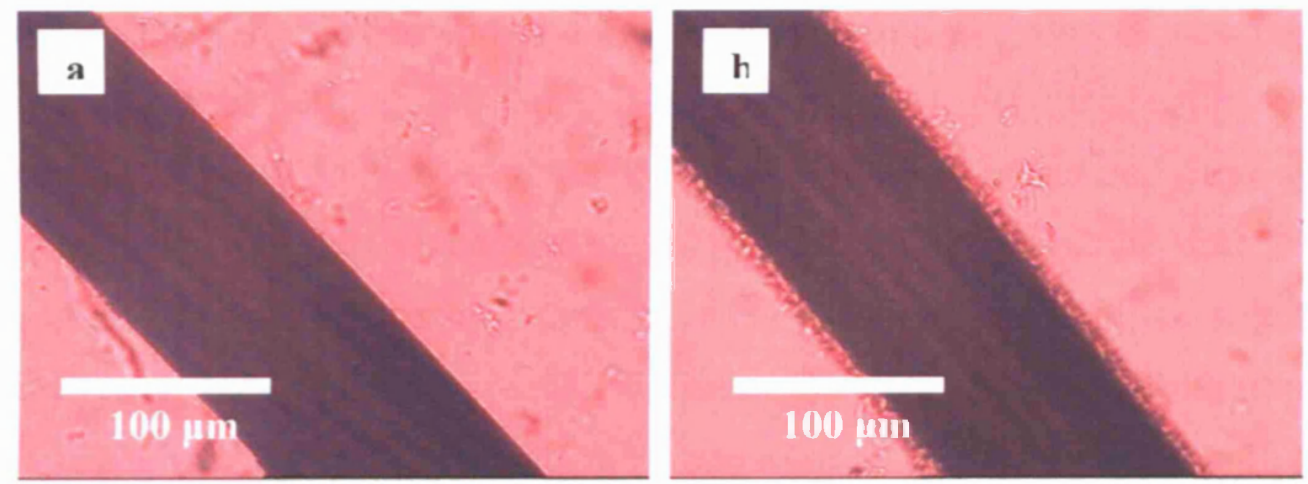

Figure 3.2: Optical images of a section of the Pt coil WE at (a) time $=0 \mathrm{~s}$; (b) time $=344 \mathrm{~s}$ showing the initial stages of $\mathrm{HbS}$ aggregate formation at the electrode surface. Experiment conditions: $\mathrm{HbS}$ concentrations $33 \mathrm{mg} \mathrm{cm}^{-3} ; 1.5 \mathrm{M} \mathrm{pH} 7.0$ phosphate buffer; $5 \mathrm{mM}$ sodium dithionite; $\mathrm{N}_{2}$ degassing (1 hr); stirring (4hrs); $\mathrm{E}=-0.70 \mathrm{~V}$ vs. $\mathrm{Ag} / \mathrm{AgCl}$ for $4000 \mathrm{~s}$.

The fur-like structure, evident in figure 3.2 (b), was the first time structural changes at the surface had been seen after electrochemical reduction of $\mathrm{O}_{2}$. The initiation of these aggregated structures occurred at time $=344 \mathrm{~s}$ and the structures subsequently grew in length as the experiment proceeded. However, due to many limitations of this preparation, such as the sporadic and non-uniform growth of the structures across the coil, inconsistent reproducibility of results and the long time taken for initiation of the structures, changes were made to the conditions to overcome these problems. The time taken for the structures to appear can be thought of as the "delay time" and was dependent on the rate of deoxygenation and 
rate of nucleation of aggregation. Consequently, the $\mathrm{HbS}$ concentration was increased from $33 \mathrm{mg} \mathrm{cm}^{-3}$ to well above saturation concentrations of $300 \mathrm{mg} \mathrm{cm}^{-3}$, whilst more importantly $0.5 \mathrm{M} \mathrm{NaCl}$ was added to increase the ionic strength and thus the conductivity of the solution. A high molarity phosphate buffer was originally used as studies have shown that high buffer concentrations are associated with polymerisation at much lower protein concentrations (see chapter 1.2.5) $[31,32]$, however, it was found that using buffer lower than $1.5 \mathrm{M}$ did not produce any results even when the HbS concentration was significantly increased. Further changes included doubling the number of turns on the coil from five to ten turns to try to maximise depletion of $\mathrm{O}_{2}$, whilst the chronoamperometric potential of the electrode was also changed to $-0.55 \mathrm{~V} v s$. the quasi-reference electrode, instead of $-0.70 \mathrm{~V}$, as $\mathrm{H}_{2}$ gas evolution was observed at potentials higher than $0.60 \mathrm{~V}$.

Figure 3.3 shows the surface morphology of the coil WE at different time intervals when a solution of $300 \mathrm{mg} \mathrm{cm}^{-3} \mathrm{HbS}$ dissolved in $1.5 \mathrm{M}$, pH 7.0 phosphate buffer was reduced $(\mathrm{E}=-0.55 \mathrm{~V}$ vs. $\mathrm{Ag} / \mathrm{AgCl}) .0 .5 \mathrm{M} \mathrm{NaCl}$ was added and there was no degassing or stirring performed and no sodium dithionite added. At time $=0 \mathrm{sec}$ the Pt electrode was bare but at time $=163 \mathrm{~s}$ the first formation of aggregated structures was seen. In other words, the onset of $\mathrm{HbS}$ aggregate formation was seen at $163 \mathrm{~s}$, whilst also visible was the elongation of aggregates after $3570 \mathrm{~s}$.
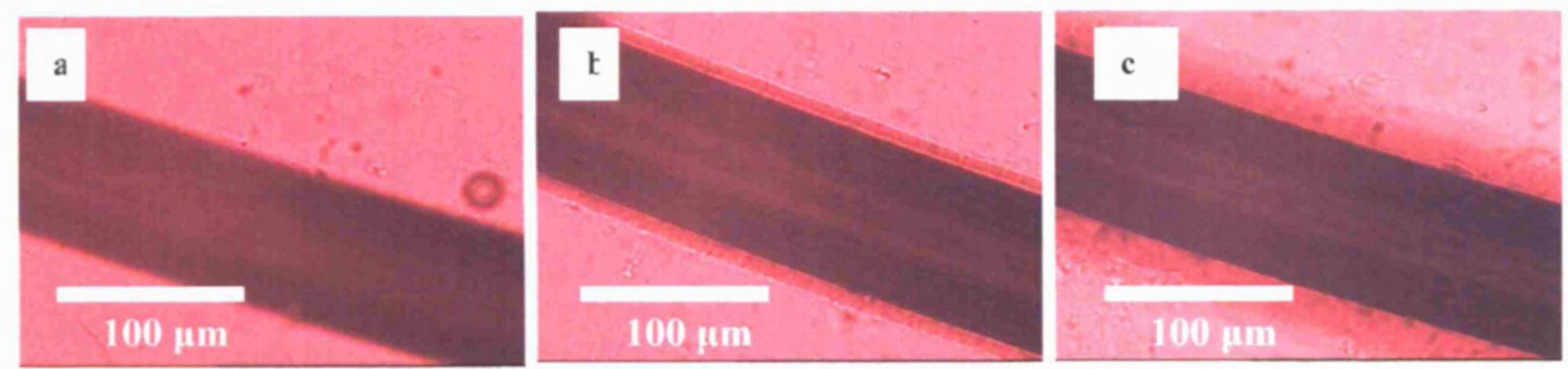

Figure 3.3: Optical images of a section of the Pt coil working electrode at (a) time $=0$ s; (b) time $=163 \mathrm{~s}$; (c) time $=3570 \mathrm{~s}$ showing the nucleation and growth of $\mathrm{HbS}$ aggregates. Experiment conditions: HbS concentrations $300 \mathrm{mg} \mathrm{cm}^{-3} ; 1.5 \mathrm{M} \mathrm{pH} 7.0$ phosphate buffer; $0.5 \mathrm{M} \mathrm{NaCl} ; \mathrm{E}=$ $0.55 \mathrm{~V}$ vs. Ag/AgCl for $6000 \mathrm{~s}$.

A significant decrease in the delay time to $163 \mathrm{~s}$ was apparent in this experiment. This was primarily due to the addition of $\mathrm{NaCl}$ which increased the ionic strength 
of the solution and had a pronounced effect on the induction times of llbs aggregate formation. The high ionic strength also provided a salting out effect for solubility purposes and thus, the use of $\mathrm{NaCl}$ as an additive was present in all further experiments. Ionic strength and salt type have been shown previously to influence aggregation and growth of HbS fibres in other experimental systems [85]. These measures decreased the delay times of nucleation and increased the growth rate through an increase of factors which affect polymer formation and hence improved experimental reproducibility.

In vivo Hb concentration per red blood cell (MCHC) is $320 \mathrm{mg} \mathrm{cm}^{-3}$ to $360 \mathrm{mg} \mathrm{cm}^{-3}$ " $[86]$ and the ionic strength of blood plasma is $0.16 \mathrm{M}[87]$. The choice of 300$) \mathrm{mg}$ $\mathrm{cm}^{-3}$ as the protein concentration allowed a direct comparison to be made with polymerisation in vivo. However, a system where lower ionic strength solution can be used still needs to be developed. Furthermore. it was also noticeable that the aggregated structures present in the optical microscope images in figure $\mathbf{3 . 3}$ did not look fibrous (unlike the single fibres observed in figure $\mathbf{1 . 1 0}$ in chapter 1.3.5). This was primarily due to the low resolution available with the optical microscope as well as possibly an increased gelation effect occurring with the use of electrochemistry and thus obscuring individual fibres. Thus, the exact nature and structure of these aggregates could not be distinguished using the optical microscope and further studies will need to be performed using AFM to elucidate the exact structural nature of the electrochemically modulated aggregates. 


\subsection{Control Experiments}

The control experiments performed in this investigation consisted of substituting $\mathrm{HbA}$ for $\mathrm{HbS}$ under the same electrochemical conditions in the thin layer cell. Once $\mathrm{O}_{2}$ was removed, there was no aggregation of $\mathrm{HbA}$ observed on or near the coil at the end of an experiment over a period of $6000 \mathrm{~s}$, figure $\mathbf{3 . 4}$ (b) versus $\mathbf{3 . 3}$ (c). The only difference between $\mathrm{HbA}$ and $\mathrm{HbS}$ is a single amino acid ( $\beta 6$ glutamic acid to valine); $\mathrm{HbA}$ monomers do not tend to aggregate even though exposure of the hydrophobic pocket occurs in $\mathrm{HbA}$ when in the $\mathrm{T}$ allosteric state as charge and size effects prevent $6 \beta$ glutamic acid from binding. Therefore any differences seen in the results performed with either protein was directly attributable to this single amino acid variation. This provided the most compelling evidence that those structures seen on the electrodes were $\mathrm{HbS}$ polymers and higher order aggregated structures and not as a result of other factors, such as salt precipitation. Furthermore, aggregated structures whose growth had been modulated electrochemically were also seen to disappear once the potential had been switched to open circuit and $\mathrm{O}_{2}$ had been allowed back into the cell. This reversibility displayed upon reoxygenation is not only specific to our system but also occurs physiologically in the blood vascular system [88].
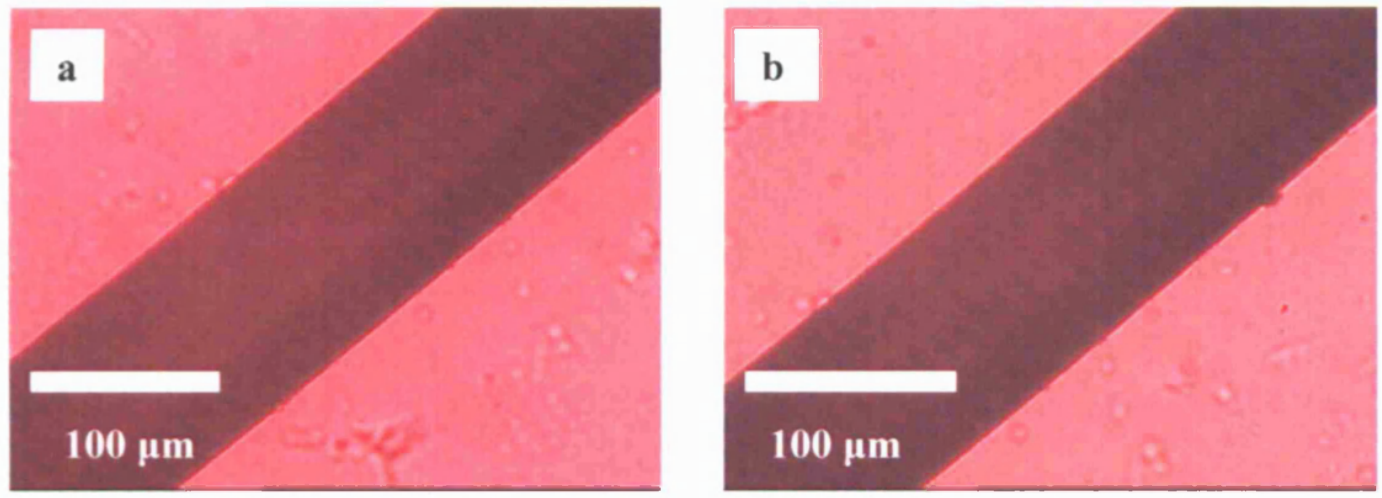

Figure 3.4: Optical images of a section of the $\mathrm{Pt}$ coil we when HbA solution was electrochemically deoxygenated. No fibre formation is seen at (a) time $=162 \mathrm{~s}$; or (b) time $=5280$ s. Experiment conditions: $\mathrm{HbA}$ concentration $310 \mathrm{mg} \mathrm{cm}^{-3} ; 1.5 \mathrm{M} \mathrm{pH} 7.0$ phosphate buffer; $0.5 \mathrm{M}$ $\mathrm{NaCl} ; \mathrm{E}=-0.55 \mathrm{~V}$ vs. $\mathrm{Ag} / \mathrm{AgCl}$ for $6000 \mathrm{~s}$.

$\mathrm{HbA}$ was an excellent control protein to use due to the high degree of similarity between the structures of $\mathrm{HbA}$ and $\mathrm{HbS}$ on the one hand but the contrasting 
polymerising behaviour on the other. Consequently, $\mathrm{HbA}$ control experiments consisting of the same conditions and procedures were used in all subsequent experiments including those performed with the Au micromesh cell, $\mathrm{Pt}$ matrix cell aswell as the direct electrochemistry experiments (data not shown for all control experiments). 


\subsection{Stages of Growth}

Another aspect which was investigated was the nature and rate of growth of these optically visualised aggregated structures over the time-course of the experiment. The optical microscope images showed three distinct stages of HbS growth. The first stage, occurring from $0 \mathrm{~s}$ to $200 \mathrm{~s}$, was the time delay where no growth was observed. This was followed by early stage growth consisting of single hair-like strands protruding out of the electrode and these structures were apparent from the initiation of growth till approximately $2000 \mathrm{~s}$ (figure $\mathbf{3 . 3}$ (b) and figure $\mathbf{3 . 5}$ (a)). Finally, late stage growth occurred from $2000 \mathrm{~s}$ to $6000 \mathrm{~s}$ and showed structures which were gel-like, consisting of domains and cells rather than hair like fibres, protruding into the bulk solution (figure 3.5 (b)). This was an interesting aspect present in all $\mathrm{HbS}$ aggregation experiments observed with the Pt coil cell.
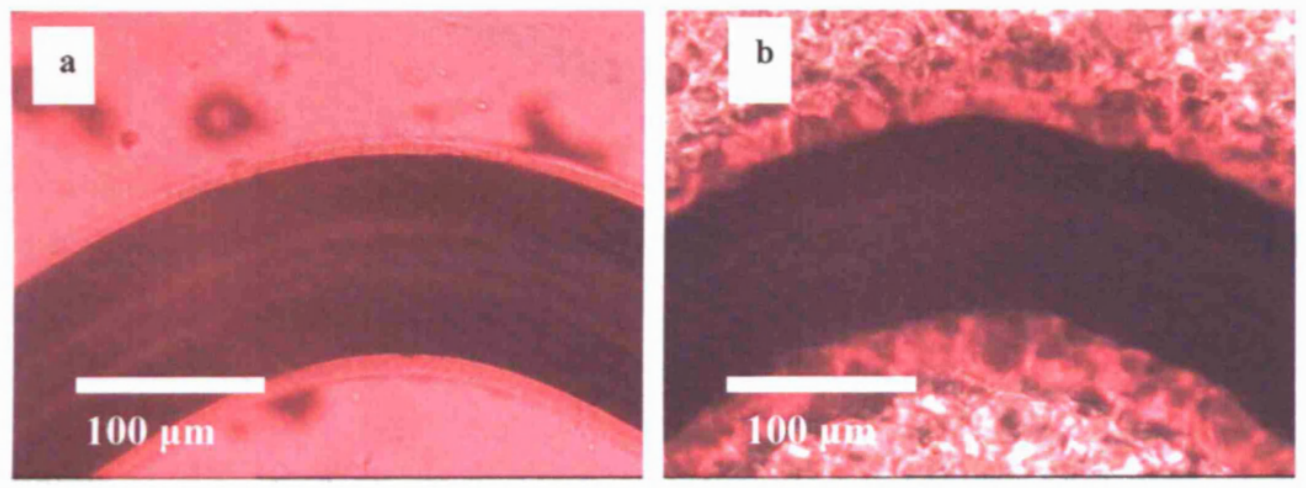

Figure 3.5: Optical images of the $\mathrm{Pt} W E$ in (a) the early stage growth, time $=338 \mathrm{~s}$; (b) the late stage growth, time $=4047 \mathrm{~s}$. Experiment conditions: $\mathrm{HbS}$ concentrations $350 \mathrm{mg} \mathrm{cm}^{-3} ; 1.5 \mathrm{M} \mathrm{pH}$ 7.0 phosphate buffer; $0.5 \mathrm{M} \mathrm{NaCl} ; \mathrm{E}=-0.55 \mathrm{~V}$ vs. $\mathrm{Ag} / \mathrm{AgCl}$ for $5000 \mathrm{~s}$.

Furthermore, optical images also showed that the formation of these aggregated structures initially occurred only at the electrode surface and not in the bulk solution (figure 3.6 (a)). The geometry of the WE indicated that complete $\mathrm{O}_{2}$ reduction of the $\mathrm{HbS}$ solution present within the coil should be achieved, whether it was the solution directly in contact with the electrode or that present in the bulk within the coil. Therefore, protein aggregation should have occurred at the electrode surface and in the bulk solution inside the coil simultaneously, but this was not seen. This was probably because growth at the surface was thermodynamically more favourable than growth in solution, due to the fact that the surface fixed molecule orientation, contributed to alignment and most 
importantly acted as an anchor for the attachment of $\mathrm{HbS}$ molecules. The conducting electrode surface itself could be thought of as an existing polymer on which growth of new polymers occurred. Once aggregation had occurred at the electrode, further nucleation on existing polymers, diffusion of aggregated structures away from the electrode and fibre breakage led to fibres in the bulk solution acting as nucleating centres, along with dirt or salt molecules, for the initiation of more polymers (figure $\mathbf{3 . 6}$ (b))
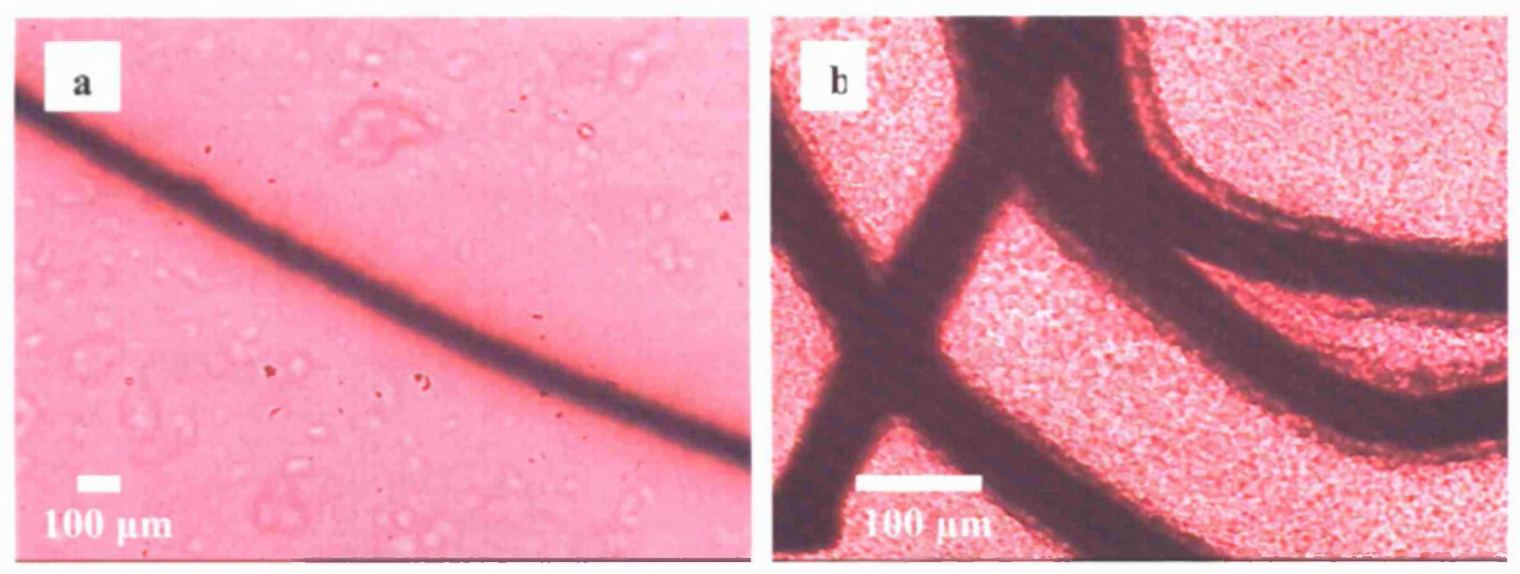

Figure 3.6: Optical images of the Pt WE in (a) time $=1276 \mathrm{sec}$; (b) time $=4989 \mathrm{sec}$. Experiment conditions: $\mathrm{HbS}$ concentrations $350 \mathrm{mg} \mathrm{cm}^{-3} ; 1.5 \mathrm{M} \mathrm{pH} 7.0$ phosphate buffer; $0.5 \mathrm{M} \mathrm{NaCl} ; \mathrm{E}=$ $0.55 \mathrm{~V} v$ s. $\mathrm{Ag} / \mathrm{AgCl}$ for $5000 \mathrm{sec}$.

The growth of $\mathrm{HbS}$ aggregates as seen with the optical images suggested that $\mathrm{HbS}$ aggregation occurs through a three step mechanism at the surface. The first step is the time delay before any growth is observed, followed by two distinct stages of growth as seen in figures $\mathbf{3 . 5}$ (a) and (b). This is in contrast to the traditional double nucleation model for $\mathrm{HbS}$ polymerisation consisting of homogeneous nucleation, which exhibits a delay time before the formation of polymers, and heterogeneous nucleation, which involves the exponential growth and branching of polymers on existing polymers. Further experiments with UV-visible spectroscopy were conducted to distinguish the mechanism of growth at the surface compared to growth in solution (see chapter 5).

It was also seen from the optical experiments that the nature of the electrochemically modulated aggregated structures on the electrode surface was different when differing additives were used. Figure $\mathbf{3 . 7}$ shows the late stage growth of two experiments, one where $5 \mathrm{mM}$ sodium dithionite has been used and another in which $0.5 \mathrm{M} \mathrm{NaCl}$ was added. The optical image where sodium 
dithionite was employed is noticeably distinct from the one in which $\mathrm{NaCl}$ had been used. The presence of granular structures in the solution surrounding the electrode is noticeable with sodium dithionite, whilst the fibres protruding from the electrode with sodium dithionite are also more compact and less domain-like than its counterpart. Sodium dithionite is a highly unstable reducing agent which scavenges residual $\mathrm{O}_{2}$, even being consumed by reducing atmospheric (as opposed to solution and $\mathrm{HbS}$ bound) $\mathrm{O}_{2}$. Furthermore, $\mathrm{H}_{2} \mathrm{O}_{2}$ results, if all the dithionite is not used up, which damages the protein. Consequently, the differences in structures seen in these images could have been as a result or a combination of these factors. The granular structures and non-domain like structures present in figure 3.7 (a) could be pockets of protein damage present in the solution due to the presence of peroxide.
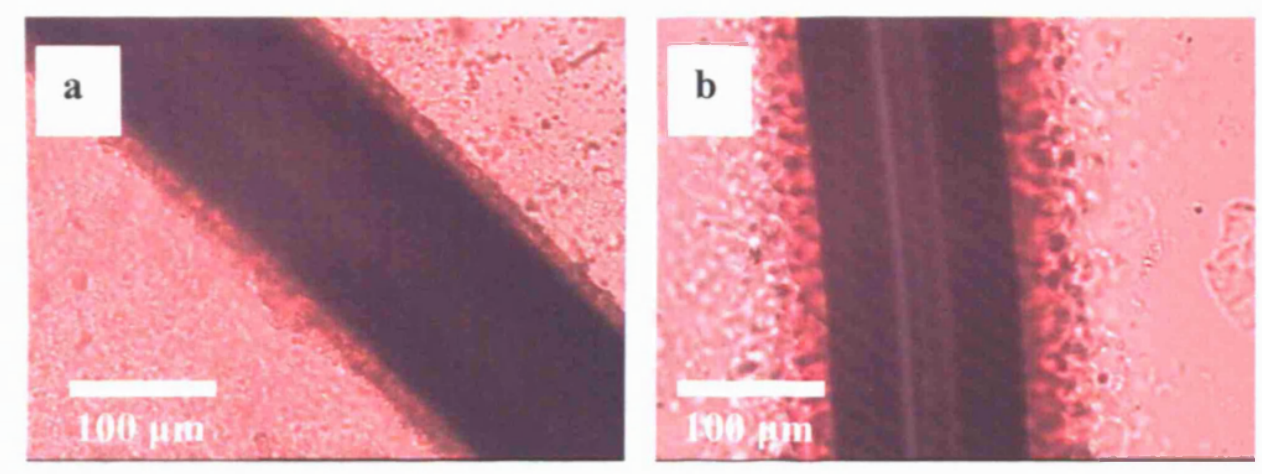

Figure 3.7: Optical images of the Pt WE showing the differences in growth when different additives (a) $5 \mathrm{mM}$ sodium dithionite; (b) $0.5 \mathrm{M} \mathrm{NaCl}$ were used. Experimental conditions: $\mathrm{HbS}$ concentrations $300 \mathrm{mg} \mathrm{cm}^{-3} ; 1.5 \mathrm{M} \mathrm{pH} 7.0$ phosphate buffer; $\mathrm{E}=-0.55 \mathrm{~V} v \mathrm{~s} . \mathrm{Ag} / \mathrm{AgCl}$ for $5000 \mathrm{~s}$. 


\subsection{Growth Rate}

A video clip of the growth of $\mathrm{HbS}$ aggregation at a bare Pt coil electrode was made by performing an experiment in which optical images of a small section of the $\mathrm{Pt}$ coil electrode was taken every $20 \mathrm{~s}$ over a period of $6000 \mathrm{~s}$ and the images were linked together using image processing software. The video showed the change in protein morphology from a strand like to a globular cell like structure on the surface of the electrode. Figure 3.8 shows a single image of the Pt electrode at 240 $\mathrm{s}$ (the film clip of the growth of protein fibres at the Pt electrode is available online as electronic supplementary information [89]).

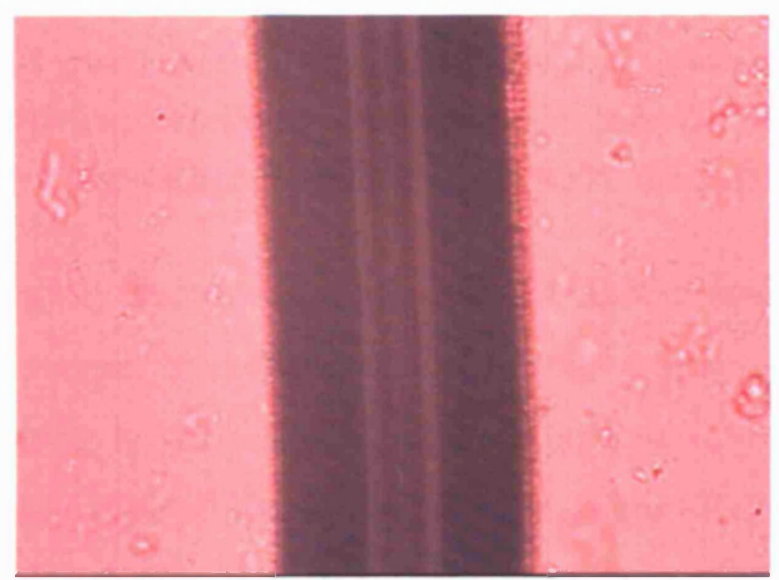

Figure 3.8: A single optical image of a section of the Pt coil WE taken at $240 \mathrm{~s}$ as part of a video clip showing growth of $\mathrm{HbS}$ aggregates at the surface. Experiment conditions: HbS concentrations $354 \mathrm{mg} \mathrm{cm}^{-3} ; 1.5 \mathrm{M} \mathrm{pH} 7.0$ phosphate buffer; $0.5 \mathrm{M} \mathrm{NaCl} ; \mathrm{E}=-0.55 \mathrm{~V}$ vs. $\mathrm{Ag} / \mathrm{AgCl}$; run time $6000 \mathrm{~s}$.

The growth rate of the $\mathrm{HbS}$ fibres shown in the video clip was ascertained by measuring the length of the hairy fibrous structures in each image and plotting a graph of growth length versus time, figure 3.9. For the growth rate measurements a time period of only $2200 \mathrm{~s}$ rather than the full $6000 \mathrm{~s}$ was used as after $2200 \mathrm{~s}$ the structures became highly globular making it very difficult to accurately obtain a definite length measurement. 


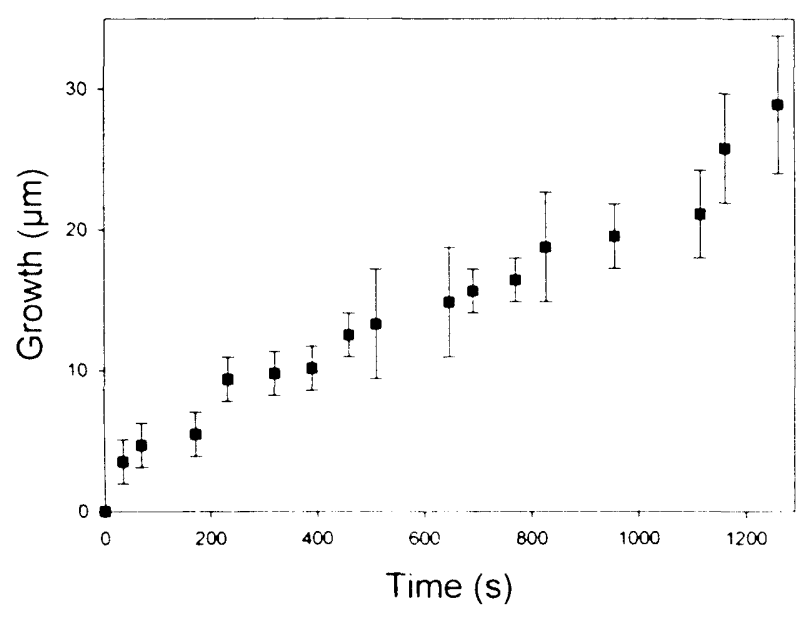

Figure 3.9: Graph of HbS growth $(\mu \mathrm{m})$ is. time (s) depicting the growth of fibrous structures over an experiment lasting $2200 \mathrm{sec}$. Experiment conditions: $\mathrm{HbS}$ concentrations $354 \mathrm{mg} \mathrm{cm} \mathrm{cm}^{-3}: 1.5 \mathrm{M}$ pH 7.0 phosphate buffer: $0.5 \mathrm{M} \mathrm{NaCl}: \mathrm{E}=-0.55 \mathrm{~V}$ vs. $\mathrm{Ag} / \mathrm{AgCl}$ : run time $2200 \mathrm{~s}$ out of $6000 \mathrm{~s}$.

The plot shows a slightly sigmoidal relationship with the initial period of growth ( $0 \mathrm{~s}$ to $150 \mathrm{~s}$ ) being steeper than the rest of the plot indicating that the delay time was a major contributing factor to the kinetics of polymerisation. The growth rates of the first and second phase of the bi-phasic relationship were calculated to be 67 $( \pm 8) \mathrm{nm} \mathrm{s}^{-1}$ and $40( \pm 5) \mathrm{nm} \mathrm{s}^{-1}$ respectively and the average growth rate at this section of the Pt coil electrode was calculated to be $54( \pm 9) \mathrm{nm} \mathrm{s}^{-1}$.

Table 3.1 shows the average growth rate of $\mathrm{HbS}$ fibres formed free in solution [42] compared with the fibre growth rate at a $\mathrm{Pt}$ coil electrode (figure 3.9). Electrochemical modulated fibre growth was seen to be slower than those formed free in solution. however, the time lines for the different sets of experiments were not taken into account as the electrochemically grown protein aggregates could only be measured up to $2200 \mathrm{~s}$ and not the full $6000 \mathrm{~s}$. Fibre growth rate values of between $0.1 \mu \mathrm{m} \mathrm{s}^{-1}$ and $2 \mu \mathrm{m} \mathrm{s}^{-1}$. determined in another study [73]. through observation of the growth of cut end fibres were in accordance with the values for growth rates seen in table $\mathbf{3 . 1}$. 


\begin{tabular}{|c|c|c|}
\hline $\begin{array}{l}\text { HbS conc. } \\
\left(\mathrm{mg} \mathrm{cm}^{-3}\right)\end{array}$ & $\begin{array}{c}\text { Temperature } \\
\left({ }^{\circ} \mathrm{C}\right)\end{array}$ & $\begin{array}{c}\text { Average growth rate } \\
\qquad\left(\mu \mathrm{m} \mathrm{s}^{-1}\right)\end{array}$ \\
\hline 830 & 28.0 & $0.116( \pm 0.007)$ \\
\hline 850 & 28.0 & $0.363( \pm 0.128)$ \\
\hline 870 & 25.3 & $0.289( \pm 0.079)$ \\
\hline 354 & 25.0 & $0.054( \pm 0.009)$ \\
\hline
\end{tabular}

Table 3.1: Average growth rates of HbS fibres formed free in solution (rows 1. 2 and 3) taken from a study performed by Samuel et al. [42] compared to the average growth rate at a Pt coil electrode (row 4). Growth of HbS fibres formed free in solution were determined from serial video frames shown by video-enhanced DIC microscopy: HbS concentration $830 \mathrm{mg} \mathrm{cm}^{-3} .850 \mathrm{mg} \mathrm{cm}^{3}$ and $870 \mathrm{mg} \mathrm{cm}^{3}$ dialysed into $0.1 \mathrm{M}$ potassium phosphate (pH 7). deoxygenated at $2{ }^{\circ} \mathrm{C}$ in an anaerobic glove box with $50 \mathrm{mM}$ sodium dithionite. Solutions were kept on ice and polymerisation was induced with a temperature jump to temperatures of $28{ }^{\circ} \mathrm{C} .28{ }^{\circ} \mathrm{C}$ and $25.3{ }^{\circ} \mathrm{C}$ respectively. The first fibres were seen 102 minutes after the temperature jump. Experimental conditions for HbS aggregates grown at a Pt coil electrode see figure $\mathbf{3 . 9}$. 


\section{$3.9 \quad$ AFM}

AFM, a high-resolution scanning probe microscopy technique, consists of a microscale cantilever with a sharp tip which is used to probe the surface of the specimen and can be used to image the growth of individual $\mathrm{HbS}$ fibres (of diameter $21.5 \mathrm{~nm}$ ) at specific points in the polymerisation cycle. When the tip is brought into the proximity of a sample surface, forces between the tip and the sample lead to a deflection of the cantilever and the deflection is measured using a laser spot reflected from the top of the cantilever into an array of photodiodes. This technique can be used to investigate the fundamental properties of nucleation and growth of $\mathrm{HbS}$ at a surface, such as induction times and growth rates whilst AFM also allows fibre spacing and length measurements to be carried out accurately enabling the kinetics and dynamics of polymerisation as well as the orientation of growth to be investigated. For delicate or soft samples such as proteins the tapping mode is used, as in contact mode the cantilever drags across the surface at constant force which can result in surface damage to the sample.

A number of $e x$-situ and in-situ AFM experiments, using contact and tapping mode in air and liquid. were performed to try to visualise the HbS fibrous and polymeric state of aggregated deoxy HbS. However, even though a number of procedures, including a variety of fibre formation techniques, and a range of conditions such as different protein concentrations, $\mathrm{pHs}$ and temperatures were attempted, only one image was obtained which showed the presence of fibre-like structures. The lack of $\mathrm{HbS}$ fibre images were most likely due to the sensitivity of the system to $\mathrm{O}_{2}$ as even small amounts of $\mathrm{O}_{2}$ could have caused fibres to dissolve, especially at the low protein concentrations being used, whilst numerous salt effects also became apparent when using the liquid tapping mode of the AFM.

Figure 3.10 shows an AFM image of $\mathrm{HbS}$ protein on mica and the presence of two fibre-like structures can be seen in the image (shown by arrows). In this experiment, $10 \mathrm{mg} \mathrm{cm}^{-3} \mathrm{HbS}$ protein was used and the $\mathrm{HbS}$ polymer solution was dip coated onto the mica surface and incubated for $10 \mathrm{~s}$. As the imaging was performed in air a fixative (glutaraldehyde) was used to fix any fibres onto the surface before any interaction with $\mathrm{O}_{2}$ occurred. 


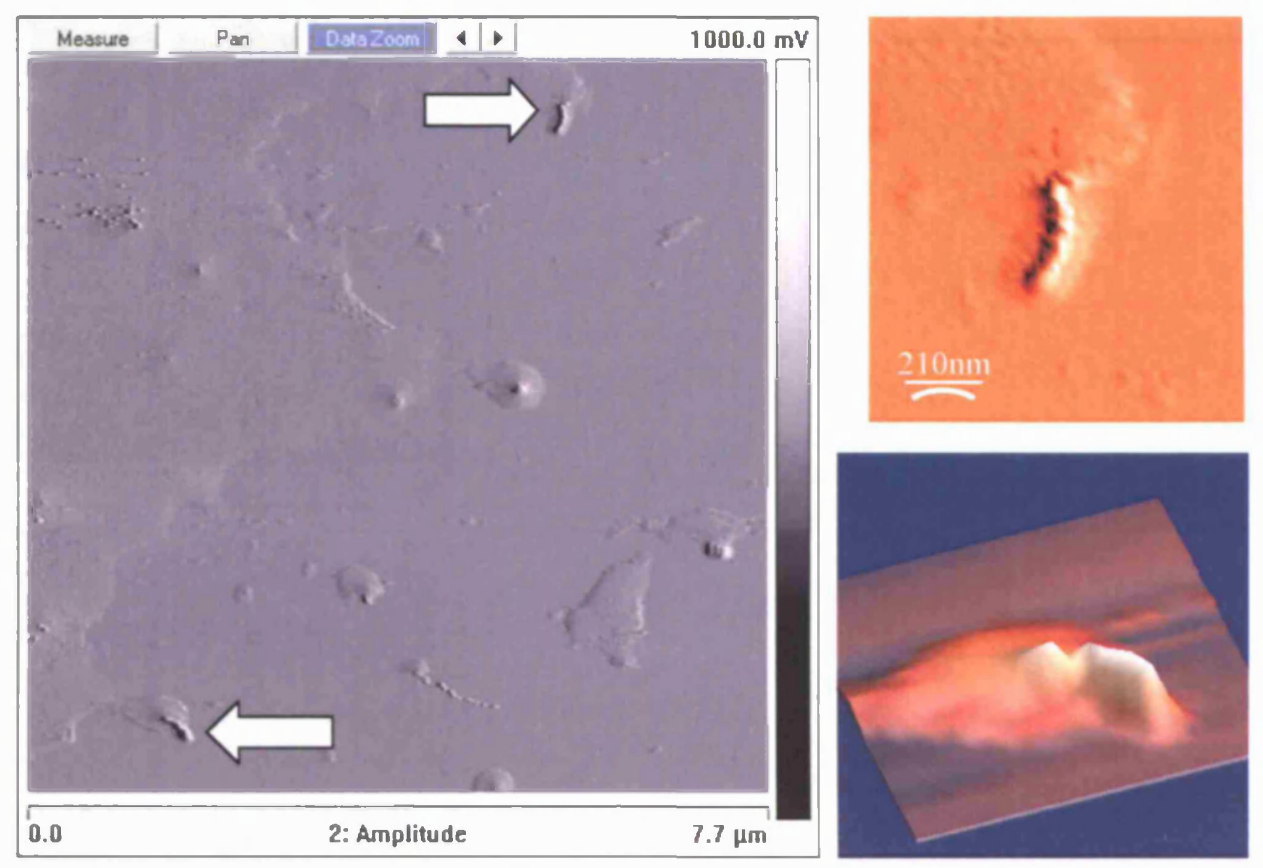

Figure 3.10: Dimension AFM imaging of HbS protein aggregates on freshly cleaved mica (scan size $10 \mu \mathrm{m} ; z$ height $75 \mathrm{~nm}$; amplitude $1.0 \mathrm{~V}$; drive amplitude $153.4 \mathrm{mV}$; silicon nitride tips (1 $\Omega)$ ); HbS aggregates were formed with $10 \mathrm{mg} \mathrm{cm}^{-3} \mathrm{HbS}$ protein in $\mathrm{pH} 7.58,2.52 \mathrm{M}$ phosphate buffer using experimental procedure 4. Mica surface was dip coated with the HbS aggregate solution stored under an inert atmosphere, incubated for $10 \mathrm{~s}$ and fixed using $3 \%$ glutaraldehyde solution.

The height of these two structures (height $=35 \mathrm{~nm}$ to $45 \mathrm{~nm}$ ) seen in the image were measured to be similar to the diameter of a single $\mathrm{HbS}$ fibre (figure 3.11), whilst these structures were also seen to be protruding from nodes and situated right on the edge of the protein and mica interface. However, it cannot be conclusively stated that these structures were $\mathrm{HbS}$ fibres as there was also a possibility that it could have been due to the presence of impurities in the system before the fixative was applied. Most of the experiments performed with HbS fibre solution deposited on mica and imaged in air showed a thick protein crust on the surface and the presence of nodes which could have been nucleating sites for the formation of HbS polymers. However, many experiments showed no images of fibres probably due to leaking of $\mathrm{O}_{2}$ into the system. In-situ experiments were performed using an electrochemical cell but no fibres were seen. 
a
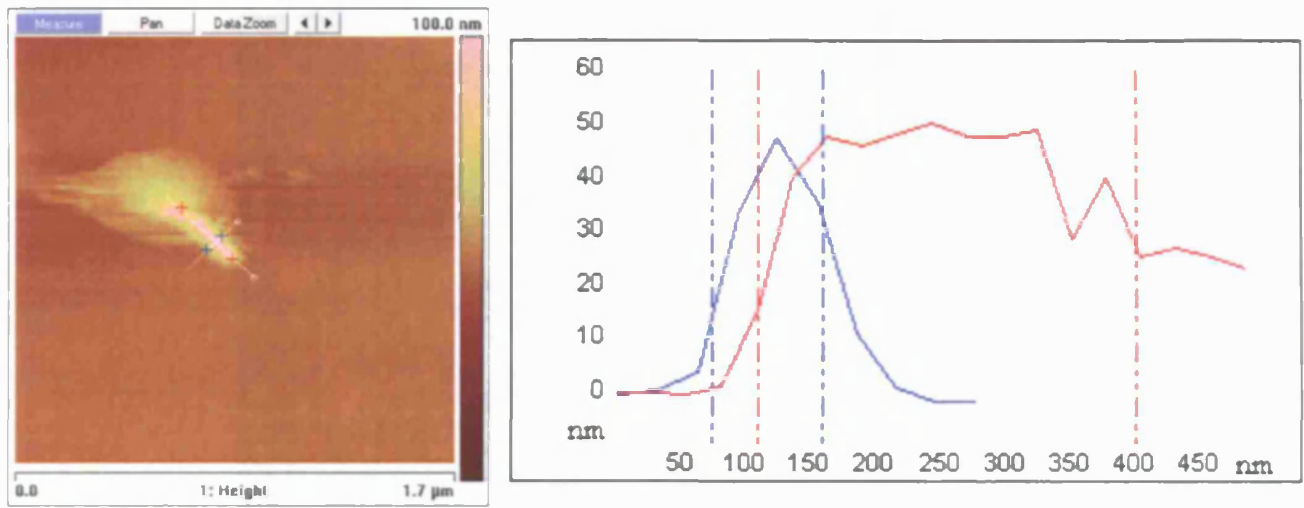

b
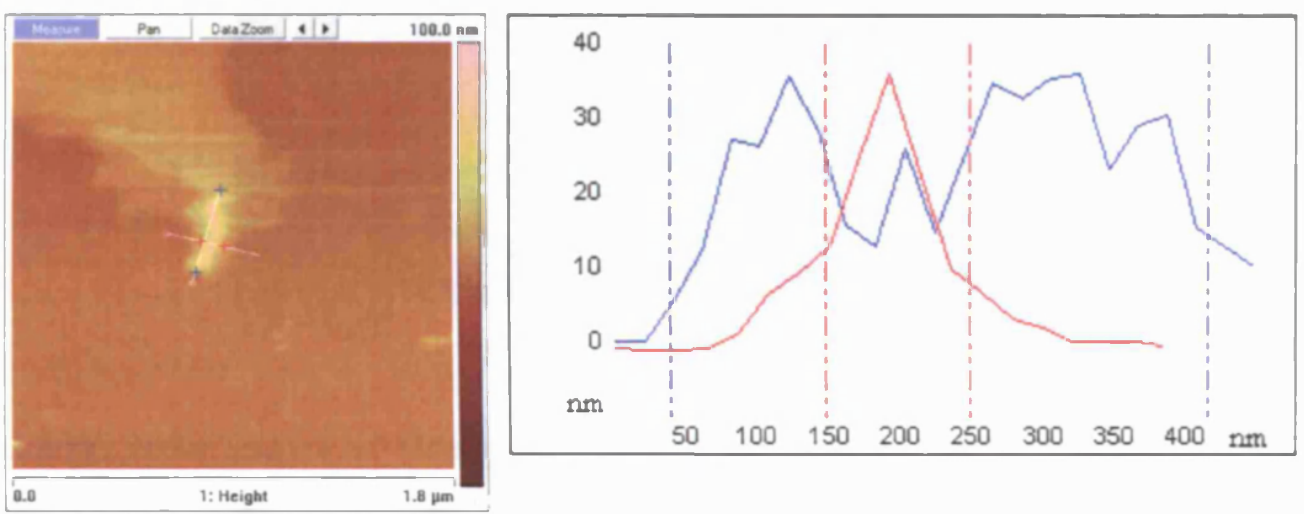

Figure 3.11: Figure showing the dimensions of the two fibre like structures seen in figure 3.10. For (a) the length $=300 \mathrm{~nm}$, width $=75 \mathrm{~nm}$, height $=45 \mathrm{~nm}$; (b) the length $=350 \mathrm{~nm}$, width $=100$ $\mathrm{nm}$, height $=35 \mathrm{~nm}$. For experimental conditions and image parameters see figure $\mathbf{3 . 1 0}$.

Studies involved in monitoring the events associated with $\mathrm{HbS}$ polymerisation have generally used DIC microscopy as the main visualising tool, as explained in chapter 1. This is because DIC microscopy allows structures to be viewed in real time without the limitations of invasive preparatory methods, thus allowing the kinetics, gel rheology and pathogenesis to be related to the underlying gel structure. However, AFM obviously has the great advantage of being able to image at far lower resolutions thus making it possible to image the growth of single $\mathrm{HbS}$ fibres. To date, only one set of AFM images on $\mathrm{HbS}$ fibres can be found in the literature [41], shown in figure $\mathbf{3 . 1 2}$, because gelation of the solution due to polymerisation makes imaging of the surface extremely difficult. Further work is required to produce a working system for the in-situ and ex-situ imaging of $\mathrm{HbS}$ fibres. 
Figure 3.12: AFM images of deoxyHbS polymers showing a variety of polymeric structures formed at $35{ }^{\circ} \mathrm{C}$ in a $220 \mathrm{mg} \mathrm{cm}^{-3}$ concentrated $\mathrm{HbS}$ solution: (a) Low-resolution image showing a variety of polymeric structures; (b-d) Higher resolution images showing thicker fibres consist of thin polymers of $22 \mathrm{~nm}$ diameter. The fibres were cross-linked with glutaraldehyde solution [4 1] 


\subsection{Conclusions}

It was found that polymerisation of $\mathrm{HbS}$ could be observed by $\mathrm{O}_{2}$ depletion using electrochemical reduction in a thin layer cell. The geometry of the WE was found to be essential for the growth of $\mathrm{HbS}$ aggregates as previous attempts with a $\mathrm{Pt}$ wire electrode did not produce any results. $\mathrm{HbS}$ polymerisation was visualised in a Pt coil electrochemical cell with an optical microscope and the conditions for reproducible growth of $\mathrm{HbS}$ aggregated structures at the $\mathrm{Pt}$ coil electrode was shown to be: $\mathrm{HbS}$ concentration of $300 \mathrm{mg} \mathrm{cm}^{-3}$ in $1.5 \mathrm{M}, \mathrm{pH} 7.0$ phosphate buffer with the addition of $0.5 \mathrm{M} \mathrm{NaCl}$ and the electrode held at a potential of $\mathrm{E}=-0.55$ $\mathrm{V}$ iersus $\mathrm{Ag} / \mathrm{AgCl}$. The use of high concentration buffer, and more importantly the addition of $\mathrm{NaCl}$ increased the ionic strength and the conductivity of the solution, and also provided a salting out effect for solubility purposes.

It was also demonstrated that three stages of polymerisation were seen from the optical images. The first was a time delay when no structures were observed and this could be thought of as the nucleation step. This was followed by two growth stages of $\mathrm{HbS}$ polymerisation, firstly growth of fibrous hair-like strands at the electrode surface and secondly globular and gel-like aggregation in the latter stages of the experiment. Furthermore, formation of the aggregated structures was seen to occur only at the electrode surface initially and not in the bulk solution showing that growth at the surface was thermodynamically more favourable than in solution. The average growth rate at a section of the bare Pt coil electrode, calculated to be $54( \pm 9) \mathrm{nm} \mathrm{s}^{-1}$, was in accordance with those presented in literature. Control experiments performed with non-polymerising HbA instead of HbS did not show growth of any structures at the electrode surface. Overall, an electrochemical technique was developed using an optimised thin layer Pt coil cell and the conditions for reproducible $\mathrm{HbS}$ aggregate growth and the different stages of polymerisation were characterised. 
Chapter 4: HbS Aggregation in Au Micromesh Cell 


\subsection{Introduction}

In this chapter, HbS aggregate formation at the surface of another in-house built thin layer electrochemical cell, a Au micromesh cell, is described. A methodology for the monitoring of $\mathrm{HbS}$ aggregation at the Au micromesh electrode by detecting turbidity changes as a result of light scattering caused by the polymerisation of $\mathrm{HbS}$ is presented. The kinetics of polymerisation using a model for fibrillogenesis describing a two-step process of nucleation followed by elongation is described, and the rate constants for two concentrations of $\mathrm{HbS}$ monomer, $50 \mathrm{mg} \mathrm{cm}^{-3}$ and $300 \mathrm{mg} \mathrm{cm}^{-3}$, have been determined. The nature of protein growth from optical microscope images is also compared with the Pt coil cell whilst the effect of DPG, a negatively charged allosteric effector is explored for further optimisation of $\mathrm{HbS}$ polymerisation conditions. 


\subsection{Experimental}

\subsubsection{Materials, Instrumentation and Procedures}

The UV-visible spectroelectrochemistry experiments were performed according to experimental procedure 6. $\mathrm{HbS}$ or $\mathrm{HbA}$ were dissolved in $1.5 \mathrm{M}(\mathrm{pH}$ 7.0) phosphate buffer solution and $\mathrm{NaCl}$ was added as supporting electrolyte. For DPG experiments, $3 \mathrm{mM}, 5 \mathrm{mM}$ and $100 \mathrm{mM}$ concentration of DPG was added to a solution containing $\mathrm{Hb}$ protein, $1.5 \mathrm{M}(\mathrm{pH} 7.0)$ phosphate buffer and $0.5 \mathrm{M} \mathrm{NaCl}$ and the UV-visible spectroelectrochemistry experiment was performed in the same manner described previously. All experiments were performed at room temperature unless stated otherwise. The electrodes used for constructing the cell were $\mathrm{Au}$ micromesh (aperture size $250 \mu \mathrm{m}$, plain weave wire diameter $60 \mu \mathrm{m}, 82$ grids per inch, $99.99 \%$ purity) as the WE, Pt wire (diameter $100 \mu \mathrm{m}$, hard temper, $99.99 \%$ purity) as the CE and silver (Ag) wire (grade 1, diameter $25 \mu \mathrm{m}$ ) as the RE. Au wire (diameter $250 \mu \mathrm{m}$, hard temper, $99.99 \%$ purity) was used as the connection between the WE and the copper wire. The general experimental and all apparatus for the above techniques are described in chapter 2. 


\subsubsection{Construction of Au Micromesh Thin Layer Electrochemical Cell}

A robust and easily constructed thin-layer cell was designed specifically for spectroelectrochemical measurements in a similar way to the construction of the $\mathrm{Pt}$ coil cell. Figure 4.1 (a) shows a schematic representation of this cell and figure 4.1 (b) shows an actual image of the cell. Three electrodes - Au micromesh $(3.0 \mathrm{~mm}$ by $4.0 \mathrm{~mm}$ ) WE, $100 \mu \mathrm{m}$ coil shaped Pt wire CE and $25 \mu \mathrm{m} \mathrm{Ag}$ wire RE - were placed in a quartz cuvette ( $1 \mathrm{~mm}$ pathlength) which had been cut in half to minimise the volume and connected to copper electrical wires using silver conductive paint. Au wire (diameter $250 \mu \mathrm{m}$ ) was looped through one of the apertures and used as the connection between the micromesh and the electrical wire and the connections were covered with epoxy resin to provide stability as well as to provide an impervious and non-conductive layer. A thin layer of typical total volume of $100 \mu \mathrm{l} \pm 10 \mu \mathrm{l}$ was produced (measured by the volume of solution required to completely fill the cell). Black tape was used to blank most of the cuvette from the light beam, except for a small window on the Au micromesh electrode $(1.0 \mathrm{~mm}$ by $1.5 \mathrm{~mm})$. All materials were thoroughly cleaned prior to its construction using acetone.

a

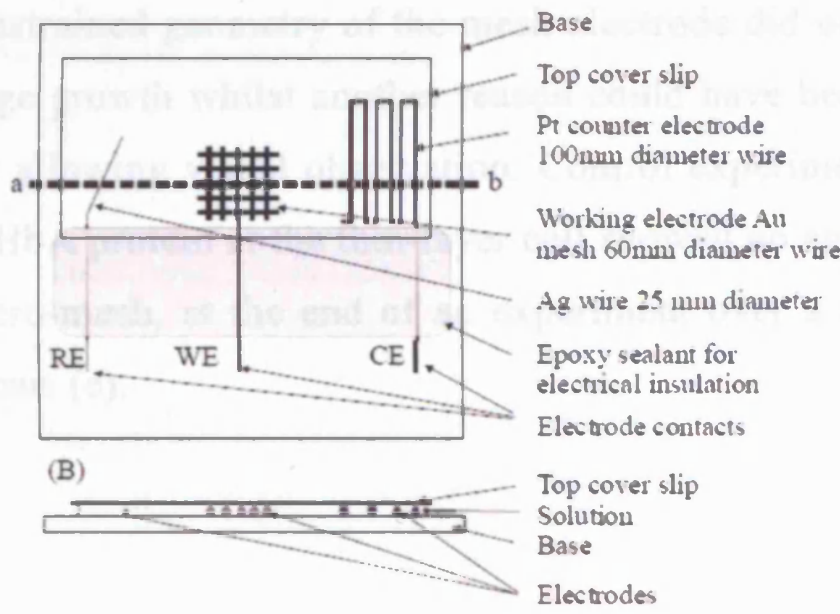

b

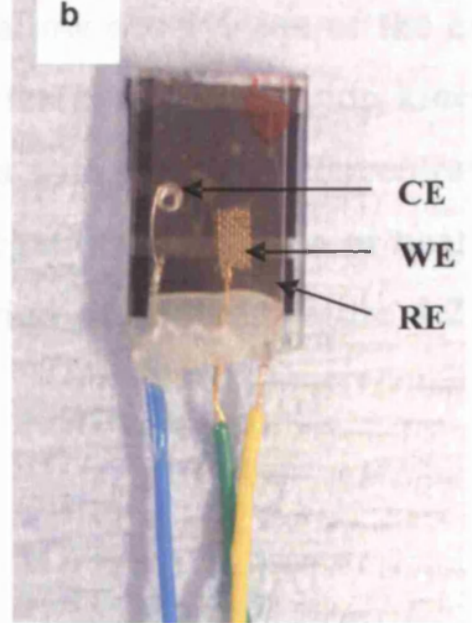

Figure 4.1: Figure showing (a) Schematic of the plan view (not to scale) (b) Actual image of the $\mathrm{Pt}$ micromesh thin layer electrochemical cell incorporating a three electrode system with a $\mathrm{Pt}$ micromesh (aperture size $250 \mu \mathrm{m}$ ) as the WE, a $100 \mu \mathrm{m}$ coil shaped Pt wire CE and a $25 \mu \mathrm{m} \mathrm{Ag}$ wire $\mathrm{RE}$. The $\mathrm{Ag}$ wire was anodised with $\mathrm{AgCl}$ prior to use. The electrodes were housed in a cuvette. Figure (b) shows the black tape covering the back of the cuvette used to blank the light beam. 


\subsection{Growth of HbS Aggregated Structures}

Figure 4.2 shows the change in morphology of the Au micromesh surface when $\mathrm{HbS}$ solution of concentration $300 \mathrm{mg} \mathrm{cm}^{-3}$ was electrochemically deoxygenated. At time $=0 \mathrm{~s}$ the Au electrode was bare and at time $=1458 \mathrm{~s}$ the first formation of 'globular structures' at the electrode was seen (Figure 4.2 (b)) which subsequently grew as the experiment proceeded (Figure 4.2 C). However, no fibrous strand-like structures were seen. The time taken for the structures to appear was again dependent on the rate of deoxygenation and rate of nucleation of aggregation.

The main difference between the growth of $\mathrm{HbS}$ protein aggregates at the $\mathrm{Pt}$ coil and Au micromesh, as seen from the optical images, was the lack of any hair-like strands present. Whereas growth of $\mathrm{HbS}$ fibrous structures at the Pt coil electrode was seen to occur in a three step mechanism, going from an initial delay to the formation of hair-like strands protruding from the surface of the electrode and finally to the formation of globular cell-like structures. The formation of protein aggregates at the Au micro-mesh electrode occurred with the establishment of the globular structures straight after the time delay. No hair-like strands were noticeable from any of the images.

Although the reasons behind the lack of early stage hair like fibrous growth in the Au micro-mesh cell was not clear, one possibility could have been that the constrained geometry of the mesh electrode did not allow observation of the early stage growth whilst another reason could have been faster polymerisation kinetics not allowing visual observation. Control experiments with the same concentration of $\mathrm{HbA}$ protein at the thin-layer cell showed no aggregation of $\mathrm{HbA}$, on or near the micro-mesh, at the end of an experiment over a period of $4500 \mathrm{~s}$, Figure 4.2 (d) versus (e). 

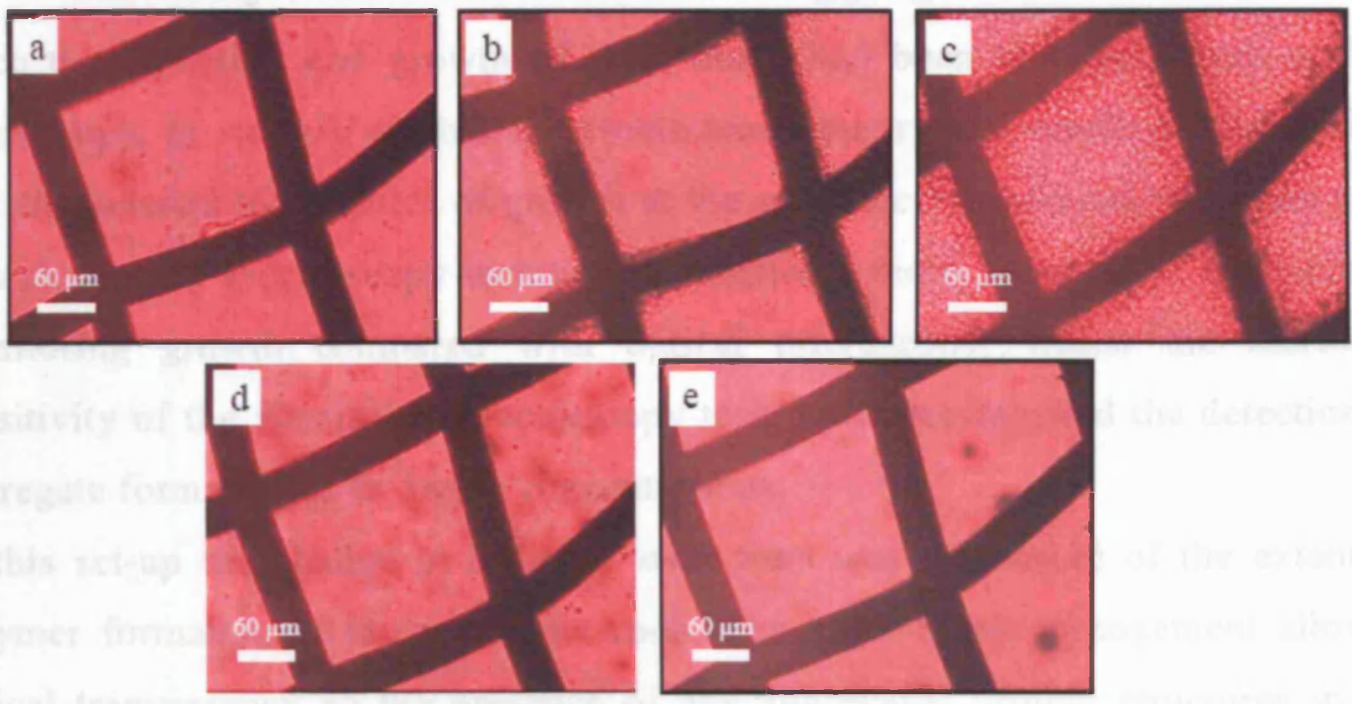

Figure 4.2: Optical microscope images showing $\mathrm{HbS}$ aggregate growth and the control $\mathrm{HbA}$ at the Au micromesh WE. Experiment conditions: HbS concentration $300 \mathrm{mg} \mathrm{cm}$; $1.5 \mathrm{M} \mathrm{pH} 7.0$ phosphate buffer; $0.5 \mathrm{M} \mathrm{NaCl} ; \mathrm{E}=-0.55 \mathrm{~V}$ vs. $\mathrm{Ag} / \mathrm{AgCl}$ for $4500 \mathrm{~s}$. (a) $\mathrm{HbS}$ at $0 \mathrm{~s}$; (b) $\mathrm{HbS}$ at $1458 \mathrm{~s} ;$ (c) $\mathrm{HbS}$ at $3327 \mathrm{~s}$; (d) $\mathrm{HbA}$ at $0 \mathrm{~s}$; (e) $\mathrm{HbA}$ at $4500 \mathrm{~s}$

Optical transparency was achieved by using an optically transparent mesh as the WE whilst a thin layer was obtained by housing the electrodes in a $1 \mathrm{~mm}$ pathlength cuvette. The micromesh geometry allowed a more efficient electrochemical reduction of $\mathrm{O}_{2}$ than a coil. Thiol modifications of the Au surface allowed surface properties to be changed easily thus enabling the effect of surface properties on nucleation and growth of $\mathrm{HbS}$ aggregates to be investigated (Chapter 6.6.2). Au surface has the advantage of undergoing fast and simple protein desorption and rapid thiol cleavage. Complete deoxygenation at the micromesh electrode was confirmed electrochemically by comparing the minimum charge needed to remove all $\mathrm{O}_{2}$ from a cell of total volume $50 \mu \mathrm{l}$ air-saturated $\mathrm{Hb}$ solution, calculated to be $1.93 \times 10^{-3} \mathrm{C}$, with the experimentally obtained value of $1.00 \times 10^{-2} \mathrm{C}$ passed over a period of $4500 \mathrm{~s}$. CV of the solution, performed after chronoamperometry, also showed the absence of the $\mathrm{O}_{2}$ present in the $\mathrm{HbS}$ solution at the start of the experiment, as illustrated in Figure 2.2. Furthermore, figure $\mathbf{2 . 3}$ shows that the conversion of oxyHbS to deoxyHbS at the mesh electrode occurred within $200 \mathrm{~s}$. 


\subsection{Turbidity Measurements of HbS Aggregated Structures}

Once the induction and growth of $\mathrm{HbS}$ fibres had been visualised with optical microscopy, in situ UV-visible spectroelectrochemistry was employed to monitor and characterise the kinetics of growth at the same electrochemical thin layer cell. The absorption spectroscopy technique permitted a more quantitative approach to monitoring growth compared with optical microscopy, whilst the increased sensitivity of the absorption spectroscopy technique also allowed the detection of aggregate formation at far lower concentrations.

In this set-up the change in turbidity over time was a measure of the extent of polymer formation at the mesh electrode. The micro-mesh arrangement allowed optical transparency so the presence of any aggregated protein structures in the apertures, formed due to electrochemical reduction of $\mathrm{O}_{2}$ in situ, could be detected as a result of wavelength independent light scattering caused by the polymers. Turbidity values were determined from the absorbance according to the relation $A$ $=\log \left(I_{0} / I\right)$, where turbidity $=\left(I_{0} / I\right)$. The intensity of scattered light by a particle is proportional to the mass squared, so a few large fibrils will scatter the same amount of light as many smaller fibrils. However, care was taken over the experimental conditions and the starting sample to ensure the solution was composed of only protein monomers meant that the results obtained were accurate and reproducible.

At a protein concentration of $300 \mathrm{mg} \mathrm{cm}^{-3}$ (the same as used in the optical microscopy experiments) large time dependent increases in turbidity were seen over the wavelength range 600 to $1100 \mathrm{~nm}$, figure 4.3. This wavelengthindependent turbidity was directly due to light scattering caused by the formation of $\mathrm{HbS}$ aggregated structures. The blank in this experiment was the HbS solution before the potential was applied, so the spectra shown in figure 4.3 shows the change in turbidity relative to the starting solution. 


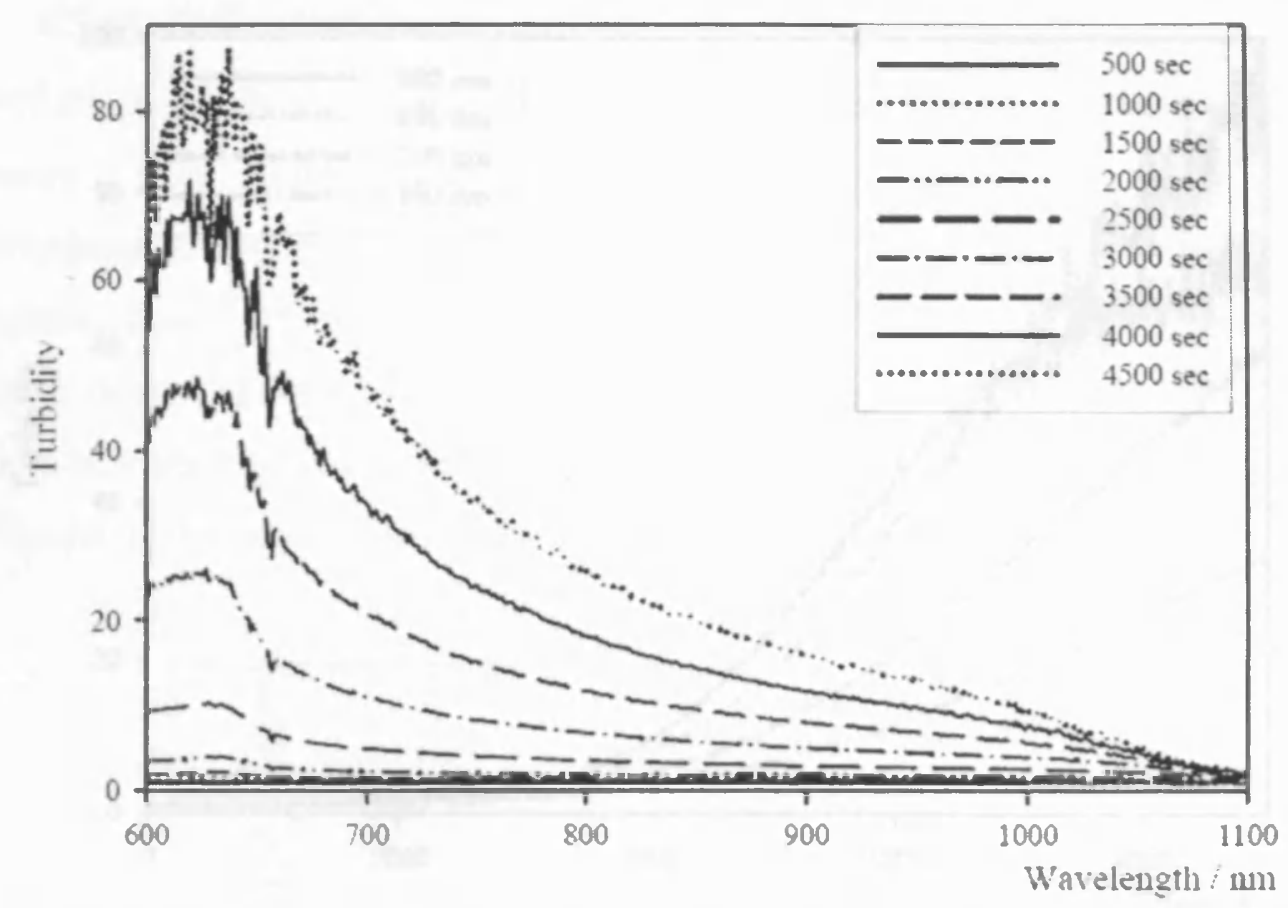

Figure 4.3: Wavelength independent light scattering due to formation of $\mathrm{HbS}$ fibres by electrochemical reduction of $\mathrm{O}_{2}$ at $\mathrm{Au}$ micromesh electrode. Experimental conditions: $\mathrm{HbS}$ concentration $300 \mathrm{mg} \mathrm{cm}^{-3}$ in $1.5 \mathrm{M}$ phosphate buffer $(\mathrm{pH} 7.0$ ); $0.5 \mathrm{M} \mathrm{NaCl} ; \mathrm{E}=-0.55 \mathrm{~V}$ vs. $\mathrm{Ag} / \mathrm{AgCl}$ for $4500 \mathrm{~s}$.

The rate of turbidity change at four specific wavelengths, $600 \mathrm{~nm}, 650 \mathrm{~nm}, 700 \mathrm{~nm}$ and $800 \mathrm{~nm}$ were monitored to investigate the kinetics of nucleation and growth, both at the early and latter stages of the polymerisation process. These four wavelengths were thought to represent the best points at which these processes could be observed. Wavelengths below $600 \mathrm{~nm}$ are associated with the macromolecular structure of the protein, in particular the effects of Soret bands upon interaction with photons and thus were not included in these results.

Figure 4.4 shows time traces for changes in absorbance at the aforementioned wavelengths. The time traces in figure $\mathbf{4 . 4}$ are from the same results as that of figure 4.3. The results showed that the rate of change in turbidity at each wavelength followed a sigmoidal pattern with an initial lag period up to $1000 \mathrm{~s}$ where little increase in absorbance was apparent (turbidity less than 2.00). This was followed by a large exponential increase from $1000 \mathrm{~s}$ to $4500 \mathrm{~s}$ where the turbidity increased forty fold to 85.36 . 


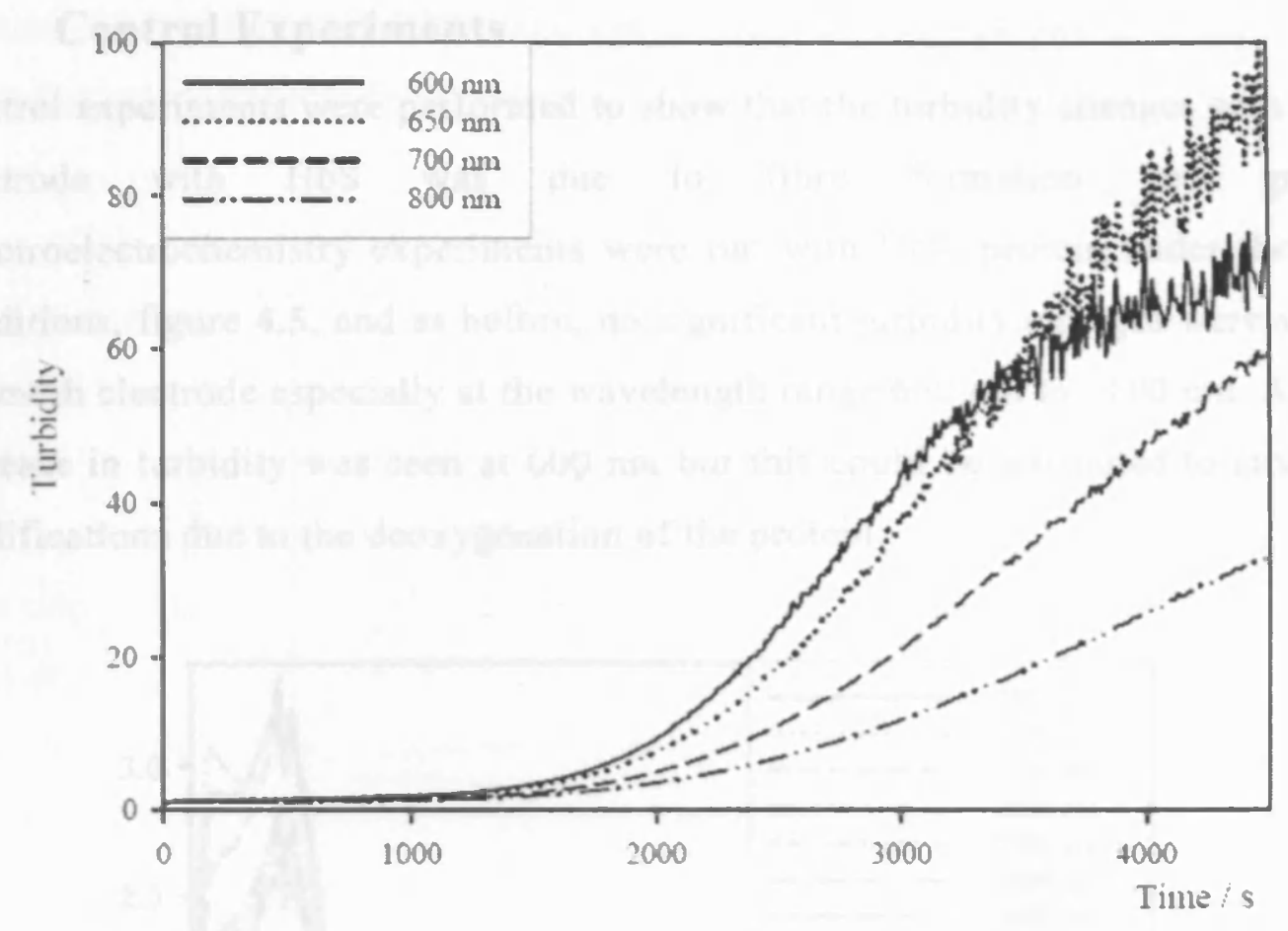

Figure 4.4: UV-visible spectroelectrochemistry time traces for $\mathrm{HbS}$ showing changes in turbidity at $\mathrm{Au}$ micromesh electrode. Experimental conditions: $\mathrm{HbS}$ concentration $300 \mathrm{mg} \mathrm{cm}^{-3}$ in pH 7.0 , $1.5 \mathrm{M}$ phosphate buffer; $0.5 \mathrm{M} \mathrm{NaCl} ; \mathrm{E}=-0.55 \mathrm{~V}$ vs $\mathrm{Ag} / \mathrm{AgCl}$ for $4500 \mathrm{~s}$.

The initial period up to $1000 \mathrm{~s}$ incorporates the nucleation step as well as limited growth on the electrode surface and hence light scattering due to $\mathrm{HbS}$ aggregation is minimal. After $1000 \mathrm{~s}$, elongation and further nucleation on existing fibres gives rise to extended growth and branching on the electrode surface and into the bulk solution thereby causing intensive light scattering. Consequently, a large increase in absorbance is obtained. The Au micromesh cell data did not provide further evidence to the hypothesis that nucleation and growth at a conducting electrode surface follows a three stage process (nucleation, early stage growth and late stage growth). This data was fitted to a kinetic scheme model which is explained in detail in section 4.6 . 


\subsection{Control Experiments}

Control experiments were performed to show that the turbidity changes seen at the electrode with $\mathrm{HbS}$ was due to fibre formation and growth. Spectroelectrochemistry experiments were run with $\mathrm{HbA}$ protein under the same conditions, figure $\mathbf{4 . 5}$, and as before, no significant turbidity changes were seen at the mesh electrode especially at the wavelength range $650 \mathrm{~nm}$ to $1100 \mathrm{~nm}$. A slight increase in turbidity was seen at $600 \mathrm{~nm}$ but this could be attributed to structural modifications due to the deoxygenation of the protein.

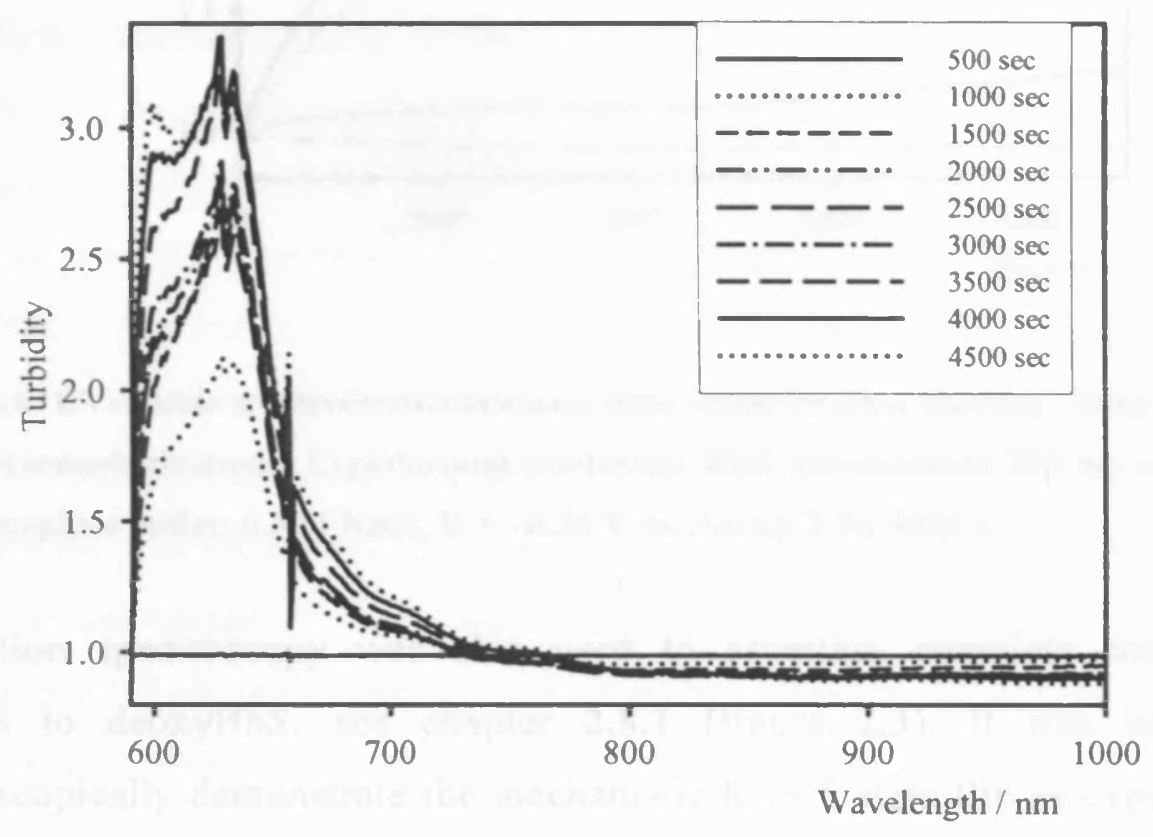

Figure 4.5: Wavelength independent light scattering of $\mathrm{HbA}$ at $\mathrm{Au}$ micromesh electrode as a result of electrochemical reduction of $\mathrm{O}_{2}$. Experimental conditions: HbA concentration $300 \mathrm{mg}$ $\mathrm{cm}^{-3}$ in $\mathrm{pH} 7,1.5 \mathrm{M}$ phosphate buffer; $0.5 \mathrm{M} \mathrm{NaCl}$; $\mathrm{E}=-0.55 \mathrm{~V}$ vs. $\mathrm{Ag} / \mathrm{AgCl}$ for $4500 \mathrm{~s}$.

Moreover, absorbance changes monitored at the four specific wavelengths (600 $\mathrm{nm}, 650 \mathrm{~nm}, 700 \mathrm{~nm}$ and $800 \mathrm{~nm}$ ) from the same HbA experiment as figure 4.5 showed no significant increases in turbidity especially at $700 \mathrm{~nm}$ and $800 \mathrm{~nm}$ and there was no characteristic sigmoidal relationship, figure 4.6. The change in turbidity at $700 \mathrm{~nm}$ for $\mathrm{HbA}(1.26$ at $4500 \mathrm{~s})$ was approximately forty six times lower than the turbidity measured for the same experiment with $\mathrm{HbS}$ in the same cell (59.37 at $4500 \mathrm{~s})$. The $\mathrm{HbA}$ controls data provided strong evidence that any 
changes in turbidity with $\mathrm{HbS}$ were due to $\mathrm{HbS}$ aggregation and growth, induced through electrochemical deoxygenation.

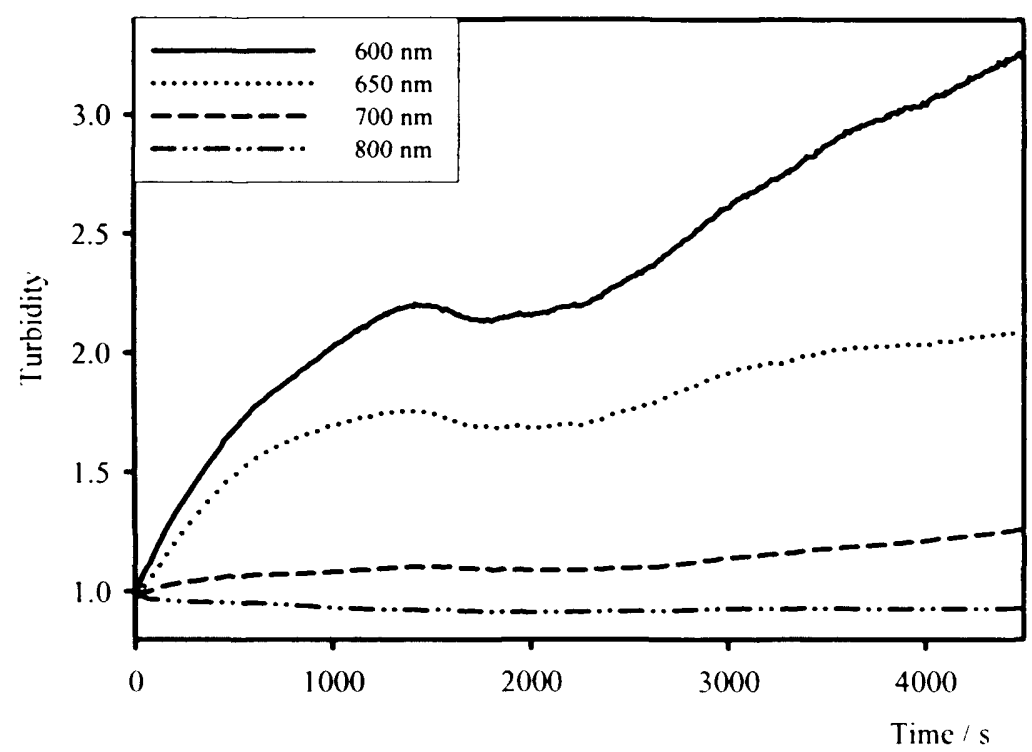

Figure 4.6: UV-visible spectroelectrochemistry time traces for $\mathrm{HbA}$ showing changes in turbidity at $\mathrm{Au}$ micromesh electrode. Experimental conditions: $\mathrm{HbA}$ concentration $300 \mathrm{mg} \mathrm{cm}^{-3}$ in $\mathrm{pH} 7.0$ $1.5 \mathrm{M}$ phosphate buffer; $0.5 \mathrm{M} \mathrm{NaCl}: \mathrm{E}=-0.55 \mathrm{~V}$ is. $\mathrm{Ag} / \mathrm{AgCl}$ for $4500 \mathrm{~s}$.

Absorption spectroscopy was also used to ascertain complete conversion of oxyHbS to deoxyHbS, see chapter 2.8.1 (figure 2.3). It was important to spectroscopically demonstrate the mechanistic $R$ to $T$ state flip as exposure of the hydrophobic pocket by which $\mathrm{HbS}$ molecules aggregate only occurs in the T state. 


\subsection{Kinetics of Protein Aggregating Systems}

One of the typical kinetic characteristics in protein fibre formation is a nucleationdependent polymerisation mechanism, used to analyse a mechanism composed of an initial nucleation phase and an elongation phase. Examples of such protein aggregating systems include $\mathrm{HbS}$ polymerisation [90], $\beta$-amyloid fibrillogenesis [91] and silk fibroin [92]. In $\beta$-amyloid fibrillogenesis, unstructured monomers in solution nucleate and form a critical nucleus which in turn forms intermediate peptides termed protofibrils. These intermediaries subsequently act as precursors by associating end to end and laterally and thereby elongating the protofibrils to form fibrils. Furthermore, a reservoir of micelle monomer associates is formed once the concentration exceeds a certain level called the critical micelle concentration (CMC), which allows an autocatalytic reaction for the aggregation of $\beta$-amyloid $[91,93]$. The assembly process of silk fibres occurs in a similar manner. The defining characteristic in all of the above mentioned protein aggregating systems is the formation of an ordered nucleus. Nucleus formation is a thermodynamically unfavourable interaction because the entropic cost encountered upon loss of molecular movement does not outweigh the resultant intermolecular polymer lattice formation. Upon nucleation, further monomers contact the growing polymer at multiple sites leading to rapid polymerisation and growth. Sabate et al. [93] have used a modification of the mathematical model developed by Kamihira et al. [94] to propose a simple two step autocatalytic reaction mechanism for $\beta$ amyloid fibril formation, thereby permitting quantitative monitoring of the kinetics of fibrillogenesis and enabling the nucleation rate and elongation rate to be determined. Knowledge of these rate constants is key to understanding the underlying molecular factors which govern fibril nucleation and growth. 


\subsubsection{Kinetics of $\mathrm{HbS}$ Polymerisation}

For $\mathrm{HbS}$ polymerisation, many studies have been devoted to investigate the kinetics using a large variety of techniques [53-56, 59-62] and the results from all of these techniques have shown the same basic kinetic features of polymerisation, a sigmoidal time course for polymerisation of an initially polymer-free solution. see figure 1.8 for a typical progress curve for $\mathrm{HbS}$ polymerisation. A marked delay in the initial part of the progress curve, during which no signal is observed, corresponds to the nucleation time or the time taken to form the critical nucleus. The energetic gain needed to form critical nuclei is dependent on the initial concentration of $\mathrm{HbS}$. The nucleation time is also found to be related to the solubility of $\mathrm{HbS}$, and thus dependent on the variables which alter the solubility of $\mathrm{HbS}$. The effect of variables which alter the solubility of $\mathrm{HbS}$ on the nucleation and growth of polymerisation has been investigated at a Pt matrix electrochemical cell in chapter $\mathbf{5}$. Nucleation is followed by a comparatively fast and highly autocatalytic formation of polymer.

The kinetic scheme developed for the fibrillation mechanism of human calcitonin by Kamihira et al. [94] and subsequently modified for $\beta$-amyloid fibrillogenesis by Sabaté et al. [93] was be fitted to our HbS polymerisation data. To analyse the kinetic properties of a system where non-aggregated $A \beta$ becomes aggregated fibrillar $A \beta$ the nucleation process can be expressed as:

$$
\mathrm{n} M \stackrel{k_{1}}{\rightarrow} P_{\mathrm{n}}
$$

and the elongation process can be described as:

$$
M+P_{\mathrm{n}} \stackrel{k_{2}}{\rightarrow} P_{\mathrm{n}+1}
$$

with $M$ representing monomeric $\mathrm{HbS}, \mathrm{n}$ the number of $\mathrm{HbS}$ molecules and $P_{\mathrm{n}}$ the fibre nucleus. The kinetics of the process is controlled by two key parameters, the nucleation rate constant $k_{l}$, and the elongation described by the rate constant $k_{2}$. The overall kinetic equation for the nucleation and growth of the fibres can be expressed as in: 


$$
\left(\frac{d f}{d t}\right)=k_{1}(1-f)+k_{2} a f(1-f)
$$

where $f$ is the fraction of fibres in the system and $a$ is the initial concentration of $\mathrm{HbS}$ in the solution. Equation $\mathbf{4 . 3}$ can be integrated under the boundary condition of $t=0, f=0$, to give:

$$
f=\frac{\rho\{\exp [(1+\rho) k t]-1\}}{\{1+\rho \exp [(1+\rho) k t]\}}
$$

where $k=k_{2} a$ and $\rho=k_{1} / k$. Least square fitting of equation 4.4, to the turbidity data at $800 \mathrm{~nm}$ for two $\mathrm{HbS}$ concentrations was used to obtain values of $k_{1}$ and $k_{2}$. As shown in figure 4.7 the fit of equation 4.4 to the normalised turbidity data (normalised using a turbidity of 75 , which was the maximum turbidity at $800 \mathrm{~nm}$ ) was good for the high protein concentration data $\left(300 \mathrm{mg} \mathrm{cm}^{-3}, \mathrm{r}^{2}=0.998\right)$ but only reasonable for the lower protein concentration $\left(50 \mathrm{mg} \mathrm{cm}^{-3}, \mathrm{r}^{2}=0.968\right)$. The fit to the low protein concentration data was affected by solution evaporation from the cell which ultimately limited the length of the experiment to $4500 \mathrm{~s}$.

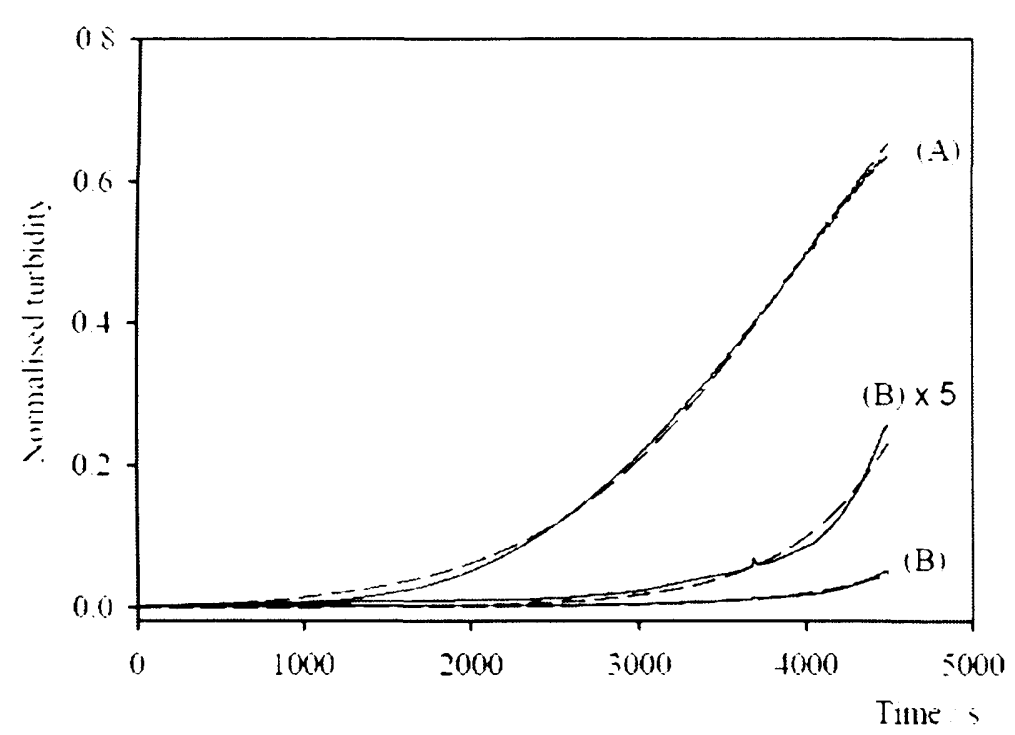

Figure 4.7: Solid lines showing the experimental values of normalised turbidity, using a $\max$ turbidity of 75 corresponding to maximum absorbance of fibres at $800 \mathrm{~nm}$, versus time for (A) 50 $\mathrm{mg} \mathrm{cm} \mathrm{cm}^{-3} \mathrm{HbS}$ and (B) $300 \mathrm{mg} \mathrm{cm}^{-3} \mathrm{HbS}$. The dashed lines are the best-fit lines to equation 4.4.

The rate constants obtained from these fits are summarised in Table 4.1. The effective growth rate constant, $a k_{2}$, did not show significant correlation with $\mathrm{HbS}$ 
concentration under these conditions. However, the values for $k_{1}$ are several orders of magnitude smaller than $k_{2}$ for both 50 and $300 \mathrm{mg} \mathrm{cm}^{-3}$ of $\mathrm{Hb}$, indicating that the nucleation process was far slower than the elongation process. There was a clear concentration dependence on the nucleation rate constant. This was expected, as in this case nucleation was expected to take place on the electrode surface where it is more thermodynamically favourable than homogenous nucleation free in solution.

\begin{tabular}{|c|c|c|c|}
\hline HbS Concentration & $k_{1} / \mathrm{s}^{-1}$ & $k_{2} / \mathrm{M}^{-1} \mathrm{~s}^{-1}$ & $a k_{2} / \mathrm{s}^{-1}$ \\
\hline $\begin{array}{c}50 \mathrm{mg} \mathrm{cm} \\
\left(7.752 \times 10^{-4} \mathrm{M}\right)\end{array}$ & $2.99( \pm 0.4) \times 10^{-8}$ & $1.39( \pm 0.6)$ & $1.08( \pm 0.2) \times 10^{-3}$ \\
\hline $\begin{array}{c}300 \mathrm{mg} \mathrm{cm}^{-3} \\
\left(4.65 \times 10^{-3} \mathrm{M}\right)\end{array}$ & $9.45( \pm 0.08) \times 10^{-6}$ & $0.26( \pm 0.01)$ & $1.22( \pm 0.03) \times 10^{-3}$ \\
\hline
\end{tabular}

Table 4.1: Nucleation rate constants $k_{1}$ and growth rate constants $k_{2}$ to describe the HbS aggregation formation for $50 \mathrm{mg} \mathrm{cm}^{-3}$ and $300 \mathrm{mg} \mathrm{cm}^{-3}$ protein concentration at a Au micromesh electrode surface. Experiment conditions: $\mathrm{HbS}$ concentrations $50 \mathrm{mg} \mathrm{cm}^{-3}$ and $300 \mathrm{mg} \mathrm{cm}^{-3} ; 1.5 \mathrm{M}$ $\mathrm{pH} 7.0$ phosphate buffer; $0.5 \mathrm{M} \mathrm{NaCl}$; temperature $25^{\circ} \mathrm{C} ; \mathrm{E}=-0.55 \mathrm{~V}$ is. $\mathrm{Ag} / \mathrm{AgCl}$ for $4500 \mathrm{~s}$. 


\subsection{2,3-DPG}

2,3-DPG acts by stabilising the deoxy or $\mathrm{T}$-state of $\mathrm{Hb}$ by binding in the cavity between the $\beta$ chains of the deoxygenated state of $\mathrm{Hb}$, making electrostatic interactions with positively charged groups surrounding this opening. However, even though the effect of 2,3-DPG in normal adult $\mathrm{Hb}$ is quite well established, the role of 2,3-DPG in the pathophysiology of sickle cell disease has been a point of long-standing dispute. Some studies have claimed that 2,3-DPG promotes the intracellular polymerisation of deoxy-HbS [51, 53, 95], whereas others assert that it has no such effect $[54,55]$.

The effect of 2,3-DPG in promoting HbS polymerisation in the Au micromesh thin-layer electrochemical system was investigated by the addition of different concentrations of this anionic organic phosphate to a solution of HbS protein and measuring the changes in turbidity. Three concentrations $3 \mathrm{mM}, 5 \mathrm{mM}$, and 100 $\mathrm{mM}$ of 2,3-DPG were used and the results are shown in figure $\mathbf{4 . 8}$.

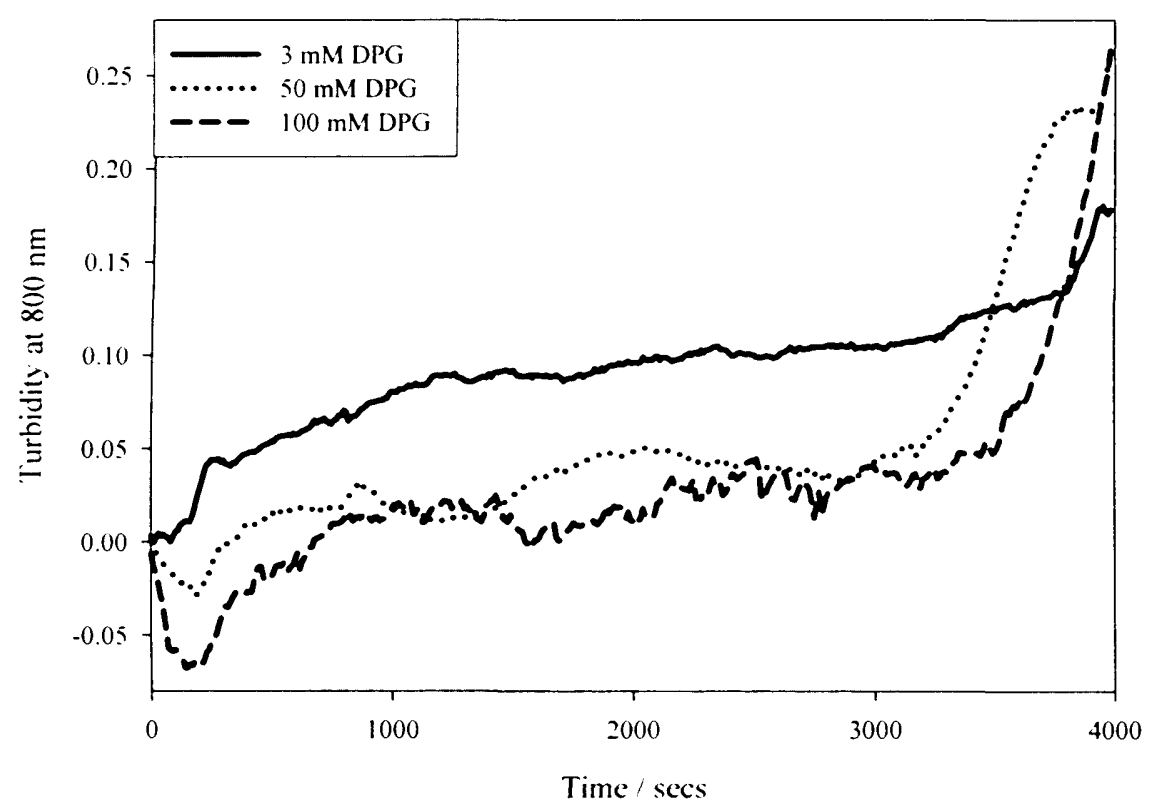

Figure 4.8: UV-visible spectroelectrochemistry time traces of HbS solution containing different concentrations of 2,3-DPG showing changes in turbidity at a bare Au micromesh electrode. Experimental conditions: $\mathrm{HbS}$ concentration $50 \mathrm{mg} \mathrm{cm}^{-3}(0.78 \mathrm{mM})$ in $\mathrm{pH} 7,1.5 \mathrm{M}$ phosphate buffer; 2,3-DPG concentrations $3 \mathrm{mM}, 50 \mathrm{mM}, 100 \mathrm{mM} ; 0.5 \mathrm{M} \mathrm{NaCl}$ : E = - $0.55 \mathrm{~V}$ vs. $\mathrm{Ag} / \mathrm{AgCl}$ for $4500 \mathrm{~s}$.

The results showed that all three 2,3-DPG concentrations had an enormous effect on the aggregation of $\mathrm{HbS}$, as $3 \mathrm{mM} \mathrm{2,3-DPG}$ showed the same turbidity levels as 
$100 \mathrm{mM}$ 2,3-DPG. In vivo $\mathrm{Hb}$ concentration per red blood cell (MCHC) is $320 \mathrm{mg}$ $\mathrm{cm}^{-3}(4.96 \mathrm{mM})$ to $360 \mathrm{mg} \mathrm{cm}^{-3}(5.58 \mathrm{mM})$ and 2,3-DPG is present in human RBCs at about the same molar ratio of $\mathrm{Hb}$ [96]. In our experiments, 2,3-DPG concentrations far greater than the experimental $\mathrm{Hb}$ concentration of $50 \mathrm{mg} \mathrm{cm}^{-3}$ $(0.78 \mathrm{mM})$ was employed, therefore the use of even $3 \mathrm{mM}$ 2,3-DPG would have ensured $\mathrm{Hb}$ binding site saturation. Subsequent increases to $50 \mathrm{mM}$ and $100 \mathrm{mM}$ 2,3-DPG therefore did not exhibit any additional effect. Further experiments need to be performed at concentrations far below saturation levels to investigate the effect of 2,3-DPG on $\mathrm{HbS}$ polymerisation in more detail. 


\subsection{Conclusions}

UV-visible spectroscopy was successfully employed to monitor changes in the nucleation and growth of $\mathrm{HbS}$ aggregates and polymers at the surface of a conducting electrode. It was shown that incorporating a $\mathrm{Au}$ micromesh WE demonstrated significant growth of $\mathrm{HbS}$ protein aggregates at the electrode. Rapid growth of these structures was primarily achieved as a result of the micromesh geometry of the WE which provided an efficient arrangement for $\mathrm{O}_{2}$ depletion within the thin layer electrochemical cell. The extent of polymerisation at the optically transparent electrode was monitored using turbidity measurements which were a measure of the extent of polymer formation at the electrode. The results showed that the rate of change in turbidity followed a sigmoidal pattern with an initial lag period where little increase in turbidity was apparent before large increases, of up to forty fold, were observed in the turbidity. The change in turbidity was shown to be dependent on $\mathrm{HbS}$ polymerisation and not protein precipitation, as shown by important control experiments replacing $\mathrm{HbS}$ for normal non-polymerising $\mathrm{HbA}$.

It was found that the turbidity versus time traces fit the kinetic model for fibre formation well. Kinetic constants were determined for two concentrations of $\mathrm{HbS}$ protein which showed that the nucleation rate was far slower than the growth. A clear concentration dependence was seen with the nucleation rate constant but the effective growth rate did not show significant correlation with $\mathrm{HbS}$ concentration at the Au micromesh cell. Moreover, the effect of DPG was also investigated to optimise conditions for maximal growth of $\mathrm{HbS}$ aggregates at a thin layer electrochemical cell and the results showed that high concentrations of this allosteric effector had a significant effect on the turbidity levels. However, further experiments need to be performed at concentrations of DPG which do not cause saturation to investigate the effect of DPG as a therapeutic agent. This method may not only be used to gain an understanding of the pathophysiology of SCD but also as a screening method for drugs that might lead to novel therapeutic strategies for disrupting nucleation and/or growth in patients with sickle cell crisis. This will be achieved by investigating the effect of new potential compounds, whose mode of action is specific to the disruption of fibre formation, in the electrochemical thinlayer cell. 
Chapter 5: $\underline{\text { HbS Aggregation in Pt Matrix Cell }}$ 


\subsection{Introduction}

In the previous chapter a novel technique was developed which monitored $\mathrm{HbS}$ polymerisation as a change in turbidity by reducing a small volume of $\mathrm{HbS}$ within a custom built thin layer electrochemical cell. A similar technique has been used in this chapter to define the effect of four parameters, $\mathrm{HbS}$ concentration, temperature, solution $\mathrm{pH}$ and ionic strength, on the kinetics and thermodynamics of $\mathrm{HbS}$ gelation in a $\mathrm{Pt}$ matrix electrochemical cell. This cell was the last in the series of electrochemical cells built to modulate electrochemical reduction at the electrode. Theoretical modeling of the depletion of $\mathrm{O}_{2}$ concentration at the matrix electrode, accurately recreated using reference diagrams, is described. Kinetic nucleation and elongation rate constants and the activation energies for deoxyHbS gelation at the Pt surface are presented and the relevance of the double nucleation mechanism at a conducting surface in our electrochemical system is discussed. Although free solution studies of factors affecting $\mathrm{HbS}$ polymerisation have been performed, this is the first known study which has combined electrochemical deoxygenation and protein polymerisation to investigate the effect of different variables on the kinetics of $\mathrm{HbS}$ aggregation at an artificial surface. 


\subsection{Experimental}

\subsubsection{Materials, Instrumentation and Procedures}

The following conditions were employed when investigating each parameter: for HbS concentration, $10 \mathrm{mg} \mathrm{cm}^{-3}, 20 \mathrm{mg} \mathrm{cm}^{-3}, 30 \mathrm{mg} \mathrm{cm}^{-3}, 40 \mathrm{mg} \mathrm{cm}^{-3}, 50 \mathrm{mg} \mathrm{cm}^{-3}$, $75 \mathrm{mg} \mathrm{cm}^{-3}$ and $100 \mathrm{mg} \mathrm{cm}^{-3} \mathrm{HbS}$ were used at a temperature of $38{ }^{\circ} \mathrm{C}$; for investigating temperature dependence, $\mathrm{HbS}$ concentrations of $30 \mathrm{mg} \mathrm{cm}^{-3}$ and 75 $\mathrm{mg} \mathrm{cm}{ }^{-3}$ were each tested at $25^{\circ} \mathrm{C}, 30^{\circ} \mathrm{C}, 34{ }^{\circ} \mathrm{C}, 38^{\circ} \mathrm{C}$ and $42{ }^{\circ} \mathrm{C}$; for $\mathrm{pH}$, phosphate buffer of $\mathrm{pH} 6.8,7.0,7.2,7.4$ and 7.62 at $30 \mathrm{mg} \mathrm{cm}^{-3}$ and $75 \mathrm{mg} \mathrm{cm}^{-3}$ $\mathrm{HbS}$ at $38{ }^{\circ} \mathrm{C}$ were used; whilst for the ionic strength experiments, $0.1 \mathrm{M}, 0.25 \mathrm{M}$, $0.50 \mathrm{M}, 0.75 \mathrm{M}$ and $1.00 \mathrm{M} \mathrm{NaCl}$ were used as the supporting electrolyte for $\mathrm{HbS}$ concentrations of $30 \mathrm{mg} \mathrm{cm}^{-3}$ and $75 \mathrm{mg} \mathrm{cm}^{-3}$ at $38{ }^{\circ} \mathrm{C}$. HbS solutions were made up by dissolving each specific $\mathrm{HbS}$ protein in air-saturated phosphate buffer solution with the addition of $\mathrm{NaCl}$. The UV-visible spectroelectrochemistry experiments were performed according to experimental procedure 6. $\mathrm{HbA}$ was used for the control experiments. Pt sheet (thickness $500 \mu \mathrm{m}$, size $25 \mathrm{~mm} \times 25 \mathrm{~mm}$, temper as rolled, $99.99 \%$ purity), Pt wire (diameter $100 \mu \mathrm{m}$, hard temper, $99.99 \%$ purity) and Ag wire (grade 1, diameter $50 \mu \mathrm{m}$ ) were used as electrodes. All experiments were performed at room temperature unless stated otherwise. Analysis of the results was performed using Sigmaplot, whilst modeling analysis was performed with $\mathrm{Comsol}^{\mathbb{R}}$ software. The general experimental and all apparatus for the above techniques are described in chapter 2 . 


\subsubsection{Construction of the Pt Matrix Thin Layer Electrochemical Cell}

A spectroelectrochemical thin layer cell similar to that described previously was constructed. However, in this case a different WE was used, figure $\mathbf{5 . 1}$ shows a schematic representation of this cell. The WE in this cell consisted of a Pt sheet (3 $\mathrm{mm} \times 4 \mathrm{~mm} \times 0.25 \mathrm{~mm}$ ) in which regular holes of $350 \mu \mathrm{m}$ diameter were drilled in a matrix style array. The distance between each hole was also $350 \mu \mathrm{m}$. A Pt coil (diameter $100 \mu \mathrm{m}$ ) served as the auxiliary electrode whilst all potentials were given versus the quasi-reference electrode $(\mathrm{Ag} / \mathrm{AgCl})$. The three electrodes were connected to copper electrical wires, placed into a $1 \mathrm{~mm}$ pathlength quartz cuvette which had been cut in half and fixed with epoxy resin. The cuvette was cut not only to minimise solution volume but also to have an open ended cell, thus allowing electrodes to be positioned from one end and the solution to be introduced from the other. The cell had a typical total volume of $100 \mu \mathrm{l} \pm 10 \mu \mathrm{l}$. The entire cuvette, except for a small window on the Pt matrix WE (1.0 mm by 1.5 $\mathrm{mm}$ ), was blanked for the light beam.

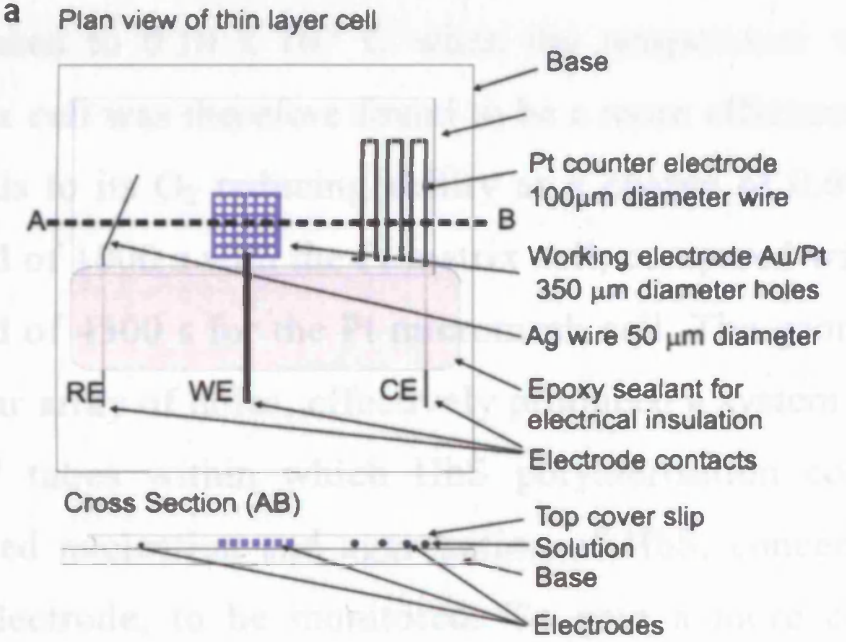

b

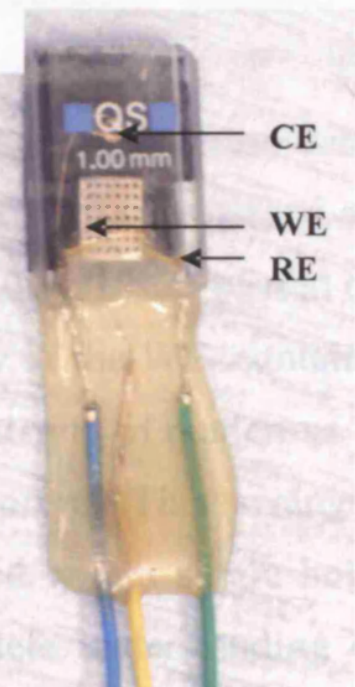

Figure 5.1: Figure showing (a) Schematic plan view and (b) actual image of the Pt matrix thin layer electrochemical cell incorporating a three electrode system with a $\mathrm{Pt}$ sheet in which a regular array of holes of $350 \mu \mathrm{m}$ diameter have been drilled as the WE, a $100 \mu \mathrm{m}$ coil shaped Pt wire CE and a $50 \mu \mathrm{m} \mathrm{Ag}$ wire $\mathrm{RE}$. The $\mathrm{CE}$ coil was composed of ten turns and the $\mathrm{Ag}$ wire was anodised with $\mathrm{AgCl}$ prior to use. The cuvette was attached to a coverslip to form the base for the wires and epoxy sealant. Black tape was fixed to the back of the cell to blank the entire light beam except a small area. Not to scale. 


\subsection{Optimisation of the Pt Matrix Electrochemical Cell}

A Pt matrix thin layer electrochemical cell was fabricated to monitor and provide additional information on the kinetics and thermodynamics of HbS polymerisation at the Pt surface. Coil and micromesh electrode geometries had been used previously but in this cell a $250 \mu \mathrm{m}$ thick Pt sheet was employed as the WE. Optical transparency was achieved by drilling holes of $350 \mu \mathrm{m}$ diameter in a matrix style array into the Pt sheet, whilst a thin layer was obtained by housing the electrodes in a $1 \mathrm{~mm}$ pathlength cuvette which had been cut in half to minimise the solution volume, figure 5.1. The modified cuvette also allowed easy access to the electrodes for cleaning purposes and removal of any air bubbles trapped beneath the WE.

Complete deoxygenation of the solution was confirmed electrochemically by comparing the minimum charge needed to remove all $\mathrm{O}_{2}$ from the Pt matrix cell with the actual experimentally obtained value. The minimum charge required for removal of $\mathrm{O}_{2}$ from a cell of total volume $100 \mu \mathrm{l}$ air-saturated $\mathrm{Hb}$ solution was calculated to be $4.63 \times 10^{-4} \mathrm{C}$, which, compared with the experimentally obtained value of $0.60 \times 10^{-2} \mathrm{C}$ passed over a period of $1000 \mathrm{~s}$ at $25{ }^{\circ} \mathrm{C}$ showed that complete deoxygenation had been achieved. The experimentally obtained value increased to $0.10 \times 10^{-1} \mathrm{C}$ when the temperature was raised to $38{ }^{\circ} \mathrm{C}$. The $\mathrm{Pt}$ matrix cell was therefore found to be a more efficient than the micromesh cell with regards to its $\mathrm{O}_{2}$ reducing ability as a charge of $0.60 \times 10^{-2} \mathrm{C}$ was passed over a period of $1000 \mathrm{~s}$ with the Pt matrix cell, compared with $1.00 \times 10^{-2} \mathrm{C}$ passed over a period of $4500 \mathrm{~s}$ for the Pt micromesh cell. The geometry of the WE, containing a regular array of holes, effectively produced a system consisting of numerous 'stand alone' tubes within which $\mathrm{HbS}$ polymerisation could occur. This arrangement allowed nucleation and aggregation of $\mathrm{HbS}$, concentrated within single holes on the electrode, to be monitored. To gain a more complete understanding of $\mathrm{O}_{2}$ depletion in the Pt matrix cell finite element modeling using $\mathrm{Comsol}^{\mathbb{R}}$ was performed, chapter 5.4. 


\subsection{Modeling of $\mathrm{O}_{2}$ Depletion in the Pt Matrix Thin Layer Cell}

The modeling was performed by Matthew Li (UCL). $\mathrm{O}_{2}$ depletion that occurred at the Pt matrix thin layer electrochemical cell during the experiment was explored by theoretical modeling using $\mathrm{Comsol}^{\mathbb{B}}$ which is based on finite element methods. The thin layer electrochemical cell was accurately recreated in $\mathrm{Comsol}^{\circledR}$ to scale, using reference diagrams and photographs of the electrochemical cell. The model was prepared such that each section of the cell could be explored in detail as shown in Figure 5.2 (a) and (b), and was described by nonlinear-diffusion equation:

\begin{tabular}{|l|l|}
\hline Area & Equation \\
\hline Bulk of the liquid & $\frac{\partial c_{O}}{\partial t}=\nabla \cdot\left(D(x) \nabla c_{O}\right)$ \\
\hline $\begin{array}{l}\text { Insulated areas and liquid } \\
\text { boundaries }\end{array}$ & $D(x) \nabla c_{O} \cdot n=0$ \\
\hline Electrode boundaries & $D(x) \nabla c_{O} \cdot n=N_{O}$ \\
\hline
\end{tabular}

Table 5.1: The bulk and boundary equations used in the model where $\mathrm{c}_{O}, \mathrm{~N}_{O}$ and $\mathrm{D}(x)$ represent the concentration, outward flux of $\mathrm{O}_{2}$ and the function of diffusion as a function of $x$ respectively $[97,98]$.

In the case of the electrode boundaries, the flux was approximated by using the Butler-Volmer equation $[99,100]$ to derive a current, and when the charge of $\mathrm{O}_{2}$ was given, could be used to deduce the depletion of $\mathrm{O}_{2}$. As $\mathrm{O}_{2}$ was the reactant of interest (and was being depleted), the area of the electrode was managed by Comsol $^{\mathbb{B}}$ and the change transfer coefficient, $\alpha$, was taken as 1 , the flux equation was simplified to the following equation:

$$
N_{o}=\frac{-c_{o} \exp \left[\begin{array}{l}
4 F \\
R T
\end{array}\left(E-E^{0 \prime}\right)\right]}{4 F}
$$

The following values were applied to the bulk liquid of the model to simulate the conditions experienced by $\mathrm{O}_{2}$ dissolved in water experimentally: 


\begin{tabular}{|l|l|}
\hline Property & Value \\
\hline Diffusion of $\mathrm{O}_{2}$ & $2.42 \times 10^{-9} \mathrm{~m} \mathrm{~s}^{-1}$ \\
\hline $\mathrm{O}_{2}$ Electrode Potential & $1.23 \mathrm{E}^{\varnothing} \mathrm{V}$ \\
\hline Initial $\mathrm{O}_{2}$ Concentration & $0.3 \mathrm{M}$ \\
\hline Temperature & $298 \mathrm{~K}$ \\
\hline Voltage applied & 2 \\
\hline
\end{tabular}

Table 5.2: Values used to approximate experimental conditions that were applied to the bulk liquid in the model [101].

Although the model was solved for a range of times, the actual time of interest in the experiments performed with the Pt matrix cell was $0 \mathrm{~s}$ to $1000 \mathrm{~s}$ (at $1 \mathrm{~s}$ intervals) and so the results for these are presented. Beyond a $1000 \mathrm{~s}$ there was little change in the results.

Time $=0$ Slice: Concentration, $\mathrm{cO}\left[\mathrm{mol} / \mathrm{m}^{3}\right]$
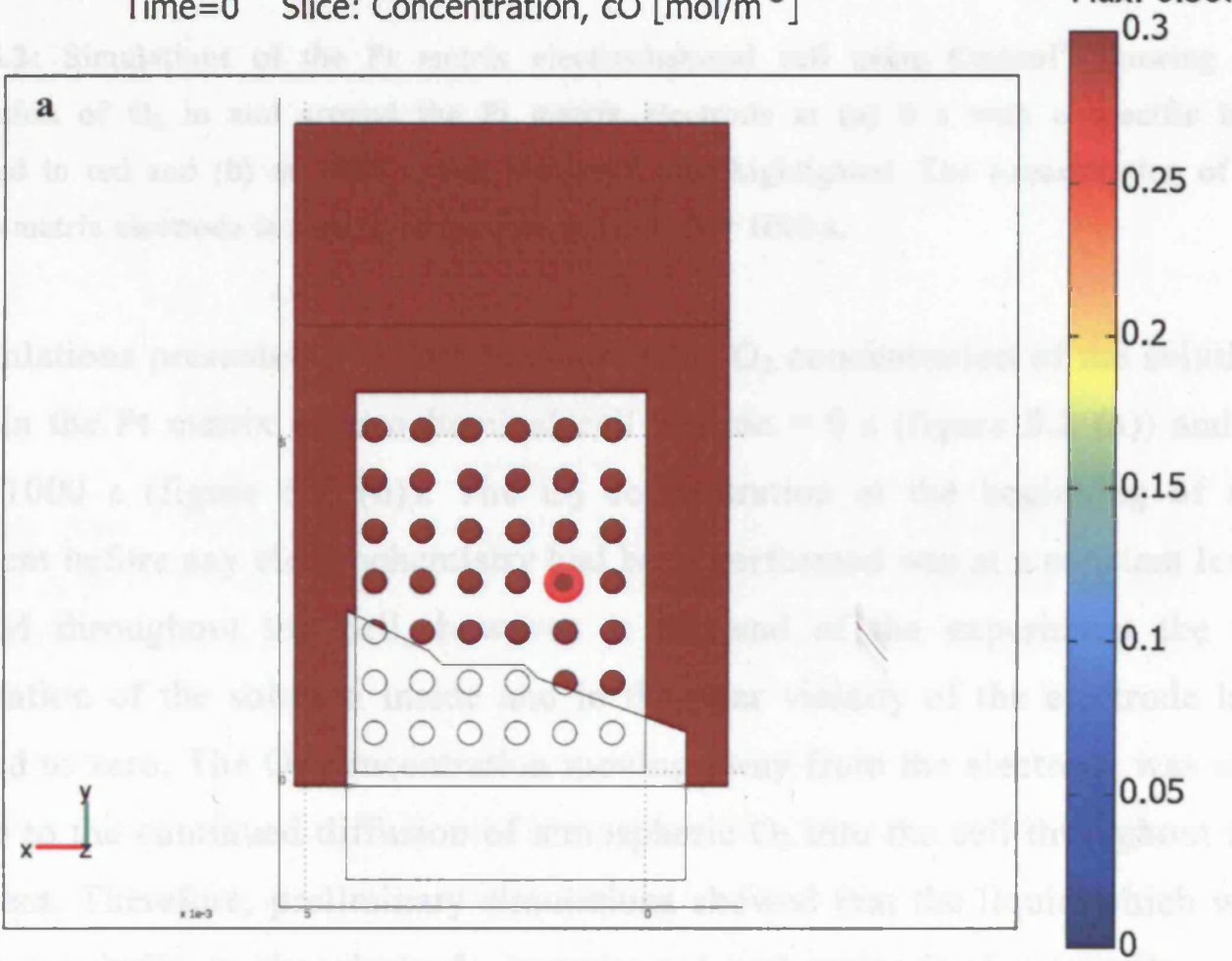

Min: 0 


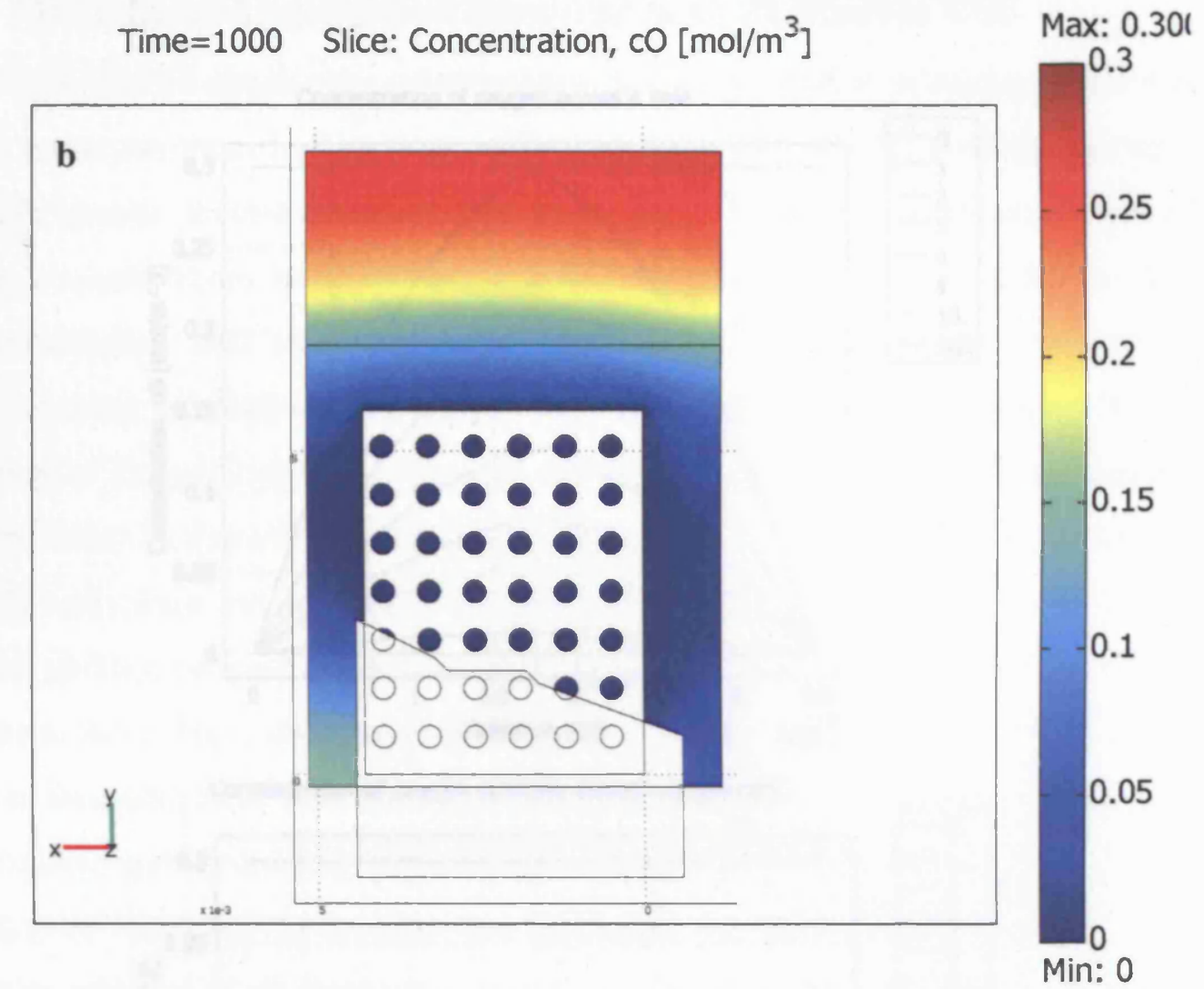

Figure 5.2: Simulations of the Pt matrix electrochemical cell using $\mathrm{Comsol}^{\$}$ showing the concentration of $\mathrm{O}_{2}$ in and around the $\mathrm{Pt}$ matrix electrode at (a) $0 \mathrm{~s}$ with a specific hole highlighted in red and (b) at $1000 \mathrm{~s}$ with sectioned area highlighted. The concentration of $\mathrm{O}_{2}$ inside the matrix electrode is seen to be reduced to zero after $1000 \mathrm{~s}$.

The simulations presented in figure $\mathbf{5 . 2}$ shows the $\mathrm{O}_{2}$ concentration of the solution present in the Pt matrix electrochemical cell at time $=0 \mathrm{~s}$ (figure 5.2 (a)) and at time $=1000 \mathrm{~s}$ (figure 5.2 (b)). The $\mathrm{O}_{2}$ concentration at the beginning of the experiment before any electrochemistry had been performed was at a constant level of $0.3 \mathrm{M}$ throughout the cell, however at the end of the experiment the $\mathrm{O}_{2}$ concentration of the solution inside and in the near vicinity of the electrode had decreased to zero. The $\mathrm{O}_{2}$ concentration moving away from the electrode was still high due to the continued diffusion of atmospheric $\mathrm{O}_{2}$ into the cell throughout the experiment. Therefore, preliminary simulations showed that the liquid which was in close proximity to the electrode experienced and maintained a very low $\mathrm{O}_{2}$ concentration when compared to areas that were not in close contact with the electrode. 

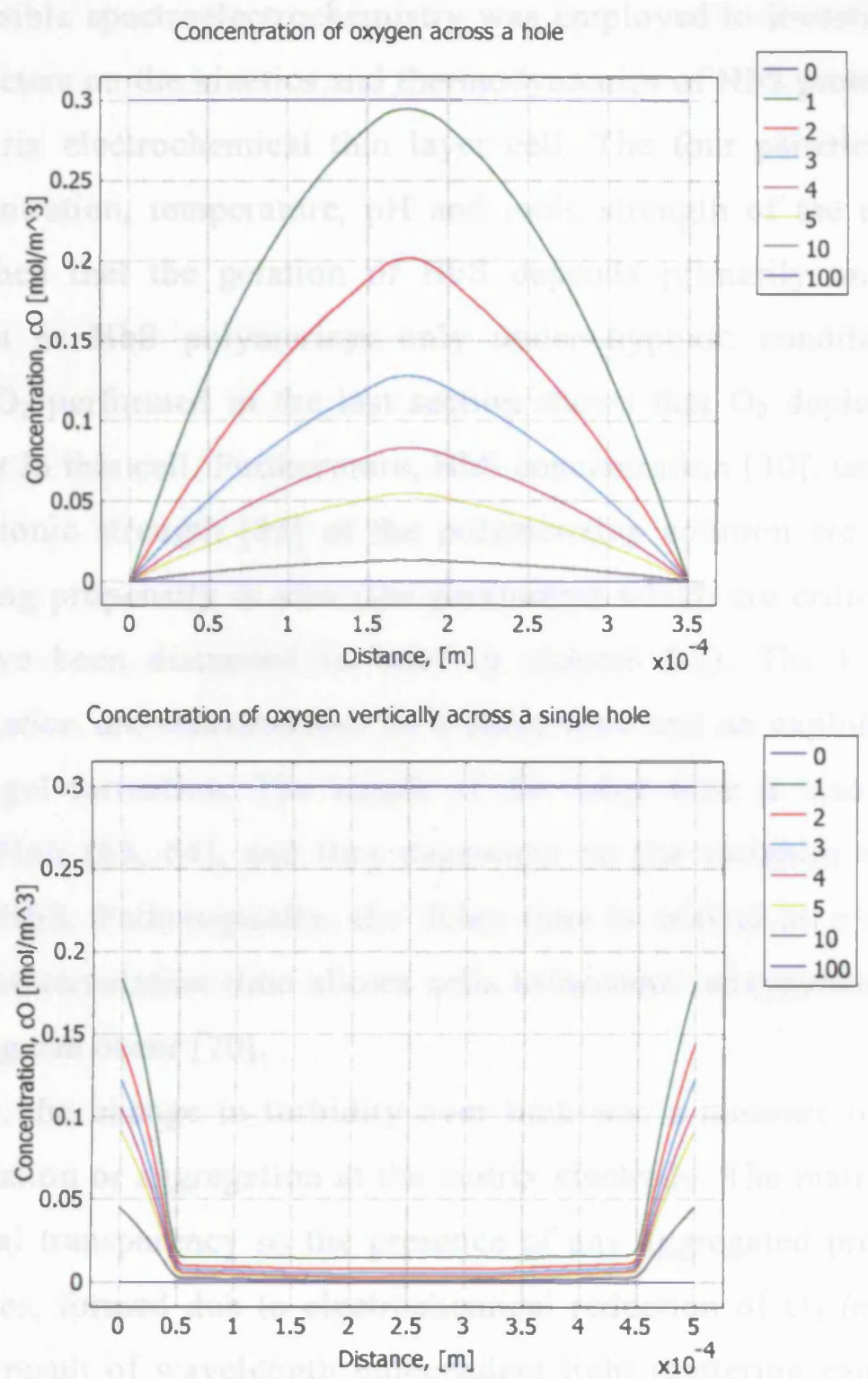

Figure 5.3: Plots showing (a) the change in $\mathrm{O}_{2}$ concentration horizontally across the hole highlighted in figure 5.2 (a) for various times; (b) the change in $\mathrm{O}_{2}$ concentration vertically $5 \mu \mathrm{m}$ away from the electrode and $5 \mu \mathrm{m}$ into the bulk at either end of the hole highlighted in figure $\mathbf{5 . 2}$ (a) at various times

Figures 5.3 (a) and (b) show $\mathrm{O}_{2}$ depletion occurring rapidly within $10 \mathrm{~s}$ and full depletion occurring before $100 \mathrm{~s}$ within a single hole in the matrix electrode. This is consistent with experimental evidence discussed later, that given the right conditions $\mathrm{HbS}$ nucleation can occur within $20 \mathrm{~s}$. From modeling $\mathrm{O}_{2}$ depletion in $\mathrm{Comsol}$ it has been shown the presence of $\mathrm{O}_{2}$ in the experiment is not a limiting factor in fibre formation due to rapid depletion within the cell. 


\subsection{Growth of Aggregated Structures at Pt Matrix Cell}

In situ UV-visible spectroelectrochemistry was employed to investigate the effect of four parameters on the kinetics and thermodynamics of $\mathrm{HbS}$ protein aggregation in the Pt matrix electrochemical thin layer cell. The four parameters were $\mathrm{HbS}$ protein concentration, temperature, $\mathrm{pH}$ and ionic strength of the solution. It has been established that the gelation of $\mathrm{HbS}$ depends primarily on the extent of deoxygenation as $\mathrm{HbS}$ polymerises only under hypoxic conditions [26]. The modeling of $\mathrm{O}_{2}$ performed in the last section shows that $\mathrm{O}_{2}$ depletion was not a limiting factor in this cell. Furthermore, $\mathrm{HbS}$ concentration [30], temperature [35], $\mathrm{pH}$ [28] and ionic strength [85] of the polymerising solution are also known to alter the gelling propensity in vivo (the parameters which are critical for polymer formation have been discussed in brief in chapter 1.2). The kinetics of $\mathrm{HbS}$ polymer formation are characterised by a delay time and an explosive and highly autocatalytic gel formation. The length of the delay time is also related to the solubility of $\operatorname{HbS}[63,64]$, and thus dependent on the variables which alter the solubility of $\mathrm{HbS}$. Pathologically, the delay time is critical as a delay which is longer than the circulation time allows cells to become reoxygenated at the lungs before sickling can occur [70].

In this set-up, the change in turbidity over time was a measure of the extent of polymer formation or aggregation at the matrix electrode. The matrix arrangement allowed optical transparency so the presence of any aggregated protein structures in the apertures, formed due to electrochemical reduction of $\mathrm{O}_{2}$ in situ, could be detected as a result of wavelength independent light scattering caused by protein aggregation. The rate of turbidity change at $600 \mathrm{~nm}, 650 \mathrm{~nm}, 700 \mathrm{~nm}$ and $800 \mathrm{~nm}$ were monitored as a function of time to investigate the kinetics of $\mathrm{HbS}$ aggregation. Turbidity values were determined from the absorbance according to the relation $A=\log \left(I_{\mathrm{o}} / I\right)$, where turbidity $=\left(I_{\mathrm{o}} / I\right)$. Control experiments with $\mathrm{HbA}$ at the same conditions showed no significant turbidity change at the Pt matrix WE especially at the wavelength range $650 \mathrm{~nm}$ to $1100 \mathrm{~nm}$ proving conclusively that any changes in turbidity were due to $\mathrm{HbS}$ protein aggregation (this data is not shown). The blank in these experiments was the HbS solution before the potential was applied, so the spectra shown in the following figures shows the change in turbidity relative to the starting solution. 


\subsubsection{Analysis of Growth Rates}

Two methods were employed to analyse the turbidity profile of each condition and obtain kinetic and thermodynamic values for the nucleation and growth phases of HbS aggregation.

\section{Kinetic Scheme:}

The modified Sabaté et al. [93] kinetic scheme model used in Chapter 4.6 was fitted to the Pt matrix cell data and least squares fitting of equation 4.4 to the turbidity data at $700 \mathrm{~nm}$ was used to obtain $k_{1}$ and $k_{2}$ values for each parameter. However, although a satisfactory to good fitting was obtained for most turbidity profiles (figure $\mathbf{5 . 4}$ (a) shows the fitting of the turbidity profile at $40 \mathrm{mg} \mathrm{cm}^{-3} \mathrm{HbS}$ concentration), some profiles exhibited a poor fit to the kinetic model especially in the early part of the curve due to the lag period for the nucleation phase not being present, figure $\mathbf{5 . 4}$ (b) shows the poor fit obtained for $100 \mathrm{mg} \mathrm{cm}^{-3} \mathrm{HbS}$ concentration. Therefore, in these cases a linear regression method was employed to obtain nucleation and growth rates. The linear regression method was also used for those profiles which exhibited a decrease in the turbidity during the experiment (termed as Phase II, figure 5.5) as the kinetic model could not recognise a decrease in turbidity values further contributing to a poor fitting.
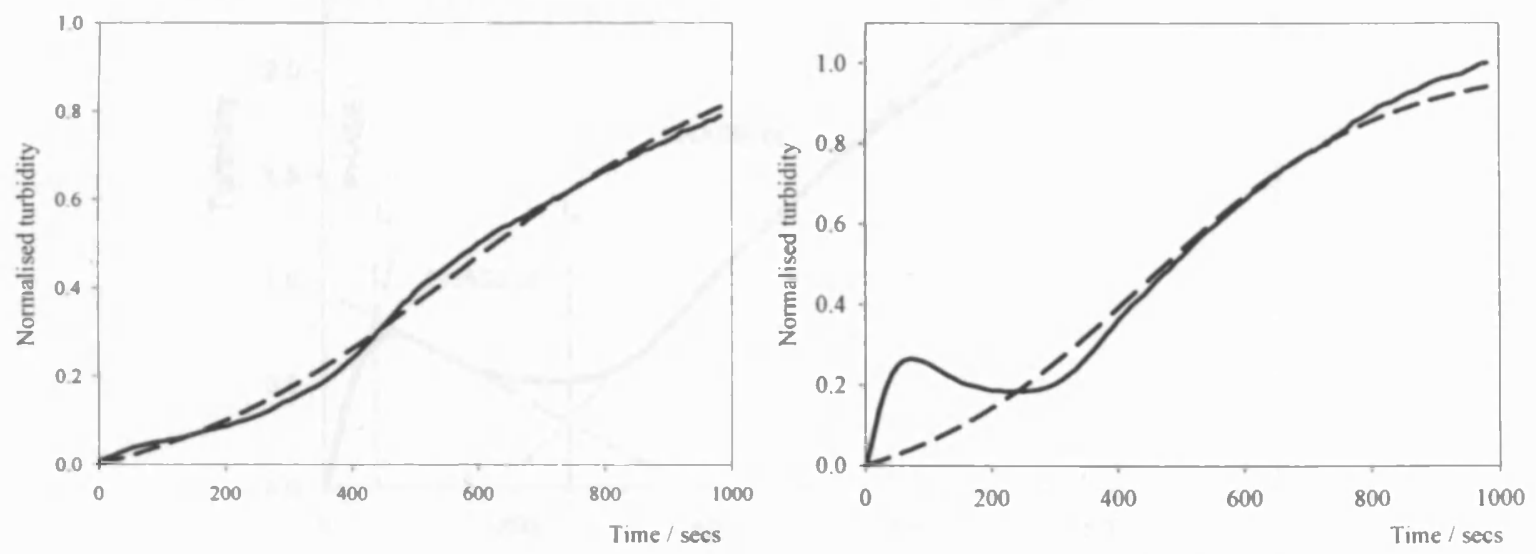

Figure 5.4: Solid lines showing the experimental values of normalised turbidity versus time for (a) $40 \mathrm{mg} \mathrm{cm}^{-3}$, and (b) $100 \mathrm{mg} \mathrm{cm}^{-3}$. The dashed lines are the best-fit lines to equation 4.4. A good fitting to the kinetic model is obtained for $40 \mathrm{mg} \mathrm{cm}^{-3}\left(\mathrm{R}^{2}=0.999\right)$, however, a poor fit is seen for $100 \mathrm{mg} \mathrm{cm}^{-3}\left(\mathrm{R}^{2}=0.935\right)$ mainly due to the absence of the time delay and a large decrease in turbidity after $150 \mathrm{~s}$. 


\section{Linear Regression:}

The linear regression method of analysis was employed to obtain growth rates, specifically for those turbidity profiles which did not satisfactorily fit the two step kinetic scheme model. Figure 5.5 shows a turbidity profile exhibiting the three phases seen experimentally: Phase I is the nucleation phase, Phase II is the intermediary phase and Phase III is the growth or elongation phase. The gradient of best fit was calculated for all phases using a linear regression fit in Sigmaplot, and these values were compared with other matrix cell rate values as well as free solution data. The value of $t_{1}$ and $t_{2}$ indicated the time at which the nucleation phase stopped and the time at which the growth phase commenced respectively, whilst the intercept on the time axis related to the delay time or the time taken for nucleation to start. This analysis was also employed for those turbidity profiles which did not possess the intermediary Phase II. In these cases, only data for Phase I and Phase III were calculated. Unlike the kinetic scheme analysis, this method cannot be used to obtain kinetic rate constants but only nucleation and growth rates.

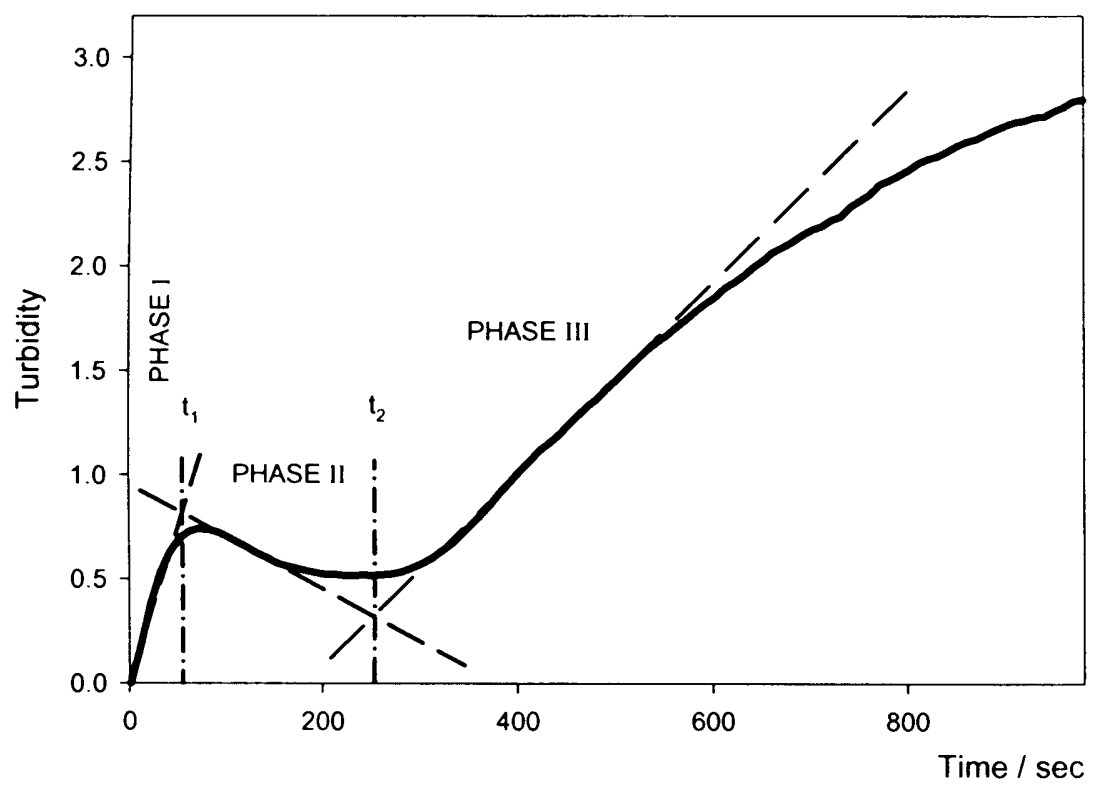

Figure 5.5: Turbidity profile exhibiting the three phases seen experimentally: Phase $I$ is the nucleation phase; Phase II is the intermediary phase; Phase III is the growth phase. The gradient of best fit was calculated using a linear regression fit in Sigmaplot. $t_{1}$ and $t_{2}$ are the times at which the nucleation phase stopped and the time at which the growth phase commenced respectively, whilst the intercept on the time axis relates to the delay time or the time taken for nucleation to start. 


\subsubsection{Effect of Changing HbS Concentration}

The effect of increasing $\mathrm{HbS}$ protein concentration on turbidity, and therefore polymer formation, at a $\mathrm{Pt}$ surface was investigated by performing experiments at protein concentrations of $10 \mathrm{mg} \mathrm{cm}^{-3}, 20 \mathrm{mg} \mathrm{cm}^{-3}, 30 \mathrm{mg} \mathrm{cm}^{-3}, 40 \mathrm{mg} \mathrm{cm}^{-3}, 50 \mathrm{mg}$ $\mathrm{cm}^{-3}, 75 \mathrm{mg} \mathrm{cm}^{-3}$ and $100 \mathrm{mg} \mathrm{cm}^{-3}$ at $38^{\circ} \mathrm{C}$. Figure $\mathbf{5 . 6}$ shows the effect of protein concentration on the rate of turbidity change at a wavelength of $700 \mathrm{~nm}$ (results at wavelength of $700 \mathrm{~nm}$ only are shown, however, all other wavelengths showed a similar trend. A wavelength of $800 \mathrm{~nm}$ was not used as the turbidity at $700 \mathrm{~nm}$ was more pronounced than $800 \mathrm{~nm}$ ).

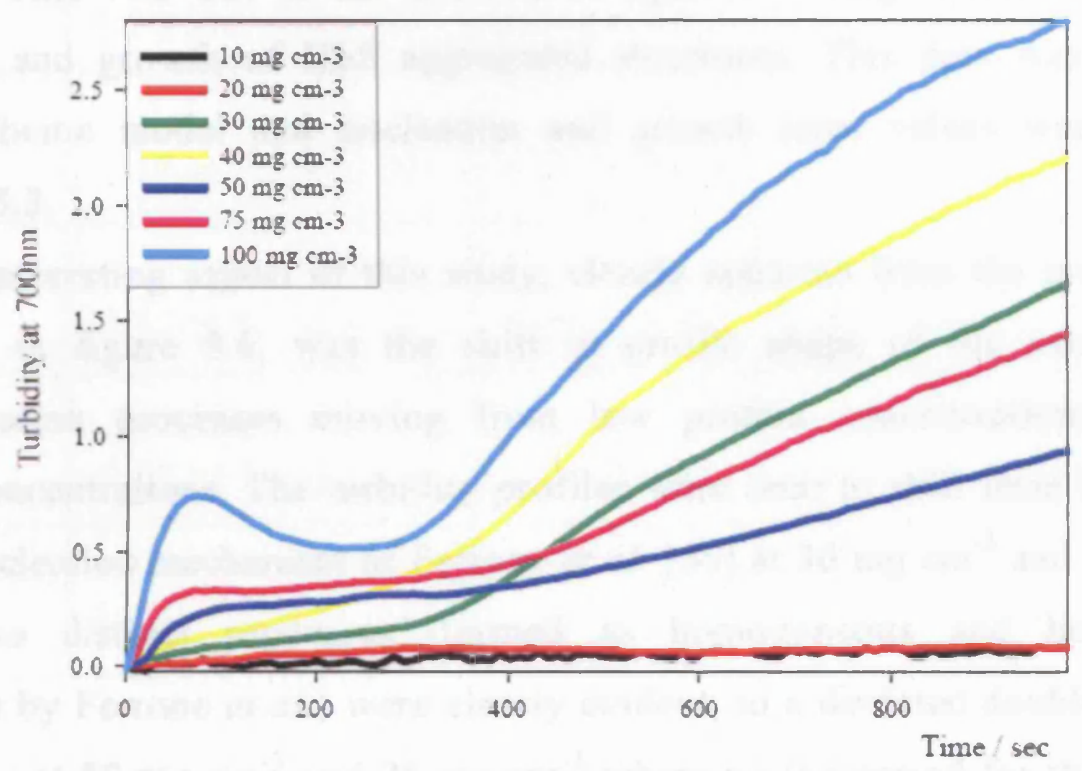

Figure 5.6: UV-visible spectroelectrochemistry time traces showing the changes seen in turbidity levels at $700 \mathrm{~nm}$ at a $\mathrm{Pt}$ matrix electrode with increasing $\mathrm{HbS}$ concentrations. Experimental conditions: $\mathrm{HbS}$ range $10 \mathrm{mg} \mathrm{cm}^{-3}$ to $100 \mathrm{mg} \mathrm{cm}^{-3} ; 1.5 \mathrm{M}$ (pH 7.0) phosphate buffer; $0.5 \mathrm{M} \mathrm{NaCl}$; $\mathrm{T}=38.0 \mathrm{C} ; \mathrm{E}=-0.55 \mathrm{~V} v$ s. $\mathrm{Ag} / \mathrm{AgCl}$; run time $1000 \mathrm{~s}$.

The results showed a clear concentration dependence on the extent of aggregate formation at the $\mathrm{Pt}$ matrix cell. DeoxyHbS aggregation occurred with a clear demonstration of a delay time (the time taken before significant growth was seen) and the results showed that the delay time was prolonged upon dilution of HbS. For instance, the delay time decreased from $250 \mathrm{~s}$ with a protein concentration of $30 \mathrm{mg} \mathrm{cm}^{-3}$ to $230 \mathrm{~s}$ with a slightly higher concentration of $40 \mathrm{mg} \mathrm{cm}^{-3}$, whilst, further increases in protein concentration to $50 \mathrm{mg} \mathrm{cm}^{-3}$ decreased the time delay to only $20 \mathrm{~s}$. At even higher protein concentrations of $75 \mathrm{mg} \mathrm{cm}^{-3}$ and $100 \mathrm{mg} \mathrm{cm}^{-3}$ 
the total disappearance of the time delay was apparent, being instead replaced with a large increase in turbidity as soon as the experiment had begun. Consequently, the kinetics of nucleation at these higher concentrations $\left(75 \mathrm{mg} \mathrm{cm}^{-3}\right.$ and $100 \mathrm{mg}$ $\mathrm{cm}^{-3}$ ) was considered to be too fast to be detected by the spectrophotometer.

The results in figure $\mathbf{5 . 6}$ also demonstrated significant $\mathrm{HbS}$ aggregation with increasing protein concentration. Low protein concentration of $10 \mathrm{mg} \mathrm{cm}^{-3}$ showed little increase in turbidity with a value of only 0.09 being recorded after $1000 \mathrm{~s}$, whilst at a higher concentration of $50 \mathrm{mg} \mathrm{cm}^{-3}$ a turbidity value of 0.94 (an increase of over ten fold) was apparent at the end of the experiment, and a thirty one fold increase (to a value of 2.80) was seen for a protein concentration of 100 $\mathrm{mg} \mathrm{cm}{ }^{-3}$. This was due to an increase in light scattering caused by extensive formation and growth of $\mathrm{HbS}$ aggregated structures. This data was fitted to a kinetic scheme model and nucleation and growth rates values were obtained, section 5.5.3.

Another interesting aspect of this study, clearly apparent from the graphical data presented in figure 5.6, was the shift in profile shape of the nucleation and polymerisation processes moving from low protein concentrations to higher protein concentrations. The turbidity profiles were seen to shift from the classical double nucleation mechanism of Ferrone et al. [66] at $30 \mathrm{mg} \mathrm{cm}^{-3}$ and $40 \mathrm{mg} \mathrm{cm}^{-3}$, where two distinct processes (termed as homogeneous and heterogeneous nucleation by Ferrone et al.) were clearly evident, to a deviated double nucleation mechanism at $50 \mathrm{mg} \mathrm{cm}^{-3}$ and $75 \mathrm{mg} \mathrm{cm}^{-3}$ where no lag period for the nucleation phase was seen but an initial increase in turbidity was followed by growth. However it was the profile at $100 \mathrm{mg} \mathrm{cm}^{-3}$ which was of real interest as an intermediary process (termed as Phase II, figure 5.5), consisting of a decrease in turbidity (from time $100 \mathrm{~s}$ to $300 \mathrm{~s}$ ), was apparent. This was the first time such a process had been seen to the best of our knowledge with regards to monitoring the polymerisation of $\mathrm{HbS}$ at a surface. This was a real life process as shown by the presence of this intermediary phase in repeat experiments and its absence in control experiments at $100 \mathrm{mg} \mathrm{cm}^{-3}$. Reasons for the occurrence of this phase are further alluded to in section 5.6. 


\subsubsection{HbS Concentration Analysis}

\section{Kinetic Scheme Analysis:}

The rate constants for each specific concentration are listed in table 5.3. Rate constants for $10 \mathrm{mg} \mathrm{cm}^{-3}$ and $20 \mathrm{mg} \mathrm{cm}^{-3} \mathrm{HbS}$ were not calculated due to nominal changes in turbidity levels being seen with these two concentrations.

\begin{tabular}{|c|c|c|c|c|}
\hline $\begin{array}{c}\mathrm{HbS} \mathrm{conc.} \\
/ \mathrm{mg} \mathrm{cm}{ }^{-3}\end{array}$ & $k_{1} / \mathrm{s}^{-1}$ & $k_{2} / \mathrm{M}^{-1} \mathrm{~s}^{-1}$ & $a k_{2} / \mathrm{s}^{-1}$ & $\mathrm{R}^{2}$ \\
\hline 30 & $0.28( \pm 0.09) \times 10^{-3}$ & $6.37( \pm 1.22)$ & $2.96( \pm 0.1) \times 10^{-3}$ & 0.988 \\
\hline 40 & $0.37( \pm 0.02) \times 10^{-3}$ & $5.71( \pm 0.16)$ & $3.54( \pm 0.1) \times 10^{-3}$ & 0.999 \\
\hline 50 & $0.36( \pm 0.47) \times 10^{-3}$ & $0.25( \pm 0.25)$ & $0.19( \pm 0.2) \times 10^{-3}$ & 0.926 \\
\hline 75 & $0.40( \pm 0.01) \times 10^{-3}$ & $1.11( \pm 0.17)$ & $1.29( \pm 0.2) \times 10^{-3}$ & 0.942 \\
\hline 100 & $0.14( \pm 0.03) \times 10^{-3}$ & $0.58( \pm 0.05)$ & $4.82( \pm 0.4) \times 10^{-3}$ & 0.935 \\
\hline
\end{tabular}

Table 5.3: Nucleation rate constants $k_{1}$ and elongation rate constants $k_{2}$ to describe the aggregation formation for $\mathrm{HbS}$ concentration in the range $30 \mathrm{mg} \mathrm{cm}^{-3}$ to $100 \mathrm{mg} \mathrm{cm}^{-3}$ at a $\mathrm{Pt}$ matrix electrode. Experiment conditions: $\mathrm{HbS}$ concentrations $30 \mathrm{mg} \mathrm{cm}^{-3}$ to $100 \mathrm{mg} \mathrm{cm}^{-3} ; 1.5 \mathrm{M}$ pH 7.0 phosphate buffer; $0.5 \mathrm{M} \mathrm{NaCl}$; temperature $38^{\circ} \mathrm{C} ; \mathrm{E}=-0.55 \mathrm{~V}$ is. $\mathrm{Ag} / \mathrm{AgCl}$ for $1000 \mathrm{~s}$.

The fit of equation 4.4 to the normalised turbidity data (normalised with the maximum turbidity value of $2.52 \mathrm{seen}$ with $100 \mathrm{mg} \mathrm{cm}^{-3}$ at $1000 \mathrm{~s}$ ) was shown to be extremely good for low protein concentrations such as $30 \mathrm{mg} \mathrm{cm}^{-3}\left(\mathrm{R}^{2}=0.988\right)$ and $40 \mathrm{mg} \mathrm{cm}^{-3}\left(\mathrm{R}^{2}=0.999\right)$ but extremely poor for the higher protein concentrations, $50 \mathrm{mg} \mathrm{cm}^{-3}\left(\mathrm{R}^{2}=0.926\right), 75 \mathrm{mg} \mathrm{cm}^{-3}\left(\mathrm{R}^{2}=0.942\right)$ and $100 \mathrm{mg} \mathrm{cm}^{-3}$ $\left(R^{2}=0.935\right)$.

The rate constants for $30 \mathrm{mg} \mathrm{cm}^{-3}$ and $40 \mathrm{mg} \mathrm{cm}^{-3}$, the two concentrations which did fit the kinetic model well, showed a clear concentration dependence on the 
effective growth rate, $a k_{2}$. The nucleation rate constant $k_{l}$ also showed concentration dependence, however the elongation rate constant $k_{2}$ did not show significant correlation with concentration. This was due to nucleation at a surface being more thermodynamically favourable than growth free in solution. Once again, $k_{1}$ was several orders of magnitude smaller than $k_{2}$ showing that the nucleation process was slower than the growth process and thus the rate limiting step.

The results seen with $30 \mathrm{mg} \mathrm{cm}^{-3}$ and $40 \mathrm{mg} \mathrm{cm}^{-3}$ at the matrix cell were significantly different to those seen with the Au micromesh cell, table 4.1. The $k_{l}$ value for $30 \mathrm{mg} \mathrm{cm}^{-3}\left(2.37( \pm 0.92) \times 10^{-4} \mathrm{~s}^{-1}\right)$ at the matrix electrode was several orders of magnitude greater than even $300 \mathrm{mg} \mathrm{cm}^{-3}\left(9.45( \pm 0.08) \times 10^{-6} \mathrm{~s}^{-1}\right)$ of $\mathrm{Hb}$ at the micromesh cell, whilst a large difference was also seen in the $k_{2}$ values between the two cells. These results indicated that the polymerisation process was far slower in the micromesh cell as compared with the matrix cell. As the modeling of $\mathrm{O}_{2}$ concentration at the matrix electrode has shown total $\mathrm{O}_{2}$ depletion was achieved within $100 \mathrm{~s}$ of the start of the experiment compared to the $200 \mathrm{~s}$ seen for the micromesh cell (figure 2.3)

\section{Linear Regression Analysis:}

Table 5.4 shows linear regression gradient rate data of Phase I, Phase II and Phase III for protein concentrations in the range $30 \mathrm{mg} \mathrm{cm}^{-3}$ to $100 \mathrm{mg} \mathrm{cm}^{-3}$. Again, 10 $\mathrm{mg} \mathrm{cm}^{-3}$ and $20 \mathrm{mg} \mathrm{cm}^{-3}$ were not analysed due to the small changes in turbidity seen at these two concentrations. 


\begin{tabular}{|c|c|c|c|}
\hline $\begin{array}{c}\text { HbS conc. } \\
/ \mathrm{mg} \mathrm{cm}^{-3}\end{array}$ & $\begin{array}{c}\text { Rate of Phase I } \\
/ \mathrm{s}^{-1}\end{array}$ & $\begin{array}{c}\text { Rate of Phase II } \\
/ \mathrm{s}^{-1}\end{array}$ & $\begin{array}{c}\text { Rate of Phase III } \\
/ \mathrm{s}^{-1}\end{array}$ \\
\hline 30 & $0.74( \pm 0.03) \times 10^{-3}$ & & $2.72( \pm 0.04) \times 10^{-3}$ \\
\hline 40 & $1.69( \pm 0.06) \times 10^{-3}$ & & $1.25( \pm 0.05) \times 10^{-3}$ \\
\hline 50 & $5.65( \pm 0.41) \times 10^{-3}$ & & $1.01( \pm 0.01) \times 10^{-3}$ \\
\hline 75 & $11.8( \pm 0.10) \times 10^{-3}$ & $-0.12( \pm 0.04) \times 10^{-3}$ & $1.86( \pm 0.01) \times 10^{-3}$ \\
\hline 100 & $17.8( \pm 0.74) \times 10^{-3}$ & $-2.48( \pm 0.03) \times 10^{-3}$ & $5.11( \pm 0.06) \times 10^{-3}$ \\
\hline
\end{tabular}

Table 5.4: Rate values for Phase I, Phase II and Phase III calculated using linear regression analysis for protein concentration in the range $30 \mathrm{mg} \mathrm{cm}^{-3}$ to $100 \mathrm{mg} \mathrm{cm}^{-3}$ at a $\mathrm{Pt}$ matrix electrode surface. Experiment conditions: $\mathrm{HbS}$ concentrations $30 \mathrm{mg} \mathrm{cm}^{-3}$ to $100 \mathrm{mg} \mathrm{cm}^{-3} ; 1.5 \mathrm{M} \mathrm{pH} 7.0$ phosphate buffer; $0.5 \mathrm{M} \mathrm{NaCl}$; temperature $38^{\circ} \mathrm{C} ; \mathrm{E}=-0.55 \mathrm{~V}$ vs. $\mathrm{Ag} / \mathrm{AgCl}$ for $1000 \mathrm{~s}$.

The results showed a clear concentration dependence on the nucleation phase with the rate values of Phase I becoming steadily faster with increasing concentrations. However, the growth phase or Phase III did not vary considerably with concentration due to the initial nucleation at the surface being more favourable than the growth process. The intermediary Phase II process which consisted of a negative turbidity gradient was only present at two concentrations. The linear regression analysis provided a closer reflection of the experimental data seen in figure 5.6 than the kinetic scheme analysis as a result of the poor fitting obtained for certain concentrations. 


\subsubsection{Effect of Changing Temperature}

In this section the dependence of $\mathrm{HbS}$ fibrillogenesis on temperature at a conducting surface is reported. The effect of a range of $\mathrm{HbS}$ solution temperatures $\left(25{ }^{\circ} \mathrm{C}, 30{ }^{\circ} \mathrm{C}, 34{ }^{\circ} \mathrm{C}, 38{ }^{\circ} \mathrm{C}\right.$ and $\left.42{ }^{\circ} \mathrm{C}\right)$ on the rate of protein aggregation at two $\mathrm{HbS}$ concentrations, $30 \mathrm{mg} \mathrm{cm}^{-3}$ and $75 \mathrm{mg} \mathrm{cm}^{-3}$, were investigated using the $\mathrm{Pt}$ matrix electrochemical cell, figure 5.7.

a

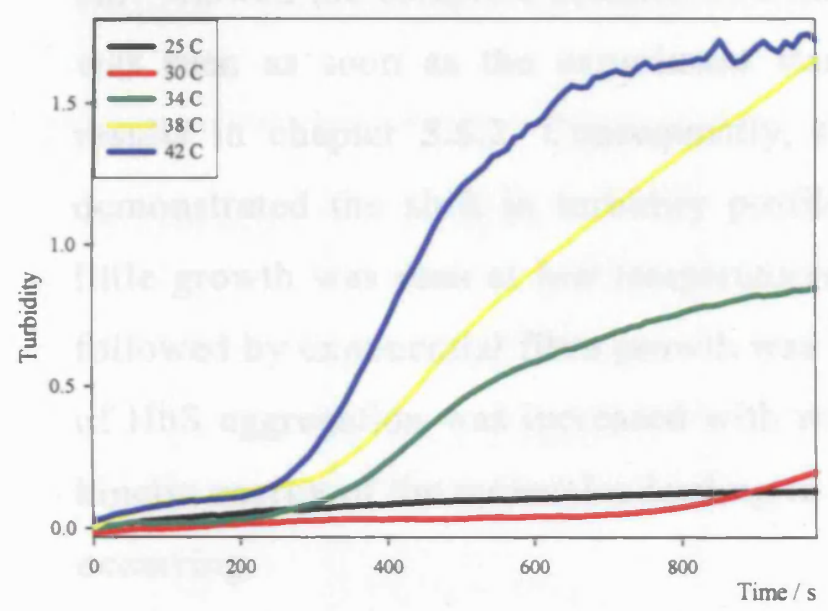

b

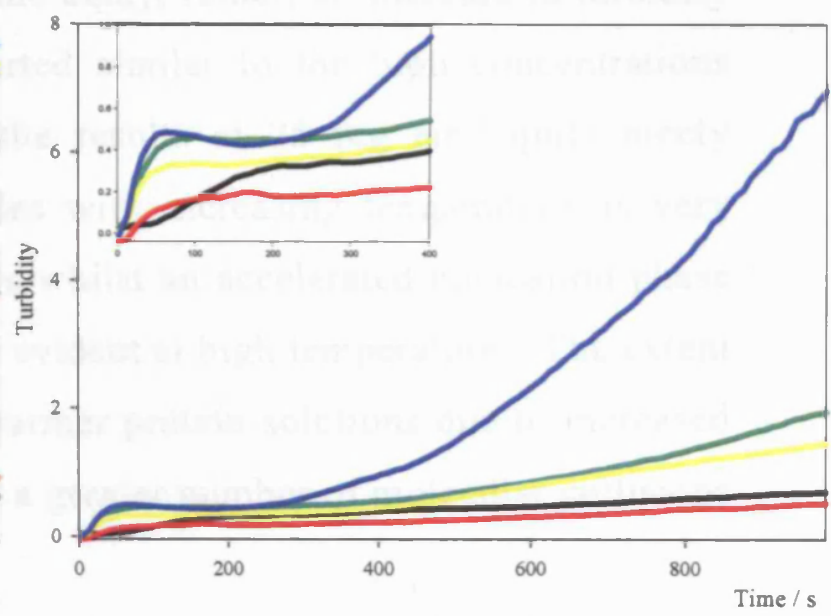

Figure 5.7: UV-visible spectroelectrochemistry time traces showing the changes seen in the turbidity at $700 \mathrm{~nm}$ at the Pt matrix electrode with increasing solution temperature for two $\mathrm{HbS}$ concentrations (a) $30 \mathrm{mg} \mathrm{cm}^{-3}$ and (b) $75 \mathrm{mg} \mathrm{cm}^{-3}$. Experimental conditions: solution temperature range $25{ }^{\circ} \mathrm{C}$ to $42{ }^{\circ} \mathrm{C} ; 1.5 \mathrm{M}$ ( $\mathrm{pH} 7.0$ ) phosphate buffer; $0.5 \mathrm{M} \mathrm{NaCl} ; 38.0{ }^{\circ} \mathrm{C} ; \mathrm{E}=-0.55 \mathrm{~V}$ vs. $\mathrm{Ag} / \mathrm{AgCl}$; run time $1000 \mathrm{~s}$.

For $30 \mathrm{mg} \mathrm{cm}^{-3} \mathrm{HbS}$ concentration (figure 5.7 (a)), a clear temperature dependence on the extent of aggregate formation was demonstrated as increasing the temperature from $25^{\circ} \mathrm{C}$ to above physiological temperature caused a reduction in the time delay and an increase in the turbidity amplitude. For instance, a solution incubated at $30{ }^{\circ} \mathrm{C}$ exhibited a delay of $575 \mathrm{~s}$ whilst at $34{ }^{\circ} \mathrm{C}$ a delay of $290 \mathrm{~s}$ was seen. Further increases in temperature to $42{ }^{\circ} \mathrm{C}$ led to the nucleation lag period occurring even faster with a delay of only $232 \mathrm{~s}$ being seen before the growth period. On the other hand, an increase in solution temperature by $12{ }^{\circ} \mathrm{C}$ (from 30 ${ }^{\circ} \mathrm{C}$ to $42{ }^{\circ} \mathrm{C}$ ) gave rise to an eight-fold increase in the final turbidity value seen at the end of the experiment.

The results obtained for a $\mathrm{HbS}$ concentration of $75 \mathrm{mg} \mathrm{cm}^{-3}$ (figure $\mathbf{5 . 7}$ (b)) did not mirror those seen with $30 \mathrm{mg} \mathrm{cm}^{-3}$. The growth of $\mathrm{HbS}$ aggregates was found to be 
largely dependent on the temperature with a substantial increase in turbidity seen with all temperatures. Increasing solution temperature by $12^{\circ} \mathrm{C}$ from $30^{\circ} \mathrm{C}$ to 42 ${ }^{\circ} \mathrm{C}$ gave rise to a thirteen-fold increase in turbidity from 0.52 to 6.96 respectively, compared to the eight fold increase seen with $30 \mathrm{mg} \mathrm{cm}^{-3}$.

However, the major difference between the two concentrations was the nucleation phase. Whereas a considerable time delay was observed for all temperatures at 30 $\mathrm{mg} \mathrm{cm}{ }^{-3}$, the experiments performed at temperatures of $38{ }^{\circ} \mathrm{C}$ and $42{ }^{\circ} \mathrm{C}$ at $75 \mathrm{mg}$ $\mathrm{cm}^{-3}$ showed the complete absence of a time delay, rather, an increase in turbidity was seen as soon as the experiment started similar to the high concentrations results in chapter 5.5.2. Consequently, the results at $75 \mathrm{mg} \mathrm{cm}^{-3}$ quite nicely demonstrated the shift in turbidity profiles with increasing temperature as very little growth was seen at low temperatures whilst an accelerated nucleation phase followed by exponential fibre growth was evident at high temperatures. The extent of $\mathrm{HbS}$ aggregation was increased with warmer protein solutions due to increased kinetic energy of the molecules leading to a greater number of molecular collisions occurring.

Furthermore, the presence of an intermediary phase, seen previously at $100 \mathrm{mg} \mathrm{cm}^{-}$ 3 in chapter 5.5 .2 (figure 5.6), was apparent once again for the $75 \mathrm{mg} \mathrm{cm}$ cm $^{-3}$ experiment performed at $42{ }^{\circ} \mathrm{C}$. This intermediary process was seen to occur at conditions which were favourable to rapid and accelerated $\mathrm{HbS}$ polymerisation such as at high temperatures and concentrations, or in other words at conditions which were conducive to fast kinetics, see chapter $\mathbf{5 . 6}$ for a discussion concerning the nature of the intermediary phase. The largest increase in polymer aggregation was seen at $42{ }^{\circ} \mathrm{C}$ for both experimental concentrations. This value is in contrast to the free solution literature reported data of $35^{\circ} \mathrm{C}$ where the solubility of $\mathrm{HbS}$ was reported to decrease to a minimum and then increase again at higher temperatures [36]. The difference between the free solution experiment and the conducting surface experiments could be due to differences in the mechanism of protein aggregation at a liquid-liquid interface as compared to liquid-solid interfaces. Further work in the future will be focussed upon investigating the mechanism of action of protein aggregation at various interfaces. 


\subsubsection{Temperature Analysis}

\section{Kinetic Scheme Analysis:}

The rate constants obtained from the turbidity experiments performed with $30 \mathrm{mg}$ $\mathrm{cm}^{-3}$ protein in the temperature range $25{ }^{\circ} \mathrm{C}$ to $42{ }^{\circ} \mathrm{C}$ are listed in table 5.5 . In this set of data, the fit of equation $\mathbf{4 . 4}$ with the normalized turbidity data (normalized with a maximum turbidity value of 1.75 at $42{ }^{\circ} \mathrm{C}$ ) was extremely good for the higher temperatures such as $38{ }^{\circ} \mathrm{C}\left(\mathrm{R}^{2}=0.996\right)$ and $42{ }^{\circ} \mathrm{C}\left(\mathrm{R}^{2}=0.996\right)$, but extremely poor for lower temperatures such as $25{ }^{\circ} \mathrm{C}\left(\mathrm{R}^{2}=0.811\right)$.

\begin{tabular}{|c|c|c|c|c|}
\hline $\begin{array}{c}\text { Temperature } \\
/{ }^{\circ} \mathrm{C}\end{array}$ & $k_{1} / \mathrm{s}^{-1}$ & $k_{2} / \mathrm{M}^{-1} \mathrm{~s}^{-1}$ & $a k_{2} / \mathrm{s}^{-1}$ & $\mathrm{R}^{2}$ \\
\hline 25 & $0.10( \pm 1.29) \times 10^{-3}$ & $0.04( \pm 4.10)$ & $0.02( \pm 0.2) \times 10^{-3}$ & 0.811 \\
\hline 30 & $0.01( \pm 0.002) \times 10^{-3}$ & $8.21( \pm 0.43)$ & $3.82( \pm 0.2) \times 10^{-3}$ & 0.934 \\
\hline 34 & $0.29( \pm 0.05) \times 10^{-3}$ & $4.90( \pm 0.43)$ & $2.28( \pm 0.2) \times 10^{-3}$ & 0.952 \\
\hline 38 & $0.19( \pm 0.01) \times 10^{-3}$ & $12.33( \pm 0.22)$ & $5.73( \pm 0.1) \times 10^{-3}$ & 0.996 \\
\hline 42 & $0.13( \pm 0.01) \times 10^{-3}$ & $21.35( \pm 0.01)$ & $9.93( \pm 0.2) \times 10^{-3}$ & 0.996 \\
\hline
\end{tabular}

Table 5.5: Nucleation rate constants $k_{1}$ and elongation rate constants $k_{2}$ to describe the $\mathrm{HbS}$ aggregation formation for temperatures in the range $25^{\circ} \mathrm{C}$ to $42{ }^{\circ} \mathrm{C}$ for $30 \mathrm{mg} \mathrm{cm}^{-3} \mathrm{HbS}$ at a $\mathrm{Pt}$ matrix electrode. Experiment conditions: $\mathrm{HbS}$ concentration $30 \mathrm{mg} \mathrm{cm}^{-3}$; temperature range $25{ }^{\circ} \mathrm{C}$ to $42{ }^{\circ} \mathrm{C} ; 1.5 \mathrm{M} \mathrm{pH} 7.0$ phosphate buffer; $0.5 \mathrm{M} \mathrm{NaCl} ; \mathrm{E}=-0.55 \mathrm{~V}$ 's. $\mathrm{Ag} / \mathrm{AgCl}$ for $1000 \mathrm{~s}$.

The results seen with those conditions which had a reasonable to good fit (i.e. 34 ${ }^{\circ} \mathrm{C}, 38{ }^{\circ} \mathrm{C}$ and $42{ }^{\circ} \mathrm{C}$ ) showed a significant temperature dependence on the effective growth rate. However, in contrast to the results seen in table 5.3, $k_{1}$ was shown to decrease with increasing temperature $\left(k_{l}\right.$ at $34{ }^{\circ} \mathrm{C}=2.88( \pm 0.5) \times 10^{-4} \mathrm{~s}^{-}$ ${ }^{1} ; k_{1}$ at $\left.42{ }^{\circ} \mathrm{C}=1.28( \pm 0.1) \times 10^{-4} \mathrm{~s}^{-1}\right)$, whilst an $8{ }^{\circ} \mathrm{C}$ increase in temperature from 
$34{ }^{\circ} \mathrm{C}$ to $42{ }^{\circ} \mathrm{C}$ caused a four fold increase in $k_{2}$. This showed that varying temperature had a significant effect on the growth process, more so than just varying the concentration. This was because equilibration of the protein solution with the required temperature before the start of the experiment had probably caused initiation of the polymerisation process even before electrochemical depletion of $\mathrm{O}_{2}$. Experiments performed with $75 \mathrm{mg} \mathrm{cm}^{-3} \mathrm{HbS}$ showed an extremely poor fit of equation $\mathbf{4 . 4}$ to the normalised turbidity data (normalised with a value of 6.96 ) for all temperatures and so no kinetic rate constants were calculated.

\section{Linear Regression Analysis:}

Table 5.6 shows the linear regression gradient data for protein concentration of 30 $\mathrm{mg} \mathrm{cm}{ }^{-3}$ at temperatures of $30^{\circ} \mathrm{C}, 34{ }^{\circ} \mathrm{C}, 38^{\circ} \mathrm{C}$ and $42{ }^{\circ} \mathrm{C}$. No data was obtained for $25^{\circ} \mathrm{C}$ as very little changes in turbidity were seen at this condition. Furthermore, only the rate of Phase I and Phase III were calculated as no intermediary Phase II was present at any of these conditions.

\begin{tabular}{|c|c|c|c|}
\hline $\begin{array}{c}\text { Temperature } \\
/{ }^{\circ} \mathrm{C}\end{array}$ & $\begin{array}{c}\text { Rate of Phase I } \\
/ \mathrm{s}^{-1}\end{array}$ & $\begin{array}{c}\text { Rate of Phase II } \\
/ \mathrm{s}^{-1}\end{array}$ & $\begin{array}{c}\text { Rate of Phase III } \\
/ \mathrm{s}^{-1}\end{array}$ \\
\hline 30 & $0.24( \pm 0.005) \times 10^{-3}$ & & $0.60( \pm 0.01) \times 10^{-3}$ \\
\hline 34 & $0.06( \pm 0.004) \times 10^{-3}$ & & $2.23( \pm 0.01) \times 10^{-3}$ \\
\hline 38 & $1.52( \pm 0.007) \times 10^{-3}$ & & $3.01( \pm 0.02) \times 10^{-3}$ \\
\hline 42 & $0.79( \pm 0.02) \times 10^{-3}$ & & \\
\hline
\end{tabular}

Table 5.6: Rate values for Phase I and Phase III, calculated using linear regression analysis, for temperatures in the range $30{ }^{\circ} \mathrm{C}$ to $42{ }^{\circ} \mathrm{C}$ for $30 \mathrm{mg} \mathrm{cm}^{-3} \mathrm{HbS}$ concentration at a $\mathrm{Pt}$ matrix electrode. Experiment conditions: $\mathrm{HbS}$ concentration $30 \mathrm{mg} \mathrm{cm}^{-3}$; temperature range $30{ }^{\circ} \mathrm{C}$ to 42 ${ }^{\circ} \mathrm{C}$; $1.5 \mathrm{M} \mathrm{pH} 7.0$ phosphate buffer; $0.5 \mathrm{M} \mathrm{NaCl}$; $\mathrm{E}=-0.55 \mathrm{~V}$ vs. $\mathrm{Ag} / \mathrm{AgCl}$ for $1000 \mathrm{~s}$. 
The results did not show a clear temperature dependence on the nucleation Phase I, however there seemed to be a slight correlation between the elongation Phase III and temperature. This correlation between the growth phase and temperature was also evident in the results obtained from the kinetic model fitting, where an increase in $k_{2}$ was seen with increasing temperature.

\begin{tabular}{|c|c|c|c|}
\hline $\begin{array}{c}\text { Temperature } \\
/{ }^{\circ} \mathrm{C}\end{array}$ & $\begin{array}{c}\text { Rate of Phase I } \\
/ \mathrm{s}^{-1}\end{array}$ & $\begin{array}{c}\text { Rate of Phase II } \\
/ \mathrm{s}^{-1}\end{array}$ & $\begin{array}{c}\text { Rate of Phase III } \\
/ \mathrm{s}^{-1}\end{array}$ \\
\hline 30 & $4.74( \pm 0.07) \times 10^{-3}$ & & $0.44( \pm 0.003) \times 10^{-3}$ \\
\hline 34 & $11.90( \pm 0.01) \times 10^{-3}$ & & $1.96( \pm 0.02) \times 10^{-3}$ \\
\hline 38 & $8.21( \pm 0.001) \times 10^{-3}$ & $0.04( \pm 0.03) \times 10^{-3}$ & $1.84( \pm 0.01) \times 10^{-3}$ \\
\hline 42 & $13.20( \pm 1.12) \times 10^{-3}$ & $0.77( \pm 0.02) \times 10^{-3}$ & $10.0( \pm 0.06) \times 10^{-3}$ \\
\hline
\end{tabular}

Table 5.7: Rate values for Phase I, Phase II and Phase III, calculated using linear regression analysis, for temperature in the range $30{ }^{\circ} \mathrm{C}$ to $42{ }^{\circ} \mathrm{C}$ for $75 \mathrm{mg} \mathrm{cm}^{-3} \mathrm{HbS}$ concentration at a $\mathrm{Pt}$ matrix electrode. Experiment conditions: $\mathrm{HbS}$ concentration $75 \mathrm{mg} \mathrm{cm}^{-3}$; temperature range $30{ }^{\circ} \mathrm{C}$ to $42{ }^{\circ} \mathrm{C} ; 1.5 \mathrm{M} \mathrm{pH} 7.0$ phosphate buffer; $0.5 \mathrm{M} \mathrm{NaCl}$; $\mathrm{E}=-0.55 \mathrm{~V}$ vs. $\mathrm{Ag} / \mathrm{AgCl}$ for $1000 \mathrm{~s}$.

The linear regression gradient data for a protein concentration of $75 \mathrm{mg} \mathrm{cm}^{-3}$ is listed in Table 5.7. The rate of Phase III showed significant correlation with temperature as the highest rate was seen at $42{ }^{\circ} \mathrm{C}$, far more so than the rate of the nucleation Phase I which was seen to be similar, possibly again due to polymerisation starting in the water bath even before the start of the experiment. 


\subsubsection{Thermodynamic Calculations}

The $k_{1}$ and $k_{2}$ values for only three temperatures, $34{ }^{\circ} \mathrm{C}, 38{ }^{\circ} \mathrm{C}$ and $42{ }^{\circ} \mathrm{C}$ at $30 \mathrm{mg}$ $\mathrm{cm}^{-3}$ were used for the thermodynamic calculations as the fitting of the kinetic model to these profiles was good. All other temperature data points showed a poor fitting to the kinetic model and with large error values and so the rate constants obtained from these fittings would not have provided accurate thermodynamic values. Therefore, rate constants for $25{ }^{\circ} \mathrm{C}, 30{ }^{\circ} \mathrm{C}$ at $30 \mathrm{mg} \mathrm{cm}^{-3}$ and all temperatures at $75 \mathrm{mg} \mathrm{cm}^{-3}$ were not used in the thermodynamic calculations.

\section{Activation Energies:}

The rate constants were used to calculate activation energies for the nucleation and elongation process using the Arrhenius equation [102]. The Arrhenius equation is an expression that shows the dependence of the rate constant, $k$, of a known chemical reaction on the temperature $\mathrm{T}$ (in kelvins) and activation energy $E_{\mathrm{a}}$ :

$$
k=A e^{-E_{a} / R T}
$$

where $\mathrm{A}$ is the pre-exponential factor or frequency factor and $\mathrm{R}$ is the gas constant. By taking the natural logarithms, the equation yields:

$$
\ln k=\left(\frac{-E_{a}}{R}\right)\left(\frac{1}{T}\right)+\ln A
$$

Therefore, a plot of $\ln k$ vs $1 / \mathrm{T}$ gives a gradient of $-\mathrm{E}_{\mathrm{a}} / \mathrm{R}$ and the slope of the straight line determines the activation energy. From figure 5.8, which shows a plot of the nucleation rate constant as a function of reciprocal temperature, the nucleation activation energy, $E_{1}$, was calculated to be $81.59( \pm 1.22) \mathrm{KJ} \mathrm{mol}^{-1}$. The nucleation activation energy can be defined as the energy required for the sequential addition of monomers to form the critical nuclei, or in other words to make the reaction thermodynamically favourable. 


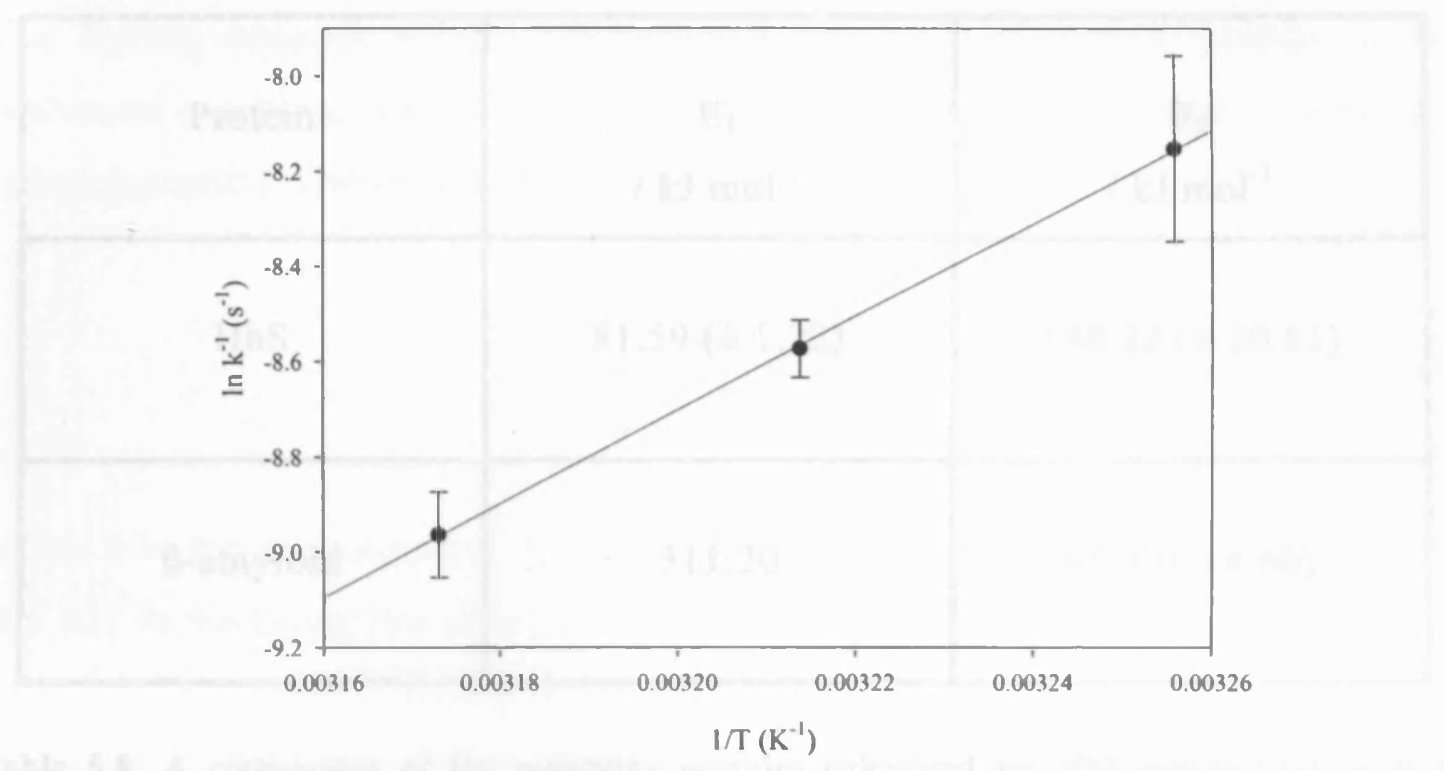

Figure 5.8: A plot of the $\log$ of nucleation rate constant, $\mathbf{k}_{1}$, as a function of reciprocal temperature in kelvin. The gradient of the best fit line which equals $-E_{a} / R$ was $9813.0( \pm 147.2) \mathrm{s}^{-1}$ $\mathrm{K}$ and the intercept was $-4.01( \pm 0.47) \mathrm{s}^{-1}$. Only three temperature data points $\left(34^{\circ} \mathrm{C}, 38^{\circ} \mathrm{C}\right.$ and $42{ }^{\circ} \mathrm{C}$ for $30 \mathrm{mg} \mathrm{cm}^{-3}$ protein concentration) were used as these showed a good fit to the kinetic model. All other temperature values showed a very poor fit to the model and so gave rate constants which had large errors and were not a true reflection of the actual experimentally obtained results.

The elongation activation energy, $E_{2}$, was calculated in a similar manner. A plot of the elongation rate constant as a function of the reciprocal temperature yielded a gradient of $17827.1( \pm 2479) \mathrm{s}^{-1} \mathrm{~K}$, from which $\mathrm{E}_{2}$ was calculated to be $148.22( \pm$ 20.61) $\mathrm{KJ} \mathrm{mol}^{-1}$. Consequently, the elongation activation energy, defined as the energy required for the initiation of the elongation phase, was calculated as requiring nearly twice as much energy as the nucleation phase. It was expected that the nucleation phase would require a larger amount of energy as this process involves the thermodynamically unfavourable sequential addition of free monomers. However, in our system nucleation occurred at a surface rather than free in solution which is more thermodynamically favourable. A comparison of the activation energies calculated for $\mathrm{HbS}$ polymerisation at an electrode surface and the activation energy of $\beta$-amyloid fibrils is shown in table $\mathbf{5 . 8}$. 


\begin{tabular}{|c|c|c|}
\hline Protein & $\begin{array}{c}\mathrm{E}_{1} \\
/ \mathrm{kJ} \mathrm{mol}^{-1}\end{array}$ & $\begin{array}{c}\mathrm{E}_{2} \\
/ \mathrm{kJ} \mathrm{mol}^{-1}\end{array}$ \\
\hline $\mathrm{HbS}$ & $81.59( \pm 1.22)$ & $148.22( \pm 20.61)$ \\
\hline B-amyloid & 311.20 & $95.30( \pm 4.60)$ \\
\hline
\end{tabular}

Table 5.8: A comparison of the activation energies calculated for $\mathrm{HbS}$ polymerisation at an electrode surface with the activation energy of $\beta$-amyloid fibrils. The nucleation activation energy, $E_{1}$ for B-amyloid fibrils was obtained from a study performed by Sabate et al [103]. No error values were provided in their calculations. Experimental conditions: $1 \mathrm{mg}$ B-amyloid protein was dissolved in $500 \mu \mathrm{l} \mathrm{HFIP,} \mathrm{incubated} \mathrm{at} \mathrm{room} \mathrm{temperature} \mathrm{for} 10$ minutes and then Tris-HCl buffer (10 mM, pH 7.4) was added; temperatures assayed from $28.5{ }^{\circ} \mathrm{C}$ to $44.5{ }^{\circ} \mathrm{C}$ at intervals of $4{ }^{\circ} \mathrm{C}$. The elongation activation energy, $E_{2}$ for $\beta$-amyloid fibrils was obtained from a study performed by Kusumoto et al [104]. Experimental conditions: $250 \mu \mathrm{m} \mathrm{B-amyloid} \mathrm{protein} \mathrm{was} \mathrm{dissolved} \mathrm{in} 0.1 \mathrm{M}$ $\mathrm{HCl} \mathrm{pH} 1$ at $4{ }^{\circ} \mathrm{C}$ and the sample was incubated for $4 \mathrm{hrs}$ at $25 \mathrm{C}$; fibrillogenesis was monitored at temperatures of $4{ }^{\circ} \mathrm{C}, 15{ }^{\circ} \mathrm{C}, 25^{\circ} \mathrm{C}$ and $35^{\circ} \mathrm{C}$. The $\mathrm{HbS}$ polymerisation $\mathrm{E}_{1}$ and $\mathrm{E}_{2}$ values were obtained by experiments performed at a $\mathrm{Pt}$ matrix electrode. Experimental conditions: HbS concentration $30 \mathrm{mg} \mathrm{cm}^{-3}$; temperature range $34{ }^{\circ} \mathrm{C}$ to $42{ }^{\circ} \mathrm{C} ; 1.5 \mathrm{M} \mathrm{pH} 7.0$ phosphate buffer; 0.5 $\mathrm{M} \mathrm{NaCl} ; \mathrm{E}=-0.55 \mathrm{~V}$ is. $\mathrm{Ag} / \mathrm{AgCl}$ for $1000 \mathrm{~s}$.

Table 5.8 shows that the $\beta$-amyloid fibril nucleation activation energy was calculated to be nearly three times larger than the value obtained for $\mathrm{HbS}$. The differences in energy values can be explained by the different experimental conditions of protein concentration and $\mathrm{pH}$ used. Moreover, several authors [105108] have also indicated that prior to nucleation the $\beta$-amyloid monomer is activated, through a slow conformational transition from the soluble peptide to the amyloid peptide. Therefore, a larger energy barrier needs to be overcome in this case. This is the first time activation energies of the HbS nucleation and aggregation processes have been calculated at a solid interface. Use of agents which increase the activation energies of these processes could be a good therapeutic strategy for achieving a major reduction in the polymerisation process. 


\section{Eyring Transition State Model:}

The Eyring equation relates the reaction rate to temperature, similar to the Arrhenius equation, and follows on from the transition state theory (activated complex model). The general form of the Eyring equation is:

$$
k=\frac{k_{B} T}{h} e^{-\Delta G^{*} / R T}
$$

where $k$ is the rate constant, $k_{B}$ is the Boltzmann constant, $h$ is Plancks constant and $\Delta G^{*}$ is the Gibbs free energy of activation. It can be rewritten as:

$$
k=\left(\frac{k_{B} T}{h}\right) \exp \left(\frac{\Delta S^{\mp}}{R}\right) \exp \left(\frac{-\Delta H^{\mp}}{R T}\right)
$$

where $\Delta S$ is the entropy of activation and $\Delta H$ is the enthalpy of activation. By taking the natural logarithms the equation becomes:

$$
\ln \left(\frac{k}{T}\right)=\frac{-\Delta H \mp}{R} \cdot \frac{1}{T}+\ln \left(\frac{k_{B}}{h}\right)+\frac{\Delta S \mp}{R}
$$

A plot of $\ln (k / T)$ as a function of reciprocal temperature gives a straight line with gradient $-\Delta H / R$ from which the enthalpy of activation can be derived, and intercept $\ln \left(\mathrm{k}_{\mathrm{B}} / \mathrm{h}\right)+\Delta \mathrm{S} / \mathrm{R}$ from which the entropy of activation can be extrapolated. For the nucleation rate constant, the slope of the straight line was $10124.44( \pm 146.0)$ and the intercept was $-46.85( \pm 0.47)$, figure 5.9. Consequently, the enthalpy of activation for the nucleation process $\Delta H_{1}$ was calculated to be $84.18( \pm 1.21) \mathrm{kJ} \mathrm{mol}^{-1}$, whilst the entropy of activation for the nucleation process $\Delta S_{1}$ was derived to be $-0.59( \pm 0.01) \mathrm{kJ} \mathrm{mol}^{-1} \mathrm{~K}^{-1}$. 


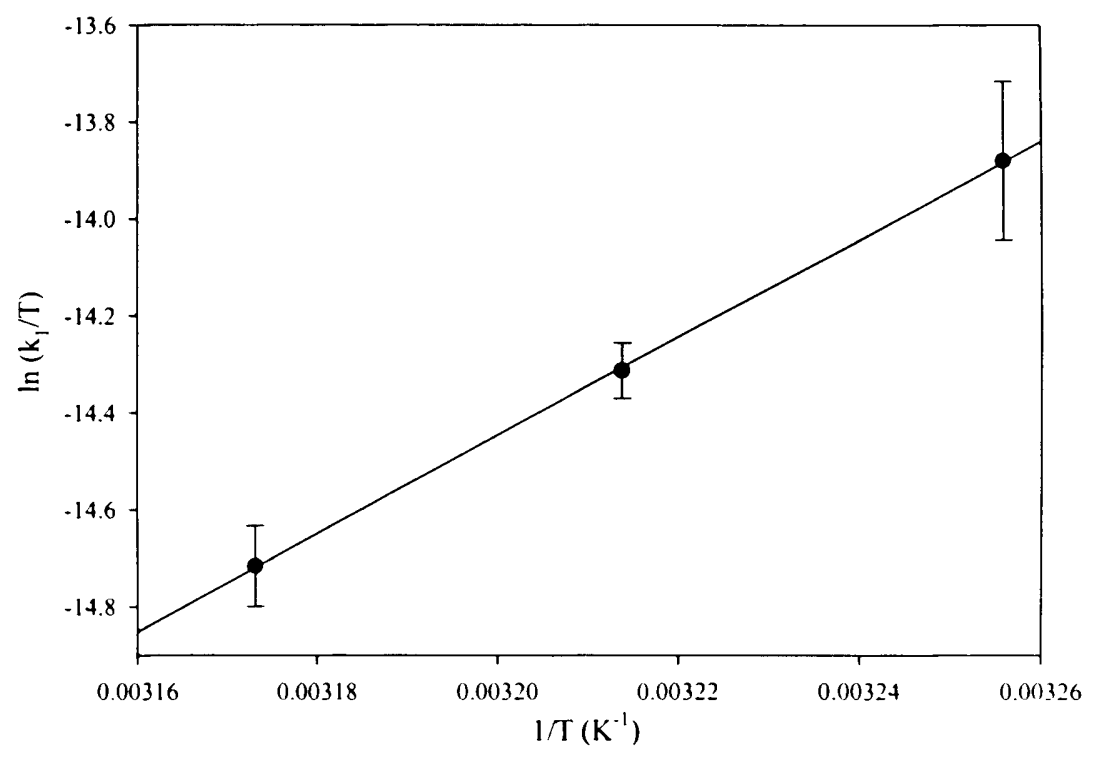

Figure 5.9: A plot of the nucleation rate constant over temperature as a function of reciprocal temperature. The gradient of the best fit line which is equal to $-\Delta H / R$ was $10124.4( \pm 146.0)$ and the intercept $\ln \left(\mathrm{k}_{\mathrm{B}} / \mathrm{h}\right)+\Delta \mathrm{S} / \mathrm{R}$ was $-46.85( \pm 0.47)$. Only three temperature data points $\left(34{ }^{\circ} \mathrm{C}, 38\right.$ ${ }^{\circ} \mathrm{C}$ and $42{ }^{\circ} \mathrm{C}$ for $30 \mathrm{mg} \mathrm{cm}^{-3}$ protein concentration) were used as these showed a good fit to the kinetic model. All other temperature values showed a very poor fit to the model and so gave rate constants which had large errors and were not a true reflection of the actual experimentally obtained results.

The enthalpy of activation, $\Delta H_{2}$, and the entropy of activation, $\Delta S_{2}$, for the elongation phase were graphically derived in the same way using $k_{2}$. Thus, $\Delta H_{2}$ was calculated to be $+145.64( \pm 20.62) \mathrm{kJ} \mathrm{mol}^{-1}$ whilst the $\Delta S_{2}$ was calculated as + $0.24( \pm 0.04) \mathrm{kJ} \mathrm{mol}^{-1} \mathrm{~K}^{-1}$. Furthermore, the Gibbs free energy of activation, $\Delta G$ can also be obtained from the following relationship:

$$
\Delta G=\Delta H-T \Delta S
$$

At physiological temperature of $310 \mathrm{~K}, \Delta G_{1}$ was calculated as $+97.79 \mathrm{~kJ} \mathrm{~mol}^{-1}$ for the nucleation phase, and $+70.31 \mathrm{~kJ} \mathrm{~mol}^{-1}$ for the elongation phase. The experimentally obtained thermodynamic parameters of deoxyHbS polymerisation are summarised in table $\mathbf{5 . 9}$ along with the values for $\beta$-amyloid fibrillation. 


\begin{tabular}{|c|c|c|c|}
\hline $\begin{array}{c}\text { Thermodynamic } \\
\text { Parameters }\end{array}$ & HbS Nucleation & HbS Elongation & B-amyloid \\
\hline $\begin{array}{c}\mathrm{E}_{1} \\
/ \mathrm{kJ} \mathrm{mol}^{-1}\end{array}$ & $81.59( \pm 1.22)$ & & 311.20 \\
\hline $\begin{array}{c}\mathrm{E}_{2} \\
/ \mathrm{kJ} \mathrm{mol}\end{array}$ & & & \\
\hline $\begin{array}{c}\Delta \mathrm{H}^{-1} \\
/ \mathrm{kJ} \mathrm{mol}\end{array}$ & $-84.18( \pm 1.21)$ & $+145.64( \pm 20.62)$ & +308.60 \\
\hline $\begin{array}{c}\Delta \mathrm{G}^{-1} \\
/ \mathrm{kJ} \mathrm{mol}\end{array}$ & $+97.79( \pm 1.21)$ & $+70.31( \pm 20.62)$ & +109.8 \\
\hline$/ \mathrm{kJ} \mathrm{mol} \mathrm{K}^{-1}$ & $-0.59( \pm 0.01)$ & $+0.24( \pm 0.04)$ & +0.641 \\
\hline & & & \\
\hline
\end{tabular}

Table 5.9: A comparison of the thermodynamic parameters for $\mathrm{HbS}$ polymerisation and $\beta$-amyloid fibrillation. HbS polymerisation experimental condition: $\mathrm{HbS}$ concentration $30 \mathrm{mg} \mathrm{cm}^{-3}$ : temperatures $34 \mathrm{C}, 38 \mathrm{C}$ and $42 \mathrm{C}: 1.5 \mathrm{M} \mathrm{pH} 7.0$ phosphate buffer; $0.5 \mathrm{M} \mathrm{NaCl} ; \mathrm{E}=-0.55 \mathrm{~V}$ is. $\mathrm{Ag} / \mathrm{AgCl}$ for $1000 \mathrm{~s}$. B-amyloid fibrillation data obtained from study performed by Sabate et al. [103], see table $\mathbf{5 . 8}$ for experimental conditions.

The summation of the thermodynamic parameters in table $\mathbf{5 . 9}$ shows that the enthalpy of activation $\left(\Delta \mathrm{H}_{1}\right.$ and $\left.\Delta \mathrm{H}_{2}\right)$ is approximately equal to the activation energy ( $E_{1}$ and $E_{2}$ respectively), the conversion of one to the other depends on the molecularity. $\Delta \mathrm{G}$ represents the driving power for a reaction and the sign of $\Delta \mathrm{G}$ determines if the reaction is spontaneous or not. The $\Delta G$ value was relatively constant for both processes. The positive sign for the $\Delta \mathrm{G}$ values shows that the nucleation and elongation processes at the surface were not spontaneous, whilst the negative enthalpy value for nucleation indicated that the reactants, in this case, the formation of the nuclei was more stable than the reactants, the HbS monomers. The 
opposite was seen for the enthalpy of elongation. In comparison, table 5.10 [60] gives a summary of the thermodynamic data obtained for deoxyHbS gelation from scanning calorimetric measurements in the temperature range $15^{\circ} \mathrm{C}$ to $45^{\circ} \mathrm{C}$. It shows that the Gibbs free energy change is relatively constant as the temperature is increased from $15^{\circ} \mathrm{C}$ to $45^{\circ} \mathrm{C}$, whilst in contrast there is a large decrease in enthalpy and entropy as a result of the large change in heat capacity accompanying polymerisation.

\begin{tabular}{|c|c|c|c|c|c|}
\hline Temp $\left({ }^{\circ} \mathrm{C}\right)$ & $\begin{array}{c}C_{\text {sat }} \\
\left(\mathrm{mg} \mathrm{cm}^{-3}\right)\end{array}$ & $\begin{array}{c}K^{b} \\
\left(\mathrm{M}^{-1}\right)\end{array}$ & $\begin{array}{c}\Delta G \\
\left(\mathrm{~kJ} \mathrm{~mol}^{-1}\right)\end{array}$ & $\begin{array}{c}\Delta H^{a} \\
\left(\mathrm{~kJ} \mathrm{~mol}^{-1}\right)\end{array}$ & $\begin{array}{c}T \Delta S \\
\left(\mathrm{~kJ} \mathrm{~mol}^{-1}\right)\end{array}$ \\
\hline 15 & 2140 & 220 & -13.0 & 31.0 & 43.9 \\
\hline 25 & 1760 & 315 & -14.2 & 16.7 & 30.9 \\
\hline 35 & 1620 & 368 & -14.7 & 2.5 & 17.2 \\
\hline 45 & 1740 & 323 & -15.5 & -12.1 & 3.3 \\
\hline
\end{tabular}

Table 5.10: Thermodynamic parameters for deoxy-HbS polymerisation obtained from scanning calorimetric measurements. Experimental conditions: $0.15 \mathrm{M}$ potassium phosphate, $0.05 \mathrm{M}$ sodium dithionite, pH 7.15. 'from van't Hoff analysis of solubility data [60].

Positive enthalpy and entropy changes and the negative heat capacity for polymer formation are characteristic of protein aggregation driven by hydrophobic interactions. These results predict that the intermolecular contacts in the polymer are composed of van der Waals interactions rather than hydrogen bonds or ion-pair bonds. The difference in values between the calorimetric measurements and those obtained from electrochemical modulated growth can be assigned to the different techniques and conditions used $[30,60]$. 


\subsubsection{Effect of Changing $\mathrm{pH}$}

The effect of changing $\mathrm{pH}$ on turbidity was investigated by performing experiments in $\mathrm{pH}$ of $6.80,7.00,7.20,7.40$ and 7.62 at $\mathrm{HbS}$ protein concentrations of $30 \mathrm{mg} \mathrm{cm}^{-3}$ (Figure 5.10 (a)) and $75 \mathrm{mg} \mathrm{cm}^{-3}$ (Figure 5.10 (b)). $0.5 \mathrm{M} \mathrm{NaCl}$ was used as an additive and the experiments was performed at a temperature of $38^{\circ} \mathrm{C}$.

a

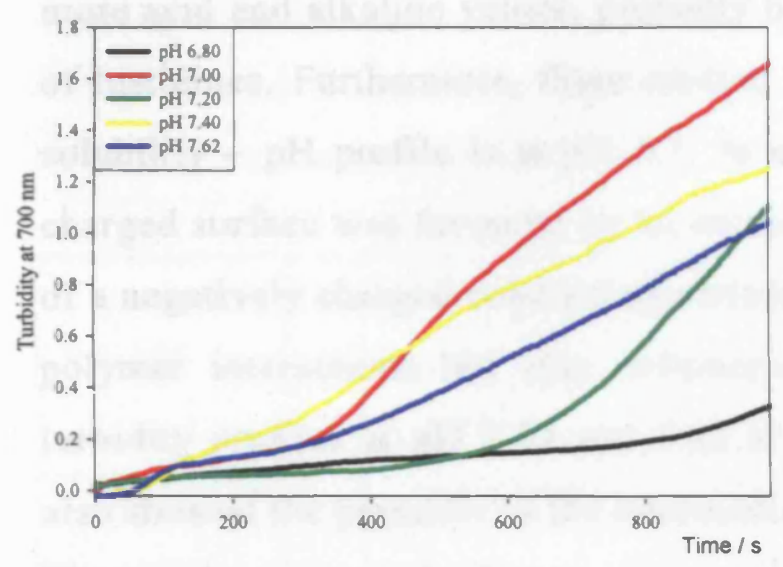

b

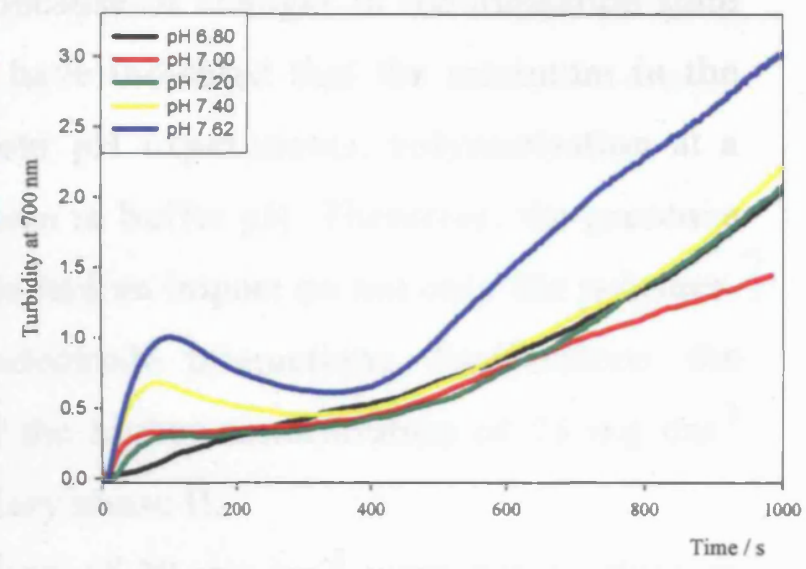

Figure 5.10: UV-visible spectroelectrochemistry time traces showing changes in turbidity at 700 $\mathrm{nm}$ at a Pt matrix electrode with increasing buffer $\mathrm{pH}$ at two $\mathrm{HbS}$ concentrations (a) $30 \mathrm{mg} \mathrm{cm}^{-3}$; (b): $75 \mathrm{mg} \mathrm{cm}^{-3}$; $\mathrm{pH}$ range 6.80 to $7.62 ; 1.5 \mathrm{M}$ phosphate buffer; $0.5 \mathrm{M} \mathrm{NaCl} ; 38.0 \mathrm{C} ; \mathrm{E}=-0.55 \mathrm{~V}$ vs $\mathrm{Ag} / \mathrm{AgCl}$; run time $1000 \mathrm{~s}$.

The aggregation of $\mathrm{HbS}$ was shown to be markedly dependent on the $\mathrm{pH}$ as the results obtained at the higher concentration of $75 \mathrm{mg} \mathrm{cm}^{-3}$ (figure $\mathbf{5 . 1 0}$ (b)) showed protein aggregation was favoured by a slightly alkaline $\mathrm{pH}$ with the extent of polymer nucleation and growth being greatest at $\mathrm{pH}$ levels of 7.62 and 7.40. The results seen at both of these slightly basic pHs showed nucleation occurring immediately with no visible time delay. Furthermore, growth of $\mathrm{HbS}$ fibres at $\mathrm{pH}$ 7.62 reached a turbidity level of 3.00 at the end of the experiment, nearly a third more than that seen at $\mathrm{pH} 7.40$. Acidic $\mathrm{pH}$ of 6.80 was the only data which showed a clear time delay for nucleation at $75 \mathrm{mg} \mathrm{cm}^{-3}$. At a pH of 7.40 and 7.62 monomeric HbS carries approximately 1 negative charge as the isoelectric point of molecular HbA is 6.80 [109], however, the overall net charge of the polymeric protein is not known as the effect of a structural change into an ordered gel-like system of $\mathrm{HbS}$ polymers on the $\mathrm{pI}$ value has not been established. Therefore, the

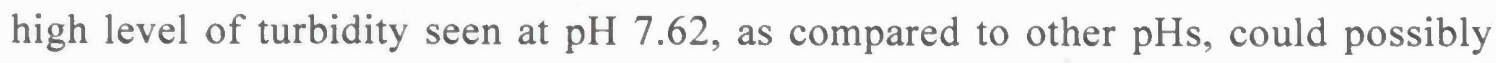


have been due to the stabilisation of $\mathrm{HbS}$ aggregates through a decrease in the net electrostatic repulsion between the polymers. Alternatively, a more basic $\mathrm{pH}$ could have provided greater hydrophobic specific interactions between HbS monomers leading to enhanced polymerisation of $\mathrm{HbS}$ fibres.

Previous free solution studies $[28,29,110,111]$ have shown that aggregation of $\mathrm{HbS}$ is markedly dependent on the $\mathrm{pH}$ (chapter 1.2.2). These studies have shown that the solubility changes very little between $\mathrm{pH} 6$ and 7 but increases sharply at more acid and alkaline values, probably because of changes in the ionisation state of histidines. Furthermore, these studies have indicated that the minimum in the solubility $-\mathrm{pH}$ profile is at $\mathrm{pH}$ 6.5. In our $\mathrm{pH}$ experiments, polymerisation at a charged surface was favoured by an increase in buffer $\mathrm{pH}$. Therefore, the presence of a negatively charged conducting surface had an impact on not only the polymerpolymer interactions but also polymer-electrode interactions. Furthermore, the turbidity profiles at pH 7.40 and 7.62 at the higher concentration of $75 \mathrm{mg} \mathrm{cm}^{-3}$ also showed the presence of the intermediary phase II.

The results seen at the lower concentration of $30 \mathrm{mg} \mathrm{cm}^{-3}$ were not as clear as those for $75 \mathrm{mg} \mathrm{cm}^{-3}$. All data contained a time delay for nucleation before growth was seen whilst a neutral $\mathrm{pH}$ of 7.00 , rather than 7.62 , exhibited the largest increase in turbidity. Acidic $\mathrm{pH}$ of 6.80 once again showed no considerable change in turbidity levels compared to the other results. 


\subsection{8 pH Analysis}

\section{Kinetic Scheme Analysis:}

The fit of equation 4.4 to the $\mathrm{pH}$ turbidity profiles obtained for $30 \mathrm{mg} \mathrm{cm}^{-3}$ was extremely good for all $\mathrm{pH}$ 's $\left(\mathrm{R}^{2}>0.990\right)$ except for $\mathrm{pH} 6.80$, table 5.11. The results showed that alkaline $\mathrm{pH}$ of 7.40 and 7.62 exhibited the largest $k_{1}$ value whilst $\mathrm{pH} 7$ and 7.2 had the largest $k_{2}$ value as shown by the turbidity time profiles seen in figure 5.10 (a). Furthermore, small changes in the $\mathrm{pH}$ gave rise to large variations in the rate constants, for example, a 0.2 unit increase in $\mathrm{pH}$ from 7.2 to 7.4 gave a 2.5 fold decrease in the $k_{1}$ value. The effective growth rate did not show significant correlation with $\mathrm{pH}$.

\begin{tabular}{|c|c|c|c|c|}
\hline $\mathrm{pH}$ & $k_{1}$ & $k_{2}$ & & $a k_{2}$ \\
& $/ \mathrm{s}^{-1}$ & $/ \mathrm{s}^{-1} \mathrm{~s}^{-1}$ & $\mathrm{R}^{2}$ & \\
\hline 6.80 & $0.16( \pm 0.15) \times 10^{-3}$ & $0.31( \pm 0.22)$ & $0.14( \pm 0.10) \times 10^{-3}$ & 0.906 \\
\hline 7.00 & $0.17( \pm 0.01) \times 10^{-3}$ & $13.32( \pm 0.22)$ & $6.19( \pm 0.10) \times 10^{-3}$ & 0.995 \\
\hline 7.20 & $0.02( \pm 0.001) \times 10^{-3}$ & $14.51( \pm 0.22)$ & $6.75( \pm 0.10) \times 10^{-3}$ & 0.991 \\
\hline 7.40 & $0.48( \pm 0.02) \times 10^{-3}$ & $5.80( \pm 0.03)$ & $2.70( \pm 0.10) \times 10^{-3}$ & 0.997 \\
\hline 7.62 & $0.25( \pm 0.003) \times 10^{-3}$ & $6.27( \pm 0.03)$ & $2.92( \pm 0.01) \times 10^{-3}$ & 0.998 \\
\hline
\end{tabular}

Table 5.11: Nucleation rate constants $k_{1}$ and elongation rate constants $k_{2}$ to describe the HbS aggregation formation for $\mathrm{pH}$ in the range 6.8 to 7.62 at $30 \mathrm{mg} \mathrm{cm}^{-3}$ at the $\mathrm{Pt}$ matrix electrode. Experiment conditions: $\mathrm{HbS} 30 \mathrm{mg} \mathrm{cm}^{-3}$; $\mathrm{pH} 6.8$ to $7.62 ; 1.5 \mathrm{M} \mathrm{pH} 7$ phosphate buffer; $0.5 \mathrm{M}$ $\mathrm{NaCl} ; 38^{\circ} \mathrm{C} ; \mathrm{E}=-0.55 \mathrm{~V}$ is. $\mathrm{Ag} / \mathrm{AgCl}$ for $1000 \mathrm{~s}$.

The fit of equation 4.4 to the turbidity profiles obtained from experiments performed at $75 \mathrm{mg} \mathrm{cm}^{-3}$ was extremely poor for all $\mathrm{pH}$ values and so rate constants were not calculated. This was due to a rapid increase in turbidity seen at the start of the experiment coupled with the decrease in turbidity seen during phase II. 


\section{Linear Regression Analysis:}

Table 5.12 shows the Phase I and Phase III linear regression data for $\mathrm{pHs} 6.8,7$, $7.2,7.4$ and 7.62 obtained for a protein concentration of $30 \mathrm{mg} \mathrm{cm}^{-3}$. It was seen that $\mathrm{pH} 7.62$ showed the fastest phase I rate with a value more than twice that seen for other pHs. The rate of phase I for pHs 7.00, 7.30 and 7.40 were similar whilst pH 6.80 exhibited the slowest rate. The rates of Phase III however did not follow this pattern; the rate values for $\mathrm{pH} 7$ and 7.2 were seen to be far greater than $\mathrm{pH}$ 7.62 whilst acidic $\mathrm{pH}$ of 6.8 once again exhibited the slowest rate. No general trend was seen for either Phase I or Phase III with $30 \mathrm{mg} \mathrm{cm}^{-3}$ protein.

\begin{tabular}{|c|c|c|c|}
\hline Solution $\mathrm{pH}$ & $\begin{array}{c}\text { Rate of Phase I } \\
/ \mathrm{s}^{-1}\end{array}$ & $\begin{array}{c}\text { Rate of Phase II } \\
/ \mathrm{s}^{-1}\end{array}$ & $\begin{array}{c}\text { Rate of Phase III } \\
/ \mathrm{s}^{-1}\end{array}$ \\
\hline 6.8 & $0.30( \pm 0.008) \times 10^{-3}$ & & $0.77( \pm 0.007) \times 10^{-3}$ \\
\hline 7.0 & $0.73( \pm 0.04) \times 10^{-3}$ & & $2.90( \pm 0.03) \times 10^{-3}$ \\
\hline 7.2 & $0.61( \pm 0.02) \times 10^{-3}$ & & $2.85( \pm 0.005) \times 10^{-3}$ \\
\hline 7.4 & $0.49( \pm 0.03) \times 10^{-3}$ & & $1.70( \pm 0.009) \times 10^{-3}$ \\
\hline 7.62 & $1.75( \pm 0.02) \times 10^{-3}$ & & $1.29( \pm 0.002) \times 10^{-3}$ \\
\hline
\end{tabular}

Table 5.12: Rate values for Phase I and Phase III, calculated using linear regression analysis, for $\mathrm{pH}$ in the range 6.8 to 7.62 for $30 \mathrm{mg} \mathrm{cm}^{-3} \mathrm{HbS}$ concentration at a Pt matrix electrode. Experiment conditions: $\mathrm{HbS}$ concentration $30 \mathrm{mg} \mathrm{cm}^{-3}$; $\mathrm{pH}$ range 6.8 to $7.62 ; 1.5 \mathrm{M} \mathrm{pH} 7.0$ phosphate buffer; $0.5 \mathrm{M} \mathrm{NaCl}$; temperature $38^{\circ} \mathrm{C} ; \mathrm{E}=-0.55 \mathrm{~V}$ vs. $\mathrm{Ag} / \mathrm{AgCl}$ for $1000 \mathrm{~s}$.

The $\mathrm{pH}$ linear regression data for $75 \mathrm{mg} \mathrm{cm}^{-3}$ is listed in table 5.13. Both Phase I and Phase III rate values were seen to increase with an increase in $\mathrm{pH}$. The fastest Phase I rates were seen with the slightly alkaline $\mathrm{pH}$ of $7.4\left(22.4( \pm 0.25) \times 10^{-3} \mathrm{~s}^{-}\right.$ $\left.{ }^{1}\right)$ and $7.62\left(22.2( \pm 0.02) \times 10^{-3} \mathrm{~s}^{-1}\right)$ whilst the slowest was pH $6.8(1.18( \pm 0.01) \times$ $10^{-3} \mathrm{~s}^{-1}$ ); Phase I rate for $\mathrm{pH} 6.8$ was shown to be ten times smaller than the rate 
value for $\mathrm{pH} 7$ whilst eighteen times smaller than the rate value for $\mathrm{pH} 7.62$. However, although a general trend of an increase in rate was seen with increasing $\mathrm{pH}$ for Phase III, only a small difference was seen as the rate of $\mathrm{pH} 7.62$ was only two and a half fold greater than the rate of $\mathrm{pH} \mathrm{6.8.} \mathrm{The} \mathrm{rates} \mathrm{of} \mathrm{Phase} \mathrm{II,} \mathrm{only}$ calculated for $\mathrm{pH} 7.4$ and 7.62 , showed a $0.6( \pm 0.01) \mathrm{ms}^{-1}$ decrease with a 0.22 increase in $\mathrm{pH}$ unit.

\begin{tabular}{|c|c|c|c|}
\hline Solution pH & $\begin{array}{c}\text { Rate of Phase I } \\
/ \mathrm{s}^{-1}\end{array}$ & $\begin{array}{c}\text { Rate of Phase II } \\
/ \mathrm{s}^{-1}\end{array}$ & $\begin{array}{c}\text { Rate of Phase III } \\
/ \mathrm{s}^{-1}\end{array}$ \\
\hline 6.8 & $1.18( \pm 0.01) \times 10^{-3}$ & & $1.90( \pm 0.01) \times 10^{-3}$ \\
\hline 7.0 & $12.00( \pm 0.01) \times 10^{-3}$ & & $1.92( \pm 0.01) \times 10^{-3}$ \\
\hline 7.2 & $8.01( \pm 0.14) \times 10^{-3}$ & & $2.69( \pm 0.02) \times 10^{-3}$ \\
\hline 7.4 & $22.4( \pm 0.25) \times 10^{-3}$ & $-1.84( \pm 0.04) \times 10^{-3}$ & $2.00( \pm 0.01) \times 10^{-3}$ \\
\hline 7.62 & $22.20( \pm 0.02) \times 10^{-3}$ & $-2.43( \pm 0.13) \times 10^{-3}$ & $4.59( \pm 0.01) \times 10^{-3}$ \\
\hline
\end{tabular}

Table 5.13: Rate values for Phase I, Phase II and Phase III, calculated using linear regression analysis, for $\mathrm{pH}$ in the range 6.8 to 7.62 for $75 \mathrm{mg} \mathrm{cm}^{-3} \mathrm{HbS}$ concentration at a Pt matrix electrode surface. Experiment conditions: $\mathrm{HbS}$ concentration $75 \mathrm{mg} \mathrm{cm}^{-3} ; \mathrm{pH}$ range 6.8 to $7.62 ; 1.5 \mathrm{M} \mathrm{pH}$ 7.0 phosphate buffer; $0.5 \mathrm{M} \mathrm{NaCl}$; temperature $38 \mathrm{C} ; \mathrm{E}=-0.55 \mathrm{~V} v$ s. $\mathrm{Ag} / \mathrm{AgCl}$ for $1000 \mathrm{~s}$. 


\subsubsection{Effect of Changing Salt Concentration}

The effect of changing salt concentration or ionic strength on HbS gelation was investigated by performing experiments at varying $\mathrm{NaCl}$ concentrations $(0.10 \mathrm{M}$, $0.25 \mathrm{M}, 0.50 \mathrm{M}, 0.75 \mathrm{M}$ and $1.0 \mathrm{M}$ ) at $\mathrm{HbS}$ concentrations of $30 \mathrm{mg} \mathrm{cm}^{-3}$ (figure 5.11 (a)) and $75 \mathrm{mg} \mathrm{cm}^{-3}$ (figure 5.11 (b)). Turbidity changes at the Pt matrix were monitored at a temperature of $38^{\circ} \mathrm{C}$.

a

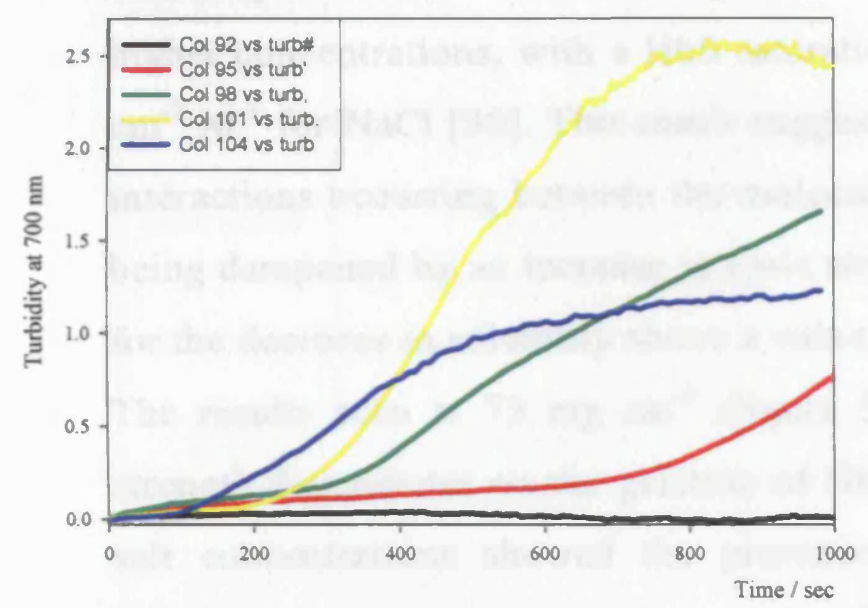

b

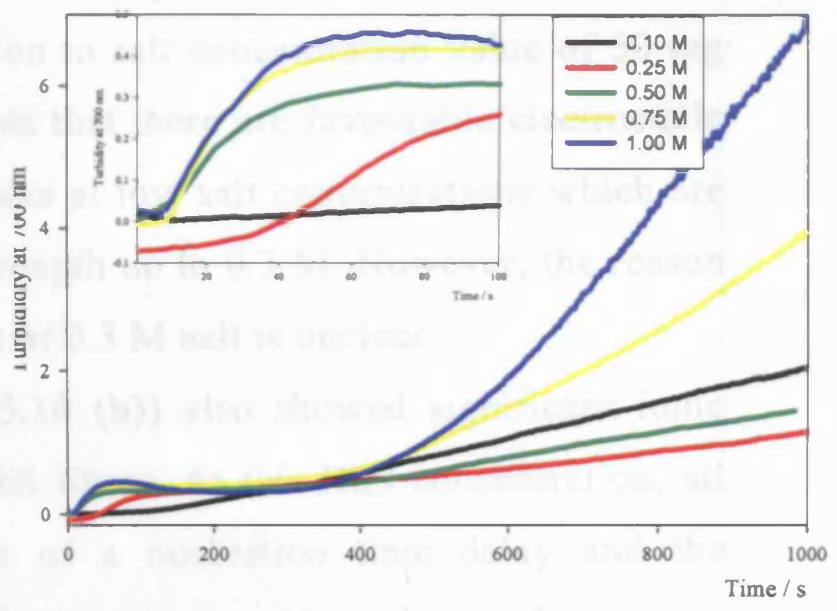

Figure 5.11: UV-visible spectroelectrochemistry time traces showing changes in turbidity at 700 $\mathrm{nm}$ in a $\mathrm{Pt}$ matrix cell with increasing $\mathrm{NaCl}$ concentration at two $\mathrm{HbS}$ concentrations (a) $30 \mathrm{mg}$ $\mathrm{cm}^{-3}$; (b) $75 \mathrm{mg} \mathrm{cm}^{-3} ; \mathrm{NaCl}$ range $0.10 \mathrm{M}$ to $1.00 \mathrm{M} ; 1.5 \mathrm{M}$ (pH 7.0) phosphate buffer; $38.0 \mathrm{C} ; \mathrm{E}=$ $-0.55 \mathrm{~V}$ vs. $\mathrm{Ag} / \mathrm{AgCl}$; run time $1000 \mathrm{~s}$.

The results seen at $30 \mathrm{mg} \mathrm{cm}$ showed that $\mathrm{NaCl}$ salt concentration had a marked effect on $\mathrm{HbS}$ fibre formation. Increasing salt concentration in the range $0.25 \mathrm{M}$ to $1.00 \mathrm{M}$ decreased the time delay from nearly $620 \mathrm{~s}$ at $0.25 \mathrm{M}$ to $90 \mathrm{~s}$ at $1.00 \mathrm{M}$. Furthermore, the turbidity amplitude also increased as the salt concentration was increased up to $0.75 \mathrm{M}$. A further increment to $1.00 \mathrm{M}$, however, slightly inhibited gelation. Although the shortest time delay was apparent with $1.00 \mathrm{M} \mathrm{NaCl}$, the largest turbidity at the end of the experiment was seen with a concentration of 0.75 $\mathrm{M}$, meaning that different factors were influencing the two distinct nucleation and growth pathways. A salting-in effect occurs at low salt concentrations where the solubility of protein is increased slightly due to the $\mathrm{Hb}$ protein being screened by the salt counter ions (ions of opposite net charge). This results in decreased electrostatic free energy of the protein and increased activity of the solvent, thus leading to increased solubility. At higher salt concentrations, a salting-out effect, 
where the solvating power of the salt ions is decreased due to the abundance of the salt ions, leads to the solubility of the proteins being decreased also. Consequently, a significant increase in polymer growth was seen at the higher salt concentrations as compared to the lower concentrations.

Literature studies of salt effects have shown that the effect of ionic strength on the aggregation and growth of $\mathrm{HbS}$ depends on the particular salt and concentration of salt used $[85,111]$. For the sodium and potassium salts of monovalent anions, the solubility increases with increasing concentration up to $0.3 \mathrm{M}$ but then decreases at higher concentrations, with a $\mathrm{HbS}$ saturation to salt concentration value of $50 \mathrm{mg}$ $\mathrm{cm}^{-3} \mathrm{M}^{-1}$ for $\mathrm{NaCl}$ [30]. This result suggests that there are favourable electrostatic interactions occurring between the molecules at low salt concentrations which are being dampened by an increase in ionic strength up to $0.3 \mathrm{M}$. However, the reason for the decrease in solubility above a value of $0.3 \mathrm{M}$ salt is unclear.

The results seen at $75 \mathrm{mg} \mathrm{cm}^{-3}$ (figure $\mathbf{5 . 1 0}$ (b)) also showed significant ionic strength dependence on the gelation of $\mathrm{HbS}$ fibres. At this HbS concentration, all salt concentrations showed the presence of a nucleation time delay and the turbidity amplitude at $1.0 \mathrm{M}$ was significantly larger than other molarities, in contrast to the results seen at $30 \mathrm{mg} \mathrm{cm}^{-3}$. Moreover, the presence of the intermediary phase was also observed with $1.0 \mathrm{M}$ salt concentration. This phenomenon, seen previously with other parameters at conditions conducive to fast polymerisation kinetics such as at high $\mathrm{HbS}$ concentrations (figure 5.6) and temperatures (figure 5.7), only occurred when the combined salt and buffer ionic strength was maximal, i.e. at a salt concentration of $1.00 \mathrm{M}$ in $1.50 \mathrm{M}$ phosphate buffer. 


\subsubsection{Salt Concentration Analysis}

\section{Kinetic Scheme Analysis:}

Table 5.14 shows the rate constants derived from $\mathrm{NaCl}$ salt concentration experiments performed at $30 \mathrm{mg} \mathrm{cm}^{-3}$. In this data set only salt concentrations of $0.50 \mathrm{M}$ and $0.75 \mathrm{M}$ showed a good fit. $k_{\mathrm{l}}$ was seen to decrease by increasing the salt molarity from $0.50 \mathrm{M}$ to $0.75 \mathrm{M}$ whilst $k_{2}$ increased three fold at the same salt range. Consequently, it was seen that the effective growth rate was dependent on salt molarity.

\begin{tabular}{|c|c|c|c|c|}
\hline Salt conc. & $k_{1} / \mathrm{s}^{-1}$ & $k_{2} / \mathrm{M}^{-1} \mathrm{~s}^{-1}$ & $a k_{2} / \mathrm{s}^{-1}$ & $\mathrm{R}^{2}$ \\
\hline 0.25 & $0.04( \pm 0.003) \times 10^{-3}$ & $7.50( \pm 0.22)$ & $3.49( \pm 0.1) \times 10^{-3}$ & 0.935 \\
\hline 0.50 & $0.24( \pm 0.02) \times 10^{-3}$ & $6.90( \pm 0.22)$ & $3.21( \pm 0.1) \times 10^{-3}$ & 0.989 \\
\hline 0.75 & $0.007( \pm 0.002) \times 10^{-3}$ & $22.30( \pm 0.23)$ & $10.4( \pm 0.1) \times 10^{-3}$ & 0.999 \\
\hline 1.00 & $0.74( \pm 1.85) \times 10^{-3}$ & $0.25( \pm 0.50)$ & $0.01( \pm 0.2) \times 10^{-3}$ & 0.947 \\
\hline
\end{tabular}

Table 5.14: Nucleation rate constants $k_{1}$ and growth rate constants $k_{2}$ to describe the HbS aggregation formation for $\mathrm{NaCl}$ salt concentration in the range $0.25 \mathrm{M}$ to $1.00 \mathrm{M}$ at $\mathrm{HbS}$ concentration of $30 \mathrm{mg} \mathrm{cm}^{-3}$ at a $\mathrm{Pt}$ matrix electrode. Experiment conditions: $\mathrm{HbS}$ concentration 30 $\mathrm{mg} \mathrm{cm} \mathrm{cm}^{-3} \mathrm{NaCl}$ salt concentration range $0.25 \mathrm{M}$ to $1.00 \mathrm{M} ; 1.5 \mathrm{M} \mathrm{pH} 7.0$ phosphate buffer; temperature $38^{\circ} \mathrm{C} ; \mathrm{E}=-0.55 \mathrm{~V}$ i's. $\mathrm{Ag} / \mathrm{AgCl}$ for $1000 \mathrm{~s}$.

On the other hand, all turbidity profiles at $75 \mathrm{mg} \mathrm{cm}^{-3}$ showed a good fit with the predicted values obtained from the kinetic model. The rate constants and $\mathrm{R}^{2}$ values for $75 \mathrm{mg} \mathrm{cm}^{-3}$ are tabulated in table 5.15 . The $k_{l}$ values were generally seen to decrease with increasing salt concentrations. A ten fold increase in $\mathrm{NaCl}$ molarity from $0.1 \mathrm{M}$ to $1.0 \mathrm{M}$ saw a six fold decrease in the polymerisation $k_{1}$ value, whilst, $k_{2}$ values were generally seen to be linearly dependent on the salt concentration. 
The effective growth rate was shown to have significant correlation with salt concentration.

\begin{tabular}{|c|c|c|c|c|}
\hline $\begin{array}{c}\text { Salt conc. } \\
/ \mathrm{M}\end{array}$ & $k_{1} / \mathrm{s}^{-1}$ & $k_{2} / \mathrm{M}^{-1} \mathrm{~s}^{-1}$ & $a k_{2} / \mathrm{s}^{-1}$ & $\mathrm{R}^{2}$ \\
\hline 0.1 & $0.16( \pm 0.004) \times 10^{-3}$ & $1.39( \pm 0.009)$ & $1.61( \pm 0.01) \times 10^{-3}$ & 0.994 \\
\hline 0.25 & $0.17( \pm 0.09) \times 10^{-3}$ & $0.07( \pm 0.007)$ & $0.08( \pm 0.01) \times 10^{-3}$ & 0.955 \\
\hline 0.50 & $0.17( \pm 0.05) \times 10^{-3}$ & $0.56( \pm 0.09)$ & $0.65( \pm 0.10) \times 10^{-3}$ & 0.945 \\
\hline 0.75 & $0.013( \pm 0.001) \times 10^{-3}$ & $2.94( \pm 0.01)$ & $3.41( \pm 0.01) \times 10^{-3}$ & 0.986 \\
\hline 1.0 & $0.028( \pm 0.002) \times 10^{-3}$ & $6.69( \pm 0.09)$ & $7.76( \pm 0.10) \times 10^{-3}$ & 0.991 \\
\hline
\end{tabular}

Table 5.15: Nucleation rate constants $k_{1}$ and growth rate constants $k_{2}$ to describe the $\mathrm{HbS}$ aggregation formation for $\mathrm{NaCl}$ salt concentration in the range $0.25 \mathrm{M}$ to $1.00 \mathrm{M}$ at $\mathrm{HbS}$ concentration of $75 \mathrm{mg} \mathrm{cm}^{-3}$ at a $\mathrm{Pt}$ matrix electrode surface. Experiment conditions: $\mathrm{HbS}$ concentration $75 \mathrm{mg} \mathrm{cm}^{-3}: \mathrm{NaCl}$ salt concentration range $0.25 \mathrm{M}$ to $1.00 \mathrm{M} ; 1.5 \mathrm{M} \mathrm{pH} 7.0$ phosphate buffer; temperature $38{ }^{\circ} \mathrm{C} ; \mathrm{E}=-0.55 \mathrm{~V}$ is. $\mathrm{Ag} / \mathrm{AgCl}$ for $1000 \mathrm{~s}$.

\section{Linear Regression Analysis:}

Table 5.16 lists the linear regression gradient data of Phase I and Phase III for 30 $\mathrm{mg} \mathrm{cm}{ }^{-3} \mathrm{HbS}$. $0.1 \mathrm{M}$ data is not shown due to very little growth being seen. No correlation was seen for either Phase I or Phase II with salt concentration. On the other hand Table 5.17 which lists the Phase I, Phase II and Phase III data for 75 $\mathrm{mg} \mathrm{cm}{ }^{-3}$ shows a significant correlation with salt concentration. The rates of Phase I and Phase III were both seen to increase significantly with increasing salt concentration. Furthermore, it can also be noticed that the rate of nucleation Phase I tended to be greater than the respective rate of growth Phase III. The initial nucleation step is usually the rate limiting step and is slower than the growth step of polymerisation but this was not seen in table $\mathbf{5 . 1 7}$. 


\begin{tabular}{|c|c|c|c|}
\hline $\begin{array}{c}\text { Salt Concentration } \\
/ \mathrm{M}\end{array}$ & $\begin{array}{c}\text { Rate of Phase I } \\
/ \mathrm{s}^{-1}\end{array}$ & $\begin{array}{c}\text { Rate of Phase II } \\
/ \mathrm{s}^{-1}\end{array}$ & $\begin{array}{c}\text { Rate of Phase III } \\
/ \mathrm{s}^{-1}\end{array}$ \\
\hline 0.25 & $0.37( \pm 0.01) \times 10^{-3}$ & & \\
\hline 0.50 & $0.49( \pm 0.02) \times 10^{-3}$ & & $1.85( \pm 0.01) \times 10^{-3}$ \\
\hline 0.75 & $0.43( \pm 0.01) \times 10^{-3}$ & & $3.01( \pm 0.02) \times 10^{-3}$ \\
\hline 1.00 & $0.33( \pm 0.02) \times 10^{-3}$ & & $6.87( \pm 0.02) \times 10^{-3}$ \\
\hline
\end{tabular}

Table 5.16: Rate values for Phase I and Phase III, calculated using linear regression analysis, for $\mathrm{NaCl}$ salt in the range $0.1 \mathrm{M}$ to $1.0 \mathrm{M}$ for $30 \mathrm{mg} \mathrm{cm}^{-3} \mathrm{HbS}$ concentration at a $\mathrm{Pt}$ matrix electrode. Experiment conditions: $\mathrm{HbS}$ concentration $30 \mathrm{mg} \mathrm{cm}^{-3} ; \mathrm{NaCl}$ salt range $0.1 \mathrm{M}$ to $1.0 \mathrm{M} ; 1.5 \mathrm{M} \mathrm{pH}$ 7.0 phosphate buffer; $0.5 \mathrm{M} \mathrm{NaCl}$; temperature $38 \mathrm{C}$; $\mathrm{E}=-0.55 \mathrm{~V} v$ s. $\mathrm{Ag} / \mathrm{AgCl}$ for $1000 \mathrm{~s}$. Salt concentration of $0.1 \mathrm{M}$ showed minimal growth and so was not analysed. Turbidity profiles showed no Phase II for these results. 


\begin{tabular}{|c|c|c|c|}
\hline $\begin{array}{c}\text { Salt Concentration } \\
/ \mathrm{M}\end{array}$ & $\begin{array}{c}\text { Rate of Phase I } \\
/ \mathrm{s}^{-1}\end{array}$ & $\begin{array}{c}\text { Rate of Phase II } \\
/ \mathrm{s}^{-1}\end{array}$ & $\begin{array}{c}\text { Rate of Phase III } \\
/ \mathrm{s}^{-1}\end{array}$ \\
\hline 0.10 & $0.40( \pm 0.01) \times 10^{-3}$ & & $2.50( \pm 0.01) \times 10^{-3}$ \\
\hline 0.25 & $5.94( \pm 0.08) \times 10^{-3}$ & & $0.97( \pm 0.01) \times 10^{-3}$ \\
\hline 0.50 & $8.18( \pm 2.00) \times 10^{-3}$ & & $1.76( \pm 0.01) \times 10^{-3}$ \\
\hline 0.75 & $17.6( \pm 0.34) \times 10^{-3}$ & & $4.78( \pm 0.01) \times 10^{-3}$ \\
\hline 1.00 & $15.4( \pm 0.32) \times 10^{-3}$ & $-1.80( \pm 0.04) \times 10^{-3}$ & $12.0( \pm 0.09) \times 10^{-3}$ \\
\hline
\end{tabular}

Table 5.17: Rate values for Phase I, Phase II and Phase III, calculated using linear regression analysis, for $\mathrm{NaCl}$ salt in the range $0.1 \mathrm{M}$ to $1.0 \mathrm{M}$ for $75 \mathrm{mg} \mathrm{cm}^{-3} \mathrm{HbS}$ concentration at a $\mathrm{Pt}$ matrix electrode surface. Experiment conditions: $\mathrm{HbS}$ concentration $75 \mathrm{mg} \mathrm{cm}^{-3} ; \mathrm{NaCl}$ salt range $0.1 \mathrm{M}$ to $1.0 \mathrm{M} ; 1.5 \mathrm{M} \mathrm{pH} 7.0$ phosphate buffer; $0.5 \mathrm{M} \mathrm{NaCl}$; temperature $38 \mathrm{C} ; \mathrm{E}=-0.55 \mathrm{~V}$ vs. $\mathrm{Ag} / \mathrm{AgCl}$ for $1000 \mathrm{~s}$. 


\subsection{The Double Nucleation Mechanism at Surfaces}

Traditionally, the nucleation controlled polymerisation mechanism of $\mathrm{HbS}$, generally referred to as the double nucleation mechanism, has been shown to consist of two types of kinetic processes in equilibrium; the rate limiting critical nuclei formation or homogeneous nucleation and autocatalytic explosive growth termed as heterogeneous nucleation. However, the absorption spectra of certain light scattering experiments conducted in this chapter showed the presence of an intermediary process (Phase II, figure 5.5), consisting of a large decrease in turbidity, after the initial nucleation step.

Figure $\mathbf{5 . 1 2}$ shows a schematic representation of the shift in turbidity profiles from low to high concentrations whilst figure $\mathbf{5 . 1 2}$ (c) specifically shows a representation of this unknown intermediary Phase II seen at a protein concentration of $100 \mathrm{mg} \mathrm{cm}^{-3}$. This phenomenon was also seen at experiments performed at high temperatures, such as $42{ }^{\circ} \mathrm{C}$, as well as at high $\mathrm{pH}$ levels and salt concentrations. To the best of our knowledge, this was the first time such a process had been seen with regards to the polymerisation of $\mathrm{HbS}$ at a conducting surface.
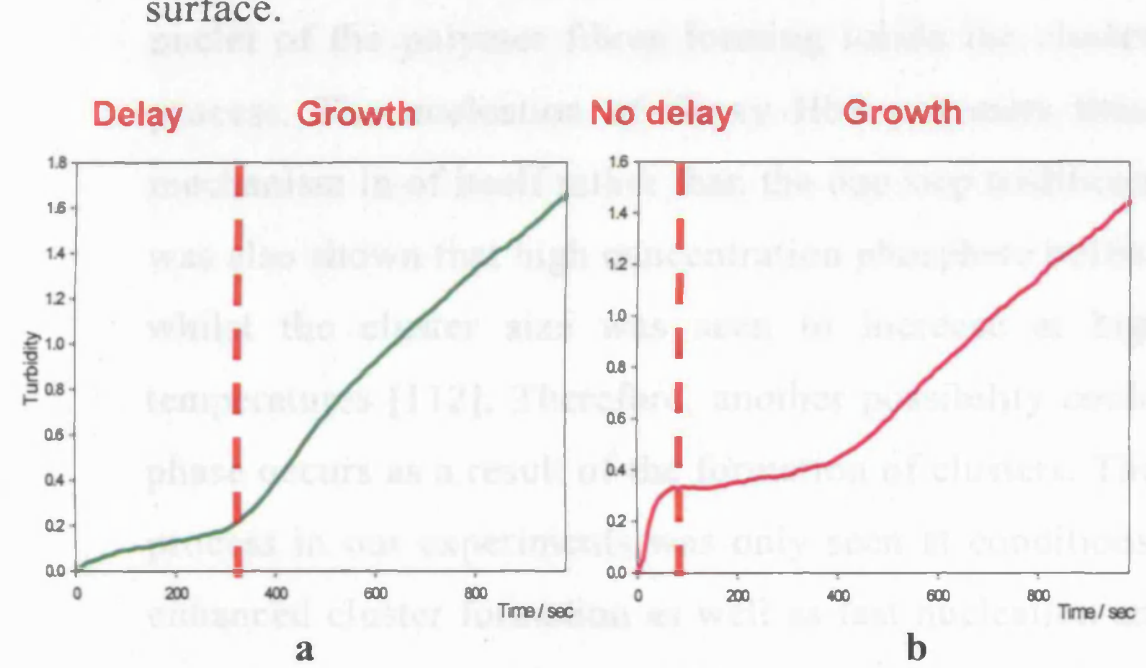

\section{No Unknown \\ Delay Process}

Figure 5.12: A schematic representation of the shift in turbidity profiles from low to high protein concentrations. (a) turbidity profile of $\mathrm{HbS}$ concentration of $30 \mathrm{mg} \mathrm{cm}^{-3}$ showing the classical two phase polymerisation process consisting of a nucleation time delay followed by growth. (b) turbidity profile of $75 \mathrm{mg} \mathrm{cm}^{-3} \mathrm{HbS}$ showing an unorthodox two phase polymerisation process with no time delay followed by steady protein growth. (c) turbidity profile of $100 \mathrm{mg} \mathrm{cm}^{-3} \mathrm{HbS}$ showing deviation from the two step mechanism, instead a three step mechanism was seen with no initial time delay followed by an unknown process, characterised by a decrease in turbidity (highlighted in red), and completed by protein growth. Not to scale. 
The large decrease in turbidity, seen in the red shaded section in figure $\mathbf{5 . 1 2}$ (c), occurred as a result of changes to the structure of the aggregates at the electrode leading to changes in their absorbance properties. This subsequently caused light to be scattered in a different way to before. Changes in polymer structure which might have caused this decrease in turbidity could have been due to the depletion of the polymer structure from the light path, such as the hair like polymer structures seen in figure $\mathbf{3 . 3}$ (b) dissolving in the solution or breaking away from within the holes, or, due to some sort of reorganisation or realignment of the fibres during the transition between the hair-like hair strands (seen in figure 3.3 (b)) and the globular phase (seen in figure 3.5 (b)). Furthermore, this phenomenon was cellspecific as this phase was only seen with experiments conducted with the Pt matrix cell. No such results were seen with the Au micro-mesh cell. Consequently, the multiple hole geometry of the Pt matrix WE aided the observation of this process.

Recent studies by Pan et al. [112, 113] have shown that metastable clusters of dense liquid, several hundred nanometres in size. can form in solutions of $\mathrm{HbS}$ within a few seconds and participate in the nucleation mechanism. The polymerisation process in this case proceeds via a three step mechanism with the nuclei of the polymer fibres forming inside the clusters followed by the growth process. The nucleation of deoxy HbS polymers thus proceeds via a two step mechanism in of itself rather than the one step traditional pathway. Furthermore, it was also shown that high concentration phosphate buffer enhanced the dense liquid whilst the cluster size was seen to increase at high $\mathrm{Hb}$ concentrations and temperatures [112]. Therefore, another possibility could be that this intermediary phase occurs as a result of the formation of clusters. The fact that the intermediary process in our experiments was only seen at conditions which were conducive to enhanced cluster formation as well as fast nucleation and growth kinetics, such as at high $\mathrm{Hb}$ concentrations of $100 \mathrm{mg} \mathrm{cm}^{-3}$, temperatures of $42^{\circ} \mathrm{C}$, pHs 7.62 of 7.40 and salt concentrations of $1.0 \mathrm{M}$, suggested that at these conditions a stronger driving force for cluster formation was provided within which nucleation of the polymer fibres could occur. Other nucleation dependent polymerisation mechanisms, such as B-amyloid fibrillogenesis are also seen to occur with the presence of intermediate peptides termed protofibrils. These form after the nucleation stage and associate end to end and laterally to form amyloid fibrils. Amyloid monomers also form micelles, once the concentration exceeds a certain 
level called the critical micellar concentration, which act as a reservoir of monomers and form nuclei through the monomers [93].

Although it has been established that the aggregation of $\mathrm{HbS}$ free in solution consists of two phases, no study thus far has focussed on the polymerisation of $\mathrm{HbS}$ at a conducting surface. Consequently, it is believed that this phenomenon was 'surface facilitated' and only detected by the light scattering experiments at conditions where kinetics tended to be fast. The presence of a surface could have acted as an anchor for the formation of intermediate structures allowing three phases to be present at any one time in equilibrium, a monomer-containing solution phase, a polymer phase and the intermediate phase. However, further work is required to ascertain the exact nature of the structures involved in our study and whether this process was an intermediary phase due to the presence of intermediate hair-like aggregate structures or the formation of intermediate dense protein clusters. The lack of studies performed in the presence of a surface, which possibly facilitates this intermediary phase II, explains why this has not been reported by other investigators previously. This finding could have a significant impact on the understanding of the fundamental mechanism of $\mathrm{HbS}$ polymerisation and thus not only the pathophysiology of the disease but also strategies to combat this condition. Although not concrete, there is information which suggests that variations to the double nucleation mechanism could exist. 


\subsection{Conclusions}

In this chapter, a Pt matrix thin layer electrochemical cell was fabricated to investigate the effect of four parameters on the gelation of $\mathrm{HbS}$ at a conducting surface. It was shown that the design of this particular cell was better than those used previously as this arrangement effectively allowed $\mathrm{HbS}$ nucleation and aggregation to be monitored in the vicinity of individual holes. Theoretical modeling of $\mathrm{O}_{2}$ depletion in the Pt matrix cell was performed with $\mathrm{Comsol}^{\circledR}$ and showed that $\mathrm{O}_{2}$ was reduced within $20 \mathrm{~s}$ of the start of the experiment, compared to the spectroscopy obtained $200 \mathrm{~s}$ seen with the Pt micromesh cell. Experiments performed with varying protein concentration showed a large concentration dependence on the kinetics of $\mathrm{HbS}$ fibre aggregation. A clear exhibition of a delay period was seen which was prolonged with dilution of $\mathrm{HbS}$ solutions, whilst protein elongation was also directly related to $\mathrm{HbS}$ concentration. This was because as solutions became more concentrated, $\mathrm{HbS}$ molecular collisions increased and thus there was more chance of a hydrophobic interaction occurring between the mutated valine residue of one $\mathrm{HbS}$ and the $B$ subunit of another, leading to a decrease in nucleation time and an increase in polymer growth. It was also shown that aggregation of $\mathrm{HbS}$ at a conducting Pt matrix surface was linearly dependent on the temperature in the range $25^{\circ} \mathrm{C}$ to $42{ }^{\circ} \mathrm{C}$ and that polymer growth at a conducting surface was favoured by elevated temperatures with the largest increase in fibre growth being seen at $42{ }^{\circ} \mathrm{C}$. This value was in contrast to the reported data of $35^{\circ} \mathrm{C}$ at which temperature the solubility-minimum of $\mathrm{HbS}$ was seen, possibly due to differences in the mechanism of protein aggregation at a liquid-liquid interface as opposed to liquid-solid interfaces. Moreover, the investigations revealed that protein aggregation was favoured by a slightly alkaline $\mathrm{pH}$ with the extent of polymer nucleation and elongation being greatest at $\mathrm{pH}$ levels of 7.62 and 7.40 whilst significant ionic strength dependence on the gelation of $\mathrm{HbS}$ fibres was also shown.

Experiments performed at protein concentrations of $100 \mathrm{mg} \mathrm{cm}^{-3}$, temperatures of $42{ }^{\circ} \mathrm{C}$, as well as alkaline $\mathrm{pH}$ levels and high salt concentrations showed the presence of an intermediary Phase II process in the turbidity profile, consisting of a large decrease in turbidity after the initial nucleation step. Comparisons with control proteins showed that this was a real process and it was postulated that this 
process could have been as a result of intermediary aggregates causing a decrease in the extent of light scattering.

Kinetic parameters were calculated using two methods of analysis. It was shown that the highest effective growth rate, calculated using the kinetic scheme model, was obtained for a temperature of $42{ }^{\circ} \mathrm{C}$ at a $\mathrm{HbS}$ concentration of $30 \mathrm{mg} \mathrm{cm} \mathrm{cm}^{-3}$ (9.93 $\left.( \pm 0.2) \times 10^{-3} \mathrm{~s}^{-1}\right)$ whilst the lowest value was obtained for a salt concentration of $0.1 \mathrm{M}$ at $75 \mathrm{mg} \mathrm{cm}^{-3} \mathrm{HbS}\left(1.61( \pm 0.01) \times 10^{-3} \mathrm{~s}^{-1}\right) . k_{1}$ was seen to be several orders of magnitude smaller than $k_{2}$ showing that the nucleation process was slower than the growth process and thus the rate limiting step. Comparison of the linear regression rate values showed that the highest nucleation Phase I value was obtained for a $\mathrm{pH}$ of 7.62 at $75 \mathrm{mg} \mathrm{cm}^{-3} \mathrm{HbS}\left(22.20( \pm 0.02) \times 10^{-3} \mathrm{~s}^{-1}\right)$ whilst the highest Phase III value was for $1.0 \mathrm{M}$ salt concentration at $75 \mathrm{mg} \mathrm{cm}^{-3}(12.0( \pm$ $\left.0.09) \times 10^{-3} \mathrm{~s}^{-1}\right) \mathrm{HbS}$. The linear regression analysis provided a closer reflection of the experimental data than the kinetic scheme as a number of conditions showed a poor fitting to the model. Thermodynamic parameters were also derived from the temperature rate constants. Activation energies for the nucleation and elongation stages of $\mathrm{HbS}$ polymerisation were calculated to be $81.59( \pm 1.22) \mathrm{kJ} \mathrm{mol}^{-1}$ and $148.22( \pm 20.61) \mathrm{kJ} \mathrm{mol}^{-1}$ respectively whilst the Gibbs free energy was calculated to be $97.79( \pm 20.62) \mathrm{kJ} \mathrm{mol}^{-1}$ and $70.31( \pm 1.21) \mathrm{kJ} \mathrm{mol}^{-1}$ respectively. A larger elongation activation energy value indicated that nucleation at the surface was more favourable than elongation.

This is the first known study which has been performed at a solid conducting metal surface, combining electrochemical deoxygenation and $\mathrm{HbS}$, to investigate the effect of different variables on the kinetics of $\mathrm{HbS}$ polymerisation. This study has shown the possibility of using this advanced electrochemical matrix cell as a screening device even when there is limited availability of protein, whilst also showing the great importance of coupling concentration with temperature to achieve an accelerated fibre growth rate for future use as a screening device. A screening device could be used to test a variety of compounds which disrupt the polymer formation as a route to a therapeutic strategy for this disease. Knowledge of how these parameters affect the kinetics and dynamics of nucleation and growth of $\mathrm{HbS}$ polymerisation at a surface will provide a better understanding of the pathophysiology of sickle cell disease in vivo in order to improve therapeutic strategies for this common, and frequently disabling, genetic disorder. 
Chapter 6: Anti-Sickling Strategies 


\subsection{Introduction}

In this chapter, therapeutic strategies which affect the anti-sickling properties of HbS polymers were investigated. Two strategies which could be investigated easily using our electrochemical system were firstly testing compounds whose mechanism of action was specific to disrupting fibre formation of $\mathrm{HbS}$ polymers. As such, the effect of two anti-sickling biological agents, vanillin and 5-HMF, on the extent of polymerisation and kinetics of growth was investigated at the $\mathrm{Pt}$ matrix WE. Secondly, the effect of changing electrode surface properties was investigated by thiolation of the conducting surface. This was performed to define properties which minimise protein growth and therefore reduce the damage which occurs to the plasma membrane in vivo during the polymerisation process. The damage encountered by the membrane during the polymerisation process forms an integral part of the pathophysiology of SCD and thus can be a targeted as a therapeutic strategy. 


\subsection{Experimental}

\subsubsection{Materials and Procedures}

The experiments were performed according to experimental procedure 6. $\mathrm{HbS}$ protein was dissolved in air-saturated $1.5 \mathrm{M}(\mathrm{pH} 7)$ phosphate buffer solution and $0.5 \mathrm{M} \mathrm{NaCl}$ and UV-visible spectroelectrochemistry was employed. The Pt matrix and $\mathrm{Au}$ micromesh thin layer electrochemical cells were used. Vanillin and 5HMF were used as supplied and added to the protein solution in concentrations ranging from $0.29 \mathrm{mM}$ to $11.6 \mathrm{mM}$. The thiol compounds used were 3-mercapto-1propenesulfonic acid, 2-mercaptoethanol, 1-butanethiol and cystamine dihydrochloride in concentrations of $2 \mathrm{mM}$. $\mathrm{HbA}$ protein was used for the control experiments and the mixtures were prepared in the same way. All experiments were performed at room temperature unless otherwise stated. The general experimental and all apparatus for the above techniques are described in chapter 2 . 


\subsubsection{Forming a Thiol Monolayer on Au}

Forming a thiol self assembled monolayer on the Au surface, be it the Au micromesh or the Au matrix cell, was performed in the same manner. A $1.6 \mathrm{mM}$ solution of dilute $\mathrm{H}_{2} \mathrm{SO}_{4}$ was placed in a beaker and $2 \mathrm{mM}$ of the thiol compound was added. The electrode surface was thoroughly cleaned electrochemically and the thiol solution was pippetted inside the coverslip and left to incubate for $2 \mathrm{hrs}$. After 2 hrs the cell was rinsed with copious amounts of water and stored in water to prevent any oxidation of the thiols occurring until used. HbS solution was placed inside the cell and CVs were performed on the thiolated Au surface to ascertain the potential window for the adsorption and desorption of thiols so that the $\mathrm{O}_{2}$ reduction process did not cause reduction of thiols. This set of experiments was performed for each thiol separately. Figure 6.1 shows a CV performed at a 3mercapto-1-propenesulfonic acid thiolated surface and the presence of two shoulders can be seen. The first shoulder was due to the presence of $\mathrm{O}_{2}(-0.4 \mathrm{~V}$ to $0.8 \mathrm{~V}$ ) and the second, in the range $-0.8 \mathrm{~V}$ to $-1.0 \mathrm{~V}$ was attributable to the reduction of the thiol.

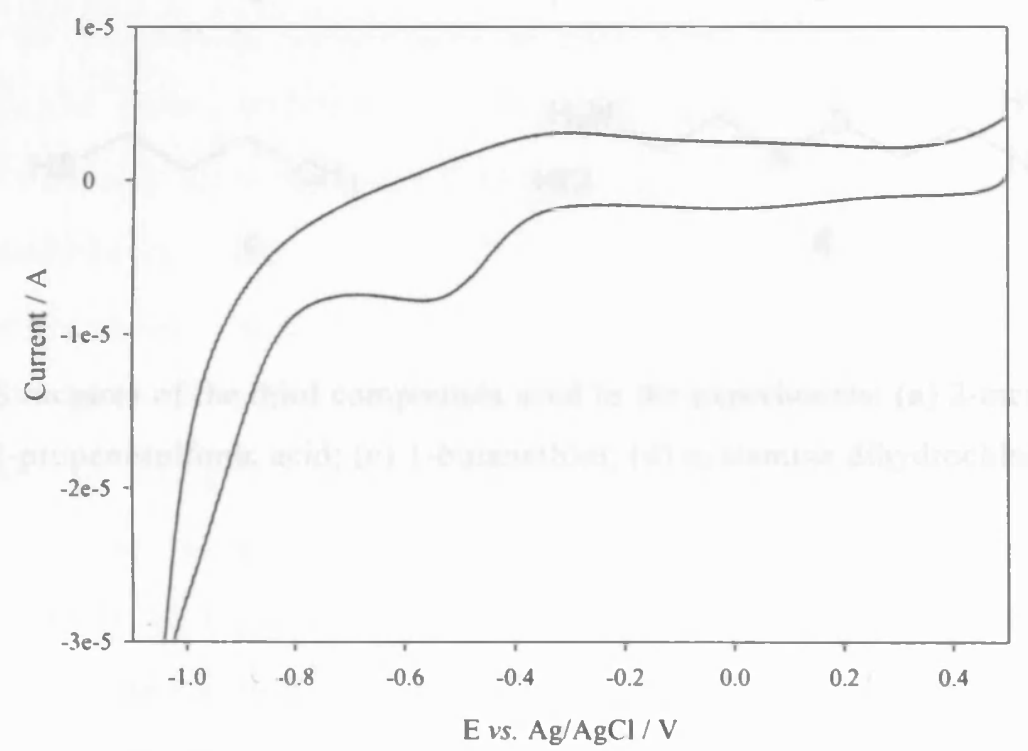

Figure 6.1: CV of 3-mercapto-1-propenesulfonic acid thiolated Au surface performed at a scan rate of $100 \mathrm{mV} \mathrm{s}^{-1}$ to ascertain the potential window for the reduction of the thiol. The first shoulder between $-0.4 \mathrm{~V}$ to $-0.8 \mathrm{~V}$ was attributable to $\mathrm{O}_{2}$ reduction whilst the thiol reduction shoulder was seen from $-0.8 \mathrm{~V}$ to around $-1.0 \mathrm{~V}$. 
Once the $\mathrm{HbS}$ experiment had finished, the removal of thiols was achieved by rinsing the cell with copious amounts of water to remove the excess protein underneath the coverslip (i.e. protein which might be stuck to the electrodes or the glass surface) and placing it in an equimolar mixture of ethanol/ $\mathrm{H}_{2} \mathrm{O}$ for 5 mins. Subsequently, the thiols were stripped by electrochemical cycling of dilute $\mathrm{H}_{2} \mathrm{SO}_{4}$ (two sets of 30 cycles were performed), a larger potential window than normal (+ $1.35 \mathrm{~V}$ to $-0.90 \mathrm{~V}$ ) was used as the reduction of thiols occurs at more negative potentials. The cell was again rinsed thoroughly to remove recycled acid along with any stripped thiols and a new solution of $\mathrm{H}_{2} \mathrm{SO}_{4}$ was used to electrochemically clean the electrodes, but this time at the normal potential window used earlier to clean the bare Au electrode $(+1.35 \mathrm{~V}$ to $-0.50 \mathrm{~V})$. A final rinse was performed to remove traces of any contaminations. Figure 6.2 shows the structures of the thiol compounds used in the thiol experiments<smiles>OCCS</smiles>

a<smiles>CCCCS</smiles>

c<smiles></smiles>

b<smiles>NCCSSCCN</smiles>

d

Figure 6.2: Structures of the thiol compounds used in the experiments: (a) 2-mercaptoethanol; (b) 3-mercapto-1-propenesulfonic acid; (c) 1-butanethiol; (d) cystamine dihydrochloride 


\subsection{Pathophysiology of SCD}

The polymerisation of $\mathrm{HbS}$ is the primary process in the pathophysiology of the disease. Normal bi-concave shaped RBCs, approximately $8 \mu \mathrm{m}$ in diameter, are elastic and therefore easily pass through smaller blood vessels of $3 \mu \mathrm{m}$ diameter [114]. However, repeated episodes of sickling cause a permanent change in the shape of the cell and loss of cell elasticity even when $\mathrm{O}_{2}$ concentration increases. Consequently, rigidified sickled cells lead to occlusion of capillaries and small vessels, triggering an avalanche of haemolysis and vaso-occlusive events including local inflammation, oxidant damage, deregulated homeostasis of nitric oxide (NO) and endothelial-cell injury. This subsequently leads to a number of complications including painful episodes, chronic haemolytic anaemia and possible end organ damage and premature mortality $[114,115]$.

HbS polymerisation, in addition to deforming the cell into a sickle shape, also causes injury to the erythrocyte by damaging the plasma membrane cytoskeleton, thus reducing cation and water content and altering the distribution of membrane proteins and lipids, such as the extracellular exposure of protein epitopes and glycolipids that are normally found inside the cell [116]. Cellular damage and the disruption of the plasma membranes in particular, increase adhesive interactions between sickle cells, endothelial cells and leukocytes; multiple studies have implicated virtually all major adhesion pathways in the interactions between sickle cells and endothelial cells [116 - 118]. Thus, sickle adhesion to the endothelium plays a significant role in sickle cell vaso-occlusion, figure 6.3.

Furthermore, plasma membrane injury and chronic haemolysis impairs cation homeostasis and triggers local inflammation [115]. Sickle cells have a reduced $\mathrm{Mg}^{2+}$ content due to the net loss of $\mathrm{Mg}^{2+}$ during sickling, possibly due to an increased activity of the $\mathrm{Na}^{+}-\mathrm{Mg}^{2+}$ exchanger, whilst the $\mathrm{K}^{+}-\mathrm{Cl}^{-}$co-transport, which mediates sickle cell dehydration, is significantly higher in patients with SCD [119]. On the other hand, dehydrated dense sickle cells expose negatively charged glycolipids on the outer layer of the plasma membrane, which subsequently activate the coagulation cascade, leading to the generation of tissue factor and thrombin, and thus promoting an inflammatory response $[116,120]$. 
Figure 6.3: Sickle cell vasoocclusion. Adhesion of sickle RBC to endothelial cells induces the expression of inflammatory and coagulation mediators leading to the activation of the vascular endothelium. Stimulated endothelial cells recruit rolling leukocytes which capture sickle RBC leading to transient episodes of vascular occlusions that are initiated in the venules [116].

Moreover, haemolytic anaemia or the premature destruction of $\mathrm{RBCs}$ causes $\mathrm{Hb}$ to be liberated into the plasma. This plasma $\mathrm{Hb}$ converts $\mathrm{NO}$ to bio-inactive nitrate whilst the substrate for the production of $\mathrm{NO}, L$-arginine, is also destroyed. Reduced endothelial bioavailablity of NO impairs important functions such as inhibition of platelet activation and repression of cell-adhesion molecule and also enhances vasoconstriction, which again increases the likelihood of sickle cell vasoocclusion and induces endothelial damage $[115,121]$. Consequently, HbS polymerisation not only causes rigid and sharp sickled cells leading to occlusion of capillaries and small vessels, but also leads to a heterogeneous population of sickle cells with damaged membrane cytoskeletons (figure 6.4), triggering a cascade of events resulting in ischaemia amd tissue and organ damage. 
Figure 6.4: Membrane cytoskeleton and plasma membrane damage due to HbS polymerisation. HbS polymers disrupt the RBC cytoskeletion and form protusions which results in exposure of the transmembrane protein epitopes and lipid exchanges, notably of phosphatidylserine (PS) between the inside and outside of the cell [116]

Although the pathophysiology of the disease is manifested and modulated through various types of factors, including genetic, cellular and environmental, two interrelated events, vaso-occlusion and haemolytic anaemia, essentially cause clinical disease. These events are driven by the degree of sickle erythrocyte adhesion to the vascular endothelium and the extent of plasma membrane damage. The presence of such diverse mechanisms and factors driving these processes need to be carefully considered before physiologically relevant therapeutic agents can be delineated. 


\subsection{Current Therapies for SCA}

Even though major strides are being made in developing pharmacologically efficacious agents, currently, no clinically useful anti-sickling agents exist even though numerous have been studied and reported. At the moment, there are four potential pathophysiological based therapeutic approaches to SCD and these mechanisms can be listed as follows:

1. inhibition of $\mathrm{HbS}$ polymerisation

2. prevention of RBC dehydration

3. prevention of RBC adhesion to vascular endothelium

4. gene therapy

\section{Inhibition of HbS Polymerisation}

The therapeutic strategy of specifically inhibiting the polymerisation of deoxygenated $\mathrm{HbS}$ to combat $\mathrm{SCD}$ can be broken down into two further approaches: pharmacological induction of $\mathrm{HbF}$ and chemical modification of $\mathrm{HbS}$ polymerisation.

\section{HbF induction:}

Pharmacological induction of $\mathrm{HbF}$ can be considered as the most successful approach to date. An increase in $\mathrm{HbF}$ levels causes hybrid $\mathrm{Hb}$ tetramers to form which are not incorporated into the polymer phase, thus causing the solubility of $\mathrm{HbS}$ to be increased as a result of a variable intracellular $\mathrm{Hb}$ composition. The mechanism of $\mathrm{HbF}$ induction is thought to occur either through gene hypomethylation or by cytotoxicity which offers a selective advantage for HbFproducing erythroid progenitors [114, 122, 123].

Hydroxyurea, a potent inducer of $\mathrm{HbF}$, was first demonstrated to be biologically active in 1928 [124] and a clinical study conducted in 1995 showed that hydroxyurea reduced the frequency of episodes of pain, acute chest syndrome, hospitalisation and the need for blood transfusion [125]. Hydroxyurea prevents RBC sickling by increasing the synthesis of HbF. Recent studies have indicated that the effects of hydroxyurea are not only caused by an increase in $\mathrm{HbF}$ concentration but may also be dependent on a number of additional mechanisms, 
including an increase in soluble guanylyl cyclase, which in turn, leads to increased cyclic guanosine monophosphate, a facilitator of $\gamma$-globin gene induction [126]. It has also been implicated in the stimulation of a potent vasodilator NO [127] and been shown to decrease the adhesion of sickle cells to endothelium [115]. However, even though currently hydroxyurea remains the only approved therapeutic agent for SCD therapy, a lack of efficacy and numerous adverse effects ensure that the long term benefits and toxicities of hydroxyurea are controversial [114] and are still being investigated.

\section{Chemical Modification of HbS Polymerisation:}

Chemical modification of $\mathrm{HbS}$ by an agent, which interacts directly with $\mathrm{HbS}$ causing an inhibition of the polymerisation process, is an attractive therapeutic approach to combat this disease. Disruption at this stage of the disease life cycle would mean the cascade of adverse events associated with the secondary processes in the pathophysiology of SCD would not be manifested. Consequently, investigations in this chapter focussed on using the thin layer electrochemical cell as a novel assay system to investigate the efficacy of potential anti-sickling agents which may disrupt the polymerisation of $\mathrm{HbS}$.

Although many compounds have been tested, the lack of success in developing a clinically useful anti-sickling agent to date has been due to the excessive amount of drug required to interact stereospecifically with the large quantity of $\mathrm{Hb}$ present in humans. Covalent modification of the $\mathrm{HbS}$ protein would require at least an equimolar concentration of the drug to increase anti-gelling activity and therefore a substance with little or no toxicity would be needed.

A number of naturally occurring and synthetic aldehydes were investigated by Zaugg et al. [128] and found that aromatic aldehydes, particularly vanillin (2,4dihydroxybenzaldehyde) and 5-hydroxymethyl-2-furfural (5HMF) markedly increased the $\mathrm{O}_{2}$ affinity of $\mathrm{HbA}$ and $\mathrm{HbS}$ under hypoxic conditions by forming Schiff base (imine) linkages with the N-terminal $\alpha$ Vall nitrogens of $\mathrm{Hb}$ [129]. In Schiff-base formation, equilibrium of the following type is established:

$$
\mathrm{Hb}-\mathrm{NH}_{2}+\mathrm{R}-\mathrm{CHO} \leftrightarrow \mathrm{Hb}-\mathrm{N}=\mathrm{CH}-\mathrm{R}+\mathrm{H}_{2} \mathrm{O}
$$


Vanillin (figure 6.5 (a)) decreases $\mathrm{HbS}$ polymerisation by allosterically modulating the $\mathrm{HbS}$ molecule to the high affinity state, and concurrently inhibiting the $\mathrm{T}$ state $\mathrm{HbS}$ polymerisation. Furthermore, vanillin is an extremely good candidate as an anti-sickling agent as it is a food additive on the GRAS (generally regarded as safe) list and has little adverse effects at high dosages [130]. However, vanillin has low oral bioavaiability due to rapid decomposition in the digestive tract, and thus a pro-drug of vanillin has been developed. The pro-drug, MX-1520, has been investigated in rodents and shown to be bioavailable after oral administration in rats and still retain its efficacy [131]. 5HMF (figure 6.5 (b)), another naturally occurring compound, has been reported to inhibit sickling by up to four times more than vanillin [132]. 5-HMF also allosterically shifts $\mathrm{O}_{2}$ equilibrium curves towards the left and was found to be rapidly absorbed into the bloodstream, binding and modifying $\mathrm{HbS}$ molecules at levels as high as $90 \%$ without being destroyed in the gastrointestinal tract [132].

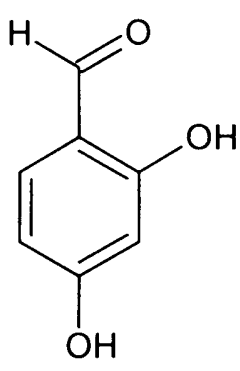

a

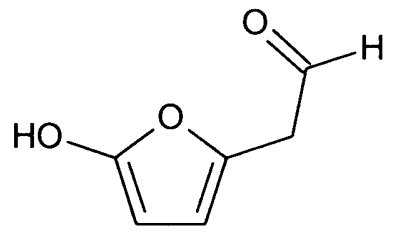

b

Figure 6.5: The structures of (a) vanillin and (b) 5HMF

\section{Prevention of RBC Dehydration}

The formation of dense and dehydrated sickle RBCs play a key role in the initiation of vaso-occlusion as $\mathrm{HbS}$ concentration directly impacts on $\mathrm{HbS}$ polymerisation. Therefore, hydration of erythrocytes by way of transport pathways that mediate red cell dehydration have led to the development of specific therapies to reduce cell density and $\mathrm{HbS}$ polymerisation. Studies have shown that decreasing the MCHC increases the delay time of sickling, providing enough time for cells to return to the lungs and be reoxygenated [114].

Currently, magnesium (Mg) pidolate [133], which increases erythrocyte Mg levels and decreases $\mathrm{K}^{+}-\mathrm{Cl}^{-}$co-transport activity and cell dehydration, as well as ICA- 
17043 [134], which is a potent inhibitor of the Gardos channel thereby preventing $\mathrm{Ca}^{2+}$ dependent dehydration of sickle cells, have shown huge promise. Both of these drugs are currently in Phase III clinical trials.

\section{Prevention of RBC Adhesion}

Cell injury as a direct result of $\mathrm{HbS}$ polymerisation leads to enhanced interaction of sickled cells with the vascular endothelium as well as to other cells such as activated neutrophils. Enhanced RBC adhesion leads to augmentation of vasoocclusive events and therefore agents which might prevent these adhesive interactions in SCD are being investigated for possible therapeutic use. One such agent is Flocor [135], a complex non-ionic surfactant block copolymer, which decreases RBC aggregation and friction between RBCs and vessel walls by blocking cell-cell or cell-protein interactions.

\section{Gene Therapy}

Gene therapy represents a vital hope for SCD cure in the long term and recent improvements in vector design have fuelled interest in gene therapy approaches to the treatment of SCD. However, this type of therapeutic strategy falls outside the remit of this thesis and therefore will not be discussed in further detail. For a concise review on this topic the reader is directed to a publication by Abdulmalik et al. [114]. 


\subsection{Use of Compounds which Modify HbS Protein Structure or Composition}

The thin layer Pt matrix electrochemical cell was used to test compounds which acted through covalent modification of $\mathrm{HbS}$ protein. Two compounds, vanillin and $5 \mathrm{HMF}$, were investigated to show that our system could be used to test for compounds which specifically disrupt the aggregation process. Whereas in the literature the effect of these compounds on the $\mathrm{O}_{2}$ affinity of the protein, through a reduction in the $\mathrm{P}_{50}$ value, was used to measure the efficacy, our system used a light scattering method where growth in protein was reflected by an increase in turbidity. Furthermore, the effect of different proportions of $\mathrm{HbS}$ was investigated using the $\mathrm{Pt}$ matrix cell by modifying the composition of $\mathrm{HbS}$ to $\mathrm{HbA}$ in the solution mixture. The experiments performed in this chapter were only preliminary investigations and not a detailed study of any particular therapeutic strategy due to the time constraints. 


\subsubsection{Vanillin}

Vanillin was added to a polymerising solution mixture composed of $75 \mathrm{mg} \mathrm{cm}^{-3}$ (1.16 mM) HbS protein and $0.5 \mathrm{M} \mathrm{NaCl}$ dissolved in $1.5 \mathrm{M}, \mathrm{pH} 7$ phosphate buffer and the experiments were performed at $38{ }^{\circ} \mathrm{C}$. Vanillin was incubated in the protein solution prior to the start of the experiment for 5 minutes to allow chemical modification of the protein structure to occur. Figure 6.6 presents the turbidity profiles of $\mathrm{HbS}$ solutions containing different concentrations of vanillin as well as control experiments performed with $\mathrm{HbA}$ and free vanillin.

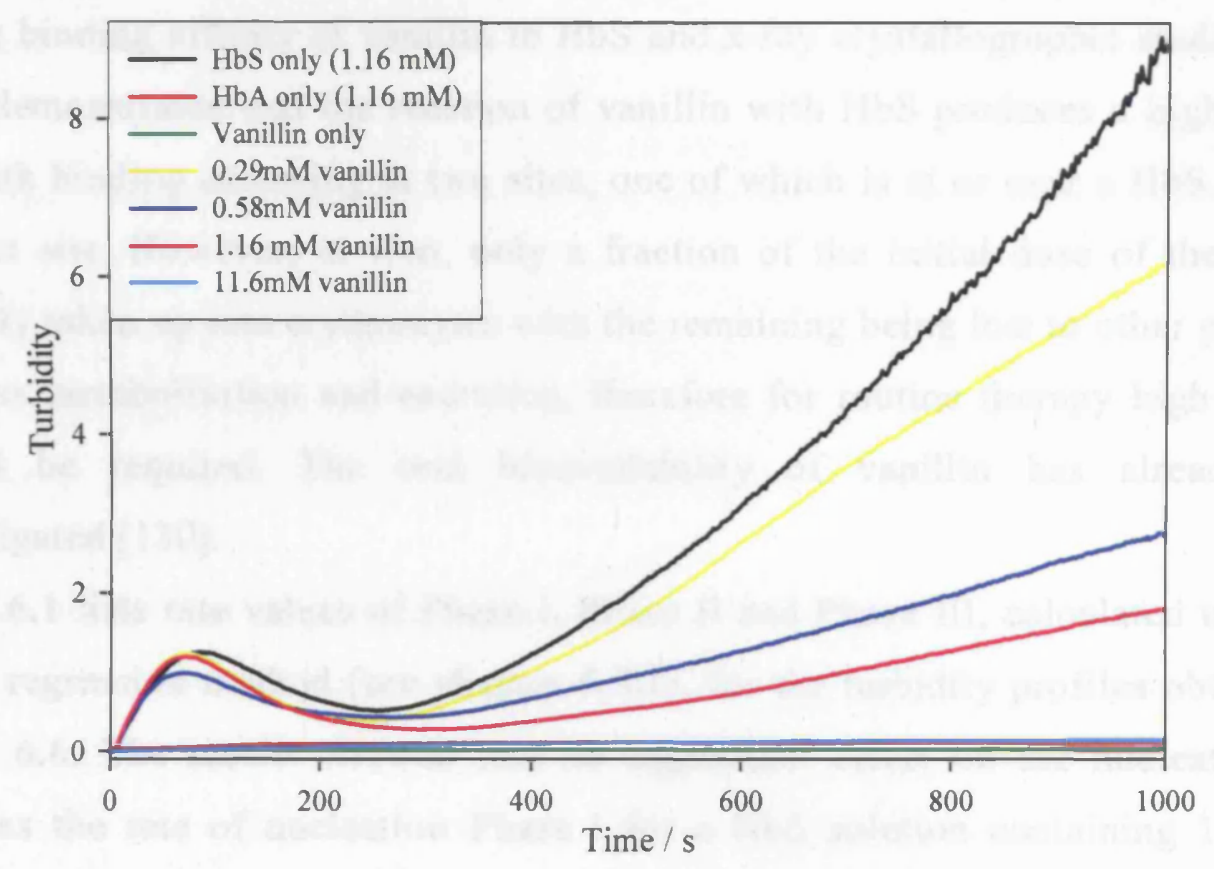

Figure 6.6: UV-visible spectroelectrochemistry time traces showing changes in turbidity at 700 $\mathrm{nm}$ at the Pt matrix electrode for different concentrations of vanillin. Experiment conditions: HbS concentration $75 \mathrm{mg} \mathrm{cm}^{-3}(1.16 \mathrm{mM})$; various concentrations of vanillin (see figure legend); $1.5 \mathrm{M}$ pH 7.0 phosphate buffer; $0.5 \mathrm{M} \mathrm{NaCl} ; \mathrm{T}=38^{\circ} \mathrm{C} ; \mathrm{E}=-0.55 \mathrm{~V} v$ s. $\mathrm{Ag} / \mathrm{AgCl}$. HbA concentration of $75 \mathrm{mg} \mathrm{cm}^{-3}(1.16 \mathrm{mM})$ was used for control experiments.

An increase in vanillin concentration was seen to cause a decrease in the nucleation and growth turbidity levels. No delay time was noticeable for any of the turbidity profiles, with vanillin concentrations up to $1.16 \mathrm{mM}$ showing a rapid increase in turbidity as soon as the experiment started. However, significant differences were seen in the growth levels. The maximum turbidity level (turbidity at $1000 \mathrm{~s}$ ) for a solution containing $\mathrm{HbS}$ only (i.e. no vanillin) decreased one and a 
half fold when $0.29 \mathrm{mM}$ concentration of vanillin was added, whilst a five fold decrease in turbidity was seen when an equimolar vanillin concentration of 1.16 $\mathrm{mM}$ was added. Furthermore, increasing the concentration of vanillin by a factor of ten to $11.6 \mathrm{mM}$ saw a sixty nine fold decrease in the turbidity. Moreover, the presence of the intermediary phase II was seen with the turbidity profiles at low concentrations of vanillin and at vanillin concentrations of $5.80 \mathrm{mM}$ and $8.70 \mathrm{mM}$ (data not shown), suggesting that although a decrease in protein growth was seen, even at these high concentrations a significant nucleation phase was present. A total disappearance of the nucleation and growth phases was seen once vanillin concentration had been increased to $11.60 \mathrm{mM}$. Therapeutic efficacy would depend on the binding affinity of vanillin to $\mathrm{HbS}$ and $\mathrm{x}$-ray crystallographic studies [130] have demonstrated that the reaction of vanillin with $\mathrm{HbS}$ produces a high affinity $\mathrm{Hb}$ with binding occurring at two sites, one of which is at or near a HbS polymer contact site. However, in vivo, only a fraction of the initial dose of the drug is actively taken up into erythrocytes with the remaining being lost to other processes such as metabolisation and excretion, therefore for routine therapy high dosages would be required. The oral bioavailability of vanillin has already been investigated [130].

Table 6.1 lists rate values of Phase I, Phase II and Phase III, calculated using the linear regression method (see chapter 5.5.1), for the turbidity profiles obtained in figure 6.6. The results showed that no significant effect on the nucleation was seen, as the rate of nucleation Phase I for a $\mathrm{HbS}$ solution containing $1.16 \mathrm{mM}$ concentration of vanillin was $31 \mathrm{~ms}^{-1}$, whilst for a $\mathrm{HbS}$ solution containing no vanillin it was $26 \mathrm{~ms}^{-1}$. Furthermore, decreasing the vanillin concentration to a quarter of the concentration of $\mathrm{HbS}(0.29 \mathrm{mM})$ showed a similar rate for the nucleation phase. The decrease in the turbidity level with increasing vanillin concentration was reflected more clearly by the Phase III growth rate values, as the growth rate for a $\mathrm{HbS}$ only experiment was $11.7 \mathrm{~ms}^{-1}$ whilst for $1.16 \mathrm{mM}$ vanillin it decreased to $2.94 \mathrm{~ms}^{-1}$. 


\begin{tabular}{|c|c|c|c|}
\hline $\begin{array}{c}\text { Vanillin } \\
\text { concentration } \\
/ \mathrm{mM}\end{array}$ & $\begin{array}{c}\text { Rate of Phase I } \\
/ \mathrm{s}^{-1}\end{array}$ & $\begin{array}{c}\text { Rate of Phase II } \\
/ \mathrm{s}^{-1}\end{array}$ & $\begin{array}{c}\text { Rate of Phase III } \\
/ \mathrm{s}^{-1}\end{array}$ \\
\hline 0 (HbS only) & $26.1( \pm 0.51) \times 10^{-3}$ & $-5.83( \pm 0.12) \times 10^{-3}$ & $11.7( \pm 0.08) \times 10^{-3}$ \\
\hline 0.29 & $30.0( \pm 0.40) \times 10^{-3}$ & $-8.74( \pm 0.09) \times 10^{-3}$ & $9.63( \pm 0.06) \times 10^{-3}$ \\
\hline 0.58 & $32.0( \pm 1.08) \times 10^{-3}$ & $-5.40( \pm 0.16) \times 10^{-3}$ & $2.94( \pm 0.01) \times 10^{-3}$ \\
\hline 1.16 & $31.3( \pm 0.54) \times 10^{-3}$ & $-8.43( \pm 0.12) \times 10^{-3}$ & $2.67( \pm 0.02) \times 10^{-3}$ \\
\hline
\end{tabular}

Table 6.1: Rate values for Phase I, Phase II and Phase III calculated using linear regression analysis for vanillin concentration in the range $0.29 \mathrm{mM}$ and $1.16 \mathrm{mM}$ at a $\mathrm{Pt}$ matrix electrode surface. HbS concentration $75 \mathrm{mg} \mathrm{cm}^{-3}(1.16 \mathrm{mM})$; various concentrations of vanillin; $1.5 \mathrm{M} \mathrm{pH}$ 7.0 phosphate buffer; $0.5 \mathrm{M} \mathrm{NaCl} ; \mathrm{T}=38^{\circ} \mathrm{C} ; \mathrm{E}=-0.55 \mathrm{~V}$ vs. $\mathrm{Ag} / \mathrm{AgCl}$.

Another study was performed with vanillin to investigate the effect of adding vanillin (of concentration $11.60 \mathrm{mM}$ ) to an already polymerising $\mathrm{HbS}$ solution at different points in the lifecycle of $\mathrm{HbS}$ aggregation. Consequently, vanillin was injected into the electrochemical cell at four stages: the early nucleation stage (before $70 \mathrm{~s}$ ); at the cusp of the intermediary Phase II (between $75 \mathrm{~s}$ to $85 \mathrm{~s}$ ); at the bottom of the trough seen in the turbidity profile before the beginning of Phase III (at $250 \mathrm{~s}$ ); and in the middle of the elongation Phase III (after $300 \mathrm{~s}$ ). The results seen in figure 6.7 showed that the injection of vanillin at all four points in the experiments all led to a sudden decrease in the turbidity levels. Although, a small decrease in turbidity was predicted straight after the injection of the solution due to disruption of the polymers decreasing light scattering, it was thought that an increase in turbidity would follow soon after with the polymers reassembling. However, this was not seen, and all experiments showed a dramatic loss in protein growth no matter at which point the vanillin was added. This could not have been due to a diluting factor as the same amount of vanillin solution, to what was already present in the cell, was added. These set of experiments were performed to 
ascertain if covalent modification by Schiff base linkage affected all stages in the polymerisation life cycle, or whether certain points in the polymerisation process showed irreversibility. It is hoped that these preliminary experiments will form the basis for future studies which will help to identify those who would be best suited to this type of therapy.

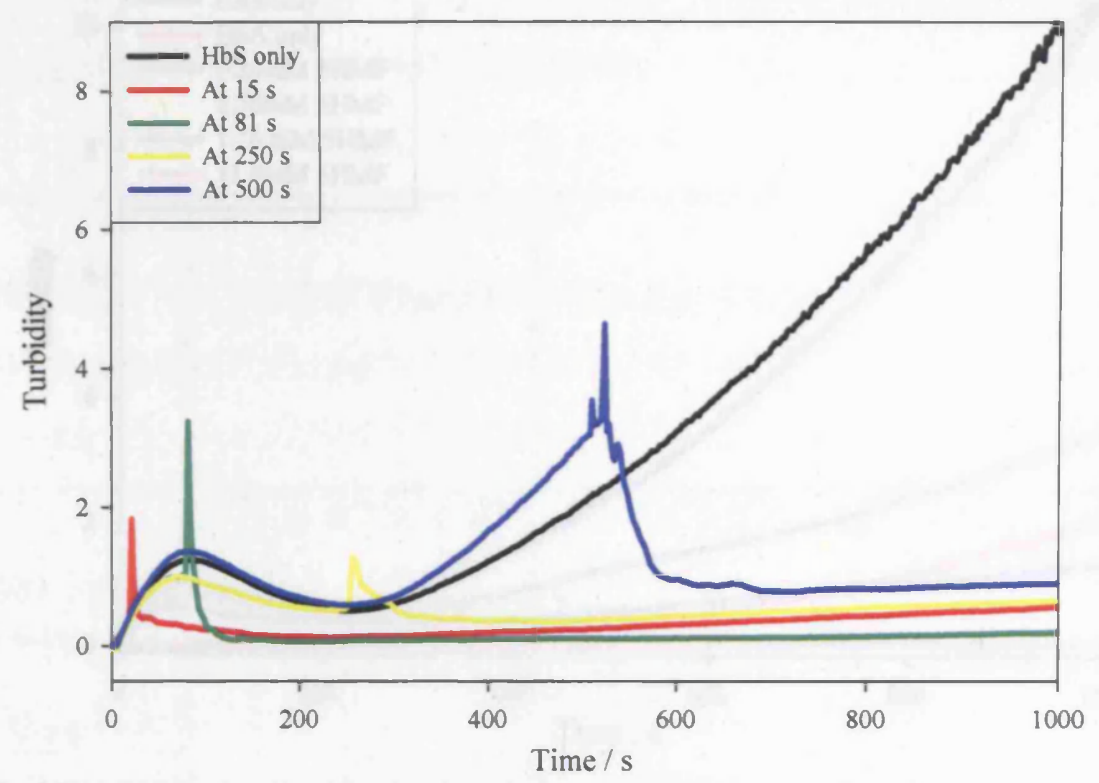

Figure 6.7: UV-visible spectroelectrochemistry time traces showing changes in turbidity at 700 $\mathrm{nm}$ at Pt matrix electrode when vanillin was added at different points in the aggregating system. Experiment conditions: HbS concentration $75 \mathrm{mg} \mathrm{cm}^{-3}(1.16 \mathrm{mM}) ; 1.5 \mathrm{M} \mathrm{pH} 7.0$ phosphate buffer solution $(100 \mu \mathrm{l}) ; 0.5 \mathrm{M} \mathrm{NaCl} ; \mathrm{T}=38{ }^{\circ} \mathrm{C} ; \mathrm{E}=-0.55 \mathrm{~V}$ vs. $\mathrm{Ag} / \mathrm{AgCl}$. Vanillin concentration 11.6 $\mathrm{mM}$ in $1.5 \mathrm{M} \mathrm{pH} 7.0$ phosphate buffer solution $(100 \mu \mathrm{l})$ added at $15 \mathrm{~s}, 81 \mathrm{~s}, 250 \mathrm{~s}$ and $500 \mathrm{~s}$. 


\subsubsection{HMF}

The same set of experiments performed previously with vanillin was performed with another naturally occurring carbonyl compound, 5HMF, which has shown to be far more efficacious than vanillin in literature [132].

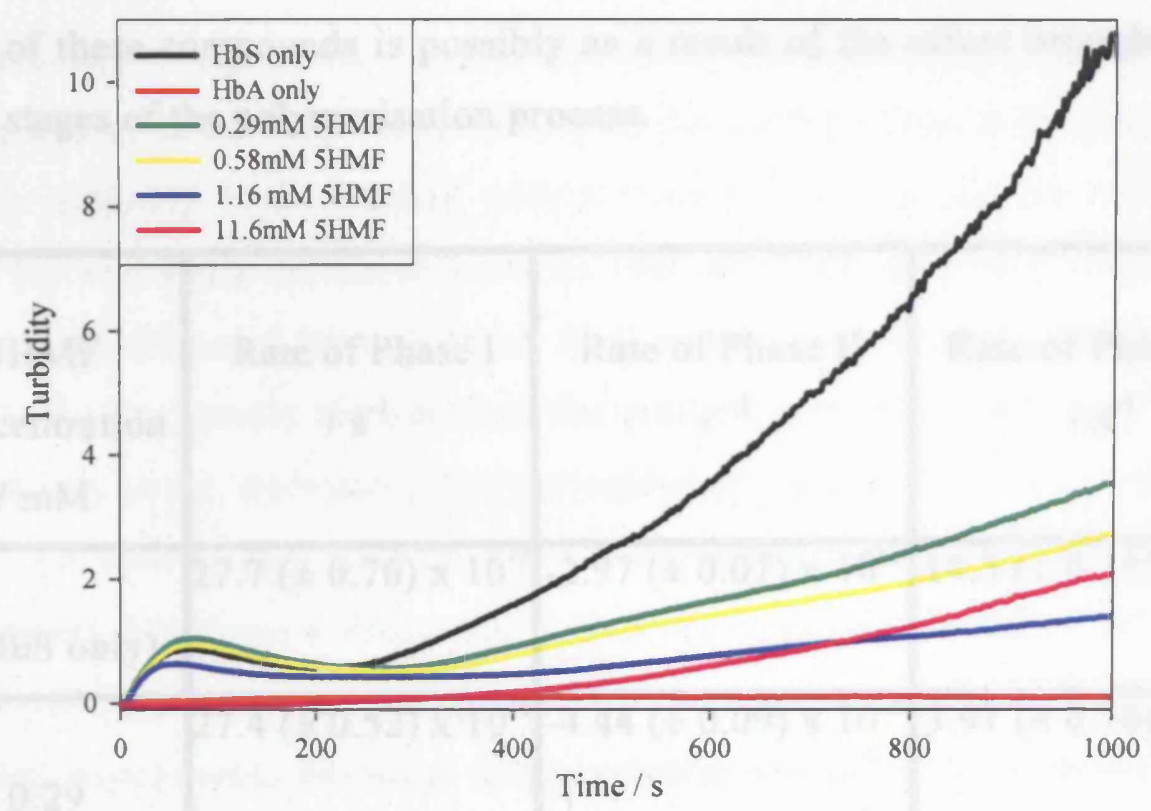

Figure 6.8: UV-visible spectroelectrochemistry time traces showing changes in turbidity at 700 $\mathrm{nm}$ at $\mathrm{Pt}$ matrix electrode for different concentrations of 5HMF. Experiment conditions: $\mathrm{HbS}$ concentration $75 \mathrm{mg} \mathrm{cm}^{-3}(1.16 \mathrm{mM})$; various concentrations of $5 \mathrm{HMF} ; 1.5 \mathrm{M} \mathrm{pH} 7.0$ phosphate buffer; $0.5 \mathrm{M} \mathrm{NaCl} ; \mathrm{T}=38^{\circ} \mathrm{C} ; \mathrm{E}=-0.55 \mathrm{~V}$ vs. $\mathrm{Ag} / \mathrm{AgCl}$. $\mathrm{HbA}$ concentration of $75 \mathrm{mg} \mathrm{cm}{ }^{-3}(1.16$ $\mathrm{mM}$ ) was used for control experiments.

Figure 6.8 shows the changes in the turbidity profiles of $\mathrm{HbS}$ protein when different concentrations of 5HMF were added. Increasing the concentration of $5 \mathrm{HMF}$ caused a significant decrease in the growth phase of $\mathrm{HbS}$ protein aggregation. This was exemplified by the eight fold decrease in maximum turbidity seen with the addition of an equimolar concentration of $1.16 \mathrm{mM} 5 \mathrm{HMF}$ compared with a $\mathrm{HbS}$ only solution. Furthermore, a quick comparison shows that only a five fold decrease in the maximum turbidity was seen with the same concentration of vanillin (i.e. $1.16 \mathrm{mM}$ ) compared with the eight fold decrease seen with 5HMF. This however was not true for all concentrations as the turbidity decreased by sixty nine times for $11.6 \mathrm{mM}$ of vanillin but only a mere five fold reduction was seen for $5 \mathrm{HMF}$ at the same concentration. 
The nucleation phase, as shown by the rate calculations shown in table 6.2, did not show much variation for low concentrations of $5 \mathrm{HMF}$. However, whereas most of the turbidity profiles showed a large increase in turbidity followed by the intermediary Phase II process, the profile for $11.6 \mathrm{mM}$ 5HMF exhibited a clear time delay of $177 \mathrm{~s}$. Moreover, the nucleation Phase I rates seen for 5HMF in table 6.2 are very similar to the Phase I rates seen for vanillin showing that the differing efficacy of these compounds is possibly as a result of the effect brought about in the later stages of the polymerisation process.

\begin{tabular}{|c|c|c|c|}
\hline $\begin{array}{c}\text { 5HMF } \\
\text { Concentration } \\
\mathrm{mM}\end{array}$ & $\begin{array}{c}\text { Rate of Phase I } \\
/ \mathrm{s}^{-1}\end{array}$ & $\begin{array}{c}\text { Rate of Phase II } \\
/^{-1}\end{array}$ & $\begin{array}{c}\text { Rate of Phase III } \\
/ \mathrm{s}^{-1}\end{array}$ \\
\hline 0 (HbS only) & $27.7( \pm 0.76) \times 10^{-3}$ & $-2.97( \pm 0.07) \times 10^{-3}$ & $14.3( \pm 0.15) \times 10^{-3}$ \\
\hline 0.29 & $27.4( \pm 0.52) \times 10^{-3}$ & $-4.44( \pm 0.09) \times 10^{-3}$ & $3.91( \pm 0.16) \times 10^{-3}$ \\
\hline 0.58 & $24.3( \pm 0.34) \times 10^{-3}$ & $-4.00( \pm 0.08) \times 10^{-3}$ & $3.64( \pm 0.02) \times 10^{-3}$ \\
\hline 1.16 & $23.7( \pm 0.66) \times 10^{-3}$ & $-1.91( \pm 0.05) \times 10^{-3}$ & $1.63( \pm 0.01) \times 10^{-3}$ \\
\hline 11.60 & & & \\
\hline
\end{tabular}

Table 6.2: Rate values for Phase I, Phase II and Phase III calculated using linear regression analysis for $5 \mathrm{HMF}$ concentration in the range $0.29 \mathrm{mM}$ and $11.6 \mathrm{mM}$ at a Pt matrix electrode surface. $\mathrm{HbS}$ concentration $75 \mathrm{mg} \mathrm{cm}^{-3}(1.16 \mathrm{mM})$; various concentrations of $5 \mathrm{HMF} ; 1.5 \mathrm{M} \mathrm{pH} 7.0$ phosphate buffer; $0.5 \mathrm{M} \mathrm{NaCl} ; \mathrm{T}=38^{\circ} \mathrm{C} ; \mathrm{E}=-0.55 \mathrm{~V}$ vs. $\mathrm{Ag} / \mathrm{AgCl}$. 


\subsubsection{Different Proportions of HbS}

Another strategy which was investigated using the thin layer Pt matrix electrochemical cell was measuring the protein growth obtained from solutions composed of different ratios of $\mathrm{HbS}$ and $\mathrm{HbA}$. Consequently, five solutions consisting of $0 \% \mathrm{HbS}$ (or $100 \% \mathrm{HbA}$ ), $25 \% \mathrm{HbS}, 50 \% \mathrm{HbS}, 75 \% \mathrm{HbS}$ and $100 \%$ $\mathrm{HbS}$ (or $0 \% \mathrm{HbA}$ ) were tested and the results are shown in figure 6.9. As studies [34] have shown, the presence of other $\mathrm{Hb}$ variants in mixtures with $\mathrm{HbS}$ generally has the effect of increasing the solubility of deoxyHbS. This is because the $\mathrm{HbS}$ molecular crowding is diminished with a variable intracellular $\mathrm{Hb}$ composition, and thus the molecular collisions between $\mathrm{HbS}$ particles are fewer. Consequently, increased proportions of $\mathrm{HbA}, \mathrm{HbF}$ or $\mathrm{HbC}$ results in decreased clinical severity (section 6.4). The results showed that the greatest protein growth was seen with $100 \% \mathrm{HbS}$. However, decreasing the percentage of $\mathrm{HbS}$ by $25 \%$, or in other words having a $75 \% \mathrm{HbS}$ to $25 \% \mathrm{HbA}$ ratio saw the maximum turbidity level decrease by nearly thirteen fold from a value near 1.0 to one below 0.1 . Further reductions in the ratio of $\mathrm{HbS}$ only caused small decreases in the turbidity. These were preliminary experiments designed to test whether any effect was present. Further work will be required to ascertain the mechanisms as well as detailed contributions of the presence of other $\mathrm{Hb}$ mixtures. 


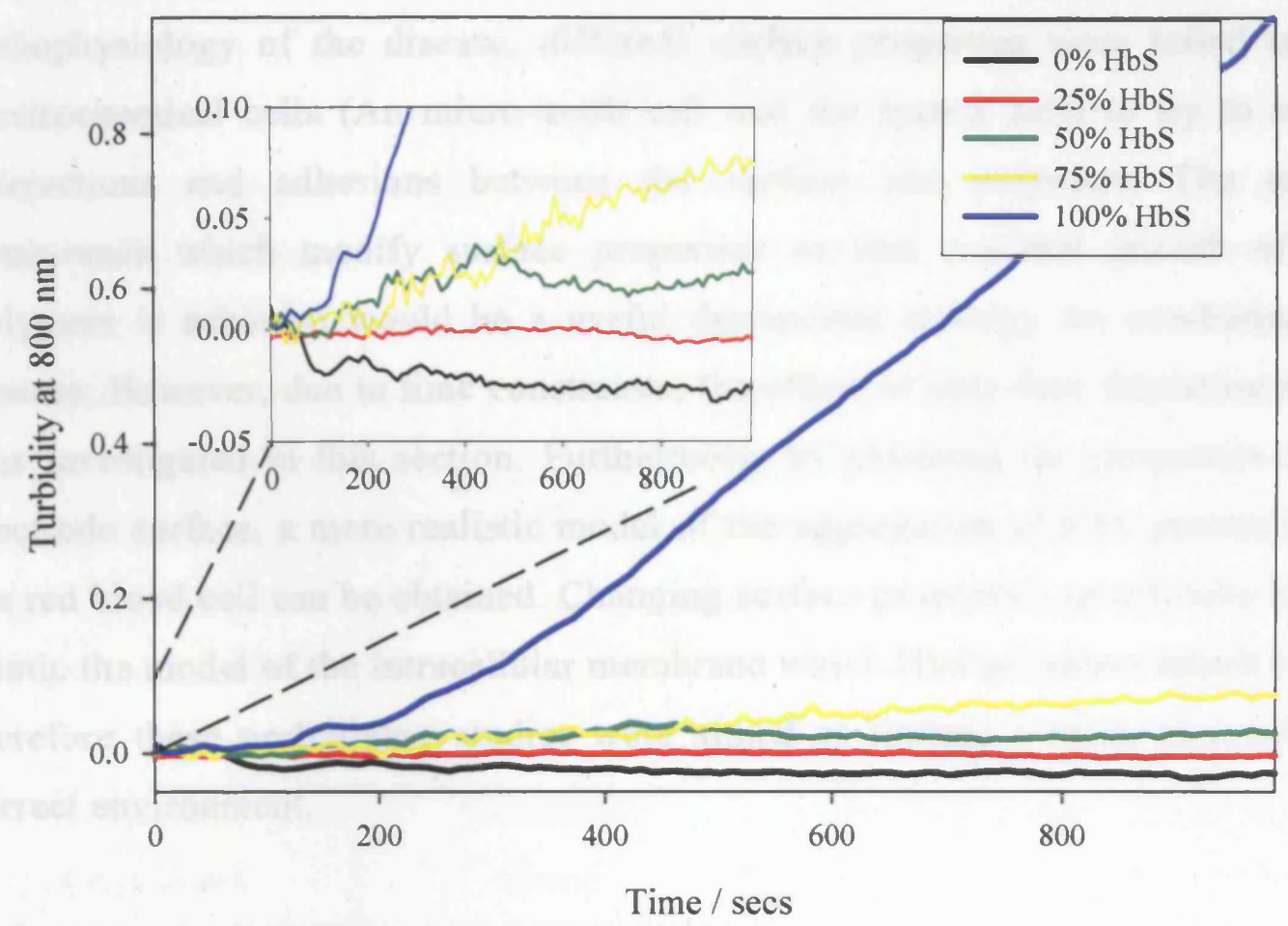

Figure 6.9: UV-visible spectroelectrochemistry time traces showing changes in turbidity at $\mathrm{Pt}$ matrix electrode for different proportions of $\mathrm{HbS}$. Experiment conditions: total protein concentration $60 \mathrm{mg} \mathrm{cm}^{-3} ; 1.5 \mathrm{M} \mathrm{pH} 7.0$ phosphate buffer; $0.5 \mathrm{M} \mathrm{NaCl} ; \mathrm{T}=38{ }^{\circ} \mathrm{C} ; \mathrm{E}=-0.55 \mathrm{~V} v$ s. $\mathrm{Ag} / \mathrm{AgCl}$; proportions of $\mathrm{HbS}: \mathrm{HbA}=0 \% ; 100 \%\left(60 \mathrm{mg} \mathrm{cm}^{-3} \mathrm{HbA}\right) ; 25 \%: 75 \%\left(15 \mathrm{mg} \mathrm{cm}^{-3} \mathrm{HbS}\right.$ : $45 \mathrm{mg} \mathrm{cm}^{-3} \mathrm{HbA}$ ); $50 \%: 50 \%$ (30 mg cm $\mathrm{mbS}^{-3} \mathrm{Hb} \mathrm{mg} \mathrm{cm}^{-3} \mathrm{HbA}$ ); $75 \%: 25 \%\left(45 \mathrm{mg} \mathrm{cm}^{-3} \mathrm{HbS}: 15\right.$ $\left.\mathrm{mg} \mathrm{cm}{ }^{-3} \mathrm{HbA}\right) ; 100 \%: 0 \%\left(60 \mathrm{mg} \mathrm{cm}^{-3} \mathrm{HbA}\right)$. 


\subsection{Use of Compounds which Modify Surface Properties}

As the damage of the plasma membrane in vivo has a big impact on the pathophysiology of the disease, different surface properties were tested in two electrochemical cells (Au micro-mesh cell and Au matrix cell) to try to reduce interactions and adhesions between the surface and polymers. The use of compounds which modify surface properties so that minimal growth of $\mathrm{HbS}$ polymers is achieved would be a useful therapeutic strategy for combating this disease. However, due to time constraints, the effect of only four thiolating agents was investigated in this section. Furthermore, by changing the properties of the electrode surface, a more realistic model of the aggregation of HbS protein inside the red blood cell can be obtained. Changing surface properties specifically tries to mimic the model of the intracellular membrane which $\mathrm{HbS}$ polymers attach to, and therefore these preliminary studies were aimed at finding a more physiological correct environment. 


\subsubsection{Effect of changing surface properties on the Growth of $\mathrm{HbS}$}

\section{Aggregates in Au matrix cell}

An investigation of the effect of surface modification on $\mathrm{HbS}$ protein aggregation was performed at an Au matrix cell by thiolating the Au surface with different thiol-based compounds. The compounds used were 3-mercapto-1-propenesulfonic acid, 2-mercaptoethanol, 1-butanethiol and cystamine dihydrochloride (the structures of these compounds are shown in figure 6.2). Each specific thiol compound provided a varied surface such that the effect of a range of different surfaces on $\mathrm{HbS}$ polymerisation could be investigated. Thus, thiolating with 3mercapto-1-propenesulfonic acid provided a $\mathrm{SO}_{3}{ }^{-}$end group giving the surface a negatively charged functionality, see table $\mathbf{6 . 3}$ for a description of each thiol group and its functionality.

\begin{tabular}{|l|l|l|l|}
\hline \multicolumn{1}{|c|}{$\begin{array}{c}\text { Thiol } \\
\text { Compound }\end{array}$} & \multicolumn{1}{|c|}{$\begin{array}{c}\text { Functional } \\
\text { Group }\end{array}$} & $\begin{array}{c}\text { Functional group } \\
\text { at pH 7 }\end{array}$ & $\begin{array}{l}\text { Functionality } \\
\text { at pH 7 }\end{array}$ \\
\hline $\begin{array}{l}\text { 3-mercapto-1- } \\
\text { propenesulfonic acid }\end{array}$ & $-\mathrm{CH}_{2}-\mathrm{CH}_{2}=\mathrm{C}_{-}-\mathrm{SO}_{3}^{-}$ & $-\mathrm{CH}_{2}=\mathrm{CH}_{2}-\mathrm{C}_{-}-\mathrm{SO}_{3}{ }^{-}$ & $\begin{array}{l}\text { Negatively } \\
\text { charged }\end{array}$ \\
\hline 2-mercaptoethanol & $-\mathrm{CH}_{2}-\mathrm{CH}_{2}-\mathrm{OH}$ & $-\mathrm{CH}_{2}-\mathrm{CH}_{2}-\mathrm{OH}_{2}{ }^{+}$ & Hydrophilic \\
\hline 1-butanethiol & $-\mathrm{CH}_{2}-\mathrm{CH}_{2}-\mathrm{CH}_{2}-\mathrm{CH}_{3}$ & $-\mathrm{CH}_{2}-\mathrm{CH}_{2}-\mathrm{CH}_{2}-\mathrm{CH}_{3}$ & Hydrophobic \\
\hline $\begin{array}{l}\text { Cystamine } \\
\text { dihydrochloride }\end{array}$ & $-\mathrm{CH}_{2}-\mathrm{CH}_{2}-\mathrm{NH}_{2}$ & $-\mathrm{CH}_{2}-\mathrm{CH}_{2}-\mathrm{NH}_{3}{ }^{+}$ & $\begin{array}{l}\text { Positively } \\
\text { charged }\end{array}$ \\
\hline
\end{tabular}

Table 6.3: Structure and functionality of the thiol-based compounds used to alter the surface properties of the gold surfaces

In this section the experiments were performed with a Au matrix cell rather than the Pt matrix cell. The matrix cell provided a system in which reduction of $\mathrm{O}_{2}$ was more efficient than the micromesh cell and thus closer to the physiological reducing power. The Au matrix cell was fabricated specifically for this investigation as the Au surface allowed the surface properties to be easily modified through thiolation of the surface. The Au matrix cell was manufactured in exactly the same way as its Pt counterpart, using an Au sheet of the same dimensions with holes of $350 \mu \mathrm{m}$ in diameter. 
The effect of changing surface properties on the turbidity was investigated at two $\mathrm{HbS}$ protein concentrations, $30 \mathrm{mg} \mathrm{cm}^{-3}$ and $75 \mathrm{mg} \mathrm{cm}^{-3}$, see figure 6.10. The $\mathrm{Au}$ electrode was incubated in a solution of the thiolating agent and $\mathrm{HbS}$ protein dissolved in $1.5 \mathrm{M}$ pH 7.0 phosphate buffer was added to the cell to study the variance in polymer growth and aggregation.

a

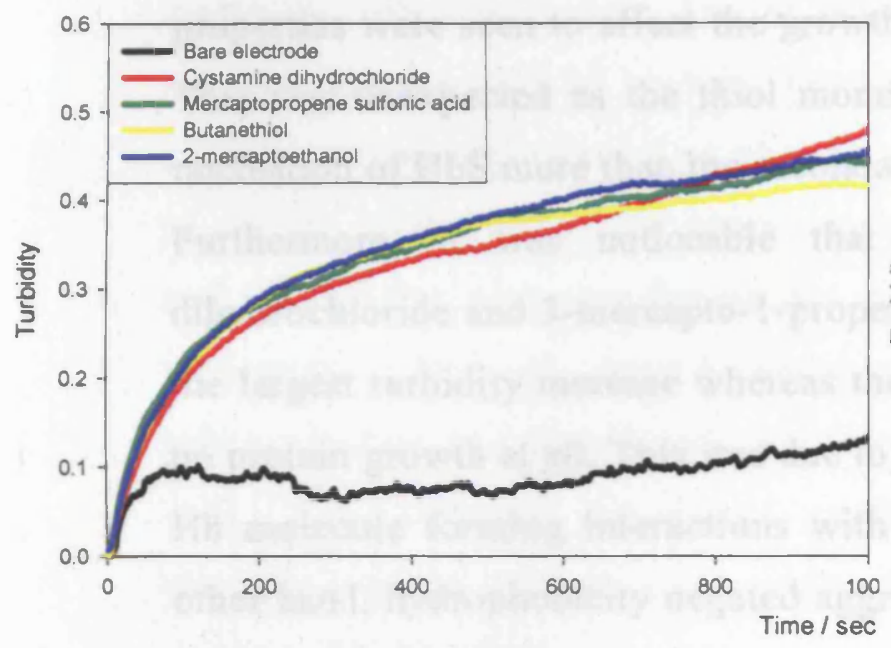

b

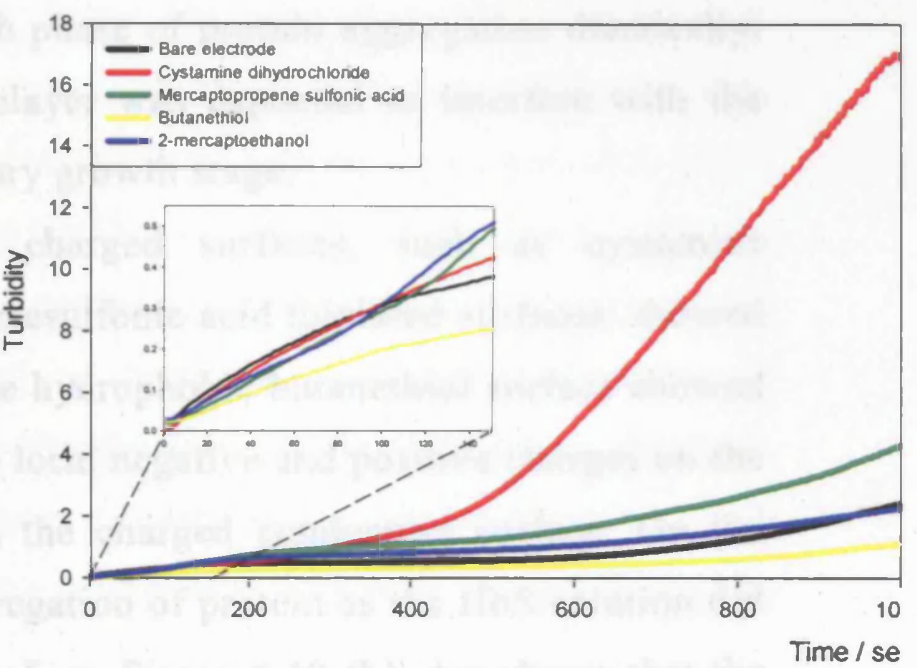

Figure 6.10: UV-visible spectroelectrochemistry time traces showing the effect of different surface properties on changes in turbidity at thiolated Au matrix electrode. Experiment conditions: (a) $\mathrm{HbS}$ concentration $30 \mathrm{mg} \mathrm{cm}^{-3}$ (b) $\mathrm{HbS}$ concentration $75 \mathrm{mg} \mathrm{cm}^{-3}$; thiol concentration $2 \mathrm{mM}$ dissolved in $1.6 \mathrm{mM} \mathrm{H}_{2} \mathrm{SO}_{4} ; 1.5 \mathrm{M} \mathrm{pH} 7.0$ phosphate buufer; $0.5 \mathrm{M} \mathrm{NaCl} ; \mathrm{T}=38{ }^{\circ} \mathrm{C} ; \mathrm{E}=-0.55 \mathrm{~V}$ vs. $\mathrm{Ag} / \mathrm{AgCl}$.

At low protein concentration of $30 \mathrm{mg} \mathrm{cm}^{-3}$, figure 6.10 (a), the turbidity profiles showed that changing surface properties seemed to have hardly no effect on the polymerisation process; neither the nucleation nor the growth process changed very much by changing the thiolating agent but all followed a similar aggregation course. Turbidity changes at a bare electrode were minimal compared with thiolated surfaces. All experiments were repeated at least three times and even with multiple repeats similar results were obtained.

Originally it was thought that the similarity in results was due to contamination of one of the thiols, however, the electrode surface was electrochemically cleaned thoroughly with dilute $\mathrm{H}_{2} \mathrm{SO}_{4}$ between each experiment until the characteristic $\mathrm{CV}$ for a clean $\mathrm{Au}$ electrode was obtained. Consequently, the similarity of all the turbidity profiles, even when using different thiol functional groups, suggested that 
the mechanism of nucleation and growth at low protein concentrations was the same as long as the surface was thiolated.

At high protein concentrations of $75 \mathrm{mg} \mathrm{cm}^{-3}$, figure 6.10 (b), the results showed that the initial nucleation phase of protein aggregation did not seem to be affected by changing surface properties; consequently, all turbidity profiles up to $300 \mathrm{~s}$ followed a similar course with extremely little growth. However, the turbidity levels from $300 \mathrm{~s}$ to $1000 \mathrm{~s}$ increased significantly and therefore changing surface properties were seen to affect the growth phase of protein aggregation drastically. This was unexpected as the thiol monolayer was expected to interfere with the nucleation of $\mathrm{HbS}$ more than the secondary growth stage.

Furthermore, it was noticeable that charged surfaces, such as cystamine dihydrochloride and 3-mercapto-1-propenesulfonic acid thiolated surfaces, showed the largest turbidity increase whereas the hydrophobic butanethiol surface showed no protein growth at all. This was due to local negative and positive charges on the $\mathrm{Hb}$ molecule forming interactions with the charged conducting surface. On the other hand, hydrophobicity negated aggregation of protein as the HbS solution did not interact well with the butanethiol surface. Figure 6.10 (b) also shows that the early stage of the turbidity profiles of all thiolating agents showed hardly any variation, similar to the results seen at $30 \mathrm{mg} \mathrm{cm}^{-3}$ (figure 6.10 (a)), and changes were only seen in the elongation phase. Consequently, it was shown that changing surface properties had little or no effect on the nucleation but it did affect the rate of polymer growth substantially. 


\subsubsection{Effect of changing surface properties on the Growth of $\mathrm{HbS}$}

\section{Aggregates in Au micromesh cell}

The effect of altering surface properties on the growth of HbS fibres was also investigated at the Au micromesh cell in the same way as the matrix cell. Consequently, the Au surface was thiolated with the same thiol-based compounds, 3-mercapto-1-propenesulfonic acid, 2-mercaptoethanol, 1-butanethiol and cystamine dihydrochloride. Figure 6.11 shows the rate of turbidity change, a measure of the rate of protein aggregation, at these thiolated surfaces. HbS experiments were performed as normal, consisting of a protein solution with $\mathrm{NaCl}$ to aid the conductivity. The results were similar to those seen in figure 6.10 (b) and showed that changing the surface properties did not seem to affect the initial nucleation phase of protein aggregation, however, the growth phase of polymerisation was significantly altered with the greatest turbidity levels obtained with the charged thiolating surfaces (cystamine dihydrochlorde and mercaptopropene sulfonic acid), whilst the lowest was seen with the hydrophobic surface of butanethiol.

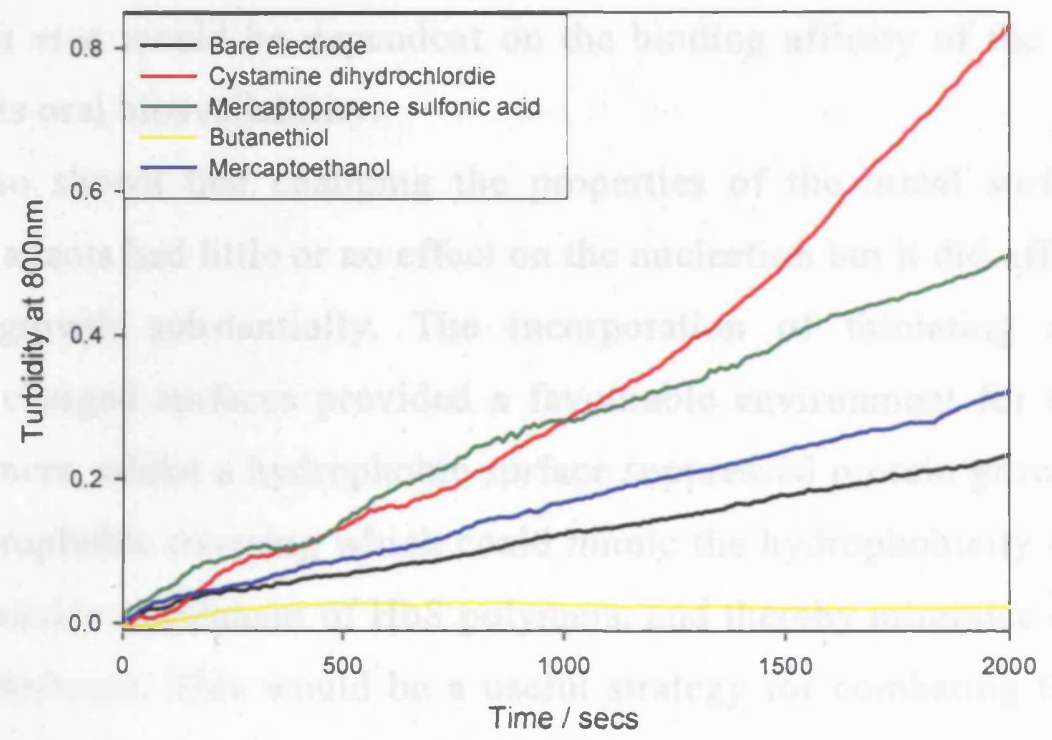

Figure 6.1: UV-visible spectroelectrochemistry time traces showing the effect of different surface properties on changes in turbidity at thiolated Au micromesh electrode. Experiment conditions: $\mathrm{HbS} 50 \mathrm{mg} \mathrm{cm}^{-3}$; thiol concentration $2 \mathrm{mM}$ dissolved in $1.6 \mathrm{mM} \mathrm{H}_{2} \mathrm{SO}_{4} ; 1.5 \mathrm{M} \mathrm{pH} 7.0$ phosphate buffer; $0.5 \mathrm{M} \mathrm{NaCl} ; \mathrm{T}=38^{\circ} \mathrm{C} ; E=-0.55 \mathrm{~V}$ vs. $\mathrm{Ag} / \mathrm{AgCl}$. 


\subsection{Conclusions}

Investigations in this chapter were focussed on using the thin layer electrochemical cell as a novel assay system to investigate the effectiveness of potential antisickling agents which cause chemical modification of the $\mathrm{HbS}$ structure. It was shown that vanillin and 5-HMF, two naturally occurring cyclic aldehyde compounds whose reported mechanism of action is Schiff base covalent modification of $\mathrm{Hb}$, caused a significant decrease in the polymerisation of $\mathrm{HbS}$ aggregates. It was seen that these biological compounds had a pronounced effect on the growth phase of aggregation but not the nucleation phase, as exemplified by the linear regression calculations of phase I and phase III. It was also seen that 5HMF was more effective than vanillin as equimolar concentrations of vanillin caused a five fold decrease in the turbidity whilst an eight fold reduction was seen with 5-HMF. Furthermore, the addition of vanillin at different points in the polymerisation life cycle was shown to disrupt the subsequent growth of polymers. Consequently, it was demonstrated that a verifiable screening device for investigating compounds as potential agents for disrupting the growth of $\mathrm{HbS}$ polymers could be developed. Compounds with a similar mechanism of action could be screened for a reduction in the turbidity levels however any therapeutic efficacy in vivo would be dependent on the binding affinity of the compound to $\mathrm{HbS}$ and its oral bioavailability.

It was also shown that changing the properties of the metal surface by using thiolating agents had little or no effect on the nucleation but it did affect the rate of polymer growth substantially. The incorporation of thiolating agents which produced charged surfaces provided a favourable environment for the growth of HbS polymers, whilst a hydrophobic surface suppressed protein growth suggesting that a hydrophobic covering which could mimic the hydrophobicity of butanethiol would minimise attachment of $\mathrm{HbS}$ polymers, and thereby minimise damage to the plasma membrane. This would be a useful strategy for combating the cascade of events associated with the pathophysiology of this disease. In future it is hoped that a similar set-up can be used to screen multiple compounds for potential efficacy against polymerisation of $\mathrm{HbS}$ fibres and even different stages of polymerisation. 
Chapter 7: Direct Electrochemistry of HbS Polymers 


\subsection{Introduction}

$\mathrm{Hb}$ contains two $\alpha$ subunits and two $\beta$ subunits, each of which has an electroactive Fe haem group. Although, $\mathrm{Hb}$ does not function physiologically as an electron carrier, it is an ideal molecule for the study of electron transfer reactions of haem proteins because of its commercial availability, moderate cost and a known and documented structure. Furthermore, $\mathrm{Hb}$ has enzyme like oxidative and reductive catalytic activities, similar to the haem enzyme cytochrome $P_{450}$ [136].

Great efforts in the field of protein electrochemistry have led to a number of studies concerning heterogeneous electron transfer and electrochemical behaviour with $\mathrm{Hb}$ being performed at bare electrodes, such as silver [137] and boron doped diamond [138], as well as using mediators and promoters which enhance the electron transfer for $\mathrm{Hb}$. However, only a handful of publications have actually described a behaviour which is consistent with the physiological function: a redox potential around $-70 \mathrm{mV} v s$. SCE and electron transfer rates exhibiting slow irreversible heterogeneous kinetics [139 - 141]. The $\mathrm{Hb}$ molecule behaves quite "redox inert" as is reflected by the rate constant of the self exchange of $3 \times 10^{-3}$ $\mathrm{mol}^{-1} \mathrm{~s}^{-1}$ and the relatively slow oxidation of ferricyanide $\left(k=7 \times 10^{4} \mathrm{~mol}^{-1} \mathrm{~s}^{-1}\right)$ $[142,143]$.

The facilitation of direct electron transfer between $\mathrm{Hb}$ and electrodes is difficult since $\mathrm{Hb}$ is a globular oligomeric protein, which may easily poison the electrodes, and the large size of the protein means that the rates of electron transfer between $\mathrm{Hb}$ and naked electrodes are extremely slow. Furthermore, proteins are generally irreversibly adsorbed at solid electrodes and to be effective, the native structural and reactivity characteristics of the protein must be retained in the adsorbed state $[136,144]$. For large protein molecules such as $\mathrm{Hb}$, the active sites are generally well separated from those in neighbouring molecules so although kinetics of direct electrochemistry tend to be slow due to inaccessibility of the haem active site, the bulkiness of $\mathrm{Hb}$ means that no significant changes should occur upon adsorption. However, the structural state of adsorbed bio-macromolecues is still subject to considerable debate.

On the other hand, use of modified electrodes by entrapment within a polymer matrix or thiolation of the surface tends to cause drastic structural changes which are not physiologically relevant as reflected by a fast electron transfer and a 
dramatic cathodic shift of the electrode potential. Examples of studies on the electrochemistry of $\mathrm{Hb}$ in stable films include the use of bovine Hb-coated polystyrene latex bead films which were prepared and deposited on PG electrodes, showing a pair of well-defined, quasi-reversible CV peaks at about $-360 \mathrm{mV}$ vs. SCE [145] as well as several other studies using ionomer films of Eastman AQ, [146] dimyristoyl phosphatidylcholine [147] and of DDAB-clay [148]. For an excellent review on the topic of direct electrochemistry of $\mathrm{Hb}$ the reader is directed to a paper by Scheller et. al. titled "Thirty years of Haemoglobin Electrochemistry" [136].

However, although numerous studies have demonstrated direct electron transfer between $\mathrm{Hb}$ monomers, to the best of our knowledge there have been no studies performed on the direct electrochemistry of HbS polymers. In this chapter, the direct electrochemistry or the electron conducting properties of $\mathrm{HbS}$ aggregates, formed by an ex-situ isothermal method, is investigated at a number of different electrodes. In theory, electrochemistry of HbS polymers should be easily achieved with no need for mediators as the spatially linked haem groups and closely aligned $\mathrm{HbS}$ active sites in the fibrous state should aid electron transfer. 


\subsection{Experimental}

\subsubsection{Materials, Instrumentation and Procedures}

Proteins $\mathrm{HbS}, \mathrm{HbA}$ and haemin were used as supplied. Ag metal wire (grade 1, diameter $0.05 \mathrm{~mm}$ ), Au metal wire (diameter $0.1 \mathrm{~mm}$, hard temper, $99.99 \%$ purity) and Pt metal wire (diameter $0.1 \mathrm{~mm}$, hard temper, $99.99 \%$ purity) were employed for the fabrication of microelectrodes. A number of bare and modified WE were used to investigate direct electrochemistry of $\mathrm{Hb}$. These can be listed as follows: $\mathrm{Au}$ microelectrode; Ag microelectrode; poly-L-lysine (PLL) modified $\mathrm{Au}$ microelectrode, 3-mercapto-1-propenesulfonic acid modified Au microelectrode, cystamine dihydrochloride modified $\mathrm{Au}$ microelectrode; iota-carrageenans modified Au microelectrode; and Au disk macroelectrode (surface area $0.78 \mathrm{~mm}^{2}$ ). The microelectrodes were fabricated by placing an $\mathrm{Au}$ or Ag wire through a $5 \mu \mathrm{l}$ pipette and cleaving the end of the wire to obtain a clean electrode surface. The pipette was subsequently covered with epoxy resin. The PLL-modified electrode was obtained by immersing the electrode in neat PLL for 15 minutes at room temperature and thoroughly rinsing with double distilled water, whilst the thiolmodified electrodes were obtained by immersing the electrodes in an acid solution (1.6 $\mathrm{mM} \mathrm{H}_{2} \mathrm{SO}_{4}$ ) containing $2 \mathrm{mM}$ thiol compound for two hours, and then rinsing with double distilled water to remove any physisorbed materials. The iotacarrageenan modified electrode was obtained by incubating for 15 minutes in a solution of $0.5 \mathrm{mg} \mathrm{cm}^{-3}$ carrageenan and $10 \mathrm{mM} \mathrm{KCl}$ dissolved in pure water. All solutions were thoroughly degassed with $\mathrm{Ar}$ gas prior to use. Before each modification and experiment the WE was cleaned by electrochemical cycling of $\mathrm{H}_{2} \mathrm{SO}_{4}$ until no further changes in the voltammetric response could be seen and then it was carefully polished to a smooth surface on silica impregnated with aluminium oxide powder suspensions of decreasing particle sizes of $1 \mu \mathrm{m}, 0.3 \mu \mathrm{m}$ and $0.05 \mu \mathrm{m}$. Finally, the electrodes were cleaned by ultrasonication in double distilled water. $\mathrm{CV}$ was performed using a $\mathrm{PC}$ operated potentiostat controlled by GPES software, in a three-electrode system with a Pt auxiliary electrode and an $\mathrm{Ag} / \mathrm{AgCl}(3 \mathrm{M} \mathrm{KCl})$ reference electrode. Absorption spectra were recorded in a 1 $\mathrm{mm}$ glass cuvettes and the temperature was maintained and controlled with the use of a small peltier device. Refer to chapter 2 for a general description of the experimental. 


\subsubsection{HbS Polymer Formation and Experimental Preparation}

$\mathrm{HbS}$ polymer formation was achieved using the ex-situ isothermal salting out method (experimental procedure 4) described in chapter 2.5 Degassed phosphate buffer solution $(2.42 \mathrm{ml}, 2.52 \mathrm{M}, \mathrm{pH} 7.0)$ at $38{ }^{\circ} \mathrm{C}$ was quickly added to $0.17 \mu \mathrm{M}$ $\mathrm{HbS}$ dissolved in $0.025 \mathrm{M}$ phosphate buffer solution also at $38{ }^{\circ} \mathrm{C}$ causing $\mathrm{HbS}$ protein aggregates to be formed. HbS polymer formation was followed spectroscopically in the UV-visible spectrometer. Spectra's which did not show an increase in absorbance, indicating polymer formation, were not used any further. All solutions were stored under $\mathrm{Ar}$ in the fridge until use and used within one day of its initial preparation.

The electrodes were prepared by drop coating small amounts of the fibre solution on to the tip of a clean electrode using a half cut pipette to reduce shear forces. This step was performed several times under an inert atmosphere. The drop coated fibre solution was left in contact with the electrode for 30 minutes and then washed by slowly dipping in deoxygenated pure water and dried by placing the electrode in an Ar environment. It was imperative that the electrode, either before or during the experiment, was not in contact with atmospheric $\mathrm{O}_{2}$ for long periods, consequently, all solutions were thoroughly degassed prior to use and care was taken to ensure all procedures were performed in an inert environment. During the experiments, Ar gas was bubbled slowly through the buffer solution at a rate which ensured that the solution remained deoxygenated but did not cause vibrations which affected the results. CV potentials ranged from $-0.7 \mathrm{~V}$ to $+0.8 \mathrm{~V}$ for the forward and reverse cycle and were scanned at a rate in the range of $25 \mathrm{mV} \mathrm{s}^{-1}$ to $250 \mathrm{mV} \mathrm{s}^{-1} v s$. the quasi-reference electrode. 


\subsection{Direct Electrochemistry of HbS Polymers}

\section{Direct Electrochemistry at Bare Electrodes:}

Figure 7.1 (a) shows the $\mathrm{CV}$ of $\mathrm{HbS}$ polymers at a bare Au microelectrode of diameter $50 \mu \mathrm{m}$ in a $1.5 \mathrm{M} \mathrm{pH} 7$ phosphate buffer solution at a scan rate of 200 $\mathrm{mV} \mathrm{s}^{-1}$. A well-defined reduction peak at around $-184 \mathrm{mV}$ vs. $\mathrm{Ag} / \mathrm{AgCl}$ is observed on the forward scan but no oxidation peak is observable on the reverse scan. The lack of an anodic peak indicates that electron transfer rate is low representing an almost irreversible process. A cathodic shift of more than a 100 $\mathrm{mV}$, compared with the redox potential generally seen for direct $\mathrm{Hb}$ monomer electrochemistry (- $70 \mathrm{mV}$ vs. SCE) is observed in our experiments. This shift is slightly less than that expected for a gel-like polymeric material such as $\mathrm{HbS}$ polymers as normally, a shift of more than $200 \mathrm{mV}$ is associated with the use of stable polymeric films which immobilise the $\mathrm{Hb}$ protein and mediate electron transfer [136]; although $\omega$-hydroxyalkane thiols modified Au electrodes investigating the electrochemical properties of $\mathrm{Hb}$ have shown a peak at $-170 \mathrm{mV}$ vs. SCE using sodium trifluroacetate as electrolyte at $\mathrm{pH} 7.1$ [149].

Control experiments performed with free $\mathrm{HbS}$ monomers at the same electrode surface and under the same conditions did not show any reduction peak in this region confirming that the peak was a result of direct electron transfer between $\mathrm{HbS}$ polymers and the Au surface. Control experiments, performed with free $\mathrm{HbA}$ and free haemin (CVs not shown) also did not show any peaks whilst the blank phosphate buffer scan showed that this peak was not due to the presence of $\mathrm{O}_{2}$. All sample preparations and electrochemical measurements were performed under a strict anaerobic environment. These experiments, however, did not allow the mechanism of electron transfer to be investigated in detail and so further work is required in this area.

Figure 7.1 (b) shows CV's of the same solution of HbS polymers performed one after the other with the latter CV (HbS fibres 2) being performed after a delay of twenty minutes. The reduction peak was present in the first CV but a repeat CV of the same solution performed after twenty minutes showed the disappearance of the peak. This indicated that the polymers adsorbed to the electrode were either breaking away from the surface due to oxidation or were being rendered electrochemically inactive thus blocking the electrochemical response. 


\section{SPECIAL NOTE}

ITEM SCANNED AS SUPPLIED

PAGINATION IS AS SEEN 
increased with more basic solutions compared to acidic ones as a result of more favourable interactions at the electrode surface.

a

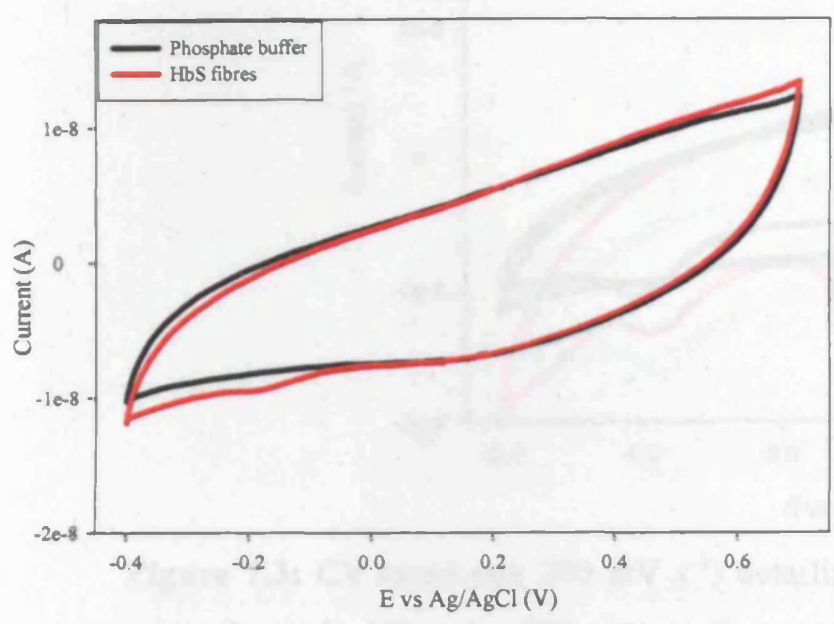

b

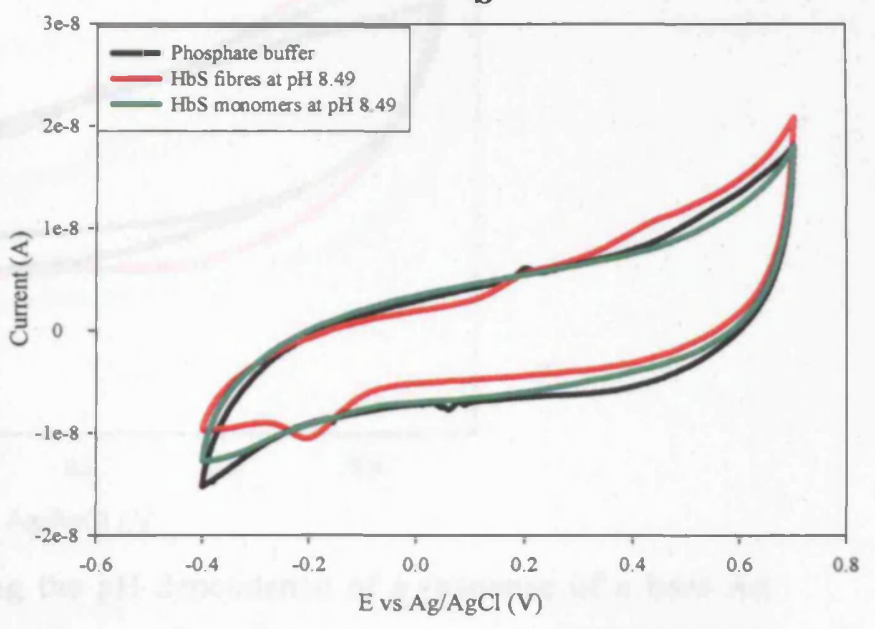

Figure 7.2: $\mathrm{CV}$ (scan rate $200 \mathrm{mV} \mathrm{s}^{-1}$ ) detailing the response of a bare Au microelectrode (diameter $250 \mu \mathrm{m}$; surface area $4.91 \times 10^{4} \mu \mathrm{m}^{2}$ ) in (a) the presence of $\mathrm{HbS}$ fibres formed using the ex-situ isothermal method in blank pH 6.1, 1.5 M phosphate buffer; and (b) in the presence of $\mathrm{HbS}$ fibres formed using the ex-situ isothermal method and $\mathrm{HbS}$ monomers in blank $\mathrm{pH} 8.49,1.5 \mathrm{M}$ phosphate buffer. Experimental conditions: HbS concentration $20 \mathrm{mg} \mathrm{cm}^{-3}, 1.5 \mathrm{M},(\mathrm{pH} 6.1$ and 8.49) phosphate buffer, temperature $38{ }^{\circ} \mathrm{C}$, dithionite $10 \mathrm{mg} \mathrm{ml}^{-1}$; potential window $+0.7 \mathrm{~V}$ to $0.4 \mathrm{~V}$. All solutions and experiments were thoroughly degassed.

Another interesting point was that increasing the $\mathrm{pH}$ of the buffer solution led to a cathodic shift in the potential of the reduction peak, as indicated in figure $\mathbf{7 . 3}$ which shows CVs of HbS polymers performed in solutions of $\mathrm{pH} 6.1, \mathrm{pH} 7.0$ and $\mathrm{pH}$ 8.49. This peak shift was probably due to polymers orientating themselves on the electrode surface in slightly different ways as a result of variances in the surface charge of the polymers at different $\mathrm{pHs}(\mathrm{pI}$ of $\mathrm{HbS}=7.2)$. Furthermore, the peak shift was another indication of the $\mathrm{pH}$ dependence. 


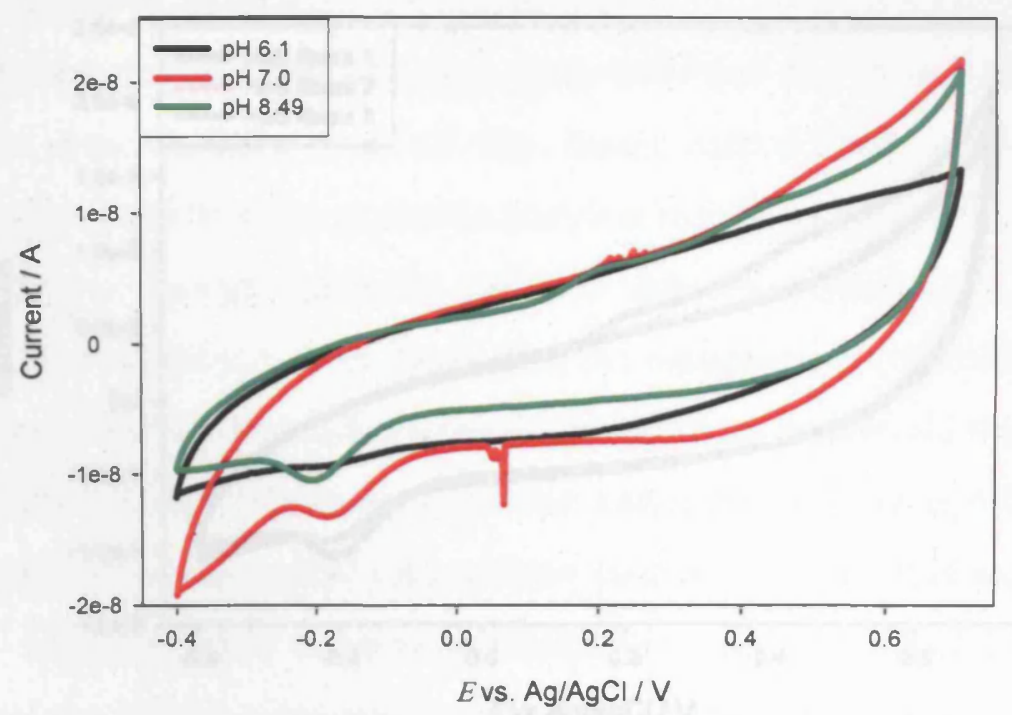

Figure 7.3: $\mathrm{CV}$ (scan rate $200 \mathrm{mV} \mathrm{s}^{-1}$ ) detailing the $\mathrm{pH}$ dependence of a response of a bare Au microelectrode (diameter $250 \mu \mathrm{m}$; surface area $4.91 \times 10^{4} \mu \mathrm{m}^{2}$ ) in the presence of HbS fibres formed using the ex-situ isothermal method in blank pH 6.1, pH 7.0 and pH 8.49 (1.5 M) phosphate buffer. Experimental conditions: HbS concentration $20 \mathrm{mg} \mathrm{cm}^{-3}, 1.5 \mathrm{M},(\mathrm{pH} 6.1$ and 8.49) phosphate buffer, temperature $38^{\circ} \mathrm{C}$, dithionite $10 \mathrm{mg} \mathrm{ml}^{-1}$; potential window $+0.7 \mathrm{~V}$ to $0.4 \mathrm{~V}$. All solutions and experiments were thoroughly degassed.

Furthermore, figure 7.4 shows a set of three CVs of $\mathrm{HbS}$ polymers run in $1.5 \mathrm{M}$ basic phosphate buffer mixture of $\mathrm{pH}$ 8.49. These CVs were run straight one after other with the same electrochemical conditions (i.e. the same potential window, + $0.7 \mathrm{~V}$ to $-0.4 \mathrm{~V}$, as well as the same scan rate, $200 \mathrm{mV} \mathrm{s}^{-1}$ ) and showed that over time there was a reduction of $0.2 \times 10^{-10} \mathrm{~A}$ in the peak size from the first scan to the second scan. No peak shift was noticeable. These results were similar to those seen in figure 7.1 (b) as they showed a reduction in the peak current over time. 


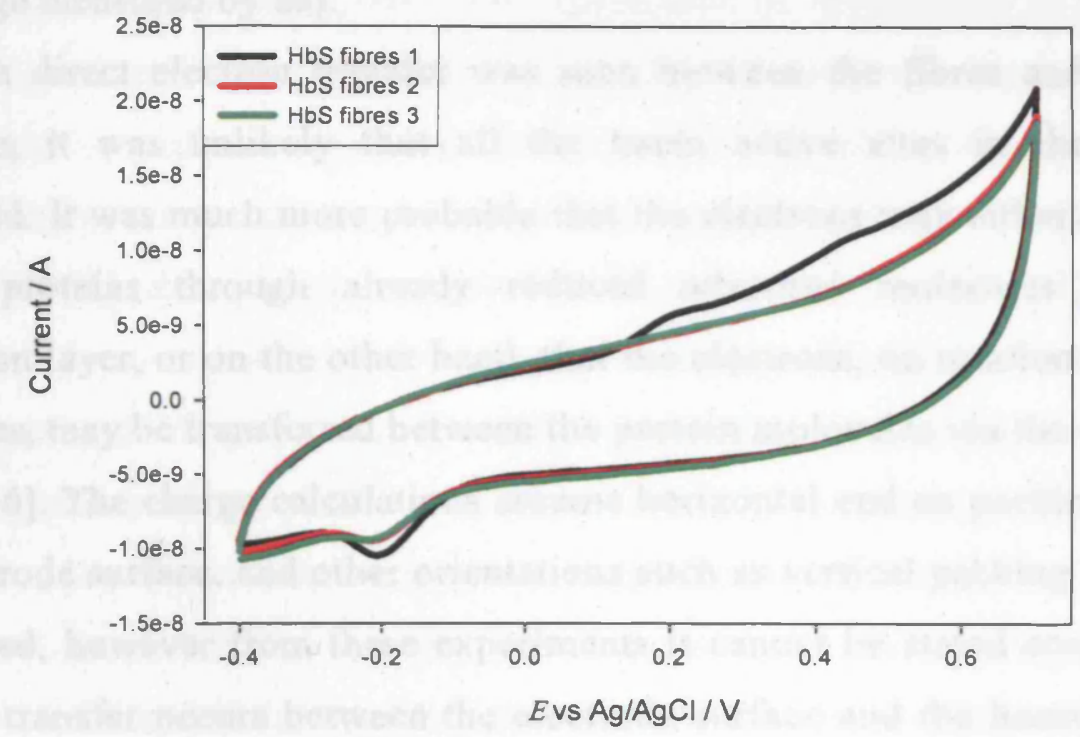

Figure 7.4: $\mathrm{CV}$ (scan rate $200 \mathrm{mV} \mathrm{s}^{-1}$ ) detailing the response of a bare Au microelectrode (diameter $250 \mu \mathrm{m}$; surface area $4.91 \times 10^{4} \mu \mathrm{m}^{2}$ ) in the presence of HbS fibres at the beginning of the experiment ( $\mathrm{HbS}$ fibres 1 ), after 5 minutes (HbS fibres 2) and after 10 minutes (HbS fibres 3 ) in blank pH 8.49, $1.5 \mathrm{M}$ phosphate buffer. Experimental conditions: HbS concentration $20 \mathrm{mg} \mathrm{cm}^{-}$ ${ }^{3}, 1.5 \mathrm{M}, \mathrm{pH} 7$ phosphate buffer, temperature $38{ }^{\circ} \mathrm{C}$, dithionite $10 \mathrm{mg} \mathrm{ml}^{-1}$; potential window +0.7 $\mathrm{V}$ to $-0.4 \mathrm{~V}$. All solutions and experiments were thoroughly degassed.

The surface coverage of protein fibres on a Au microelectrode of diameter $250 \mu \mathrm{m}$ in $\mathrm{pH} 7$ buffer solution (figure 7.1 (a)) was calculated to be $2.039 \times 10^{-5}{\mathrm{~mol} \mu \mathrm{m}^{-2}}^{-2}$ from the equation:

$$
\Gamma=\mathrm{Q} / \mathrm{n} \cdot \mathrm{F} \cdot \mathrm{A}
$$

where $Q$ is the charge of the peak seen in figure 7.1 (a), calculated to be $5.32 \times 10^{-}$ ${ }^{9} \mathrm{C}$; $\mathrm{n}$ is the number of moles of $\mathrm{HbS}\left(5.51 \times 10^{-14}\right.$ moles $)$; $\mathrm{A}$ is the surface area of the electrode $\left(4.91 \times 10^{4} \mu \mathrm{m}^{2}\right)$ and $\mathrm{F}$ is the Faraday constant.

If $\mathrm{HbS}$ fibres (single fibre $21.5 \mathrm{~nm}$ wide and $1 \mu \mathrm{m}$ long) are attached edge on, 178 molecules will be in contact with the electrode $\left(5.4 \times 10^{-3} \mu \mathrm{m}\right.$ per molecule $)$ and therefore for a monolayer, $2289719 \times 178$ electrons are expected per fibre translating to a value of $6.77 \times 10^{-16}$ moles or a charge of $6.50 \times 10^{-11} \mathrm{C}$. A much higher $\mathrm{HbS}$ fibre charge than corresponds to the reduction of one monolayer was obtained by us $\left(5.32 \times 10^{-9} \mathrm{C}\right)$, either due to a very rapid exchange of adsorbed molecules occurring or the charge transfer occurring through several adsorption layers (if the Fe centres were close enough in the fibre to have fast electron 
transfer then a charge of $3.3 \times 10^{-9} \mathrm{C}$ would be obtained for a bi-layer, similar to the charge measured by us).

Although direct electron transfer was seen between the fibres and the bare $\mathrm{Au}$ electrode, it was unlikely that all the haem active sites in the fibres were connected. It was much more probable that the electrons may either be transferred to the proteins through already reduced adsorbed molecules reaching the adsorption layer, or on the other hand, that the electrons, on rotation of the protein molecules, may be transferred between the protein molecules via the exposed haem edge [136]. The charge calculations assume horizontal end on packing of fibres on the electrode surface, and other orientations such as vertical packing have not been considered, however from these experiments it cannot be stated conclusively that electron transfer occurs between the electrode surface and the haem group. Some studies performed previously have suggested that the electrode reaction with haemoproteins involves electron transfer from the electrode to the prosthetic group and not the iron protoporphyrin redox centre [150]. A detailed mechanism of electron transfer between aggregated $\mathrm{HbS}$ structures and a naked electrode surface cannot be elucidated with the $\mathrm{CV}$ experiments performed in this chapter and further work is required on the direct electrochemistry of HbS polymers to carry forward the work demonstrated in this chapter. Direct electrochemistry experiments were also performed at a bare in-house built $\mathrm{Ag}$ microelectrode, similar to the fabrication of the Au microelectrode, but the results did not show any electrochemical behaviour. 


\section{Direct Electrochemistry at modified electrodes:}

Numerous modified electrodes were fabricated to investigate if facilitation of electron transfer between $\mathrm{HbS}$ polymers and the electrode surface is achieved through the use of mediators and promoters. In literature, many studies of $\mathrm{Hb}$ electrochemistry have shown that the use of modified electrodes, be it mediatormodified [151], nanoparticle-modified [148] or polymer-modified [152] helps the transfer of electrons but no such studies have been performed for HbS polymers. Consequently, $\mathrm{HbS}$ polymers, formed through the same isothermal salting out method, were drop coated onto $\mathrm{Au}$ and $\mathrm{Ag}$ microelectrodes modified with PLL, iota-carrageenans and thiolating agents such as cystamine dihydrochloride and 3mercapto-1-propenesulfonic acid, however, no electrochemical response was observed with any of the modified electrodes. Cystamine dihydrochloride and 3mercapto-1-propenesulfonic acid were used, as these two thiolating agents had shown the largest increases in protein growth with the Au matrix cell in chapter 6. Many different conditions were also employed such as dip coating the electrodes into the polymer solution instead of drop coating, using lower salt concentrations and higher temperatures as well as different $\mathrm{pH}$ values but again no electrochemistry was observed.

Further work is required to achieve electrochemistry between $\mathrm{HbS}$ polymers and modified electrodes. The use of different types of electrodes, such as carbon electrodes, need to be incorporated into these studies, whilst more experiments need to be performed with different thiolating agents. One such study describing the electrochemistry of $\mathrm{Hb}$ at L-cysteine modified $\mathrm{Ag}$ electrodes, has obtained cathodic and anodic peaks for $\mathrm{Hb}$ at potentials around $70 \mathrm{mV}$ and $270 \mathrm{mV}$ vs. $\mathrm{Ag} / \mathrm{AgCl}$ [150]. 


\subsection{Conclusions}

It was demonstrated that the direct electrochemistry of $\mathrm{HbS}$ aggregates could be observed at a bare Au microelectrode, confirmed by control experiments with free $\mathrm{HbS}$ monomers. A distinct reduction peak was seen but no oxidation peak was present indicating that the electron transfer rate was low representing an almost irreversible process. It was shown that the observation of a cathodic peak was $\mathrm{pH}-$ dependent as alkaline $\mathrm{pH}$ of 8.49 showed a prominent peak at $-207 \mathrm{mV}$ vs. $\mathrm{Ag} / \mathrm{AgCl}$ whilst a weak peak at $-182 \mathrm{mV}$ vs. $\mathrm{Ag} / \mathrm{AgCl}$ was seen in $\mathrm{pH} 6.1$ phosphate buffer. A cathodic shift in the potential of the reduction peak at different pHs was also observed, most probably due to variances in the orientation of polymers on the electrode surface. Furthermore, it was shown that the reduction peak slowly disappeared over time indicating that adsorbed polymers were breaking from the surface or polymers were dissolving as a result of $\mathrm{O}_{2}$ leakage into the system. Charge and surface coverage calculations indicate either the presence of more than one fibrous layer on the electrode surface or rapid exchange between adsorbed molecules. As a result it cannot be conclusively stated that reduction of haem group as opposed to prosthetic groups is occurring. Experiments performed with modified electrodes did not provide an electrochemical response.

These experiments which exhibited the direct transfer of electrons between polymeric $\mathrm{Hb}$ active sites and $\mathrm{Au}$ electrode could have a potential application as molecular nano-wires which could undergo reversible and controlled switching between a globular protein and the fibrous state by electrochemical modulation of $\mathrm{O}_{2}$ partial pressures. 


\section{Chapter 8: Concluding Remarks}




\subsection{Conclusions}

A method was devised for monitoring the aggregation of $\mathrm{HbS}$ at a conducting surface by electrochemical depletion of $\mathrm{O}_{2}$ in a series of specially constructed thin layer electrochemical cells. The electrochemical cells consisted of a three electrode system and provided optical transparency and small solution volumes whilst the geometry of the working electrode was found to be essential for the growth of $\mathrm{HbS}$ aggregate structures. A matrix geometry composed of an array of small holes was found to deplete $\mathrm{O}_{2}$ more efficiently than other cells with full depletion occurring within a 100 seconds of the start of the experiment as shown by theoretical modeling. The conditions for reproducible growth of $\mathrm{HbS}$ aggregated structures at the Pt electrode were obtained and shown to consist of a high protein concentration (ca. $300 \mathrm{mg} \mathrm{cm}^{-3}$ ) when using the Pt coil cell but much lower (ca. $30 \mathrm{mg} \mathrm{cm}^{-3}$ ) with the Pt matrix cell. High phosphate buffer of $1.5 \mathrm{M}(\mathrm{pH} 7)$ with the addition of $0.5 \mathrm{M} \mathrm{NaCl}$ salt was also used. $\mathrm{NaCl}$ was found to be an important additive as it increased the ionic strength and the conductivity of the solution and also provided a salting-out effect for solubility purposes and the electrode was held at a potential of $\mathrm{E}=-0.55 \mathrm{~V}$ versus $\mathrm{Ag} / \mathrm{AgCl}$, demonstrated by cyclic voltammetry to be situated in the $\mathrm{O}_{2}$ reduction shoulder.

An understanding of the factors which affect polymerisation at the surface and an insight into the dynamics and mechanism of polymer aggregation was provided by monitoring the extent of polymerisation at an optically transparent electrode using turbidity measurements. The presence of any aggregated protein structures formed at the electrode surface due to electrochemical reduction of $\mathrm{O}_{2}$ in situ was detected as a result of wavelength independent light scattering. The Pt matrix electrochemical cell was employed to investigate the effect of protein concentration, temperature, $\mathrm{pH}$ and ionic strength on the gelation of $\mathrm{HbS}$ at a conducting surface and the results showed that the kinetics of HbS nucleation and elongation were linearly dependent on the concentration, temperature and ionic strength; an increase in these factors saw a reduction in the time delay and an increase in the growth of aggregation, whilst the protein aggregation was also shown to be favoured by a slightly alkaline $\mathrm{pH}$. Furthermore, most profiles followed the double nucleation mechanism and demonstrated a sigmoidal rate of change in turbidity with an initial lag period where little increase in turbidity was 
apparent before large increases were observed. However, experiments performed at certain conditions showed the presence of an intermediary Phase II process in the turbidity profile, consisting of a large decrease in turbidity after the initial nucleation step. This was postulated to be as a result of intermediary aggregates.

The kinetics of polymerisation were investigated using a model for fibrillogenesis describing a two-step process of nucleation followed by elongation and the rate constants at monomer concentration of $300 \mathrm{mg} \mathrm{cm}^{3}$ were determined to be 9.45 ( \pm $0.08) \times 10^{-6} \mathrm{~s}^{-1}$ and $1.22( \pm 0.03) \times 10^{-3} \mathrm{~s}^{-1}$ respectively, showing that nucleation was far slower than the growth and thus the rate limiting step.. A similar difference between the rate constants for the nucleation $\left(2.99( \pm 0.4) \times 10^{-8} \mathrm{~s}^{-1}\right)$ and growth $\left(1.08( \pm 0.2) \times 10^{-3} \mathrm{~s}^{-1}\right)$ was seen at monomer concentration of $50 \mathrm{mg} \mathrm{cm}^{-3} \mathrm{HbS}$. These results obtained from a Au micromesh electrode showed that nucleation was monomer concentration dependent, however growth was largely independent of monomer concentration. A similar pattern was seen with rate constants obtained with the Pt matrix cell; the nucleation rate constant was several orders of magnitude smaller than the elongation rate constant showing that the nucleation process was slower than the growth process. Activation energies for the nucleation and elongation stages of $\mathrm{HbS}$ polymerisation were calculated $\left(81.6( \pm 1.2) \mathrm{kJ} \mathrm{mol}^{-1}\right.$ and $148.2( \pm 20.6) \mathrm{kJ} \mathrm{mol}^{-1}$ respectively) and compared with the activation energies of another protein polymerising system, $\beta$-amyloid fibrillation $(311.2 \mathrm{~kJ}$ $\mathrm{mol}^{-1}$ and $95.3( \pm 4.6) \mathrm{kJ} \mathrm{mol}^{-1}$ respectively). The $\beta$-amyloid fibril nucleation activation energy was nearly three times larger than the value obtained for $\mathrm{HbS}$ protein due to the amyloid monomer undergoing activation through a slow conformational transition. Larger elongation activation energy indicated that nucleation at the surface was more favourable than elongation; however, this could have been due to the initiation of aggregation before the start of the experiment. The Gibbs free energy was also calculated for the nucleation $\left(97.8( \pm 20.6) \mathrm{kJ} \mathrm{mol}^{-}\right.$ $\left.{ }^{1}\right)$ and elongation phases $\left(70.3( \pm 1.2) \mathrm{kJ} \mathrm{mol}^{-1}\right)$.

Optical microscopy was also coupled with chronoamperometry to visualise the growth of $\mathrm{HbS}$ aggregates at a Pt coil electrode. The optical images showed that aggregation occurred only at the surface initially and not in the bulk solution indicating that growth at the surface was thermodynamically more favourable than in solution, whilst polymerisation at the surface was demonstrated to occur in three stages: a time delay when no structures were observed was followed by growth of 
fibrous hair-like strands and then globular and gel-like aggregation in the latter stages of the experiment. The optical microscope allowed direct visualisation of the growth of aggregated structures at the electrode, however, the absorption spectroscopy technique permitted a more quantitative approach to monitoring growth compared with optical microscopy, and the increased sensitivity of the absorption spectroscopy technique also allowed the detection of aggregate formation at far lower concentrations.

This methodology was also used as a screening method for drugs that act to alleviate sickle cell crisis by disrupting the nucleation and/or growth of $\mathrm{HbS}$ polymerisation in vivo. Two naturally occurring cyclic carbonyl compounds, vanillin and $5 \mathrm{HMF}$, were tested in this system and were shown to have a large effect on the elongation phase of polymerisation, demonstrated by a four fold decrease with the addition of vanillin and a nine fold reduction with 5HMF, but no effect was seen in the nucleation phase. Both of these compounds reportedly act by covalently modifying the $\mathrm{N}$ terminal of $\mathrm{Hb}$ monomers and so should have had a pronounced effect on the nucleation phase, however, the nucleation rate with the addition of vanillin $\left(31.3( \pm 0.54) \times 10^{-3} \mathrm{~s}^{-1}\right)$ and 5HMF $\left(23.7( \pm 0.66) \times 10^{-3} \mathrm{~s}^{-1}\right)$ was found to be similar to a HbS only solution. Similarly, changing the surface properties of the electrode by using thiolating agents was shown to have little or no effect on the nucleation but a substantial effect on the rate of polymer growth. The incorporation of thiolating agents which provided negatively or positively charged surfaces provided a favourable environment for the growth of $\mathrm{HbS}$ polymers, whilst a hydrophobic surface suppressed protein growth. The effect of surface properties on protein aggregation was investigated to identify the conditions which cause minimal protein growth and therefore reduce interaction between the surface and polymers.

Direct electrochemistry of $\mathrm{HbS}$ fibres was also demonstrated at a $\mathrm{Au}$ microelectrode with a reduction peak being observed for the fibres in the region of - $200 \mathrm{mV}$ versus $\mathrm{Ag} / \mathrm{AgCl}$. No peak was seen in the background solution or $\mathrm{HbS}$ monomer control experiment. A pH dependence on the reduction peak was observed whilst charge and surface coverage calculations indicated a multi-layer deposition of fibres on the electrode. The mechanism of electron transfer could not be elucidated in this study. 
This methodology has been used to gain an understanding of the parameters which affect the kinetics and dynamics of $\mathrm{HbS}$ polymerisation at a surface compared with free in solution. It has also demonstrated the ability to provide a better understanding of the pathophysiology of SCD in vivo and been employed as a screening method for drugs that disrupt nucleation and growth of $\mathrm{HbS}$ aggregates and thus could help improve current as well as lead to novel therapeutic strategies for this common and frequently disabling disorder. The electrochemical cell will be utilised to investigate new potential compounds, whose mode of action is specific to the disruption of fibre formation 


\subsection{Future Work}

\subsubsection{Characterisation using AFM}

There is still a lot of work to be done regarding further characterisation of $\mathrm{HbS}$ polymerisation, in particular the dynamics and orientation of polymer growth at a surface. AFM is one technique which can be used to characterise the growth in further detail as the nanometre resolution of this technique allows individual fibres of diameter $21.5 \mathrm{~nm}$ to be imaged in situ thus allowing the process of polymerisation to be followed in real-time. Although numerous experiments have been performed regarding ex-situ AFM imaging of $\mathrm{HbS}$ aggregates during the course of this work, further work is required to develop an electrochemical system in which the nucleation and growth of individual HbS fibres, grown through the electrochemical depletion of $\mathrm{O}_{2}$ at a surface, can be monitored using the AFM. Insitu $\mathrm{HbS}$ polymerisation imaging with AFM at a surface would allow the fundamental mechanism of polymerisation to be investigated and compared to the established double nucleation mechanism, as well as allow the fundamental properties of $\mathrm{HbS}$ nucleation (at short time processes of less than $200 \mathrm{~s}$ ), such as induction times to be explored in greater detail. Furthermore, AFM would also allow the intermediary phase II seen in chapter 5 to be investigated and any accompanying structural changes at the surface as a result of this phase to be defined. An electrochemical AFM cell for in-situ imaging, incorporating a three electrode system similar to those fabricated in this thesis would need to be constructed, requiring a flat conducting surface as the working electrode. The imaging surface needs to be flatter than the sample being imaged, therefore, materials such as atomic gold sputtered on mica or highly orientated pyrolytic graphite (HOPG) surface would be used. The cell would need to be enclosed like a well to keep the HbS solution in constant contact with the electrodes.

The optical microscope experiments have served as a foundation and basis for the visualisation of the growth of $\mathrm{HbS}$ fibres, however, further AFM experiments will provide a system in which the reversible and controlled switching between a globular protein and fibrous state by electrochemical modulation can be achieved. Consequently, the kinetic and thermodynamic properties of the fibres grown at an electrode will be determined much more accurately, whilst the investigation of the dynamics and orientation of growth will be augmented using AFM, most probably 
through the covalent modification of a gold working electrode. Further characterisation of the kinetics and growth dynamics of $\mathrm{HbS}$ polymerisation and a detailed knowledge of polymerisation mechanisms at different interfaces are crucial not only towards the identification of new drug therapies for SCD but also for those processes which have a similar mechanism such as $\beta$-amyloid fibrillisation which is implicated in the development of many neuro-degenerative diseases.

In-situ AFM imaging of sickled RBCs from a normal bi-concave state to the sickled state will also be performed to investigate different aspects of the pathophysiology of the disease such as plasma membrane damage and the increased adhesion of the cells to each other and surfaces. A modified electrochemical cell, fabricated to mimic the narrow capillaries found in the body, will be used for the screening of therapeutic drugs and the analysis of the mechanism of action of biological agents which modify or disrupt the structure of $\mathrm{HbS}$ polymers or decrease the adhesion of RBCs to the conducting surface. 


\subsubsection{Screening for SCA and Anti-sickling Agents}

In this thesis, the observation of $\mathrm{HbS}$ polymerisation by $\mathrm{O}_{2}$ depletion in a thin layer electrochemical cell has been demonstrated. Future work in this field would be directed towards developing a medical device in which this system could be used as a diagnostic tool for the detection of the $\mathrm{HbS}$ variant and even the severity of the disease, in other words testing whether the subject is a carrier of SCA or has more severe traits. The device would incorporate a three electrode system comprised of indium tin oxide (ITO) conducting glass as the base and working electrode, providing the cell with optical transparency and include a fluorescent tag which would cause fluorescence upon sickling to aid visual detection. The device would hold a thin layer of solution and so would be similar in design to the electrochemical cells fabricated previously; however, lot of work will be required to design a commercially viable cell. Further work will also be performed on finding physiologically relevant conditions for reproducible growth of fibres upon electrochemical deoxygenation.

Currently, newborn babies in England are given screening for sickle cell blood disorders within two weeks of birth using a heel-prick test. However, as it takes approximately twelve weeks for the $\mathrm{HbF}$ to be replaced in $\mathrm{HbA}$ in newborns this device could be used as a pre-screening test for the parents to establish whether a baby has an increased risk of SCD. This application would be far more useful in developing countries such African countries where there is such a high proportion of babies born with SCD. This method would be far cheaper and quicker than the traditional method of genetic screening.

Another future application of this assay could be to act as a high-throughput screening device where many different compounds are tested simultaneously. The device would be an electrochemical cell similar to the one described above, however, instead of using ITO the working electrode would be composed of multiwell plates with each of the wells acting as individual cells for the testing of different compounds simultaneously. The wells could be pre-treated with compounds such as thiolating agents to increase the extent of $\mathrm{HbS}$ aggregation to determine efficacy of the different compounds being tested whilst the metal plates could be heated to change the conditions to physiological temperature. Current fluorescence techniques could be modified to act as a sophisticated and practical 
detection method where labelled flourophores could be emitted upon interaction of $\mathrm{HbS}$ molecules, causing colouration, whilst the fluorescence could be quenched upon disaggreagation. The effectiveness of current therapeutic compounds that specifically target the aggregation of $\mathrm{HbS}$ monomers would be assessed in greater detail and subsequently new potential compounds will be tested in the hope of finding a cure for this debilitating disease. Naturally occurring five-membered heterocyclic aldehydes and its analogues and those compounds which form Schiff base adducts in a symmetrical fashion with the $\mathrm{N}$-terminal $\alpha$ Vall nitrogens of $\mathrm{Hb}$ would be targeted initially. The preliminary work performed in this regard in chapter 6 will aid future studies in this area. 


\subsubsection{Direct electrochemistry}

Further work will also be pursued in investigating the direct electrochemistry of $\mathrm{HbS}$ fibres at a number of bare and modified electrode surfaces to determine the electron conducting properties of the fibres. Furthermore, the dependence of fibre conductivity on the conditions of growth will also be investigated in more detail to provide insights into the mechanism of complex biological electron transfer reactions in-vivo.

The direct electrochemistry of $\mathrm{HbS}$ will be coupled to the orientation of fibre growth work performed using the AFM and the manipulation of growth will be investigated using the incorporation of connecting groups to achieve connectivity and functionality at the fibre ends. A future application for this could be molecular nano-wires which conduct electrical current and be used in molecular electronic devices. The added advantage of $\mathrm{HbS}$ fibres as molecular nano-wires is that switching between the globular protein and the fibrous state is relatively easy to achieve through depletion of $\mathrm{O}_{2}$. Further work regarding the electrochemical characterisation of different surface properties will also be performed. This will be achieved by using thiols and the relevance of this system to a physiological environment will be investigated. 


\subsection{Summary}

Overall, a lot of progress has been made regarding the characterisation of the nucleation and elongation of $\mathrm{HbS}$ polymerisation at an electrode surface and also in understanding how they are formed and affected by a number of conditions at a conducting surface. Furthermore, a screening device has also been presented which could be useful to the pharmaceutical industry. However, there is a lot of information still to be obtained and a lot of interesting work yet to be done on utilising the electrochemically modulated growth of $\mathrm{HbS}$ polymers in investigating the pathophysiology of SCA in greater detail as well as improving current therapeutic strategies and finding new ones which could aid in finding a cure for this disease. 
Chapter 9: References 
[1] R.S. Olney. (1999). Am. J. Prev. Med., 16 (2), 116.

[2] F. Haurowtiz. (1938). Z. physiol. Chem., 255, 264.

[3] http://www.chemistry.wustl.edu/ edudec/LabTutorials/Hemoglobin/MetalC omplexinBlood.html

[4] K. Sheng, M. Shariff, R. P. Hebbel (1998). Blood, 9, 3467.

[5] L. Puling, H. A. Itano, S. J. Singer, I. C. Wells. (1949). Science, 111, 543.

[6] V. M. Ingram. (1956). Nature, 178, 792.

[7] L. Sokolov, I. Mukerji. (2000). J. Phys. Chem. B, 104, 10835.

[8] B. C. Wishner, K. B. Ward, E. E. Lattman, W E. Love. (1975). J. Mol. Biol., 98, 179.

[9] E. A. Padlan, W. E. Love. (1985). J. Bio. Chem., 260 (14), 8280.

[10] D. J. Harrington, K. Adachi, W. E. Royer Jr. (1997). J. Mol. Biol., 272, 398.

[11] A. Malavalli, B. N. Mansura, J. M. Freidman, A. S. Acharya (2000). J. Protein Chem., 19 (4), 255.

[12] R. Josephs, H. S. Jarosch, S. J. Edelstein (1976). J. Mol. Biol., 102. 409.

[13] R. H. Crepeau, G. Dykes, R. Garrell, S. J. Edelstein. (1978). Nature, 274. 616

[14] Z. Wong, G. Kishchenko, Y. Chen, R. Josephs. (2000) J. Struct. Bio.. 131. 197

[15] G. Dykes, R. H. Crepeau, S. J. Edelstein. (1979). J. Mol. Biol., 130, 451.

[16] B. Carragher, D. A. Bluemke, B. Gabriel, M. J. Potel, R. Josephs. (1988). J. Mol. Biol., 199, 315.

[17] S. J. Watowich, L. J. Gross, R. Josephs. (1993). J. Struct. Biol., 111, 161.

[18] S. J. Watowich, L. J. Gross, R. Josephs. (1989). J. Mol. Biol., 209, 821.

[19] I. J. Sherman. (1940). Bull. Johns Hopkins Hosp., 67. 309.

[20] J. G. Pumphrey, J. Steinhardt. (1976). Bio. Biophys. Chem. Comm., 69 (1). 99

[21] J. G. Pumphrey, J. Steinhardt. (1977). J. Mol. Biol., 112, 359.

[22] T. E. Wellems, R. Josephs. (1979). J. Mol. Biol., 135, 651.

[23] W. A. McDade, R. Josephs. (1993). J. Struct. Biol., 110, 90.

[24] T. E. Wellems, R. J. Vasser, R. Joseph. (1981). J. Mol. Biol., 153, 1011.

[25] J. Hofrichter, P. D. Ross, W. A. Eaton. (1976). Proceedings of the Symposium on Molecular and Cellular Aspects of Sickle Cell Disease, 185. DHEW Publ. No. (NIH) 76-1007, Bethesda, Maryland. 
[26] H. R. Sunshine, J. Hofrichter, F. A. Ferrone, W. A. Eaton. (1982). J. Mol. Biol., 158, 251.

[27] C. T. Noguchi, D. A. Torchia, A. N. Schechter. (1980). Proc. Natl. Acad. Sci. USA, 77, 5487.

[28] M. A. Goldberg, M. A. Husson, H. F. Bunn. (1977). J. Bio. Chem., 252 (10), 3414 .

[29] R. W. Briehl, S. Ewert. (1973). J. Mol. Biol., 80, 445.

[30] W. A. Eaton, J. Hofrichter. (1990). Adv. Protein. Chem., 40, 63.

[31] K. Adachi, T. Asakura.(1979). J. Bio. Chem., 254, 12273.

[32] K. Adachi, T. Asakura.(1980). J. Mol. Biol., 144, 467.

[33] G. R. Sergeant. (1985). "Sickle Cell Disease”. Oxford Univ. Press, London and New York.

[34] N. N. Poillon, B. C. Kim, G. P. Rodgers, C. T. Noguchi, A. N. Schechter. (1993). Proc. Natl. Acad. Sci. USA, 90, 5039.

[35] B. Magdoff-Fairchild, W. N. Poillon, T. Li, J. F. Bertles (1976). Proc. Natl. Acad. Sci. USA, 73 (4), 990.

[36] P. D. Ross, A. P. Minton. (1977). J. Mol. Biol., 112, 437.

[37] F. A. Ferrone, J. Hofrichter, E. A. Eaton. (1985). J. Mol. Biol., 183, 591.

[38] A. Mozzarelli, J. Hofrichter, W. A. Eaton. (1987). Science, 237, 800.

[39] D. Pletcher, S. Sotiropolous. (1995). J. Chem. Soc. Faraday Trans., 91 (3). 457.

[40] M. S. Turner, J. Wang, C. W. Jones, F. A. Ferrone, R. Josephs, R. W. Briehl. (2002). Langmuir, 18, 7182.

[41] O. Galkin, K. Chen, R. L. Nagel, R. E. Hirsch, P. G. Vekilov. (2002). Proc. Natl. Acad. Sci. U.S.A., 99 (13), 8479.

[42] R. E. Samuel, E. D. Salmon, R. W. Briehl. (1990). Nature, 345, 833.

[43] R. M. Bookchin, T. Baloze, Z. Wang, R. Josephs, V. I. Lew. (1999). J. Bio. Chem., 274 (10), 6689.

[44] K. Adachi, T. Asakura.(1983). J. Bio. Chem., 144, 467.

[45] O. Galkin, P. G. Vekilov. (2004). J. Mol. Biol., 336, 43.

[46] J. D. Corbett, W. E. Mickola, M. F. Maestre. (1995). J. Bio. Chem., 270 (6), 2708 .

[47] R. W. Briehl. (1995). J. Mol. Biol., 245, 710. 
[48] G Agarwal, J. C. Wang, S. Kuong, S. M. Cohen, F. A. Ferrone, R. Josephs, R. W. Briehl. (2002). J. Mol. Biol., 322, 395.

[49] A. C. Allison. (1957). Biochem. J., 65, 212.

[50] J. F. Bertles, R. Rabinowitz, J. Dobler. (1970). Science, 169, 375.

[51] H. R. Sunshine, J. Hofrichter, W. A. Eaton. (1979). J. Mol. Biol., 133, 435.

[52] P. D. Ross, J. Hofrichter, W. A. Eaton. (1975). J. Mol. Biol., 96, 239.

[53] G. C. Thompson, M. R. Waterman, G. L. Cottam. (1975). Arch. Biochem. Biophys., 166, 193.

[54] W. A. Eaton, J. Hofrichter, P. D. Ross, R. G. Tschudin, E. D. Becker (1976). Biochem. Biophys. Res. Commun., 69, 539.

[55] K. Malfa, J. Steinhardt. (1974). Biochem. Biophys. Res. Commun., 59, 887.

[56] J. W. Harris,H. B. Bensusan. (1975). J. Lab. Clin. Med., 86, 564.

[57] S. Kowalczykowski, J. Steinhardt. (1977). J. Mol. Biol., 115, 201.

[58] K. Moffat, Q. H. Gibson. (1974). Biochem. Biophys. Res. Commun., 61, 237.

[59] S. J. Gill, R. Spokane, R. C. Benedict, L. Fall, J. Wyman. (1980). J. Mol. Biol., 140, 299.

[60] S. Basak, F. A.Ferrone, J. T. Wang. (1988). Biophys. J., 54, 829.

[61] R. W. Briehl, G. W. Christoph. (1987). Exponential progress curves and shear in the gelation of haemoglobin S. In "Pathophysiological Aspects of Sickle Cell Vaso-Occlusion" (R. L. Nagel, ed.), 129. Liss, New York.

[62] M. R. Waterman, G. R. Cottam. (1976). Biochem. Biophys. Res. Commun., 73, 639 .

[63] J. Hofrichter, P. D. Ross, W. A. Eaton. (1974). Kinetic and thermodynamic investigation of deoxyhemoglobin S gelation. In "Proceedings of the First National Symposium on Sickle Cell Disease" (J. I. Hercules, A. N. Schechter, W. A. Eaton, R. E. Jackson, eds.), 43. DHEW Publ. No. (NIH), 75. Bethesda, Maryland.

[64] J. Hofrichter, P. D. Ross, W. A. Eaton. (1974). Proc. Natl. Acad. Sci. U.S.A., 71, 4864 .

[65] F. A. Ferrone, J. Hofrichter, E. A. Eaton. (1976). Proc. Natl. Acad. Sci. U.S.A., 73, 3034.

[66] F. A. Ferrone, J. Hofrichter, E. A. Eaton. (1985). J. Mol. Biol., 183, 611.

[67] R. Mircher, F. A. Ferrone. (1997). J. Mol. Biol., 265, 475. 
[68] J. G. Louderback, S. K. Ballas, D. B. Kim-Shapiro. (1999). Biophys., 76, 2216.

[69] F. A. Ferrone, M. Ivanovu, R. Jasuja. (2002). Biophys., 82, 399.

[70] P. A. Altman, D. S. Ditmer. (1971). Resp. Circul., 498, 417.

[71] A. Shirayayev, X. Li, J. D. Gunton (2006). J. Chem Phys., 125, 024902

[72] J. D. Corbett, W. E. Mickols, M. F. Maestre (1995). J. Bio. Chem., 270 (6), 2708 .

[73] R. W. Briehl, A. E. Guzman. (1994). Blood, 83 (2), 573.

[74] H. Wroblowa, Y. L. Pan, J. Razumney. (1976). J. Electroanal. C'hem., 69. 195.

[75] P. P. Birkin, J. M. Elliot, Y. E. Watson. (2000). Chim. Commun., 1690.

[76] N. M. Markovic, T. J. Schmidt, V. Stamenkovic, P. N. Ross. (2001). Fuel Cells, 1 (2), 105.

[77] D. Pletcher, S. Sotiropolous. (1995). J. Chem. Soc. Faraday Trans., 91 (3), 457.

[78] R. W. Zurilla, R. K. Sen, E. Yeager. (1978). J. Electrochem. Soc., 125 (7). 1103.

[79] Southampton Electrochemistry Group, Southampton University. Instrumental Methods in Electrochemistry: $2^{\text {nd }}$ Edition (1993) Ellis Horwood Limited. Ashford Press: Southampton.

[80] A.C. Fisher. Electrode Dynamics: $1^{\text {st }}$ Edition (1996) Oxford University Press: Oxford.

[81] K. Adachi, T. Asakura. (1981) J. Biol. Chem., 256 (4), 1824.

[82] Anderson et al (1994) Art. cells, blood subs., and Immob. Biotech, 22 (3). 753.

[83] L. Stryer, Biochemistry, $4^{\text {th }}$ Edition, (1995). W. H. Freeman and Company. New York.

[84] D. Barham and P. Trinder (1972) Analyst, 97, 142.

[85] W. N. Poillon, J. F. Bertles. (1979). J. Biol. Chem., 254, 3462.

[86] http://www.nlm.nih.gov/medlineplus/ency/article/003648.htm

[87] R. G. Bates, C. A. Vega, D. R. White, Jr, (1978) Anal. Chem., 50 (9), 1295.

[88] M. Kamihira, A. Naito, S. Tuzi, A. Y. Nosaka, H. Saito, (2000) Protein Sci., 9, 867.

[89] http://www.rsc.org/suppdata/AN/b6/b613381a/index.sht 
[90] K. Adachi, T. Asakura (1979) J. Bio. Chem., 254 (16), 7765.

[91] L. O. Tjernberg, A. Tjernberg, N. Bark, Y. Shi, B. P. Ruzsicska, Z. Bu, J. Thyberg, D. J. E. Callaway (2002) Biochem. J., 366, 343.

[92] T. Arai, G. Freddi, R. Innocenti, M. Tsukada (2004). J. Appl Pollm Sci, 91. 2383.

[93] R. Sabate'. M. Gallardo, J. Estelrich (2003) Biopolymers (Peptide Sci.) 71. 190 .

[94] M. Kamihira, A. Naito, S. Tuzi, A. Y. Nosaka, H. Saito (2000) Protein Sci., 9. 867 .

[95] A. C. Allison. (1957). Biochem. J., 65, 212.

[96] P. J. Mcquilney, P. W. Kuchel (1999) Biochem. J., 342 (3). 597.

[97] A. Fick (1855) Phil Mag., 10, 30.

[98] A. Fick, (1855) Poggendorffs Annel. Physik., 94, 59.

[99] J. A. V. Butler (1924). Trans. Faraday Soc. 19, 734.

[100] T. Erdey Gruz, M. Volmer (1930), Z. Physik. Chem., 150A, 203

[101] D. Lide (editor). CRC, Handbook of Chemistry and Physics, $75^{\text {th }}$ Ed. (1994/95), CRC Press: Cleveland, OH.

[102] S. Arrhenius (1889). Zeitschrift für physikalische Chemie 4, $226 \mathrm{ff}$

[103] R. Sabate, M. Gallardo, J. Estelrich (2005) Int. J. Bio. Macromol. 35, 9.

[104] Y. Kusumoto, A. Lomakin, D.B. Teplow, G.B. Benedek, (1998) Proc. Natl. Acad. Sci. USA. 95, 12277.

[105] B.M. Taylor, R.W. Sarver, G. Fici, R.A. Poorman. B.S. Lutzke. A. Molinari, T. Kawabe, K. Kappenman, A.E. Buhl, D.E. Epps (2003). J. Protein Chem. 22, 31.

[106] W.P. Esler, A.M. Felix, E.R. Stimson, M.J. Lachenmann, J.R. Ghiraldi. Y.A. Lu, H.V. Vinters, P.W. Mantyh, J.P. Lee, J.E. Maggio, (2000). J. Struc. Biol. 130, 174.

[107] J.C. Rochet, P.T. Lansbury Jr., (2000). Curr. Opin. Struct. Biol. 10, 60.

[108] T.R. Serio, A.G. Cashikar, A.S. Kowal, G.J. Sawicki, J.L. Moslehi, L. Serpell, M.F. Arnsdorf, S.L. Lindquist, (2002). Science, 289, 1317.

[109] J. M. Hempe, R. D. Craver (2000). Electrophoresis, 21, 743.

[110] M. Manno, P. L. San Biagio, M. U. Palma (2004). Proteins: Structure. Function \& Bioinformatics, 55, 169. 
[111] F. Hook, M. Rodahl, B. Kasemo, P. Brezezinski (1998). Proc. Natl. Acad. Sci. USA, 95, 12271.

[112] W. Pan, O. Galkin, L. Filobelo, R. L. Nagel, P. G. Vekilov (2007). Biophys. $J ., 92,267$.

[113] W. Pan, A. B. Kolomeisky, P. G. Vekilov (2005). J. Chem. Phys. 122. 174905.

[114] O. Abdulmalik, D. Obeng, T. Asakura., (2005). Expert Opin. Ther. Patents. 15 (11), 1497.

[115] M. H. Steinberg (2006). Trends in Pharmalogical Sciences, 27 (4), 204.

[116] P. S. Frenette, G. F. Atweh (2007). The Journal of Clinical Investigation, $117(4), 850$.

[117] R. Hoover, R. Rubin, G. Wise, R. Warren (1979). Blood., 54, 872.

[118] C. C. Johneskiss, R. L. Ackley, E. P. Orringer, E. A. Wayner, L. V. Parise (1993). Blood., 82, 3548.

[119] A. I. Khan, C. Drew, S. E. Ball, V. Ball, J. C. Ellory, J. S. Gibson (2004). Bioelectrochem., 62, 141.

[120] D. Chiu, B. Lubin, B. Roelofsen, L. L. Van Deenan (1981). Blood, 58, 398.

[121] C. D. Ritter (2002). Nat. Med., 8, 1383.

[122] D. N. Levasseur, T. M. Ryan, M. P. Reilly, S. L. McCune, T. Asakura, T. M. Tornes (2004). J. Bio. Chem., 279 (26) 27518.

[123] M. H. Steinberg (2005). Blood, 105 (2), 441.

[124] F. Rosenthal, I. Wislicki, R. Koller (1928). Klin. Wochenschr., 7, 972.

[125] S. Charache, M. I. Terrin, R. D. Moore (1995). N. Engl. J. Med., 332 (20), 317.

[126] V. P. Cokic, R. D. Smith, B. B. Beleslin-Cockic (2003). J. Clin. Invest., 111 (2), 231.

[127] J. Jiang, S. J. Jordon, D. P. Barr, M. R. Gunther, Maedah. R. P. Mason (1997). Mol. Pharmacol., 52 (6), 1081.

[128] R. H. Zaugg, J. A. Walder, I. M. Klotz (1977). J. Bio. (hem.. 252 (33). 8542 .

[129] M. K. Safo, O. Abdulmalik, R. Danso-Danquah, J. C. Burnett, S. Nokuri, G. S. Joshi, F. N. Musayev, T. Asakura, D. J. Abraham (2004). J. Med. Chem., 47, 4665 . 
[130] D. J. Abraham, A. S. Mehanna, F. C. Wireko, J. Whitney, R. P. Thomas, E. P. Orringer (1991). Blood., 77 (6), 1334.

[131] C. Ziang, X. Li, L. Lian, Q. Chen, O. Abdulmalik, V. Vassilev, C. Lai, T. Asakura (2004). Br. J. Haemotol. 125 (6), 788.

[132] O. Abdulmalik, M. K. Safo, Q. Chen (2005). Br. J. Haemotol., 128 (4), 552.

[133] C. Brugnara, (2003). J. Pediatr. Hematol. Oncol., 25 (12), 927.

[134] J. W. Stocker, L. De Francheschi, G. A. Mcnaughton-Smith, R. Corrocher, Y. C. Beuzard Brugnara, (2003). Blood, 101 (6), 2412.

[135] E. P. Orringer, J. F. Casella, K. I. Ataga (2001). JAMA, 286 (17), 2099.

[136] F. W. Scheller, N. Bistolas, S. Liu, M. Janchen, M. Katterle, U. Wollenberger (2005). Adv. Coll. Interf. Sci., 116, 111.

[137] X. Chen, C. Ruan, J. Kong, R. Yang, J. Deng (1998). Electroanalysis, 10. 695.

[138] O. Nekrassova, N. S. Lawrence, R. G. Compton (2004). Analyst, 129, 804.

[139] G-J. A. Vidugiris, V. J. Razumas, A. A. Drungiliene, J. J. Kulys, (1988). Bioelectrochem Bioenerg, 19, 513.

[140] F. Scheller, H. J. Prumke, H. E. Schmidt, P. Mohr (1976). Bioelectrochem. Bioenerg., 3, 328

[141] K. L. Hanrahan, S. M. MacDonald, S. G. Roscoe (1996). Electrochim. Acta., 41, 2469.

[142] A. Mauk, H. Gray, (1979). Biochem. Biophys. Res. Commun.. 86. 206.

[143] G. Dryhurst, K. M. Kadish, F. W. Scheller, R. Rennenberg. Biological Electrochemistry, vol. 1. New York: Academic Press; (1982), 398.

[144] F. A. Armstrong (2002). J. Chem. Soc., Dalton Trans., 661.

[145] H. Sun, N. Hu. (2004). Biophys. Chem., 110, 297.

[146] J. Yang, N. Hu, J. F. Rusling. (1999). J. Electroanal. Chem., 463, 53.

[147] J. Yang, N. Hu, J. F. Rusling. (1999). Bioelectrochem. Bioenerg., 48, 117.

[148] X. Chen, N. Hu, Y. Zeng, J. F. Rusling, J. Yang. (1999). Langmuir, 15. 7022.

[149] J. I. Blankman, N. Shahzad, C. J. Miller, R. D. Guiles (2000). Biochemistry. 39, 14806.

[150] M. Katterle, U. Wollenberger, F. W. Scheller (1997). Electroanalysis, 9 (18), 1393.

[151] H. Ju, L. Dong, H. Chen (1996). Anal. Lett., 29, 587. 
[152] L. Wang, N. Hu (2001). Bioelectrochemistry, 53, 205. 
Appendices

$\underline{\text { Appendices }}$ 


\section{Appendix A: Publication}




\section{Electrochemical modulation of sickle cell haemoglobin polymerisation $\dagger$}

Zeshan Iqbal, ${ }^{a}$ Rachel McKendry, ${ }^{b}$ Michael Horton ${ }^{b}$ and Daren J. Caruana*u

Reccived 14th September 2006, Accepted 2nd November 2006

First published as an Advance Article on the web 17th November 2006

DOI: $10.1039 / \mathrm{b} 613381 \mathrm{a}$ 
Appendix B: Colour enhanced HbS polymer Images published on the front cover of The Analyst 


\section{SPECIAL NOTE}

\section{THIS ITEM IS BOUND IN SUCH A}

MANNER AND WHILE EVERY

EFFORT HAS BEEN MADE TO

REPRODUCE THE CENTRES, FORCE

WOULD RESULT IN DAMAGE 


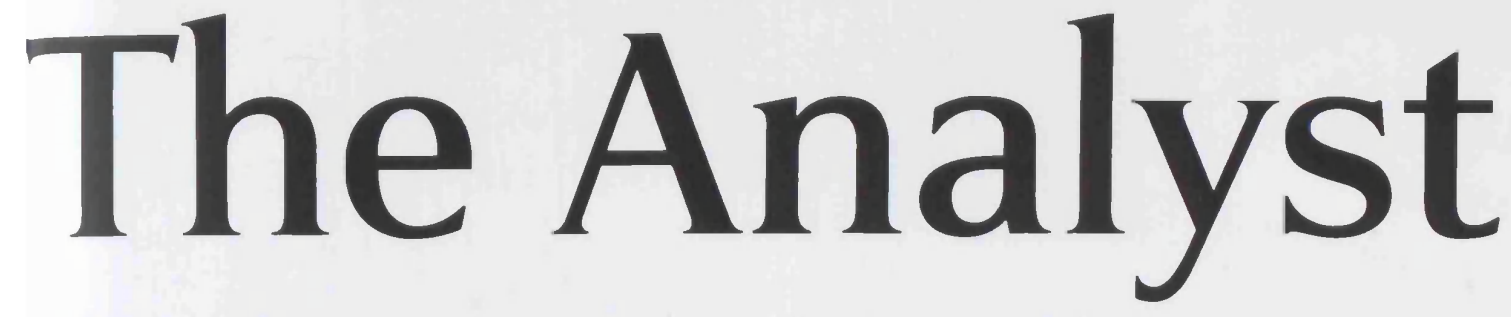

Interdisciplinary detection science

www.rsc.org/analyst

Volume 132 | Number 1 | January 2007 | Pages 1-84

\section{FORUM}

Kevin A. Francesconi

Toxic metal species and food

RSCPublishing regulations-making a healthy choice

\section{COMMUNICATION}

Alain Brunelle et al.

Lipid cartography of atherosclerotic plaque by cluster-TOF-SIMS

imaging

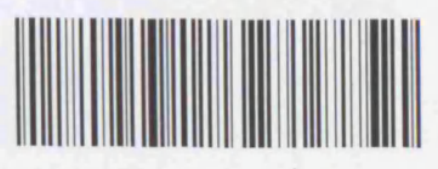

0003-2654(2007)132:1;1-N 
Appendix C: "Sickle cell microcell": Article published in Chemical Biology 


\section{SPECIAL NOTE}

\section{THIS ITEM IS BOUND IN SUCH A}

MANNER AND WHILE EVERY

EFFORT HAS BEEN MADE TO

REPRODUCE THE CENTRES, FORCE

WOULD RESULT IN DAMAGE 


\section{Research highlights}

Haemoglobin reduced to provide potential drug screening method Sickle cell microcell 